B I B L IO TECA INSTITUTO DE QUIMICA

Universidade de São Paulo 20648

Universidade de São Paulo

Instituto de Química

\title{
Estudos da estabilidade conformacional da tropomiosina e de suas interações com as outras proteínas do filamento fino
}

\author{
LUIS MARCELO FERNANDES HOLTHAUZEN
}
Tese de doutorado submetida ao Departamento de Bioquímica do Instituto de Química da Universidade de São Paulo Orientador: Dr. Shaker Chuck Farah

São Paulo

31 de julho de 2003 

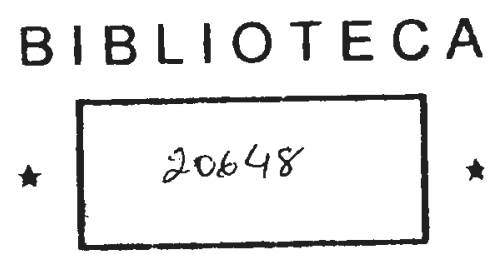

INSTITUTO DE QUIMICA UNIVERSIDADE DE SAO PAULO

Ficha Catalográfica

Elaborada pela Divisão de Biblioteca e

Documentação do Conjunto das Químicas da USP.

\section{Holthauzen, Luis Marcelo Fernandes}

H758e Estudos da estabilidade conformacional da tropomiosina e de suas interações com as outras proteínas do filamento fino

/ Luis Marcelo Fernandes Holthauzen. -- São Paulo, 2003. $156 \mathrm{p}$.

Tese (doutorado) - Instituto de Química da Universidade de São Paulo. Departamento de Bioquímica.

Orientador : Farah, Shaker Chuck

1. Biofísica 2. Proteína : Estabilidade conformacional : Bioquímica 3. Interação proteina - proteina : Bioquímica I. T. Il. Farah, Shaker Chuck, orientador. 


\section{"Estudos da estabilidade conformacional da tropomiosina e de suas interações com as outras proteínas do filamento fino"}

\section{LUIS MARCELO FERNANDES HOLTHAUZEN}

Tese de Doutorado submetida ao Instiftuto de Química da Universidade de São Paulo como parte dos requisitos niecessários à obtenção do grau de Doutor em Ciências - Área: Bioquímica.

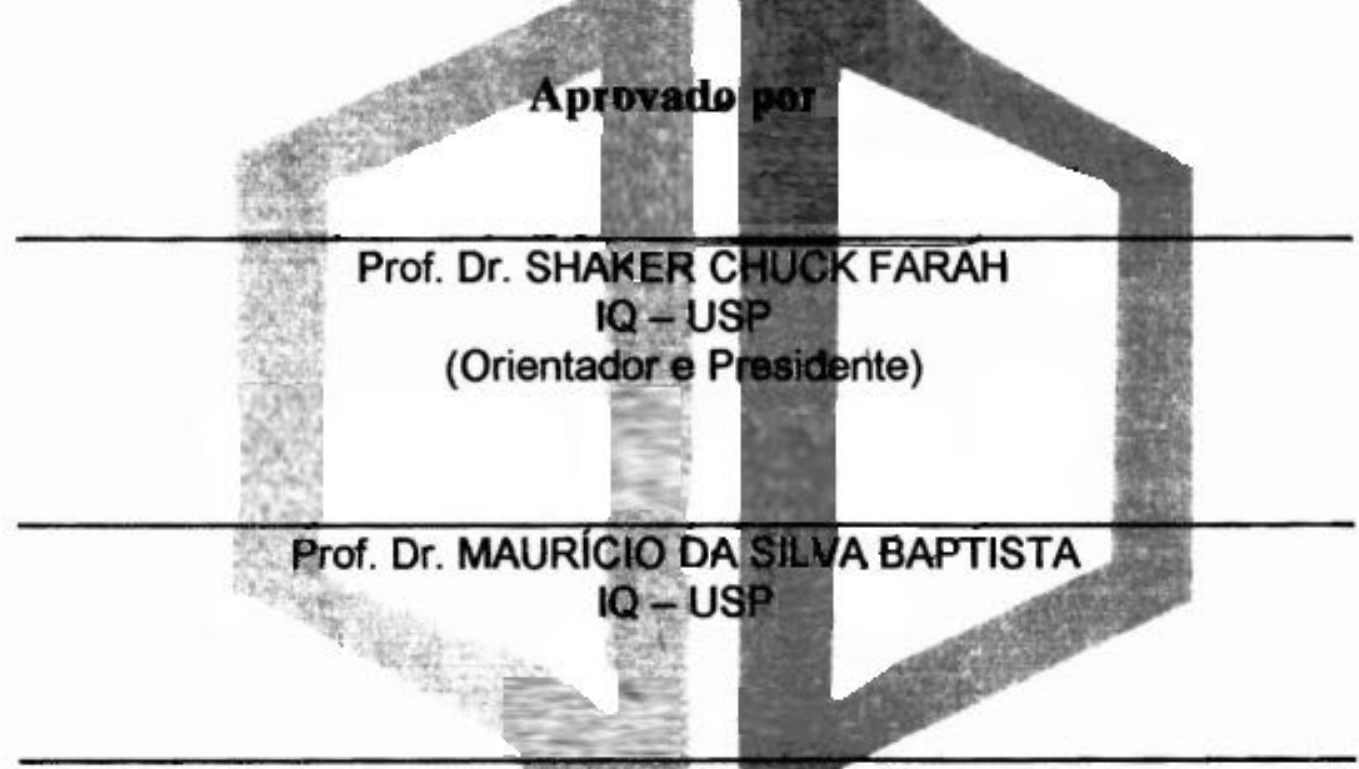

Prof. Dr. PAULOLEE HO

Instituto Butantan

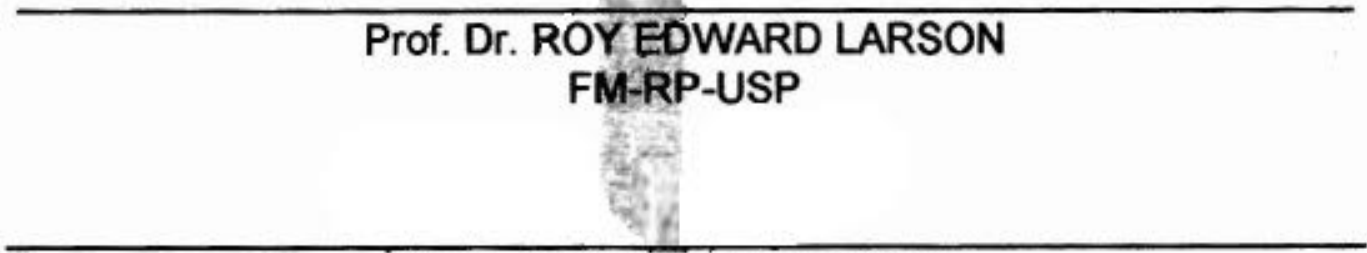

Profa. Dra. DEBORA FOGUEL

UFRJ 
He who bends to fimself a joy Doth the wingèd life destroy; But he who kisses the Joy as it flies Lives in Etemity's sunrise.

William Blake 
Agradeço a meus pais

Ricardo e Elza

Por todo o carinho, apoio e compreensão

Ao longo de tantos anos 
À Adriana, meu grande amor,

Por me mostrar que a vida realmente vale a pena 


\section{AGRADECIMENTOS}

Aos meus avós, com muito amor, Manoel e Maria

$$
\text { À Tia Eliza }
$$

Ao Tio Luiz e à Tia Ângela

Ao Maurício e à Elaine

Aos amigos pela alegria e companheirismo e pelas discussões filosófico-científicas...

Dr. Chuck Farah, pela orientação e amizade Aos padrinhos Eric, Sandro e Daniele Marcos Alegria

Ângela Mika Katsuyama

Leonor Galvão de Botton

Dra. Izaura, Robson et al.

Dra. Aurea

Drs. DF e Deodoro

Dras. Daniela Mara e Tharin Blumenschein

Elaine Favaro

Dr. Ronaldo Bento Quaggio (pelas discussões filosóficas) et al.

Dr. Carlos Ramos

D. Cleusa e Alê

Fernando e Cris

E a todos os amigos do IQ

Agradeço à FAPESP

Sem a qual este trabalho não poderia ter sido realizado 


\section{INDICE}

Resumo 1

Abstract 3

Objetivos 5

Introdução 6

Parte I - Sistema Muscular

1. Apresentação do sistema 7

1.1. Miosina 10

1.2. Actina 11

1.3. O ciclo $\mathrm{Mg}^{2+}$-ATPásico da actomiosina 14

1.4. Alguns aspectos da interação entre a actina e a miosina 16

1.5. Troponina 18

1.6. Tropomiosina 24

2. Regulação da contração muscular 33

Parte II - Fluorescência

3. Fluorescência 38

3.1. Fluorescência em proteínas 42

3.2. Análogos de triptofano 44

3.3. Supressão de fluorescência 45

3.4. Usos da supressão de fluorescência no estudo de interações protéicas e no mapeamento de interações entre proteínas 50

Materiais e Métodos 52

4. Soluções gerais 52

5. Purificação das proteínas 53

5.1. Tropomiosinas recombinantes 53

5.2. Complexo troponina 56

5.3. Actina 59

5.4. Fragmento S1 da miosina 60

6. Ensaios de co-sedimentação com actina 61

7. Regulação da $\mathrm{Mg}^{2+}$-ATPase da miosina $\mathrm{S} 1$ por filamentos finos reconstituidos contendo tropomiosinas mutantes 62

8. Ensaios de estabilidade 63

9. Ensaios de supressão de fluorescência 65

$\begin{array}{ll}\text { Resultados } & 70\end{array}$

10. Ligação da tropomiosina à actina: ensaios de co-sedimentação 
11. Regulação da $\mathrm{Mg}^{2+}$-ATPase da miosina $\mathrm{Sl}$ por filamentos finos reconstituidos contendo tropomiosinas mutantes

12. Ensaios de estabilidade 74

13. Ensaios de supressão de fluorescência 104

Discussão

14. Ensaios de co-sedimentação

15. Regulação da $\mathrm{Mg}^{2+}$-ATPase da miosina $\mathrm{S} 1$ por filamentos finos reconstituidos contendo tropomiosinas mutantes

16. Ensaios de estabilidade conformacional das tropomiosinas mutantes

17. Ensaios de supressão de fluorescência 126

Conclusões 


\section{ABREVIATURAS}

ASTm - topomiosina recombinante com fusão dipeptídica Ala-Ser

ATP - trifosfato de adenosina

DEAE - diaminoetil

DTT - ditiotreitol

EDTA - ácido etileno-diamino-tetracético

EGTA - ácido etileno-glicol-bis( $\left(\beta\right.$-aminoetil-éter)- $N, N, N^{\prime}, N^{\prime}$-tetraacético

IPTG - isopropil- $\beta$-D-tiogalactopiranosídeo

MOPS - ácido 3-( $N$-morfolino)propanosulfônico

$\mathrm{P}_{\mathrm{i}}-$ fosfato inorgânico

S1 - subfragmento 1 da miosina 


\section{RESUMO}

Uma série de mutantes recombinantes da tropomiosina com a sonda fluorescente 5-hidroxitriptofano inserida em várias posições ao longo da seqüência primária vêm sendo utilizados em nosso laboratório para o estudo em nivel molecular do controle do processo de contração muscular. Estes mutantes têm sido produzidos em cepas de bactéria auxotróficas para triptofano em meio mínimo ao qual adicionamos 5-hidroxitriptofano, um análogo do aminoácido triptofano. Esta sonda fluorescente apresenta a vantagem de absorver energia numa faixa de comprimentos de onda não absorvida pelo triptofano (temos usado com sucesso o comprimento de onda de $312 \mathrm{~nm}$ para excitar seletivamente o 5-hidroxitriptofano). Desta forma, o ambiente da sonda pode ser estudado em situações nas quais outras proteínas que possuam triptofanos, como, por exemplo a actina, estejam presentes.

Procedemos a uma caracterização dos mutantes utilizados quanto à sua ligação à actina na ausência e presença de troponina $\left(+/-\mathrm{Ca}^{2+}\right)$ e na presença de acrilamida por meio de ensaios de co-sedimentação com actina. O comportamento funcional dos diversos mutantes foi investigado pela análise da regulação da atividade $\mathrm{Mg}^{2+}$-ATPásica da acto-S1 miosina destes mutantes na ausência e na presença de troponina $\left(+/-\mathrm{Ca}^{2+}\right)$. Estudos da estabilidade destes mutantes da tropomiosina por meio de desnaturação por temperatura seguida por dicroísmo circular foram realizados para analisarmos o efeito das mutações na estabilidade global da molécula. Ensaios de desnaturação por uréia seguidas por fluorescência também foram realizados para analisarmos a estabilidade da molécula próxima à região da sonda fluorescente. O presente estudo compreendeu ainda a análise da supressão de fluorescência pelos supressores extrínsecos acrilamida e iodeto para diversos mutantes da tropomiosina na presença e ausência de outras proteínas do filmento fino, o que permitiu a obtenção de informações sobre o grau de exposição da sonda fluorescente nas diversas situações estudadas bem como sobre o ambiente eletrostático ao redor das sondas nestas diferentes situações. Estes resultados permitiram a obtenção de um modelo 
para a ligação da tropomiosina ao filamento de actina na presença de troponina $\left(+1-\mathrm{Ca}^{2+}\right)$. Este modelo propõe que as bandas $\alpha$ do padrão de repetição $\alpha / \beta$ inicialmente proposto por McLachlan e Stewart (1975 e 1976) se liguem ao filamento na ausência de íons cálcio. A introdução de cálcio no sistema é capaz de induzir uma rotação e um deslocamento na molécula de tropomiosina com relação ao filamento de actina. Nesta situação, seriam as bandas $\beta$ da tropomiosina as responsáveis pela ligação desta molécula ao filamento de actina. 


\section{ABSTRACT}

Several recombinant mutants of tropomyosin with the fluorescent probe 5-hydroxytryptophan inserted at several positions along the primary sequence are being used in our laboratory for studying the control of the muscular contraction process at a molecular level. These mutants are produced in bacterial strains auxotrophic to tryptophan in minimal medium to which 5hydroxytryptophan, a tryptophan analogue, is added. This fluorescent probe has the advantage of absorbing light in a range of wavelengths not absorbed by the amino acid tryptophan (we have been successfully using the wavelength of $312 \mathrm{~nm}$ to selectively excite the 5-hydroxytryptophan). The environment of the probe can thus be studied even when other tryptophan containing proteins, such as actin, are present.

We have characterized the mutants as to their ability to bind to actin in the absence and in the presence of troponin $\left(+/-\mathrm{Ca}^{2+}\right)$ and in the presence of acrylamide through actin co-sedimentation assays. The functional behavior of the several mutants constructed was assessed by analyzing their ability to regulate the acto-S1 myosin $\mathrm{Mg}^{2+}$-ATPase activity in the absence and in the presence of troponin $\left(+/-\mathrm{Ca}^{2+}\right)$. Studies on the stability of these tropomyosin mutants by thermal denaturation followed by circular dichroism were performed to analyze the effect of the mutations on the molecule's global stability. Urea denaturation assays followed by fluorescence were also performed to allow us to investigate the stability of the molecule in the vicinity of the fluorescent probe. The present study also involved the analysis of the fluorescence quenching by the extrinsic quenchers acrylamide and iodide for divers tropomyosin mutants in the presence and in the absence of other thin filament proteins. This allowed us to obtain information on the degree of exposure of the fluorescent probe in the several conditions studied as well as on the electrostatic microenvironment surrounding the probes in these different situations. These results enabled us to propose a model for the binding of tropomyosin to the actin filament in the presence of troponin $(+/-$ $\left.\mathrm{Ca}^{2+}\right)$. In this model the $\alpha$-bands from the $\alpha / \beta$ repetition pattern initially proposed by McLachlan and Stewart (1975 and 1976) would be binding the 
filament in the absence of calcium ions. The introduction of calcium to the system would induce a rolling motion in and a displacement of the tropomyosin molecule with relation to the actin filament. In this situation tropomyosin's $\beta$-bands would be responsible for the binding of this molecule to the actin filament. 


\section{OBJETIVOS}

O presente estudo teve como objetivos principais:

1 - Caracterização de mutantes da tropomiosina com a sonda fluorescente 5hidroxitriptofano inserida em diversas posições da molécula quanto a sua capacidade de ligar actina e quanto a sua capacidade de regular a atividade $\mathrm{Mg}^{2+}$-ATPásica da acto-S1 miosina;

2 - Analisar o efeito das mutações e da inserção da sonda fluorescente 5hidroxitriptofano na estabilidade global da molécula de tropomiosina por meio de análise de desnaturação térmica seguida por dicroísmo circular;

3 - Estudar a estabilidade local da molécula de tropomiosina na região das sondas fluorescentes por meio de desnaturações por uréia acompanhada por variação no sinal de fluorescência destas sondas;

4 - Analisar o microambiente eletrônico próximo à região das sondas fluorescentes em diferentes situações (na presença de actina na ausência e presença de troponina $+/-\mathrm{Ca}^{2+}$ ) por meio de supressão por iodeto da fluorescência das sondas inseridas na molécula de tropomiosina;

5 - Analisar a variação no grau de exposição das sondas fluorescentes inseridas na molécula de tropomiosina em diversas posições quando da ligação de actina e de actina e troponina na presença e ausência de íons cálcio por meio da supressão por acrilamida da fluorescência destas sondas. 


\section{INTRODUÇÃO}

Este projeto teve como objetivo o estudo a nível molecular da regulação da contração do músculo esquelético. O enfoque principal foi sobre a molécula de tropomiosina e a sua relação com as outras proteínas do filamento fino no contexto da regulação da contração. Este complexo sistema está descrito em detalhes na PARTE I - Sistema muscular da INTRODUÇÃO

A principal ferramenta utilizada para o estudo deste sistema foi o fenômeno de fluorescência e, particularmente, a variação na intensidade da fluorescência em função da concentração de supressores de fluorescência adicionados ao sistema. Por isso, a segunda parte da introdução (PARTE II Fluorescência) descreve esta importante ferramenta. 


\section{PARTE I - Sistema muscular}

\section{Apresentação do sỉstema}

O processo de contração muscular é um fenômeno bastante complexo do ponto de vista bioquímico. O sistema macromolecular responsável pela contração do músculo esquelético e seu controle é composto por quatro proteinas principais: actina, miosina, tropomiosina e troponina. A miosina é o principal componente do filamento grosso e é a responsável pelo powerstroke causador do deslizamento relativo entre a actina e a miosina. A actina, a tropomiosina e o complexo troponina compõem o filamento fino. Estas duas últimas proteínas estão relacionadas com o controle, mediado por íons cálcio, da interação entre a actina e a miosina através de um processo ainda não inteiramente elucidado.

O músculo esquelético consiste de um agrupamento de fibras longas e paralelas de 20 a $100 \mu \mathrm{m}$ de diâmetro (Figura 1). Cada uma destas fibras é uma célula multinucleada composta de agrupamentos de miofibrilas de cerca de 1 a $2 \mu \mathrm{m}$ de diâmetro. A unidade básica de organização da miofibrila é denominada sarcômero. Cada uma destas unidades é composta pelo empacotamento de filamentos grossos de miosina e filamentos finos de actina que podem deslizar um sobre o outro durante a contração muscular isométrica (Figura 1C e D) ou gerar tensão durante a contração muscular isotônica. Esse deslizamento causador da contração muscular deve-se à existência de geradores independentes (pontes cruzadas = "cross-bridges") de força na região de sobreposição dos dois tipos de filamento. Estas pontes cruzadas são, na realidade, domínios globulares da miosina que interagem com a actina numa maneira cíclica, dependente de ATP. 


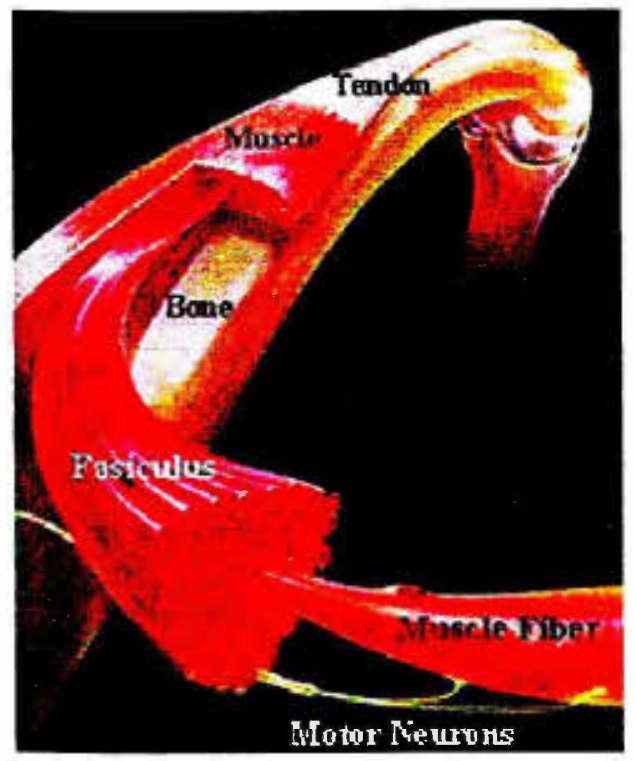

A

B
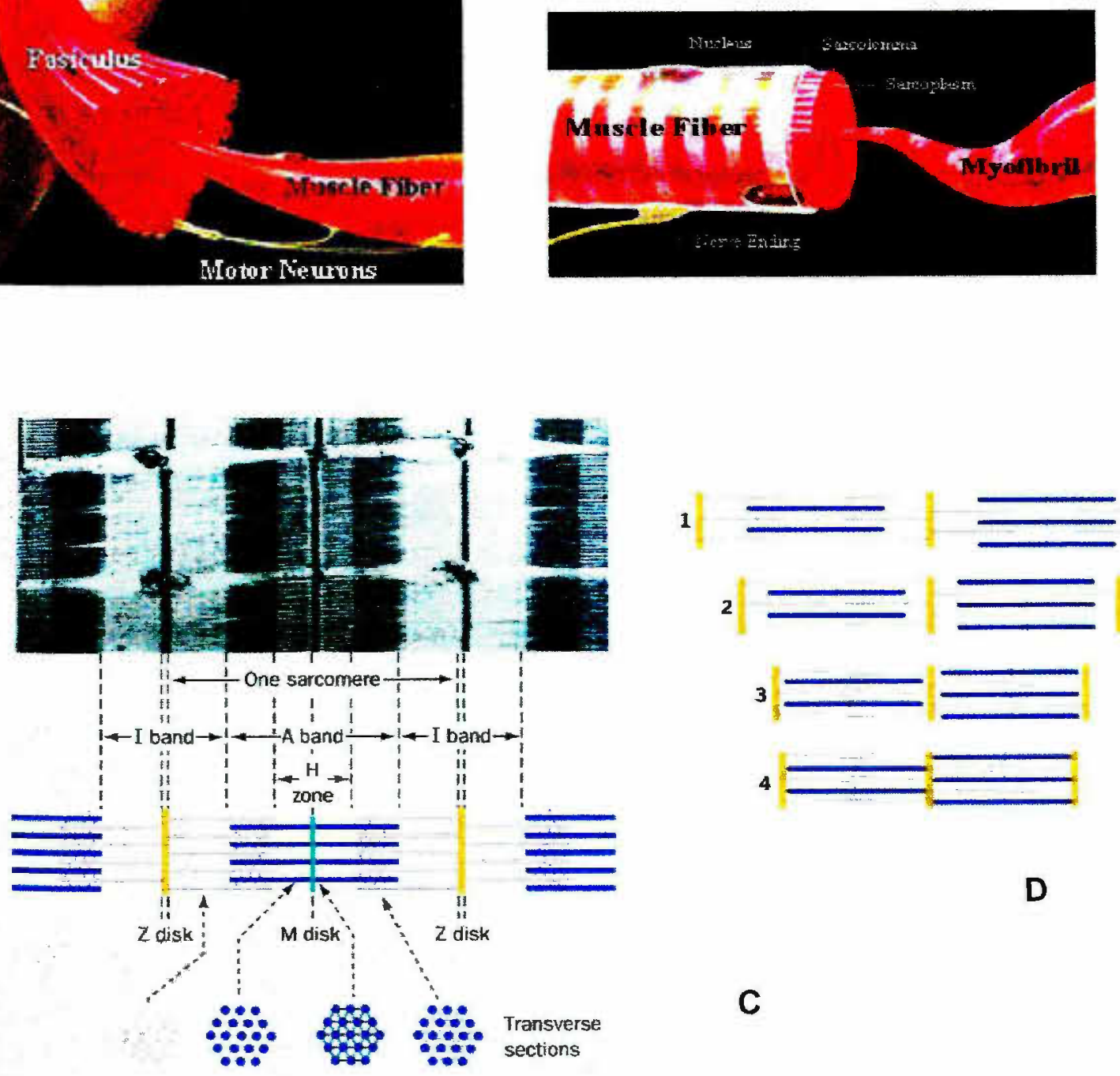

D

C

Figura 1. Esquema do músculo estriado (A e B) e do sarcômero (C e D). O painel C mostra uma análise do típico padrão estriado do músculo esquelético. Um esquema simplificado de um sarcômero contraindo pode ser visualizado no painel D. Como indicado, o deslizamento relativo entre os filamentos grossos de miosina (linhas azuis) e os filamentos finos de actina (linhas rosa) está intimamente relacionado com o fenômeno de contração muscular. [painéis A e B : www.ucsf.edu/cooke/research/researchframe.htm; painéis C e D: Voet e Voet, 1995 cortesia de Hugh Huxley, Brandeis University)] 
A regulação do processo muscular dá-se pela variação na concentração intracelular de $\mathrm{Ca}^{2+}$ (vide revisões de Zot e Potter, 1987; da Silva e Reinach, 1991; Farah e Reinach, 1995; Tobacman, 1996; Squire e Morris, 1998). Para isto, o músculo vale-se da ação do complexo troponinatropomiosina associado aos filamentos de actina. Cada complexo troponinatropomiosina é diretamente responsável pela regulação da interação entre sete actinas e a miosina. Esta regulação dá-se pela inibição, na ausência de $\mathrm{Ca}^{2+}$, ou ativação, na presença deste, da interação ATPásica entre actina e miosina. Num modelo bastante aceito atualmente, embora ainda não compreendido em seus detalhes, a tropomiosina impede espacialmente a interação da miosina com a actina na ausência de $\mathrm{Ca}^{2+}$ (Huxley, 1972; Haselgrove, 1972; Parry e Squire, 1973). Quando o $\mathrm{Ca}^{2+}$ está presente e ligase à troponina, o bloqueio é retirado (ver figura 2).

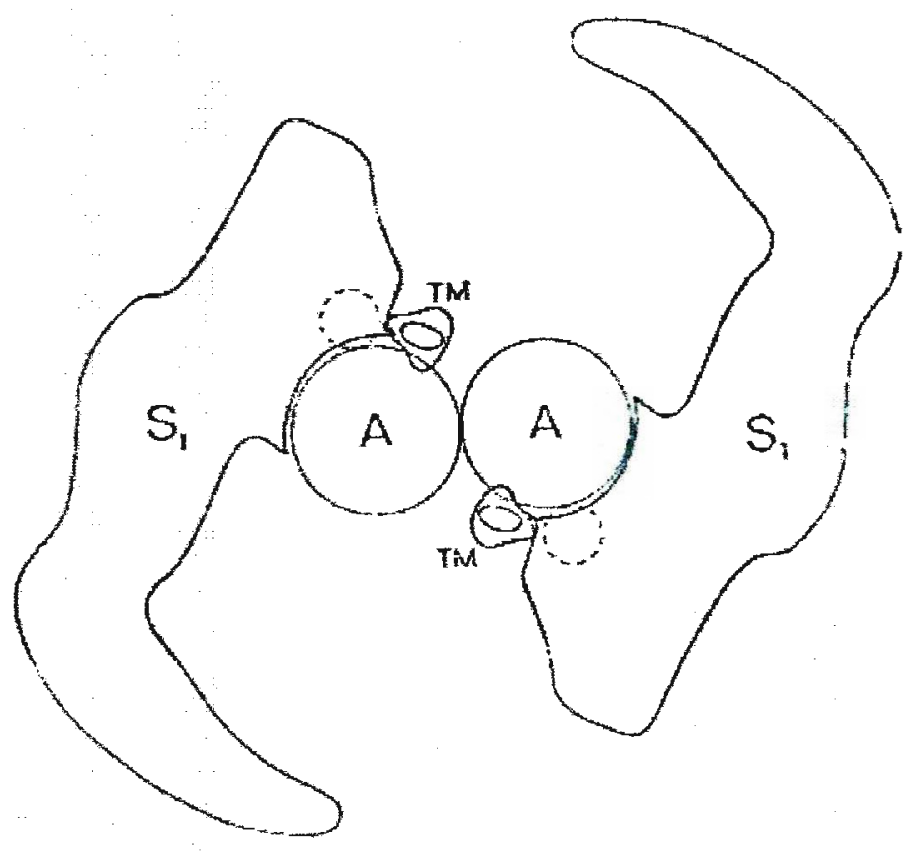

Figura 2. Figura clássica de Huxley (1972) indicando o modelo do bloqueio estérico. S1 - cabeça de miosina; A - actina; TM - tropomiosina. Visão ao longo do eixo do filamento de actina. $\mathrm{Na}$ ausência de cálcio a tropomiosina ocupa uma posição que inibe a interação da actina com a miosina (TM linhas pontilhadas). A presença de cálcio faz com que a tropomiosina se movimente liberando os sítios de interação da miosina (TM - linhas cheias). 


\subsection{Miosina}

Os filamentos grossos de vertebrados compõe-se em maior parte da proteína miosina (Figura 3). Esta proteína é composta de seis cadeias polipeptídicas: duas cadeias pesadas e dois pares de cadeias leves. Ocorre uma associação entre as duas cadeias pesadas por meio de uma interação do tipo "coiled-coil" envolvendo seus domínios carbóxi-terminais. Em condições fisiológicas, moléculas de miosina polimerizam para formar filamentos bipolares (o filamento grosso).

A clivagem da miosina com tripsina produz dois fragmentos (Figura 3): a meromiosina leve (LMM) que é responsável pela polimerização mas que não possui nem atividade ATPásica nem a habilidade de associar-se com o filamento fino e a meromiosina pesada (HMM) que por tratamento com papaína (ou quimotripsina) produz dois subfragmentos globulares idênticos (S1) e um subfragmento filamentar (S2). A S1 (Figura 4), que possui os sítios de ligação de ATP e actina, foi cristalizada por Rayment et al. (1993b) e consiste da metade $\mathrm{N}$-terminal de uma cadeia pesada associada com as duas cadeias leves (Figura 4).

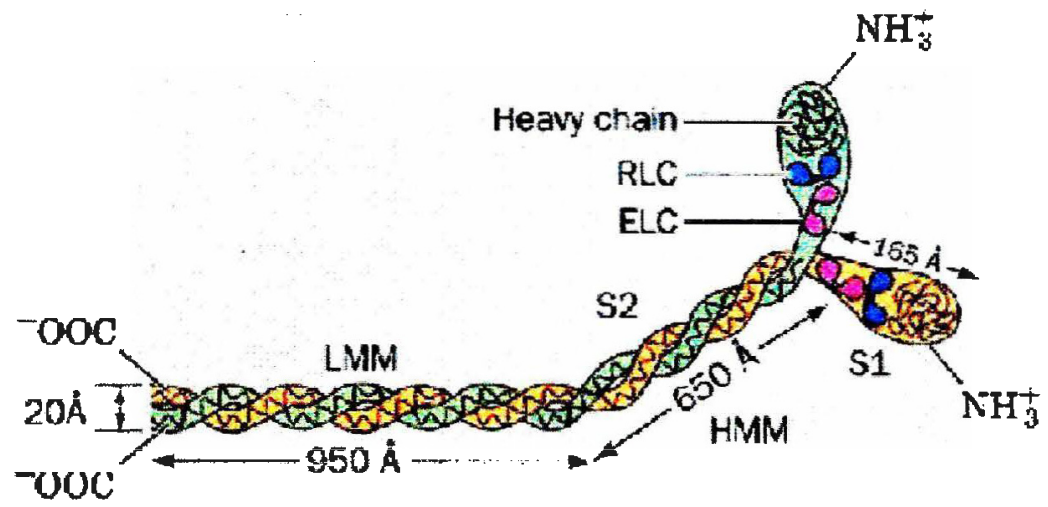

Figura 3. A molécula de miosina é composta de duas regiões que podem ser clivadas por tripsina: uma longa região coiled-coil (LMM - light meromyosin) e uma região que pode ser subsequentemente clivada por quimotripsina em dois subfragmentos globulares (S1) com atividade ATPásica e um subfragmento filamentar (S2). RLC - regulatory light chain; ELC - essential light chain; HMM - heavy meromyosin [Voet e Voet, 1995 cortesia de Henry Slayter, Harverd Medical School]. 


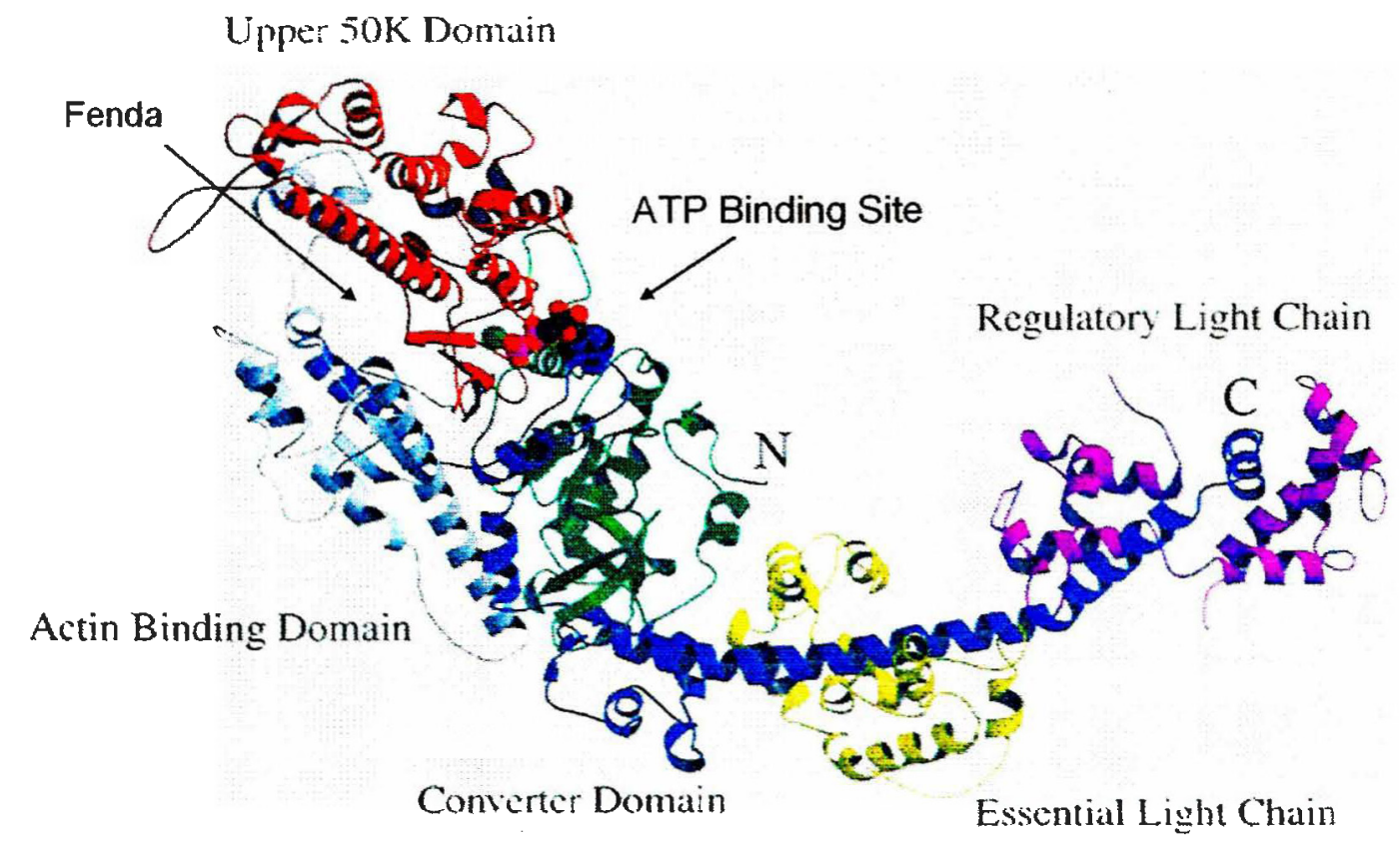

Figura 4. O subfragmento S1 da miosina (Rayment et al, 1993b) possui uma cabeça alongada consistindo de uma folha- $\beta$ de sete fitas e uma cauda ou "pescoço" C-terminal que carrega duas cadeias leves tipo calmodulina - a cadeia leve regulatória (magenta) e a essencial (amarelo). A estrutura está colorida de acordo com seus três fragmentos trípticos da seguinte forma: $25 \mathrm{~K}$ (N-terminal), verde; 50K, vermelho e cinza; e 20K (C-terminal), azul. O fragmento $50 \mathrm{~K}$ possui dois domínios: o domínio 50K superior (upper $50 \mathrm{~K}$ domain) e o domínio 50K inferior ou ligante de actina (Actin Binding Domain) colorido em cinza. Todos os três fragmentos $(25 \mathrm{~K}, 50 \mathrm{~K}$ e $20 \mathrm{~K}$ contribuem para a formação de uma folha- $\beta$ de sete fitas no centro da estrutura. Várias $\alpha$ hélices que envolvem a folha- $\beta$ formam uma fenda profunda que se extende do sítio de ligante de ATP até o sítio de ligação de actina. [Geeves e Holmes, 1999]

\subsection{Actina}

A actina (Figura 5) é o constituinte principal dos filamentos finos. A baixa força iônica a actina encontra-se na forma monomérica (G-actina). Sob condições fisiológicas (presença de $\mathrm{Mg}^{2+}$, ATP e força iônica > 25mM), entretanto, ela polimeriza-se formando filamentos (F-actina) (Straub, 1942). A G-actina foi cristalizada na forma complexada com DNasel (Kabsch et al., 1990). A molécula de actina é praticamente um quadrado com 5-6 $\mathrm{nm}$ de lado e com aproximadamente $3.5 \mathrm{~nm}$ de expessura. A actina é dividida em dois 
domínios de tamanhos aproximadamente iguais, denominados domínio maior e domínio menor, por uma fenda contendo o cátion $\left(\mathrm{Mg}^{2+}\right)$ e o ATP ligados (necessários à polimerização da actina). A região que liga os dois domínios possui apenas duas fitas próximas de cadeia polipeptídica, formando uma "dobradiça" que pode permitir uma movimentação relativa significante dos domínios (Kabsch et al, 1990). Cada domínio é dividido em dois subdomínios. O domínio menor contém os subdomínios I e ll e o domínio maior contém os subdomínios III e IV (Figura 5). A estrutura cristalina da G-actina em combinação com estudos da F-actina por microscopia eletrônica (Hanson e Lowy, 1963; Milligan et al., 1990; Lehman, 1994) e por difração de raio-X (Moore et al., 1970) permitiram a obtenção de um modelo molecular da Factina apresentado na figura 6 (Holmes et al., 1990).

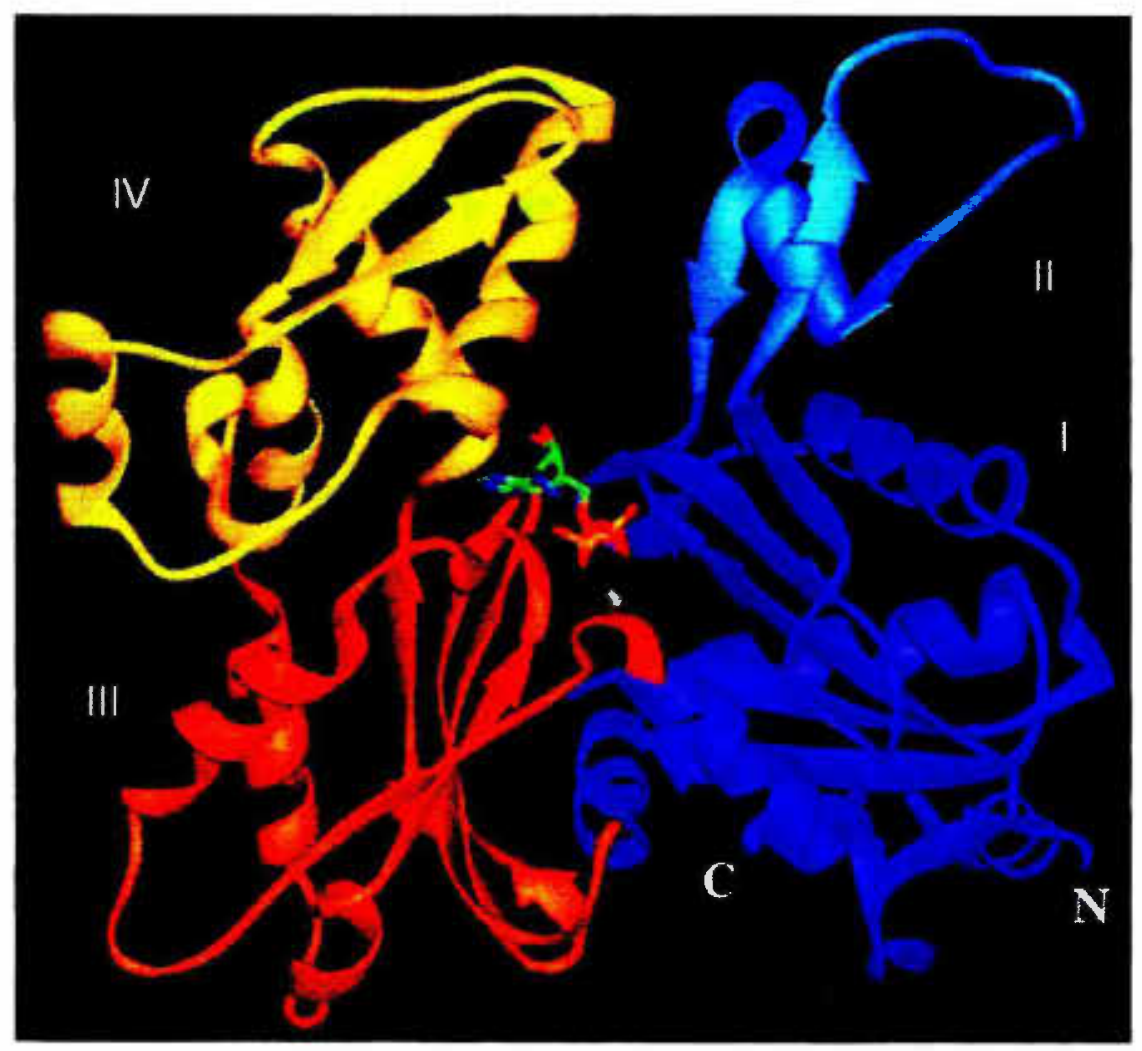

Figura 5. A molécula de actina (Kabsch et al, 1990). Os subdomínios I (magenta), II (azul), III (vermelho) e IV (amarelo) estão indicados na figura. O ATP (molécula no centro) e o magnésio (esfera cinza) também estão indicados. 


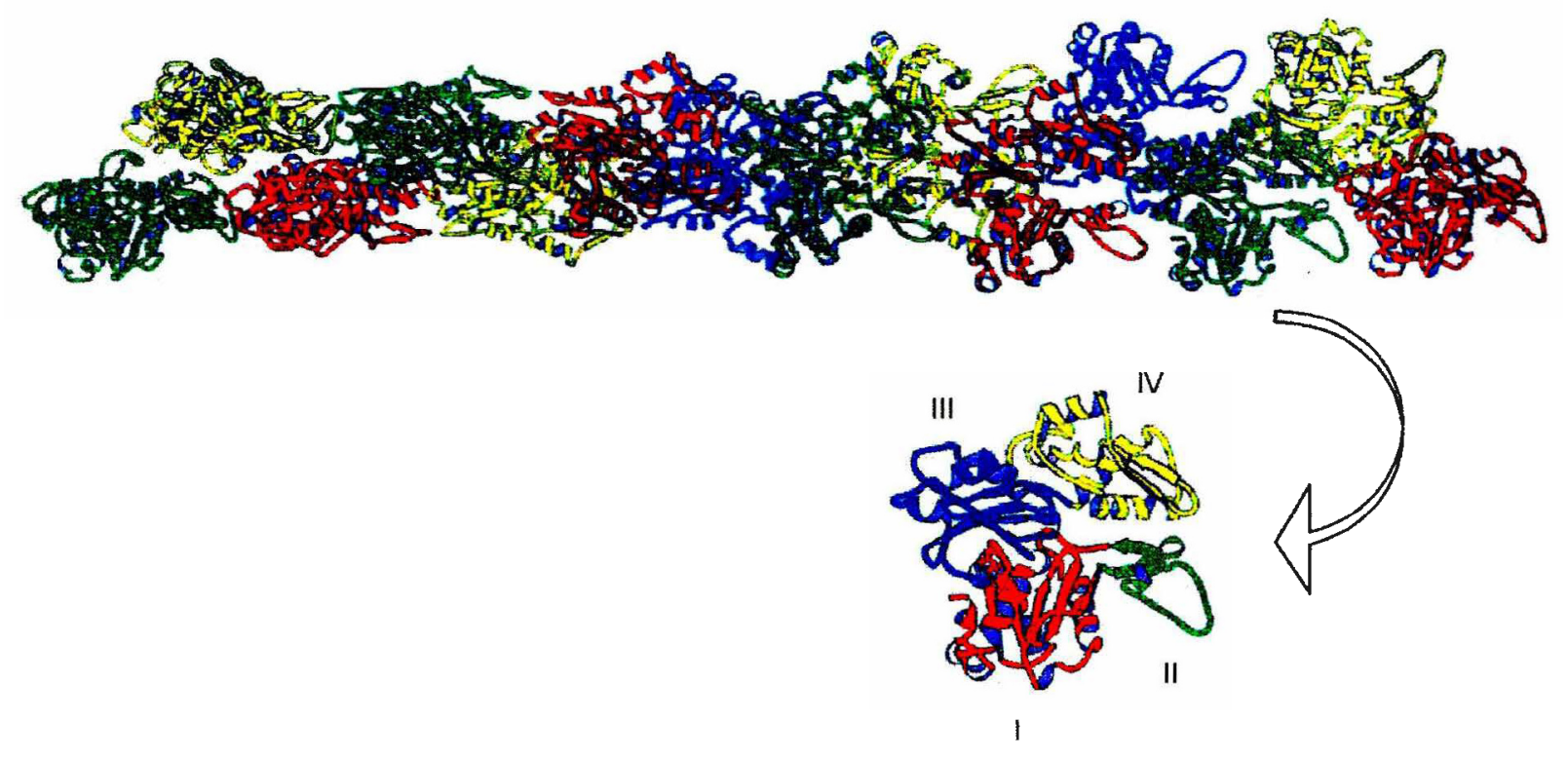

Figura 6. O filamento de actina gerado por Holmes et al. (1990) por meio da montagem dos monômeros de actina (Kabsch et al, 1990) numa hélice 13/6 para modelar dados de difração de raios-X de fibras a partir de géis de filamentos de actina orientados.

Uma representação esquemática da estrutura da F-actina pode ser visualizada na figura 6 . O filamento de actina é helicoidal com 13 moléculas de actina a cada 6 voltas (Holmes et al., 1990). Alternativamente podemos considerar o filamento de actina como contendo duas fitas paralelas, entrelaçadas (mão esquerda), contendo treze monômeros por volta. $O$ modelo para a F-actina indica que o domínio maior (subdomínios III e IV) localiza-se mais para o centro do filamento helicoidal dupla-fita. O domínio menor, que inclui as regiōes $\mathrm{N}$ - e $\mathrm{C}$-terminal no subdomínio 1 , encontra-se mais exposto ao solvente. 


\section{3. $\mathrm{O}$ ciclo $\mathrm{Mg}^{2+}$-ATPásico da actomiosina}

O processo de contração muscular consome ATP. A interação molecular responsável pelo mecanismo de contração muscular consiste num ciclo no qual a miosina alterna entre estados de ligação forte com a actina ou com nucleotídeos. O mecanismo da reação de ATPase neste processo pode ser esquematizado da seguinte forma:

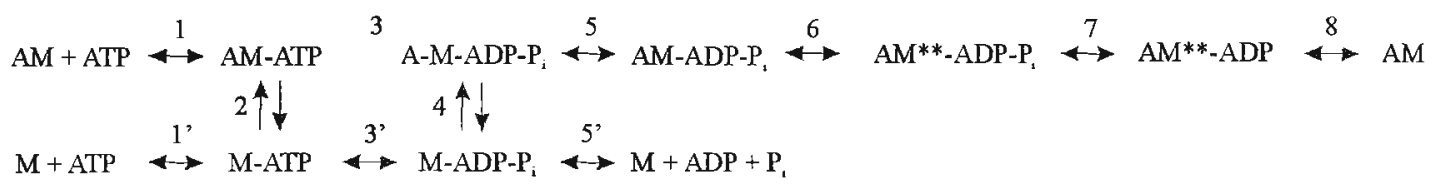

O passo 1 indica a ligação rápida de ATP que dá origem ao complexo actomiosina-ATP (AM-ATP). A actina então dissocia-se rapidamente devido à sua baixa afinidade ao complexo miosina-ATP dando origem a actina mais miosina-ATP (M-ATP) (passo 2). Em seguida ocorre uma hidrólise rápida e reversível do ATP na cabeça (S1) da miosina (passo 3'). À forças iônicas fisiológicas a dissociação de AM-ATP em A + M-ATP é bastante alta de forma que virtualmente toda a clivagem do ATP ocorre na miosina dissociada (desta forma, o passo 3 praticamente não acontece) (White et al., 1997). A velocidade de dissociação do $P_{i}$ a partir do complexo AM-ADP- $P_{i}$ é > $50 \times$ a velocidade de dissociação a partir do M-ADP-P. Sob condições fisiológicas ocorre uma rápida reassociação (passo 4) da actina e M-ADP- $P_{i}$ formando um estado fracamente ligado A-M-ADP- $P_{i}$ que isomeriza (passo 5) para um estado mais fortemente ligado AM-ADP- $P_{i}$. Este é provavelmente a transição regulada por cálcio em sistemas contendo tropomiosina e troponina ( $\mathrm{Ma} \mathrm{e}$ Taylor, 1994). Acredita-se que este estado mais fortemente ligado isomeriza para gerar força e $A M^{* *}-A D P-P_{i}$ (passo 6 - movimentação do braço da miosina (lever arm motion)) (Pate e Cooke, 1989; White e Taylor, 1976). Esta forma é então estabilizada no passo 7 pela liberação de $P_{i}$ pela "porta dos fundos" do sítio de ligação ao nucleotídeo (ver 1.4. Alguns aspectos da interação entre a actina e a miosina). A transição do estado fracamente 
ligado $A-M-A D P-P_{i}$ para o estado fortemente ligado $A M^{* *}$-ADP é a transição na qual ocorre a geração de força. Por fim ocorre uma isomerização irreversível do estado $A M^{* *}$-ADP para um estado $A M^{*}$-ADP (não mostrada no esquema) seguida pela rápida dissociação de ADP (passo 8) (revisões podem ser encontradas em Gordon et al., 2000 e Cooke, 1997).

O ciclo ATPásico descrito acima pode ser visualizado de forma mais ilustrativa na figura 7 (a relação desta figura com o esquema acima encontrase explicada na legenda da figura).

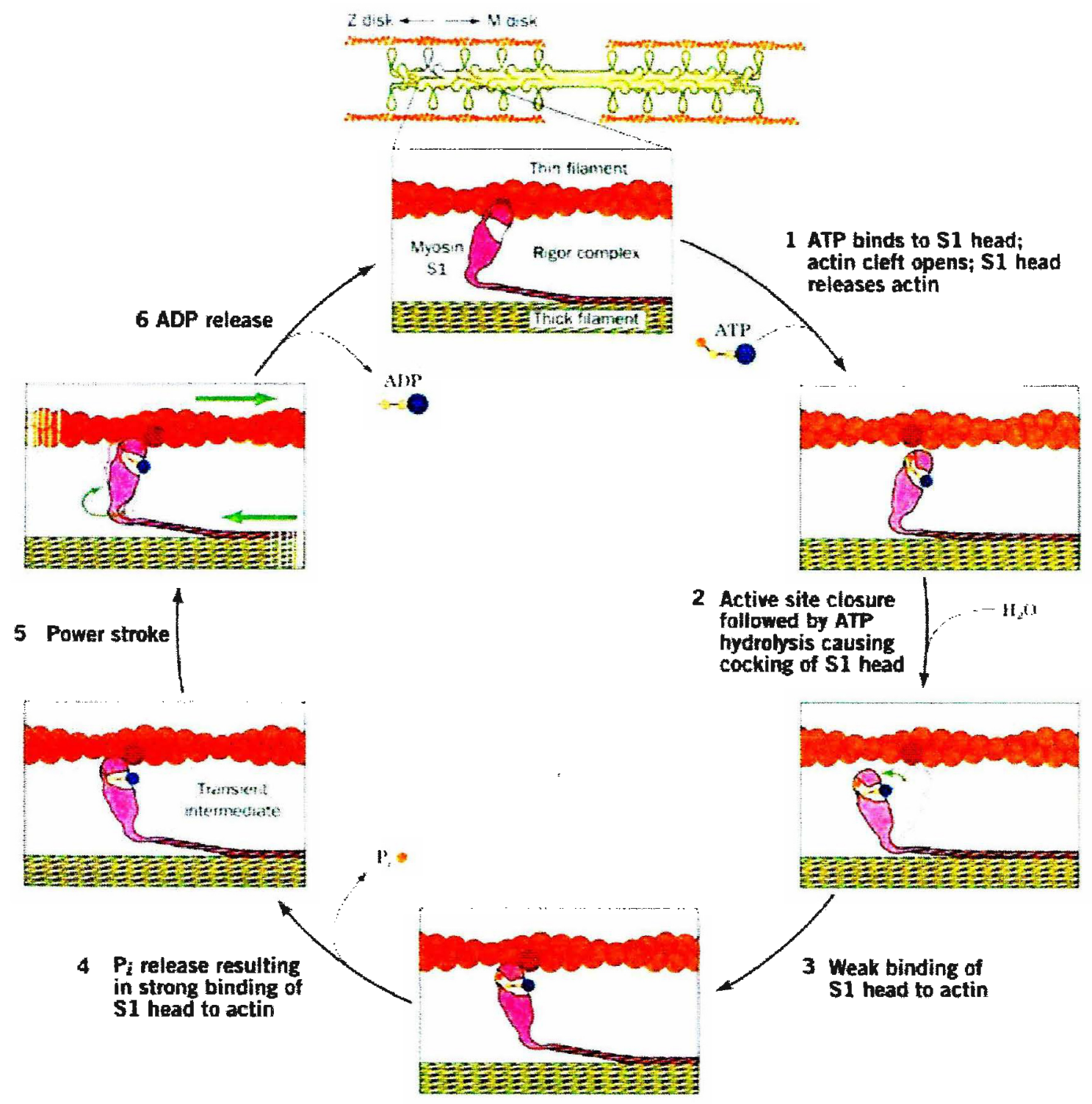


Figura 7 (página anterior). Esquema ilustrativo do ciclo ATPásico da contração muscular com uma representação das proteínas envolvidas. 1 na figura representa os passos 1 e 2 no esquema anterior; 2 representa o passo 3'; 3 representa o passo 4; 4 e 5 representam os passos 5, 6 e 7 (Se a geração de força ocorre no passo 6 , como indicado no esquema, ou se a ligação forte à actina, a geração de força e a liberação de $\mathrm{Pi}$ ocorre simultaneamente (4 e 5 na figura) ainda não está bem estabelecido); 6 na figura representa o passo 8 do esquema. [Rayment e Holden, 1993]

É interessante notar que a hidrólise do ATP (passo $3^{\prime}$ ) não ocorre no mesmo momento do ciclo no qual dá-se a produção de trabalho (passo 6). A produção de força decorre provavelmente de uma mudança no orientação da região do pescoço da miosina enquanto a região com atividade catalítica permanece rigidamente ligada ao filamento de actina. A energia livre decorrente da hidrólise do ATP torna-se disponível quando a miosina não está ligada na actina ou quando ligada fracamente (passo $3^{\prime}$ ). Assim, esta energia não é diretamente utilizada no "power-stroke" mas gera mudanças conformacionais no complexo acto-miosínico que, em última instancia, dá origem à contração. Desta forma, a energia responsável pela geração de força pode estar vindo diretamente da formação de uma ligação forte entre a actina e a miosina que ocasiona o enterramento de uma extensa área hidrofóbica causando a liberação de uma quantidade considerável de energia livre (passo 6) (Pate e Cooke, 1989; White e Taylor, 1976). Após o "power stroke" a actina e a miosina ficam com uma extensa interface de ligação bastante forte. A ligação de ATP, que se liga fortemente à molécula de miosina quando esta não está interagindo com a molécula de actina e muito mais fracamente à actomiosina, fornece a energia necessária para romper a interação entre a actina e a miosina, permitindo a continuação do ciclo ATPásico.

\subsection{Alguns aspectos da interação entre a actina e a miosina.}

Uma questão fundamental para a compreensão do mecanismo de contração muscular envolve a determinação das superfícies de interação entre a cabeça globular da miosina e o filamento de actina (ver, por exemplo, Geeves e Holmes, 1999; Gordon, 2000; Cooke, 1993; Sheterline et al., 1998; 
Milligan, 1996). Devido às proporções deste complexo e a natureza filamentosa da actina, estruturas do complexo miosina-actina por RMN ou cristalografia não são possiveis de se obter no momento. Entretanto, um modelo atômico entre o filamento de actina e a miosina no complexo 'rigor' (a ligação forte entre estas duas proteínas obtidas na ausência de ATP) foi construido a partir do 'docking' das estruturas cristalinas da cabeça de miosina e o modelo do filamento de actina em uma estrutura de baixa resolução obtida por microscopia crioeletrônica (Rayment et al, 1993a) (Figura 8). Outras estruturas de miosina foram determinadas com análogos de ATP (Fischer et al., 1995; Smith e Rayment, 1996; Gulick et al., 1997; Houdusse e Sweeney, 2001).

A estrutura da cabeça de miosina (S1) utilizada para o 'docking' não continha ATP, devendo estar, portanto, numa conformação parecida com a do estado 'rigor'. Neste modelo, a cabeça da miosina (S1) liga-se a uma actina e faz contatos consideráveis com a actina que vem imediatamente abaixo no filamento. A fenda da miosina (Figura 4) extende-se do sítio de ligação de ATP ao sítio de ligação à actina. Desta froma os movimentos relativos nesta fenda podem fornecer uma ligação física entre estes dois sítios (Rayment et al, 1993b).

Acredita-se que a miosina deva ligar-se ao filamento de actina inicialmente através de ligações iônicas (Rayment et al, 1993a). A formação de uma ligação forte estereoespecífica entre a cabeça de miosina e o filamento de actina parece estar relacionada ao fechamento da fenda na miosina, evitando contatos estericamente desfavoráveis com o filamento de actina, e permitindo que o fosfato hidrolisado durante o ciclo ATPásico (ver acima) escape por uma 'porta dos fundos' do sítio de ligação ao nucleotídeo (Rayment e Holden, 1994; Rayment et al., 1993a; Yount et al., 1995) . 


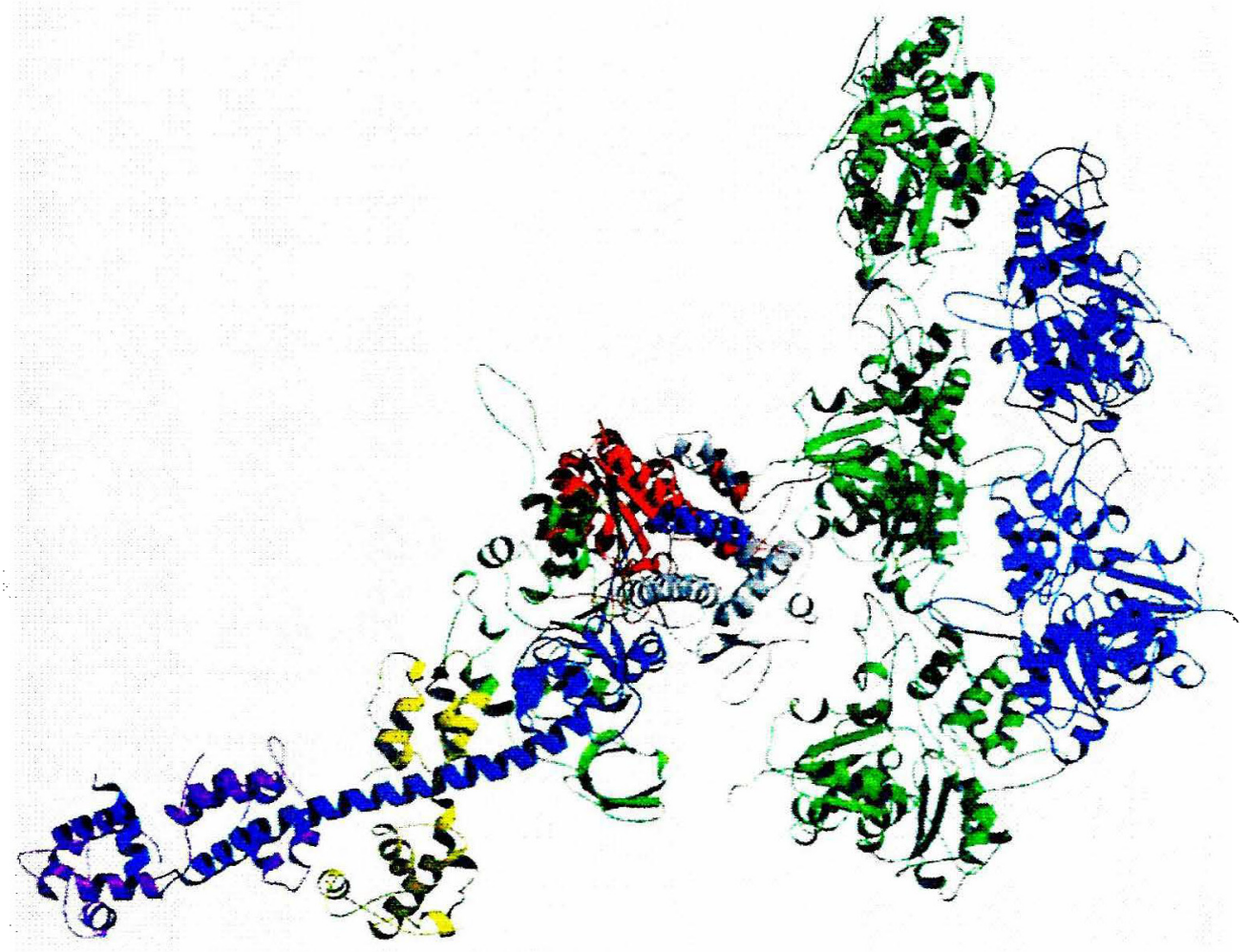

Figura 8. Estrutura do complexo actomiosina (Rayment et al., 1993) mostrando (à direita) cinco moléculas de actina na hélice de actina e (à esquerda) uma ponte cruzada de miosina (S1).

\subsection{Troponina}

A troponina possui três subunidades: TnC, uma proteína que liga $\mathrm{Ca}^{2+} ; \mathrm{Tnl}$, que se liga à actina e inibe a atividade ATPásica da actomiosina; e TnT, uma molécula alongada, que se liga à tropomiosina (Greaser e Gergeley, 1973; Mak e Smillie, 1981).

\section{A subunidade $C$}

A contração do músculo estriado é regulada pela ligação de $\mathrm{Ca}^{2+}$ à TnC. A estrutura de raio- $X$ de alta resolução de músculo esquelético de ave (Herzberg e James, 1985; Sundaralingam et al., 1985) apresenta uma molécula assimétrica com uma grande porcentagem de $\alpha$-hélice com dois 
domínios globulares conectados por uma longa hélice central (Figura 9). Cada domínio contém um par de sítios do tipo $E-F$ hand que ligam $\mathrm{Ca}^{2+}$, mas no $\mathrm{pH}$ baixo do cristal apenas os sítios com maior afinidade (os do domínio C-terminal) estão ocupados.

Os sítios C-terminais III e IV possuem alta afinidade por $\mathrm{Ca}^{2+}\left(\sim 10^{7} \mathrm{M}^{-1}\right)$ (Zot e Potter, 1982) e suficiente afinidade por $\mathrm{Mg}^{2+}$ de forma que no músculo relaxado este íon encontra-se normalmente ligado. Estes sítios são denominados sítios estruturais porque a ligação a estes íons aumenta a interação TnC-Tnl e a ligação de TnC ao filamento fino (Zot e Potter, 1982). Os sítios $\mathrm{N}$-terminais I e II são os sítios regulatórios com menor afinidade $\left(\sim 10^{5} \mathrm{M}^{-1}\right)$ e alta seletividade por $\mathrm{Ca}^{2+}$ em detrimento de $\mathrm{Mg}^{2+}$ (Potter e Gergely, 1974).

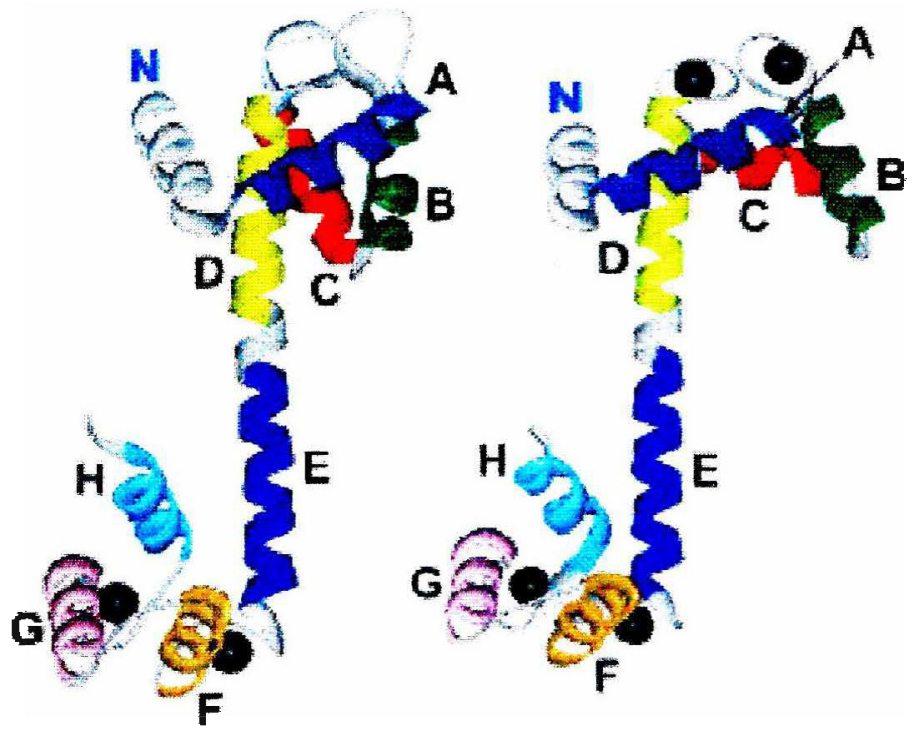

Figura 9. À esquerda: representação da estrutura cristalina da $\mathrm{TnC}$ de peru com $\mathrm{Ca}^{2+}$ (círculos sólidos) ligado aos sítios estruturais $\mathrm{C}$-terminais. O Nterminal está indicado na figura $(\mathrm{N})$ e as oito hélices estão indicadas e coloridas para mostrar sua orientação (Herzberg e James, 1985). À direita: representação da $\mathrm{TnC}$ de coelho com $\mathrm{Ca}^{2+}$ (círculos sólidos) ligado tanto nos sítios estruturais $\mathrm{C}$-terminais quanto nos sítios regulatórios $\mathrm{N}$-terminais (Houdusse et al., 1997). A mudança estrutural observada expõe uma superfície hidrofóbica que pensa-se interaja com a Tnl e seja responsável pela liberação da inibição à contração muscular. [Gordon et al., 2000; ver também Takeda et al. 2003] 
A ligação de $\mathrm{Ca}^{2+}$ aos sítios $\mathrm{N}$-terminais da $\mathrm{TnC}$ faz com que hélices desta região adotem uma conformação mais aberta, mais perpendicular à hélice central da molécula, expondo assim um sulco com superfície hidrofóbica que interage com a Tnl aliviando assim a inibição (Herzberg et al., 1987; Takeda et al., 2003).

A subunidade /

A Tnl é a subunidade da troponina essencial para a inibição da contração muscular na ausência de $\mathrm{Ca}^{2+}$. Contendo aproximadamente 180 aminoácidos, esta proteína globular liga-se à actina, à tropomiosina, à TnT e à TnC (Ohtsuki et al., 1986; Zot e Potter., 1987; Reinach et al., 1997). Seu efeito inibitório está relacionado com sua capacidade de interagir com o sistema actina-tropomiosina e com a TnC de maneira dependente de $\mathrm{Ca}^{2+}$ (Perry et al., 1972; Greaser e Gergely, 1971, 1973). Sua atividade inibitória é bem menor que a do complexo troponina inteiro (Ebashi et al., 1971). Estudos com fragmentos proteolíticos da $\mathrm{Tnl}$ identificaram a sequência central desta (resíduos 96-116 na proteína de coelho) como responsável pela atividade inibitória (Syska et al., 1976). Esta região inibitória foi definida com mais precisão por Talbot e Hodges (1981), que mostraram que a região correspondente aos resíduos 104-115 (Ip) contém a sequência mínima necessária para a inibição e a ligação à actina. A região C-terminal da $\mathrm{Tnl}$ também participa da inibição (Farah et al., 1994). Na presença de $\mathrm{Ca}^{2+}$, estas duas regiões desligam da actina e ligam à TnC (Farah et al., 1994; Farah e Reinach, 1995). A região N-terminal da Tnl é responsável pela ligação desta à TnC de forma independente de $\mathrm{Ca}^{2+}$ (Syska et al., 1976, Farah et al., 1994). 
A subunidade $\operatorname{TnT}$ é a responsável pela ligação do complexo da troponina à tropomiosina (Greaser e Gergeley, 1971, 1973). Esta subunidade possui dois domínios que podem ser liberados por proteólise: TnT-1 (resíduos 1-158) e TnT-2 (resíduos 159-259). O domínio globular C-terminal (TnT-2) é responsável pelas interações com a $\mathrm{Tnl}$ e a TnC para formar o domínio globular do complexo troponina (Heeley et al., 1987). A afinidade deste domínio pela tropomiosina diminui na presença de $\mathrm{Ca}^{2+}$ (Heeley et al., 1987). O dominio $\mathrm{N}$-terminal (TnT-1) interage fortemente com a actinatropomiosina (Ohtsuki, 1979; Tanokura et al., 1983). Esta região da TnT de músculo esquelético é 68\% $\alpha$-helicoidal (Pearlstone et al., 1977; Tanokura et al., 1983) e em co-cristais de baixa resolução com a tropomiosina parece estar associada com os últimos 100 aminoácidos desta incluindo a região "cabeça-cauda" (ver abaixo) das tropomiosinas vizinhas (White et al., 1987). Sua estrutura é, entretanto, desconhecida como o são os resíduos da tropomiosina e da TnT que estão realmente envolvidos nesta interação.

Recentemente Takeda et al. (2003) resolveram a estrutura de um "complexo mínimo" do complexo troponina cardíaco humano na forma saturada com $\mathrm{Ca}^{2+}$. A análise das estruturas geradas mostraram que este complexo mínimo é subdividido em subdomínios distintos estruturalmente, conectados por ligações flexíveis, tornando esta molécula altamente flexível. A Tnl e a TnT formam um subdomínio em coiled-coil, o braço IT, que contém as regiões prováveis de interação com a tropomiosina (Figura 10). 


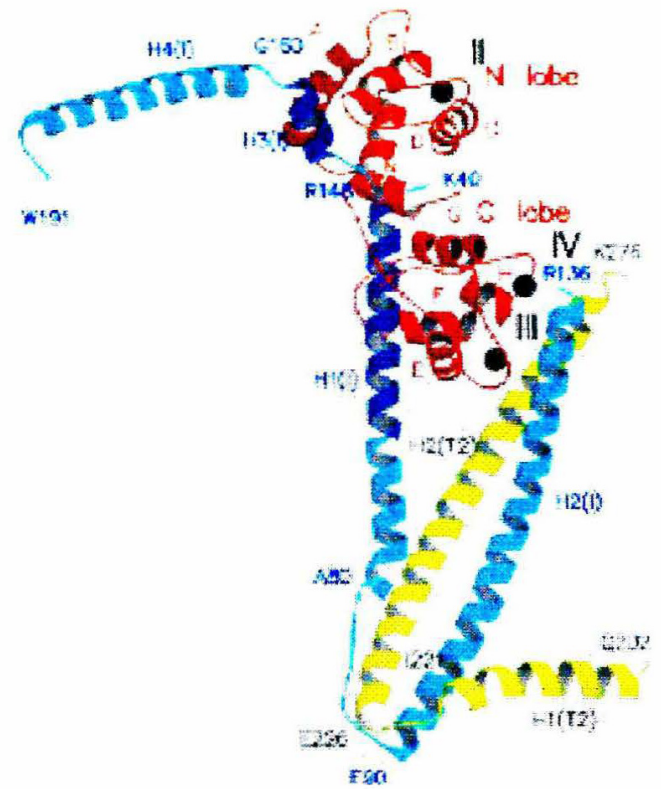

Figura 10. Estrutura cristalina do "complexo mínimo" da troponina obtido por Takeda et al. (2003). A TnC está em vermelho e a TnT em amarelo. A Tnl está colorida em azul claro exceto por dois segmentos de hélices anfifílicas (sítios de ligação à $\mathrm{TnC}$ ), que estão coloridos em azul escuro. Os três íons cálcio estão ligados aos sítios de ligação de cálcio (II-IV) e estão representados por esferas negras. Cada hélice da Tnl e TnT está indicada pelo número da hélice e cada hélice na TnC está indicada por uma letra maiúscula ( $\mathrm{N}$ e $\mathrm{A}-\mathrm{H})$.

Para revisões sobre as subunidades da troponina e seu papel no controle da contração muscular vide Farah e Reinach (1995), Tobacman (1996) e Squire e Morris (1998).

O complexo troponina num contexto funcional

O complexo troponina funciona como um modulador da contração muscular. A ligação de íons cálcio aos sítios regulatórios $\mathrm{N}$-terminais da TnC favorece uma mudança conformacional no complexo troponina pela exposição de sítios hidrofóbicos (Figura 9) e ligação à TnI. Um diagrama indicando o efeito da ligação de cálcio à TnC na interação entre as várias proteínas do filamento fino pode ser visualizado na figura 11 (Takeda et al., 2003). 


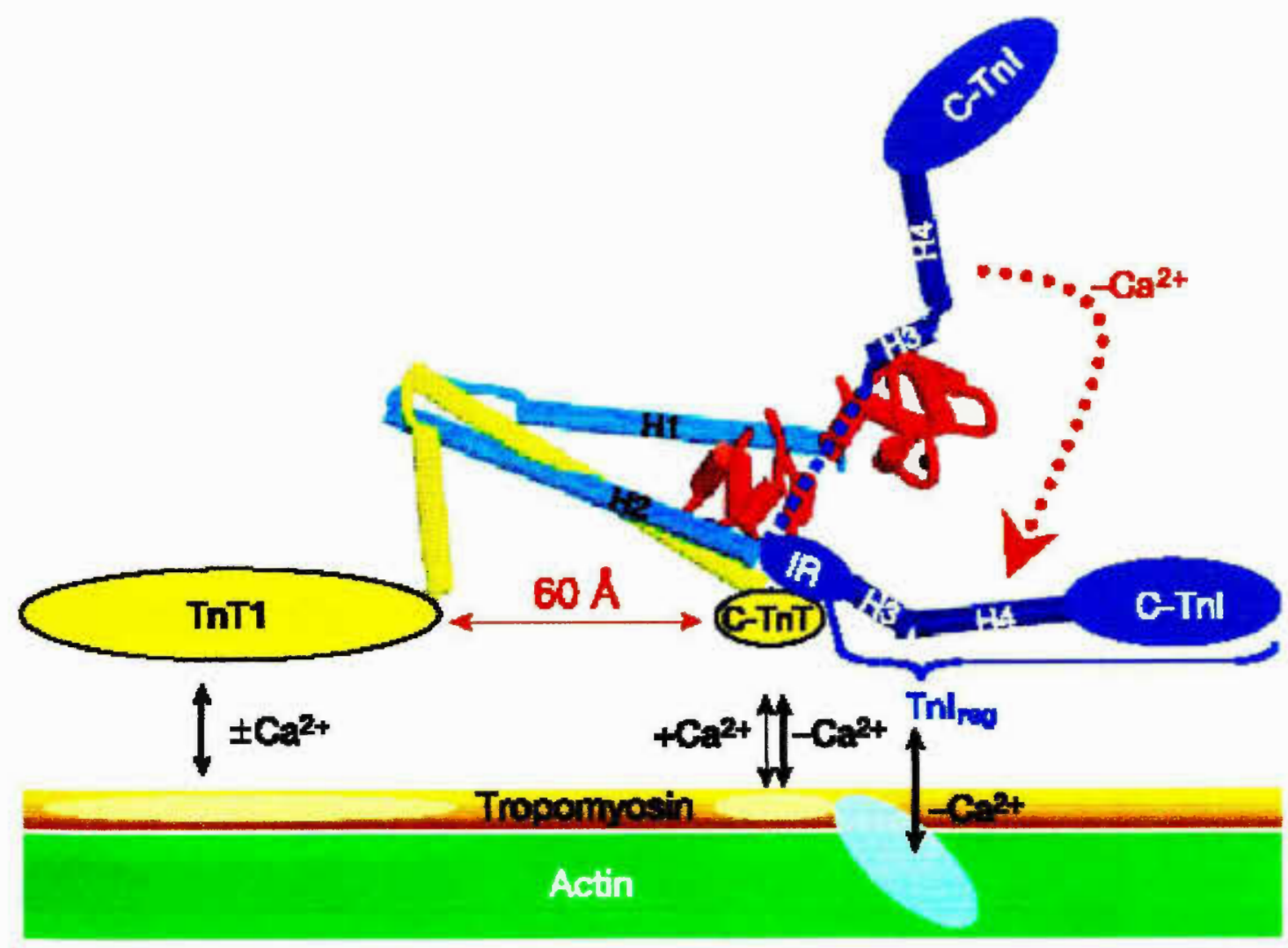

Figura 11. Representação esquemática das interações entre a troponina e outras proteinas do filamento fino. As regiões de interação entre a troponina e a actina-tropomiosina estão indicadas: TnT1 e C-terminal da TnT estão representadas por elipses amarelas; e a região inibitória (IR) e o C-terminal da $\mathrm{Tnl}$ estão representadas por elipses azuis. Os filamentos de actina e tropomiosina estão indicados em verde e laranja, respectivamente. As flechas grossas indicam interações mais fortes ao passo que as flechas finas indicam interações mais fracas. O "complexo mínimo" da troponina presente nesta figura encontra-se mais detalhado na figura 10. [Takeda et al., 2003]

Acredita-se que estas variações na interação entre as subunidades do complexo ternário troponina e as outras proteínas do filamento sejam responsáveis pela mudança na posição relativa entre a molécula de tropomiosina (ver item 1.6 Tropomiosina) e o filamento de actina, resultando na liberação dos sítios de interação forte entre a cabeça $\$ 1$ de miosina e o filamento de actina e permitindo a ocorrência do ciclo ATPásico (ver item 1.3. O ciclo ATPásico e item 2. Regulação da contração muscular). 


\subsection{Tropomiosina}

Isoformas da tropomiosina podem ser encrontradas virtualmente em todas as células musculares e não musculares. Em músculo esquelético e cardiaco, a tropomiosina é a responsável, junto com o complexo ternário ligante de cálcio troponina, pelo mecanismo bioquímico de regulação da contração muscular.

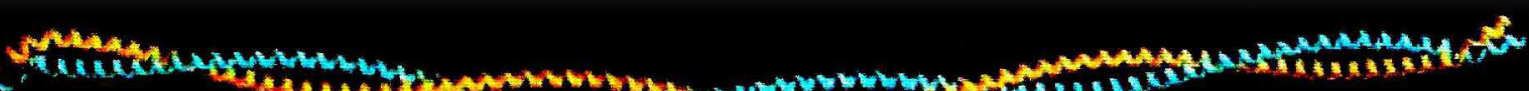

Figura 12. Modelo molecular do coiled-coil da tropomiosina baseado na estrutura cristalográfica de $7 \AA$ de resolução obtida por Whitby e Phillips Jr. (2000).

A tropomiosina de músculo esquelético é uma proteína dimérica, linear, com um comprimento aproximado de $40 \mathrm{~nm}$, ligante de actina, com duas subunidades $\alpha$-helicoidais com 284 resíduos associadas em paralelo e em fase organizadas numa estrutura macromolecular denominada "coiledcoil' (Stewart \& McLachlan, 1975; Johnson \& Smillie, 1975; Cohen \& Holmes, 1963). Um modelo estrutural da tropomiosina obtido a $7 \AA$ por cristalografia de raio-X (Whitby \& Phillips, Jr., 2000) pode ser visualizada na figura 12. Cada coiled-coil de tropomiosina associa-se por interações predominantemente iônicas de forma cabeça-cauda (McCubbin e Kay, 1969) gerando um longo polímero que se enrola ao longo do filamento de actina.

O motivo 'coiled-coil' foi descrito pela primeira vez em 1953 por Pauling e Corey e por Crick como sendo o elemento estrutural principal de uma grande classe de proteínas fibrosas. Uma revisão bastante abrangente sobre este motivo estrutural pode ser encontrado em Lupas (1996). O motivo 'coiled-coil' é caracterizado por um grupo de $\alpha$-hélices enroladas para formar uma super-hélice. A torção de mão esquerda do 'coiled-coil' sobre a de mão 
direita da $\alpha$-hélice permite que o número de resíduos por volta com relaçao ao eixo do supercoil seja reduzido para 3.5, fazendo com que a posição das cadeias laterais repita-se após duas voltas. A sequência dos 'coiled-coil' revelam, portanto, uma repetição heptapeptídica na natureza química das cadeias laterais $(2 \times 3.5=7$ aminoácidos $/ 2$ voltas $)$.

Seguindo este padrão, a estrutura terciária da tropomiosina deriva de uma repetição heptapeptídica em sua estrutura primária (abcdefg) na qual as posições a e $d$ são preferencialmente ocupadas por resíduos hidrofóbicos enterrados na interface entre as duas $\alpha$-hélices (Figura 13). As outras posições da repetição heptapeptídica são ocupadas preferencialmente por resíduos hidrofilicos, com posições e e $g$ frequentemente ocupadas por resíduos carregados envolvidos em pontes salinas inter-hélices (Smillie, 1979).

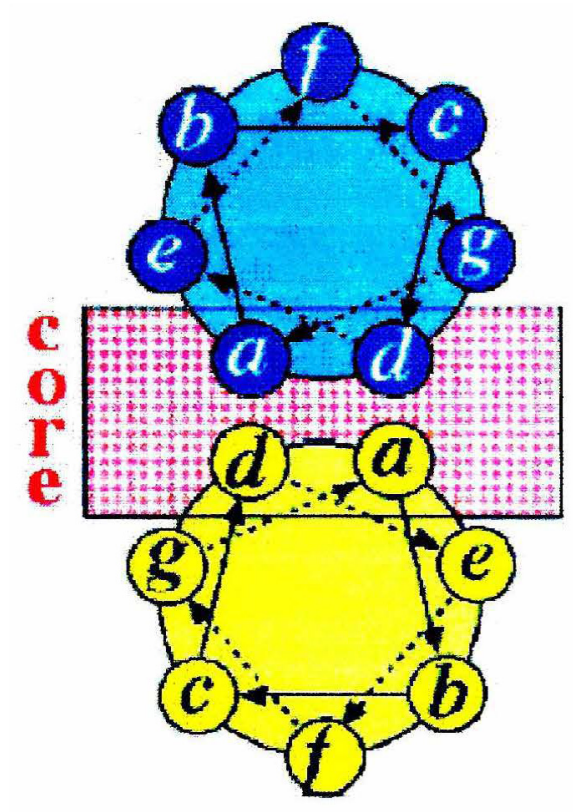

Figura 13. Esquema de uma fatia de um coiled-coil indicando a região do 'core' hidrofóbico responsável pela manutenção da estrutura quaternária da molécula. [Stewart, 2001] 
As moléculas de tropomiosina associam-se através de interações cabeça-cauda (McLachlan e Stewart, 1975) para formar longos filamentos que enrolam-se na hélice de F-actina. Esta interação envolve uma superposição/interação entre os primeiros e últimos dez resíduos da molécula (ver figura 16). Uma análise do equilíbrio de polimerização da tropomiosina em função da força iônica pode ser encontrado em Sousa e Farah (2002). Este estudo ressalta a natureza eletrostática da interação cabeça-cauda mostrando que a constante de afinidade varia de quase duas ordens de magnitude numa faixa de força iônica de $50 \mathrm{mM}$.

Pseudo repetições "7-fold" e "14-fold" na estrutura primária da tropomiosina: as bandas $\alpha$ e $\beta$

Baseado na análise da natureza química dos resíduos expostos ao solvente na sequência da tropomiosina, McLachlan e Stewart (1975 e 1976) indentificaram 14 pseudo-repetições de 19 a 20 resíduos, as quais podem ser agrupadas em sete pares de bandas $\alpha$ e $\beta$ (Figuras 14 e 15).

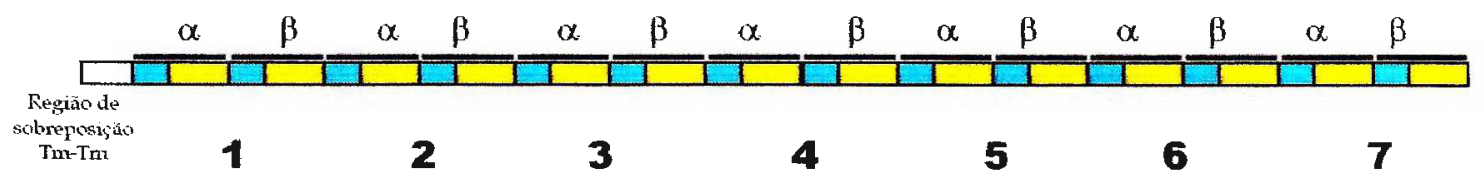

Figura 14. Esquema da periodicidade proposta por McLachlan e Stewart (1975) para a sequência primária da tropomiosina. Os nove primeiros aminoácidos encontram-se envolvidos na interação cabeça-cauda $e_{\text {, por }}$ esse motivo não foram considerados na análise dos autores, que dividiram 275 aminoácidos em 7 pseudo-repetições de cerca de 39 1/3 aminoácidos. Cada uma dessas repetições estaria envolvida na interação com um monômero de actina (esfera rosa), no estado "ligado" (banda $\beta$ ) ou "desligado" (banda $\alpha$ ). Cada banda $\alpha$ ou $\beta$, por sua vez, divide-se em duas porções: uma predominantemente positiva/hidrofóbica contendo aproximadamente 8 resíduos (azul) e outra predominantemente negativa contendo aproximadamente 12 resíduos (laranja). 
$\mathrm{Na}$ figura 15 podemos ver a sequência de aminoácidos da $\alpha$ tropomiosina esquelética de galinha arranjada de forma a realçar o padrão $\alpha / \beta$ (baseado em McLachlan e Stewart, 1976). Nesta figura também estão indicados os resíduos da tropomiosina que tiveram seus códons mutados para códons de triptofano nos estudos desta tese (sublinhados, vide abaixo). Estes mutantes foram utilizados neste projeto com o análogo de triptofano 5hidroxitriptofano sendo utilizado como sonda fluorescente no lugar deste (ver Parte II da Introdução e também Materiais e Métodos e Resultados).

\footnotetext{
bandas $\alpha$
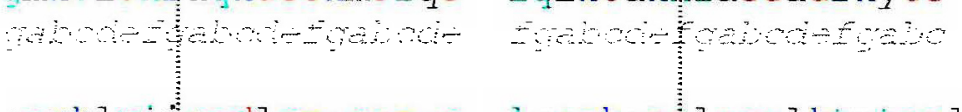

lseskcaelleeelktvtnnl

Figura 15. Sequência primária da a-tropomiosina esquelética de galinha (Gooding et al., 1987). Os resíduos que foram mutados para triptofano estão sublinhados. A posição na repetição heptapeptídica está indicada em itálico sob cada linha da sequência primária. A sequênica está arranjada de forma a evidenciar o padrão de repetição $\alpha / \beta$ (McLachlan e Stewart, 1976). As linhas pontilhadas indicam dentro de cada banda a zona positiva (à esquerda da linha pontilhada) e negativa (à direita da linha pontilhada). Resíduos negativos estão indicados em vermelho, resíduos positivos em azul e residuos não carregados em posições externas $(b, c, e, f$ e $g)$ em verde.
} 
Cada uma das bandas $\alpha$ e cada uma das bandas $\beta$ possui uma zona estreita de carga líquida positiva e uma zona mais larga carregada negativamente (Figura 15). Em sobreposição a cada zona positiva existe uma zona hidrofóbica que sempre possui pelo menos um grupo não-polar na superficie exterior (resíduos em verde na figura 15). Anomalias na distribuição de carga podem ser observadas na região próxima à Cys190 e à extremidade C-terminal. McLachlan e Stewart (1976) sugeriram que as regiōes carregadas negativamente são estatisticamente mais significantes que as regiões positivas.

McLachlan e Stewart (1976) hipotetizaram que as bandas $\alpha$ e $\beta$ poderiam representar conjuntos alternativos de sítios que ligar-se-iam a sítios complementares na superfície da actina na presença ou ausência de íons cálcio. Como o espaçamento de aproximadamente 20 resíduos entre as bandas $\alpha$ e $\beta$ corresponde a uma rotação de aproximadamente $90^{\circ}$ na superhélice do coiled-coil esta hipótese implicaria no rolamento da tropomiosina sobre a superfície da actina num movimento disparado pela ligação de íons cálcio ao complexo troponina. Bacchiocchi e Lehrer (2002) apresentaram evidências para a rotação da tropomiosina na superfície da actina baseandose em dados de transferência de energia de fluorescência entre o ácido 5-(2iodoacetil-amino-etil-amino)naftaleno-1-sulfônico posicionado na Cys-190 da tropomiosina e o isotiocianato de faloidina-tetra-metilrodamina $\mathrm{B}$ ligado à $\mathrm{F}$ actina Os autores mostraram que a variação observada na eficiência da transferência de energia neste sistema não pode ser explicada por uma simples variação azimutal na posição da tropomiosina o que implica num rolamento da tropomiosina sobre a superfície da actina acoplado a este deslocamento azimutal.

A ligação preferencial das bandas $\alpha$ e $\beta$ da tropomiosina à actina numa maneira dependente de íons cálcio, apesar de ser um modelo bastante atrativo, ainda não possui base experimental direta. Este aspecto fundamental da regulação da contração muscular e da interação entre a 
tropomiosina e a actina foi abordado diretamente na pesquisa desenvolvida neste doutorado.

Papel da tropomiosina na regulação da contração muscular

A tropomiosina está diretamente envolvida na regulação da interação entre a actina e a miosina responsável pela contração muscular: ela transmite a mudança conformacional local induzida por cálcio na troponina para o arranjo helicoidal de sítios ligantes de miosina na superfície do filamento de actina. Um complexo trimérico troponina (TnC-Tnl-TnT) associa-se com a metade C-terminal da tropomiosina, que por sua vez encompassa sete monômeros de actina em cada fita de F-actina. A ligação de cálcio à troponina dispara uma série de mudanças conformacionais (Farah \& Reinach, 1995; Tobacman, 1996; Gordon et al., 2000; Takeda et al., 2003) que reposicionam a molécula de tropomiosina, expondo sítios ligantes de miosina na superfície da actina (ver figura 17 abaixo), levando a uma forte ligação estereoespecífica entre a actina e a miosina e à geração de força (Tobacman, 1996; Holmes, 1995; Squire \& Morris, 1998; McKillop \& Geeves, 1993; Vibert et al., 1997; Lehman et al., 2001; Lehman et al., 1994; Huxley, 1972; Haselgrove, 1972; Parry \& Squire, 1973; Xu et al., 1999; Lehman et al., 2000). A figura 16 apresenta uma representação esquemática do filamento fino. A tropomiosina recobre, na ausência de íons cálcio, toda a superfície de interação forte entre a actina e a cabeça S1 de miosina (ver figura 17). Uma discussão mais aprofundada sobre os modelos de regulação da contração muscular será realizada no ítem 2. Regulação da contração muscular. 


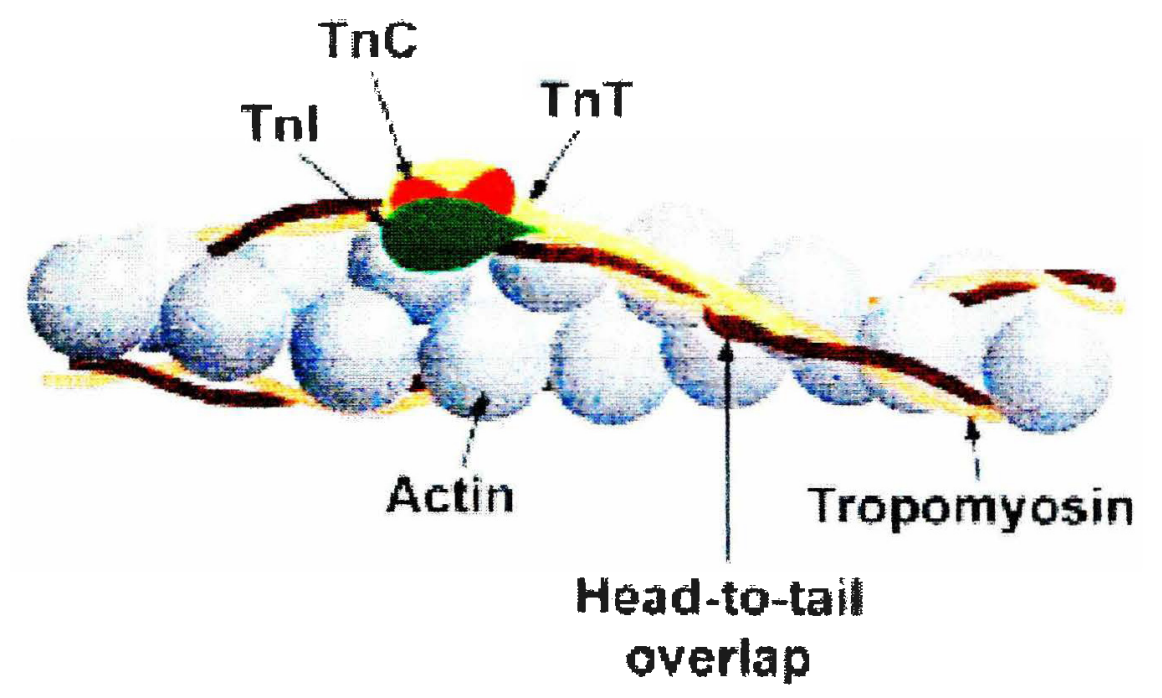

Figura 16. Representação do filamento fino indicando o complexo ternário troponina e a tropomiosina envolvendo o filamento de actina. [Gordon et al., 2000 modificado de Heeley et al., 1987]

Tropomiosina e sua ligação à actina.

Acredita-se que, durante a regulação da contração muscular, a tropomiosina possa assumir três posições distintas sobre o filamento de actina, que serão analisadas com detalhes no ítem 2. Regulação da contração muscular. Os resíduos envolvidos na interação entre a tropomiosina e a actina nestes três estados da regulação (ver abaixo e Phillips et al., 1986 e McKillop e Geeves, 1993; para outras possibilidades ver Squire e Morris, 1998) ainda não foram determinados. A literatura especializada indica algumas possibilidades para este tipo de interação, resumidas na tabela I. Esta tabela apresenta alguns resíduos da actina que se acredita estejam envolvidos na ligação com a tropomiosina, bem como os métodos utilizados para sua determinação (Sheterline et al., 1998). Resíduos específicos da tropomiosina envolvidos em interações com a actina ainda não foram identificados. 
Tabela I. Resíduos da actina envolvidos na ligação com a tropomiosina segundo vários autores.

\begin{tabular}{|c|c|c|c|}
\hline $\begin{array}{c}\text { Resíduos da } \\
\text { actina envolvidos }\end{array}$ & Evidência & $\begin{array}{c}\text { Residuos da } \\
\text { actina envolvidos }\end{array}$ & Evidência \\
\hline N-term & $\begin{array}{l}\text { Competição por } \\
\text { anticorpo }^{\mathrm{a}}\end{array}$ & $\begin{array}{l}338,326,328, \\
336 \text { (fechado) }\end{array}$ & Derivatização9 \\
\hline$N$-term & Mutagênese $^{b}$ & 336 (bloqueado) & Derivatização \\
\hline 61 & Derivatização $^{c}$ & $374-375$ & $\mathrm{RMN}^{\mathrm{h}}$ \\
\hline 95 & Derivatização ${ }^{d}$ & 374,375 & Deleçãoi \\
\hline 215,307 & $\begin{array}{l}\text { Modelagem da } \\
\text { estrutura }^{\mathrm{e}}\end{array}$ & $\begin{array}{c}\text { Subdominio } 4 \\
\text { (fechado) }\end{array}$ & Mutagênese $^{\mathrm{j}}$ \\
\hline $222-233$ & Deleção $^{f}$ & $\begin{array}{c}\text { Subdominio } 4 \\
\text { (aberto) }\end{array}$ & Mutagênese $^{k}$ \\
\hline
\end{tabular}

Referências: (a) Mejean et al., 1992; (b) Aspenstrom et al., 1992; (c) Miki e dos Remedios, 1988; (d) Johnson e Blazyk, 1978; (e) Milligan et al., 1990 e Kabsch e Vandekerckhove, 1992; (f) Hirono et al., 1990 e Hirono et al., 1987; (g) el Saleh et al., 1984 e Szilagyi e Lu, 1982; (h) Moir e Levine, 1986; (i) O’Donoghue et al., 1992; (j) Saeki et al., 1996; (k) Saeki et al., 2000.

Um dos objetivos fundamentais no estudo da regulação da contração muscular é o posicionamento da tropomiosina sobre o filamento de actina. Estudos de micrografia eletrônica (Vibert et al., 1997) permitiram que se tenha uma idéia do posicionamento relativo médio que a molécula de tropomiosina deve assumir nos diferentes estados da regulação (ausência de ions cálcio, presença de altas concentrações de íons cálcio e presença de cabeças ligantes S1 de miosina) sobre cada monômero de actina (Figura 17). $\mathrm{Na}$ figura, os sítios de ligação de miosina estão indicados pelos resíduos coloridos. Na ausência de cálcio, apenas sítios fracos de ligação à miosina estão expostos (resíduos em verde). Quando ions cálcio ligam-se à $\mathrm{TnC}$, a tropomiosina desloca-se sobre a superfície da F-actina liberando outros sítios de ligação à miosina (vermelho e azul). Quando S1 liga-se à actina a tropomiosina sofre um deslocamento adicional expondo todos os sítios de ligação à miosina (verde, vermelho, azul e roxo). Este modelo não leva em consideração o caráter dinâmico da tropomiosina. Como sugerido por Phillips, Jr. e colaboradores (1986), a flexibilidade da tropomiosina pode ser suficiente para que flutuações térmicas sejam capazes de movê-la entre as condições 
na presença de íons cálcio e na presença de S1 ligada. Recentemente (Smith et al., 2003; Smith e Geeves, 2003), um modelo de regulação foi descrito levando em consideração o efeito da flexibilidade da molécula de tropomiosina na regulação da contração muscular.
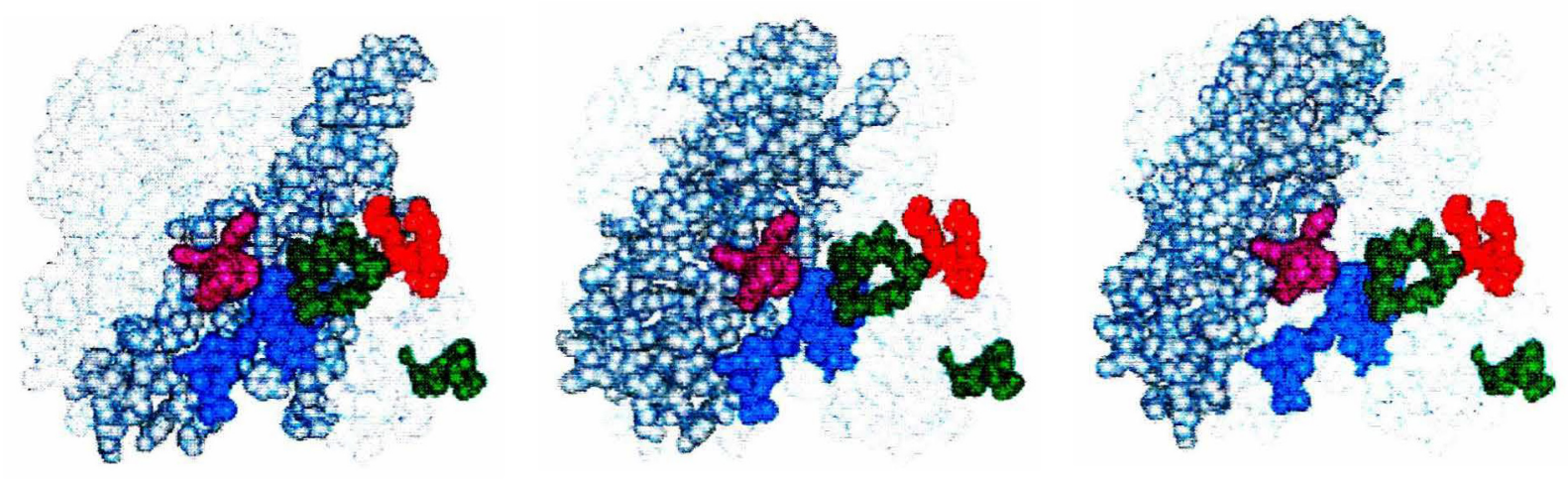

Figura 17. Modelo de monômero de actina com a posição aproximada da tropomiosina indicada em cinza. $\dot{A}$ esquerda: bloqueado, ausência de íons cálcio; No centro: fechado, presença de alta concentração de íons cálcio; $\dot{A}$ direita: Estado aberto, ligante de $\mathrm{S} 1$. Os resíduos da actina que interagem com a miosina estão indicados em cores: verde - resíduos 1-4, 24-28; azul 144-128, 340-346; roxo - 332-336; vermelho - 93-96. Na ausência de cálcio (diagrama à esquerda) apenas os sítios ligantes eletrostáticos, 1-4, 24-28 (verde) estão expostos. A presença de cálcio (diagrama central) deixa apenas os resíduos hidrofóbicos 332-336 (roxo) escondidos. No estado aberto (diagrama à direita) todos os sítios ligantes de miosina indicados estão expostos. [Vibert et al., 1997]

Estes resultados (Vibert et al., 1997) não são suficientes, entretanto, para se determinar o posicionamento do coiled-coil da tropomiosina sobre o filamento de actina. Além disso, como pode ser apreciado da tabela I, poucos são os dados diferenciando os diferentes estados de ativação da tropomiosina na regulação da contração muscular mediada por cálcio. Além disso, como dito anteriormente, tem-se sugerido a importância da flexibilidade da molécula de tropomiosina no controle da contração muscular (Phillips, Jr. et al., 1986; Earley, 1991; Narita et al., 2001; Smith et at., 2003 e Smith e Geeves, 2003). 


\section{Regulação da contração muscular}

Nesta seção abordaremos de uma forma mais profunda os diversos modelos existentes para a regulação da contração muscular.

Sabe-se que a chegada de um estímulo nervoso na membrana de uma fibra muscular esquelética provoca uma liberação de íons $\mathrm{Ca}^{2+}$ no interior da célula. Este cálcio liga-se à subunidade $C$ da molécula de troponina existente no filamento fino do sistema muscular (Ebashi et al., 1969). A troponina encontra-se associada numa estequiometria de 1:1 com a tropomiosina que, por sua vez, liga a actina (Figura 16). Como citado acima, uma questão ainda não resolvida de importância fundamental para a compreensão da regulação da contração muscular está relacionada ao modo pelo qual a tropomiosina desloca-se sobre o filamento de F-actina e à identificação dos resíduos envolvidos na ligação à actina na presença e ausência de íons cálcio e/ou miosina.

\section{Modelo do bloqueio estérico}

Estudos iniciais sugeriram que a tropomiosina pode ser a responsável por um bloqueio estérico da interação entre a S1 e a actina (Moore et al, 1970). Estudos de difração de raio-X (Haselgrove, 1972; Huxley, 1972; Parry e Squire, 1973) foram interpretados como indicativos de uma movimentação da molécula de tropomiosina em direção à periferia do filamento fino (Figura 2). Estes estudos, entretanto, não foram conclusivos e dúvidas foram levantadas com relação à interpretação dos resultados. Particularmente, não se sabia ao certo se componentes relacionados a mudanças no complexo troponina ou modificações estruturais na actina poderiam ser responsáveis pelas mudanças observadas no padrão de difração e que foram atribuídas exclusivamente à tropomiosina (ver Squire e Morris, 1998 para discussão). Mudanças estruturais nos próprios monômeros da actina (Al-Khayat et al., 1995) podem ser cruciais para o processo de regulação da contração muscular. Sugeriu-se (Haselgrove, 1972; Huxley, 1972; Parry e Squire, 
1973), adicionalmente, que a molécula de tropomiosina, quando ativada, mover-se-ia de uma posição que estaria bloqueando estericamente a interação entre a miosina e o filamento de actina para uma posição que liberaria os sítios de interação entre estas duas proteinas e permitiria que a contração muscular ocorresse. Em 1973, Hitchcock e colaboradores sugeriram que a ligação de íons cálcio ao complexo troponina iniciaria este movimento, dando origem ao modelo do bloqueio estérico.

Alguns estudos de transferência de energia de fluorescência por ressonância (Miki et al., 1998; Tao et al., 1983) chegam a sugerir que a tropomiosina possa não estar movendo-se quando da ligação de cálcio à troponina, favorecendo um modelo onde há movimento apenas da troponina. Por outro lado, demonstramos que a ligação de íons cálcio à troponina resulta numa mudança no microambiente de uma sonda na posição 122 da tropomiosina, um sítio que não interage diretamente com a troponina (Farah e Reinach, 1999). Como citado anteriormente na seção 1.6. Tropomiosina Pseudo repetições "7-fold" e "14-fold" na estrutura primária da tropomiosina: as bandas $\alpha$ e $\beta$, Bacchiocchi e Lehrer (2002) apresentaram evidências para a rotação da tropomiosina na superfície da actina baseando-se em dados de transferência de energia de fluorescência. A variação observada na eficiência da transferência de energia não pôde ser explicada por uma simples variação azimutal na posição da tropomiosina o que implicaria numa rotação da tropomiosina sobre a superfície da actina acoplado a este deslocamento azimutal. Nós também detectamos mudanças no valor da constante cinética bimolecular para o processo de supressão $\left(k_{q}\right)$ para a supressão da intensidade da fluorescência por acrilamida de sondas fluorescentes inseridas ao longo da molécula de tropomiosina induzidas por ions cálcio (ver adiante, RESULTADOS, 13. Ensaios de supressão de fluorescência Supressão por acrilamida). Este fato sugere que a ligação de cálcio esteja modificando a interação entre a tropomiosina e a actina. 
Modelo estérico dinâmico de três estados

McKillop e Geeves (1993) sugeriram um modelo de regulação da contração muscular conhecido como o modelo estérico dinâmico de três estados. Este modelo implica a existência do filamento fino em três estados distintos: 1) 'bloqueado', na ausência de $\mathrm{Ca}^{2+}$, onde pode haver a formação de um complexo de colisão entre a actina e a miosina (ligação fraca, não estereoespecífica), com baixa atividade ATPásica; 2) 'fechado', na presença de $\mathrm{Ca}^{2+}$, onde uma ligação estereoespecifica fraca com a miosina pode ocorrer mas onde a atividade ATPásica ainda é baixa; e 3) 'aberto', onde ocorre uma forte ligação estereoespecífica da miosina, com alta atividade ATPásica e alta geração de força. Estes estados podem ser visualizados na reconstrução da figura 18.

bloqueado

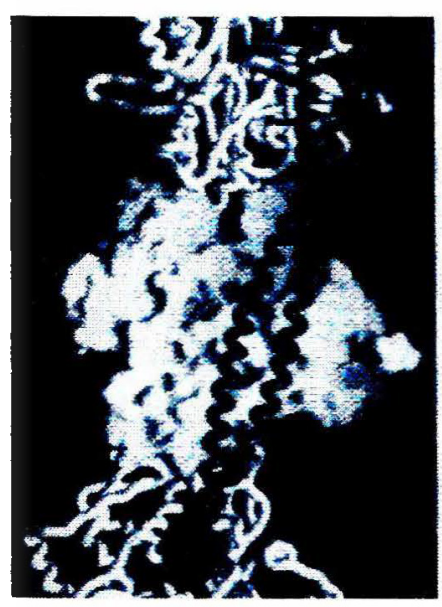

$-\mathrm{Ca}^{2+}$ fechado

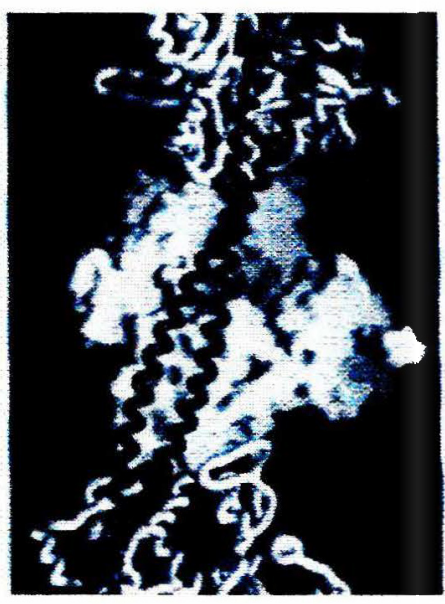

$+\mathrm{Ca}^{2+}$ aberto

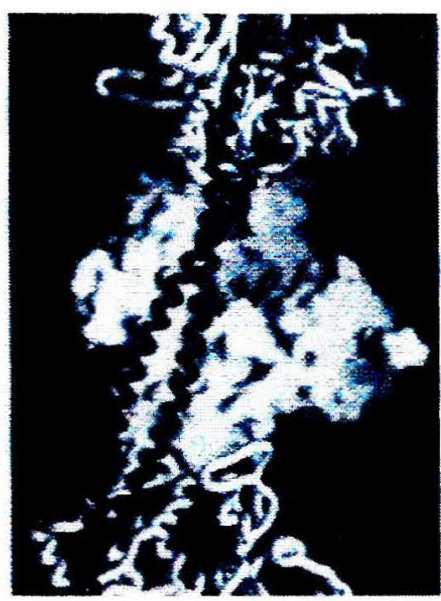

$+\mathrm{Ca}^{2+}+$ miosina

Figura 18. Posicionamento relativo da tropomiosina sobre o filamento de actina dentro do modelo de três estados de McKillop e Geeves (1993). Ver figura 17 para comparação. [Holmes, 1995 (estados bloqueado e fechado baseado em estudos de espalhamento de raios-X por Poole et al., 1994; estado aberto baseado em modelagem a partir de reconstrução de microscopia eletrônica de filamentos finos decorados de S1 (Milligan e Flicker, 1987; Milligan et al., 1990))] 
No nível molecular, este modelo sugere o seguinte (ver figuras 17,18 e 19): 1) No estado 'bloqueado', na ausência de $\mathrm{Ca}^{2+}$, a subunidade I do complexo troponina liga-se fortemente à actina, mantendo a tropomiosina numa posição bloqueadora no subdomínio 1 da actina (Figura 18 à esquerda); 2) No estado 'fechado', a ligação de $\mathrm{Ca}^{2+}$ à subunidade $\mathrm{C}$ da troponina causa uma mudança conformacional do complexo troponina aumentando a afinidade da $\mathrm{Tnl}$ pela $\mathrm{TnC}$ e diminuindo a afinidade da Tnl pela actina. Esta mudança conformacional permite o movimento da tropomiosina sobre o filamento da actina. Isto torna a ligação estereoespecífica fraca da miosina à actina mais provável, embora ainda iniba uma ligação forte (Figura 18, no centro); e 3) A transição gradual de algumas cabeças de miosina para uma ligação forte desloca ainda mais a tropomiosina levando o filamento para o estado 'aberto' (Figura 18 à direita), com um aumento da atividade ATPásica.

Estudos de difração de raios-X com fibras desencapadas ("skinned fibers") e filamentos orientados (Haselgrove, 1972; Huxley, 1972; Parry e Squire, 1973) e reconstruções de micrografia eletrônica de filamentos finos isolados (Lehman et al, 1994; Lehman et al, 1995; Vibert et al, 1997; Xu et al., 1999) parecem dar suporte para este modelo de três estados (McKillop e Geeves, 1993) para a regulação da contração do músculo esquelético. Reconstruções de micrografia eletrônica de músculo estriado de Limulus e de rã (Lehman et al, 1994; Lehman et al, 1995; Vibert et al, 1997) e de filamentos rapidamente congelados (Xu et al., 1999) indicam que na ausência de íons cálcio a tropomiosina parece estar ocupando uma posição que bloqueia a maior parte dos sítios de interação entre a actina e a cabeça $\mathrm{S} 1$ de miosina (Figura 17, à esquerda). Este seria o estado 'bloqueado'no modelo de McKillop e Geeves (1993). A ligação de cálcio parece deslocar a tropomiosina de $\sim 25^{\circ}$ sobre a superfície do filamento de actina (Vibert et al, 1997; Xu et al, 1999) a partir de sua posição na ausência de cálcio. Este movimento expõe diversos sítios de interação entre a actina e a miosina (Figura 17, no centro). Este seria o estado 'fechado'de McKillop e Geeves (1993). A adição de S1 dá origem ao estado 'aberto' do modelo de McKillop e Geeves (1993). Aparentemente, neste estado, a tropomiosina move-se mais 
$\sim 10^{\circ}$ sobre o filamento de actina expondo todos os sítios de interação com a miosina (Figura 17 e 18, à direita).

A figura 19 ressalta as interações entre as proteínas envolvidas nos três estados do filamento fino e os três tipos de interação entre a actina e a miosina (eletrostática, fraca e forte) indicados acima.

2

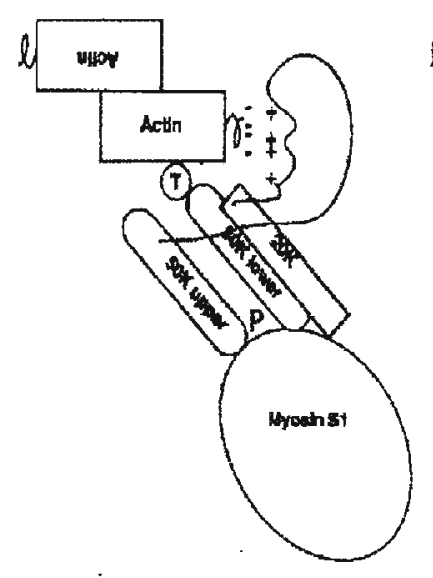

b

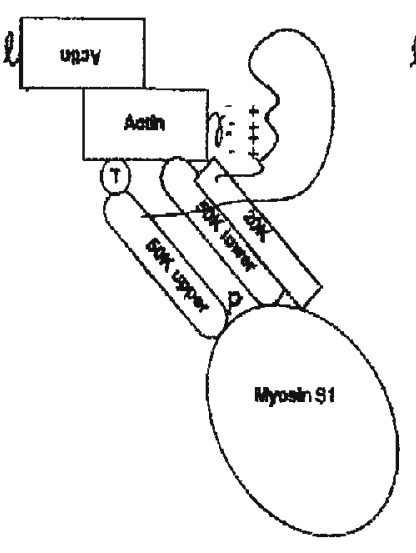

C

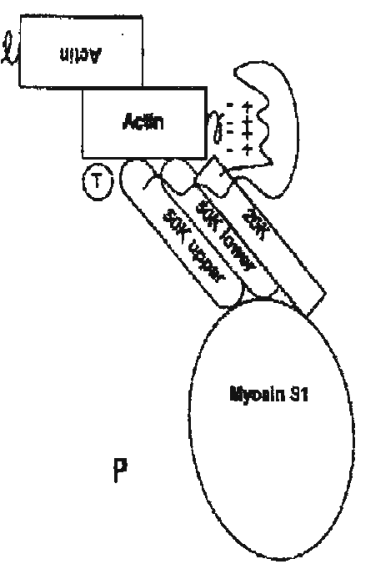

Figura 19. Modelo estérico dinâmico de três estados ressaltando as interações envolvidas. (a) estado 'bloqueado' onde apenas interações fracas eletrostáticas são possíveis; (b) movimentação da tropomiosina ( $T$ ) permitindo interações maiores, dando origem ao estado 'fechado'; (c) estado 'aberto' gerado por mais um deslocamento da tropomiosina, expondo os sítios de interação forte entre a actina e a miosina. Os fragmentos de $50 \mathrm{Ke}$ $20 \mathrm{~K}$ da miosina estão indicados na figura. [Holmes, 1995]

Devemos notar, entretanto, que o grau de resolução dos estudos acima indicados não é suficiente para se saber quais resíduos da tropomiosina estão envolvidos na ligação à actina na presença e ausência de íons cálcio e/ou miosina. A elucidação destes sítios poderia revelar detalhes das mudanças conformacionais envolvendo a tropomiosina no filamento fino. 


\section{PARTE II - Fluorescência}

\section{Fluorescência}

A emissão de fótons a partir de estados eletronicamente excitados recebe o nome de luminescência. O fenômeno de luminescência pode ser dividido em dois tipos principais em função da natureza dos estados fundamental e excitado. No estado singlete ${ }^{1}$ excitado, o elétron no orbital mais energético possui spin oposto ao do segundo elétron do orbital mais baixo (elétrons pareados). Neste caso, o retorno ao estado fundamental não requer uma mudança no spin do elétron. Por outro lado, no estado triplete, os elétrons encontram-se despareados, possuindo o mesmo spin. Neste caso, o retorno ao estado fundamental requer uma mudança no spin do elétron.

Fluorescência é o nome dado à emissão que resulta do retomo ao orbital de menor energia de um elétron pareado, ou seja, sem necessidade de mudança de spin. Estas são transições "permitidas" e possuem tempos de vida ${ }^{2}$ típicos de $10^{-1}$ a $10^{1} \mathrm{~ns}$.

As emissões resultantes do retorno ao orbital de menor energia a partir de um estado triplete excitado recebe o nome de fosforescência. Estas transições são "proibidas" e requerem uma mudança no spin do elétron. São, por isso, transições bastante lentas com tempos de vida que variam de milissegundos a segundos.

Geralmente, substâncias com fluorescência significativa possuem estrutura rigida (anéis) e elétrons delocalizados presentes em ligações duplas conjugadas. Podemos citar como algumas substâncias fluorescentes

\footnotetext{
${ }^{1}$ No estado fundamental, todos os elétrons se encontram em orbitais duplamente ocupados e dois elétrons no mesmo orbital devem ter seus spins pareados. Entretanto, dois elétrons em orbitais moleculares diferentes podem tanto ter seus spins pareados como despareados. Chamamos de estado singlete se os elétrons estiverem pareados e triplete, se despareados. Estados que possuem o mesmo número de elétrons despareados possuem a mesma multiplicidade.

${ }^{2}$ O tempo de vida é o período médio de tempo no qual o fluoróforo permanece no estado excitado.
} 
(fluoróforos) típicas o quinino, a fluoresceína, o antraceno e os aminoácidos tirosina e triptofano.

O princípio de Franck-Condon

O princípio de Franck-Condon diz que a transição do estado fundamental ao estado excitado é essencialmente instantânea quando comparado com o tempo necessário para haver qualquer mudança nas coordenadas nucleares.

O processo de excitação é extremamente rápido $\left(10^{-15} \mathrm{~s}\right)$ quando comparado a outros processos como conversão interna $\left(10^{-10} \mathrm{~s}\right)$ ou relaxamento vibracional $\left(10^{-12} \mathrm{~s}\right)$. A emissão a partir do nível excitado de menor energia também é bem mais lento do que o processo de excitação $\left(10^{-9} \mathrm{~s}\right)$. Desta forma, o estado excitado de menor energia pode ser considerado um estado semi-estável quando comparado ao estado inicial de absorção.

Devemos ainda notar que o nível vibracional atingido no estado excitado depende do comprimento de onda da luz usada para a excitação. $O$ retorno ao estado fundamental por fluorescência, por outro lado, sempre ocorre a partir do estado excitado de equilíbrio (nível de menor energia do estado excitado).

\section{O diagrama de Jablonski}

Uma forma bastante ilustrativa de representar as energias dos estados eletrônicos de uma molécula é a utilização do diagrama de Jablonski (figura 20). Uma discussão interessante sobre este diagrama pode ser encontrado em Carroll, F.A. (1998). Neste diagrama, os estados eletrônicos fundamental, primeiro e segundo estão representados respectivamente por $S_{0}, S_{1}$ e $S_{2}$. Em cada um destes níveis eletrônicos, pode existir um certo número de níveis energéticos vibracionais representados pelas linhas em cada nível eletrônico na figura 20. Cada um destes níveis vibracionais pode 
ser subdividido por sua vez em diversos niveis rotacionais, aqui excluídos por motivo de clareza. Na figura, as flechas em preto representam processos radiativos, que ocorrem através de absorção ou emissão de luz. As flechas em vermelho, por sua vez, representam processos não-radiativos, ocorrendo sem absorção ou emissão de luz.

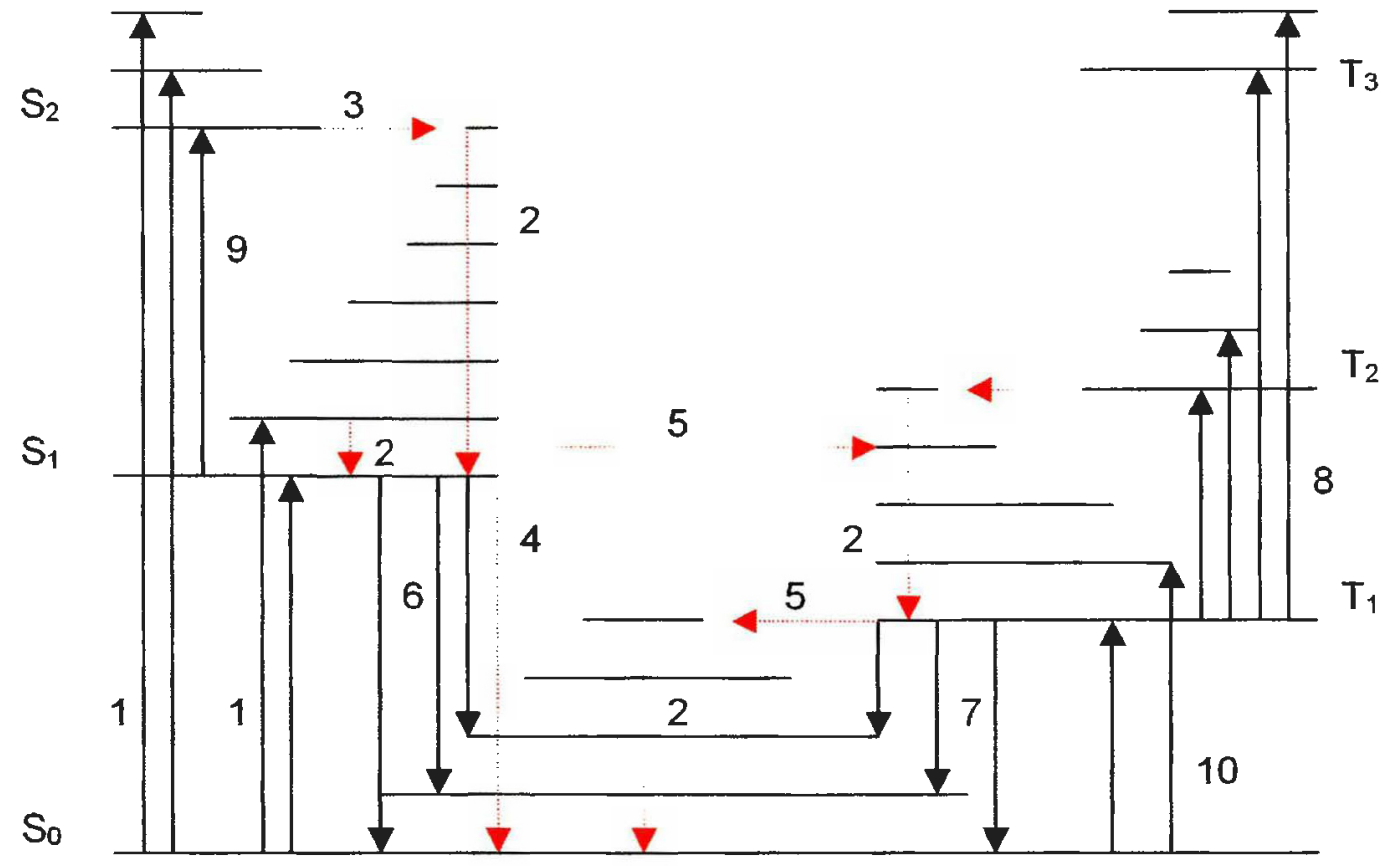

Figura 20. Uma representação do diagrama de Jablonski. Os processos indicados estão explicados no texto.

Os números na figura 20 indicam os seguintes processos:

1 - Absorção de luz (constante de velocidade $\sim 10^{15} \mathrm{~s}^{-1}$ ) - uma molécula no estado fundamental pode absorver um fóton de luz tornando-se excitada. As transições mais comumente observadas são $S_{0} \rightarrow S_{1}$ e $S_{0} \rightarrow S_{2}$, embora transições para níveis eletrônicos mais energéticos também sejam possiveis.

Processos não radiativos:

2 - Relaxamento vibracional (constante de velocidade $\sim 10^{12} \mathrm{~s}^{-1}$ ) - ocorre um processo bastante rápido que relaxa os níveis vibracionais mais altos do estado excitado para o primeiro nível vibracional do estado excitado. 
3 - Conversão interna (constante de velocidade $\sim 10^{10} \mathrm{~s}^{-1}$ ) - processo que converte estados eletrônicos mais elevados em estados mais baixos de mesma multiplicidade (a conversão ocorre entre o estado menos energético de $S_{2}$ para um estado vibracional de mesma energia em $S_{1}$, que então relaxa pelo processo 2 até o estado de menor energia de $S_{1}$ ).

4 - Decaimento não-radiativo (constante de velocidade $<10^{6} \mathrm{~s}^{-1}$ ) - processo pelo qual estados eletronicamente excitados retornam ao estado fundamental sem emissão de luz.

5 - Cruzamento entre sistemas - conversão do estado singlete para o estado triplete (ou vice versa). Requer inversão do spin do elétron. A probabilidade de cruzamento entre sistemas depende, entre outras coisas, da diferença de energia entre os estados singlete e triplete de forma que valores para sua constante de velocidade variam entre $10^{6}$ a $10^{10} \mathrm{~s}^{-1}$.

Processos radiativos:

6 - Fluorescência - emissão de luz de um estado excitado para um estado fundamental de mesma multiplicidade (geralmente $S_{1} \rightarrow S_{0}$; regra de Kasha (Kasha, 1950)). Fluorescência anômala $\left(S_{2} \rightarrow S_{0}\right)$ pode ocorrer em alguns compostos, como, por exemplo, o azuleno.

7 - Fosforescência - emissão de luz de um estado excitado para um estado fundamental de multiplicidade diferente (geralmente de um estado triplete excitado ao estado fundamental singlete). Este processo envolve não apenas uma mudança no estado eletrônico mas também uma inversão no spin, sendo, portanto, um processo proibido por spin.

8 - Absorção triplete-triplete - a absorção de um fóton por uma molécula no estado excitado triplete dando origem a um estado triplete mais energético. 
9 - Absorção singlete-singlete - semelhante a 8 , mas menos freqüente devido ao menor tempo de permanência no estado singlete excitado.

10 - Absorção singlete-triplete - como a fosforescência, este processo é proibido por spin.

Outros processos podem competir com a emissão de fluorescência, como, por exemplo, a transferência de energia por ressonância e o processo de supressão ('quenching') de fluorescência que foi extensamente utilizado neste estudo e será analisado com detalhes mais adiante (item 3.3. Supressão de fluorescência).

\subsection{Fluorescência em proteínas}

Três são os aminoácidos comumente presentes em proteínas que podem contribuir para sua fluorescência ultravioleta: tirosina, triptofano e fenilalanina. Seus espectros de absorção e emissão podem ser visualizados na figura 21 .

Em geral, utilizam-se comprimentos de onda de excitação para proteínas próximos do máximo de absorção a $280 \mathrm{~nm}$ ou em comprimentos de onda maiores. Como pode ser observado no painel (a) da figura 21, nesta faixa de comprimentos de onda não ocorre excitação da fenilalanina. Além disso seu rendimento quântico em proteínas também é baixo, o que faz com que a fluorescência deste resíduo raramente seja observada. No comprimento de onda usualmente utilizado de $\sim 280 \mathrm{~nm}$, podemos excitar os resíduos de tirosina e triptofano. Comprimentos de onda acima de $295 \mathrm{~nm}$ excitam praticamente apenas o triptofano. 

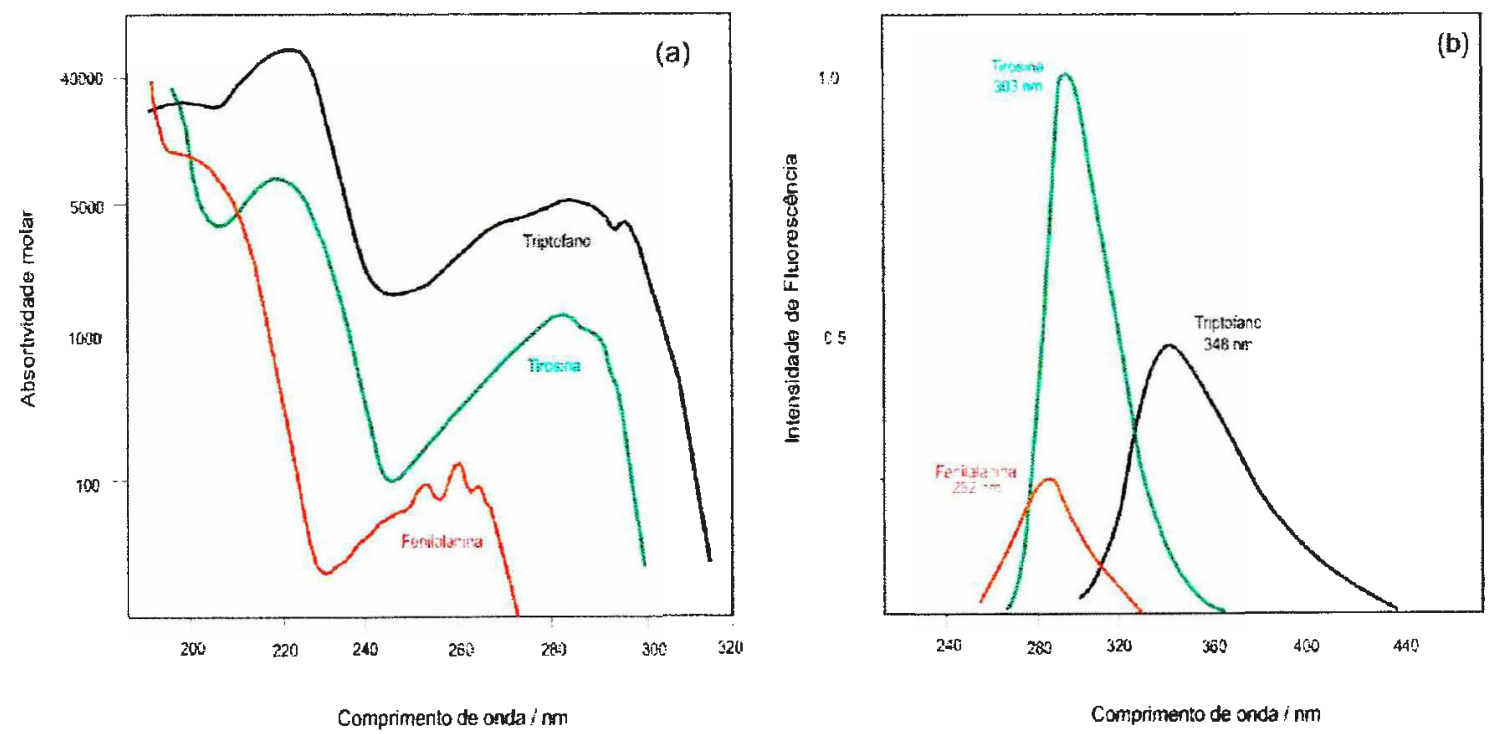

Figura 21. (a) Espectros de absorção dos aminoácidos aromáticos [Wetlaufer, 1962]; (b) Espectros de emissão dos aminoácidos aromáticos [Teale e Weber, 1957].

O comprimento de onda máximo de emissão da tirosina em água é $\sim 303$ $\mathrm{nm}$ e o do triptofano é de $\sim 348 \mathrm{~nm}$, mas varia grandemente com a polaridade do meio. É interessante notarmos que, sob excitação a $280 \mathrm{~nm}$, praticamente toda a fluorescência observada em proteinas advém do triptofano. Embora a tirosina possua um rendimento quântico alto em água e uma absorbância relativamente alta a $280 \mathrm{~nm}$, a emissão da tirosina na maioria das proteínas é bastante pequena e, muitas vezes, não detectável. Este efeito dá-se principalmente pela supressão da fluorescência dos resíduos de tirosina por grupos carboxila e amino que estejam na vizinhança da tirosina. Além disso, ocorre o fenômeno de transferência de energia da tirosina excitada para os resíduos de triptofano (a distância de Förster para a transferência tirosinatriptofano é suficientemente grande (Cantor e Schimmel (1980) fazem referência a um valor de $\sim 9$ A para esta distância; Lakowicz (1983) cita um valor de $\sim 14 \AA$ ) para haver transferência de energia apreciável quando consideramos as distâncias médias esperadas para os pares mais próximos tirosina-triptofano em proteinas globulares). 


\subsection{Análogos de triptofano}

O triptofano é, sem dúvida, o fluoróforo intrínseco mais utilizado para o estudo de proteínas por fluorescência. Uma revisão aprofundada sobre as transições eletrônicas que dão origem à fluorescência deste aminoácido pode ser encontrada em Callis (1997). Sua ampla utilização deve-se principalmente ao fato de que, comparado com outros aminoácidos (ver seção 3.1. Fluorescência em proteínas), sua absorção ultravioleta e sua fluorescência extendem-se a comprimentos de onda maiores, sua absortividade é a maior, seu rendimento quântico é o maior $e$, mais importante, seu espectro de fluorescência e a intensidade são os mais sensiveis ao ambiente local (microambiente).

a.<smiles>NC(=O)C([NH3+])Cc1c[nH]c2ccccc12</smiles>

b.<smiles>N[C@@H](Cc1c[nH]c2ccc(O)cc12)C(=O)[O-]</smiles>

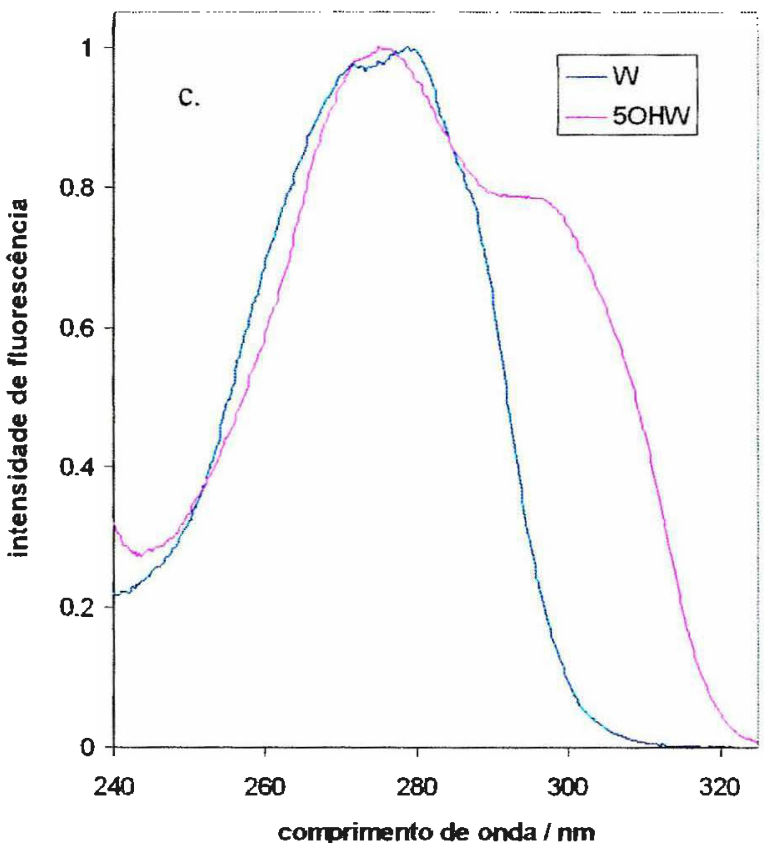

comprimento de onda / $\mathrm{nm}$

Figura 22. (a) molécula de triptofano; (b) 5-hidroxitriptofano; (c) comparação entre os espectros normalizados de excitação do triptofano (W) e do 5hidroxitriptofano (50HW). O ombro entre 300 e $320 \mathrm{~nm}$ no espectro do $50 \mathrm{HW}$ permite sua excitação preferencial mesmo na presença de triptofano. 
O uso de análogos de triptofano pode ser de bastante utilidade para o estudo de proteínas (Ross et al., 1997). Por exemplo, o estudo de interações entre proteínas por fluorescência pode trazer a desvantagem de que mais do que um triptofano possa estar presente no sistema estudado, causando uma dificuldade na interpretação dos resultados. Em alguns casos este problema pode ser resolvido pela utilização de análogos fluorescentes do triptofano, como o 5-hidroxitriptofano (ver figura 22), que podem ser excitados a comprimento de ondas nos quais o triptofano não é excitado. Além disso, sondas sensiveis à polaridade do ambiente, como o 7-azatriptofano, também estão disponíveis e podem ser de utilidade para o estudo de proteínas.

\subsection{Supressão de fluorescência}

Consideremos um fluoróforo $F$ que absorve certa quantidade de energia hv e passa ao estado excitado $F^{*}$ :

$$
\mathrm{F}+\mathrm{h} v_{1} \rightarrow \mathrm{F}^{*}
$$

Este fluoróforo excitado pode retornar ao estado fundamental pela emissão de fluorescência:

$$
F^{\star} \rightarrow F+h v_{2}
$$

onde $h v_{2}$ é tipicamente menor que $h v_{1}$ devido a uma perda prévia de energia causada por decaimentos não radiativos (como o relaxamento vibracional; ver seção 3. Fluorescência - O diagrama de Jablonskl). Desta forma, o comprimento de onda de emissão é geralmente maior que o comprimento de onda de excitação $(v=c / \Lambda)$.

Entretanto, este fluoróforo também pode decair de maneira não radiativa como, por exemplo, através de reações no estado excitado, transferência de energia, formação de complexos e supressão colisional. 
No caso da supressão colisional, podemos ter a supressão desta fluorescência de modo que uma parte (ou toda) a energia do estado excitado deste fluoróforo passe para moléculas supressoras que a absorvam e decaiam de maneira não radiativa (relaxamento vibracional). A velocidade deste processo é regida pela constante cinética bimolecular para o processo de supressão $\left(k_{q}\right)$. Esquematicamente:

$$
\begin{gathered}
F^{*}+Q \rightarrow F+Q^{*} \\
Q^{*} \rightarrow Q \text { (não radiativo) }
\end{gathered}
$$

Nesta seção trataremos do processo de supressão colisional e de sua utilização e análise para o estudo da interação entre proteínas.

Supressão colisional

Além do decaimento monomolecular, moléculas fotoexcitadas podem exibir um decaimento bimolecular resultante de interações com outras moléculas no estado fundamental. Estas moléculas supressoras (quenchers) absorvem a energia do estado excitado do fluoróforo e, em seguida, decaem por processos não radiativos, suprimindo a fluorescência total do sistema. Desta forma uma titulação do fluoróforo com moléculas supressoras fornecerá uma curva típica que pode revelar aspectos interessantes sobre o ambiente deste fluoróforo. Por exemplo, esta titulação pode informar sobre o grau de exposição do fluoróforo inserido em uma proteína. Além disso, o uso de supressores carregados, como por exemplo o iodeto, pode revelar informações sobre o microambiente eletrostático ao redor do fluoróforo em uma proteína.

Revisões bastante completas sobre supressão de fluorescência e análise dos dados obtidos podem ser encontradas em Eftink e Ghiron (1981), em Lakowicz (1983), em Eftink (1991) e em Laws e Contino (1992). 
$\mathrm{Na}$ existência de apenas um fluoróforo em apenas um ambiente de emissão e na presença exclusiva de supressão dinâmica, onde a reação difusional entre $F^{*}$ e $Q$ é a etapa limitante do processo de supressão, a queda no sinal de fluorescência causada pela adição de um supressor colisional ao sistema pode ser descrita pela clássica equação linear de SternVolmer.

Podemos deduzir esta equação considerando as intensidades de fluorescência observadas na ausência e na presença do supressor. A intensidade de fluorescência observada para um fluoróforo é proporcional à sua concentração no estado excitado $\left(F^{\star}\right)$. Sob iluminação continua uma população constante de fluoróforos excitados passa a existir e, portanto, $d\left(F^{\star}\right) / d t=0$. Na ausência e na presença do supressor, respectivamente, as equações diferenciais que descrevem $\left(\mathrm{F}^{\star}\right)$ são:

$$
\begin{gathered}
d\left(F^{\star}\right) / d t=f(t)-\Gamma\left(F^{\star}\right)_{0}=0 \\
d\left(F^{\star}\right) / d t=f(t)-\left(\Gamma+k_{q}[Q]\right)\left(F^{\star}\right)=0
\end{gathered}
$$

onde $f(t)$ é a função de excitação constante, que é facilmente eliminada destas equações. $\Gamma=\tau_{0}^{-1}$ é a constante de decaimento do fluoróforo na ausência do supressor (Lakowicz, 1983). Das equações acima obtemos

$$
F_{0} / F=\left(\Gamma+k_{q}[Q]\right) /(\Gamma)=1+k_{q} \tau_{0}[Q]=1+K_{s V}[Q]
$$

onde $F_{0}$ e $F$ são, respectivamente, a intensidade da fluorescência na ausência e na presença do supressor, $K_{s v}$ é a constante de Stern-Volmer e [Q] é a concentração do supressor. $K_{\text {sv }}$ relaciona-se com o tempo de vida de fluorescência $\left(\tau_{0}\right)$ por meio da equação $K_{S V}=k_{q} \tau_{0}$, onde $k_{q}$ é a constante cinética bimolecular para o processo de supressão (Lakowicz, 1983). Como pode ser inferido da equação 1 , a relação $F_{0} / F$ varia linearmente com a 
concentração do supressor. Desvios desta situação, entretanto, são comumente encontrados (ver figura 23). Os casos mais importantes estão relacionados com a ocorrência de supressão estática (curvatura para cima no grafico de Stern-Volmer) e a existência de fluoróforos em ambientes heterogêneos (curvatura para baixo no gráfico de Stern-Volmer) (Eftink e Ghiron, 1981). Estes dois casos serão analisados em seguida.

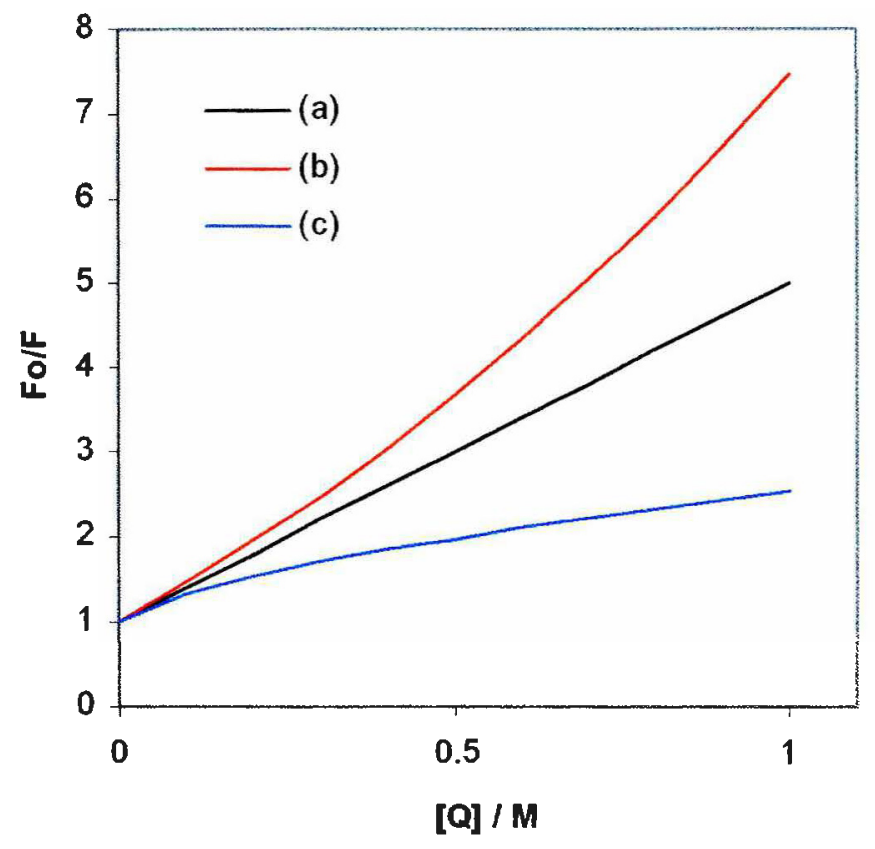

Figura 23. Gráficos de Stern-Volmer simulados. A curva (a) representa um sistema com apenas um fluoróforo na ausência de supressão estática e com um valor de $K_{S V}=4 \mathrm{M}^{-1}$. A curva (b) representa o efeito da supressão estática $\left(K_{\mathrm{SV}}=4 \mathrm{M}^{-1}, \mathrm{~V}=0.4 \mathrm{M}^{-1}\right.$ ). A curva (c) representa um sistema no qual dois fluoróforos em ambientes diferentes estão presentes, na ausência de supressão estática $\left(f_{1}=f_{2}=0.5, \mathrm{~K}_{\mathrm{sv}}(1)=7.5 \mathrm{M}^{-1}\right.$ e $\left.\mathrm{K}_{\mathrm{sv}}(2)=0.5 \mathrm{M}^{-1}\right)$. [Q] é a concentração de supressor.

Supressão estática

Para muitos sistemas em fase líquida, não se observa um gráfico linear de $F_{0} / F$ vs $[Q]$, como seria de se esperar da equação de Stern-Volmer. 
Muitas vezes ocorre uma acentuada curvatura para cima (figura 23). Este desvio pode ser levado em conta se considerarmos um mecanismo de supressão adicional, a supressão estática. Assim, devemos modificar a equação (1) para:

$$
F_{0} / F=\left(1+K_{s v}[Q]\right){ }^{*} \exp (V[Q])
$$

onde $\mathrm{V}$ é a constante de supressão estática. Esta constante pode ser vista como uma representação de um elemento de volume ativo ao redor do fluoróforo excitado. Neste caso, uma supressão virtualmente instantânea pode ocorrer quando uma molécula do quencher se encontra dentro deste elemento de volume no momento da absorção de um fóton (ver Eftink e Ghiron, 1981).

\section{Supressão de sistemas heterogêneos}

A fluorescência da maioria das proteínas não é homogênea devido à variedade de ambientes químicos aos quais os diferentes fluoróforos numa proteína podem estar expostos. Fluoróforos enterrados numa proteína sofrem supressão colisional com menor freqüência que fluoróforos expostos. A supressão de $n$ fluoróforos em ambientes químicos diferentes numa proteína na presença de supressão estática pode ser analisada pela equação:

$$
F o / F=\left(\sum_{i=1}^{n} f_{i} /\left(1+K_{i}[Q]\right) * \exp \left(V_{i}[Q]\right)\right)^{-1}
$$

onde $f_{i}$ é a contribuição fracional de cada componente para a fluorescência total.

No caso da supressão de dois fluoróforos diferentes na ausência de supressão estática, a equação 4 pode ser simplificada para: 


$$
F_{0} / F=\left\{\left[f_{1} /\left(1+K_{1}[Q]\right)\right]+\left[f_{2} /\left(1+K_{2}[Q]\right)\right]\right\}^{-1}
$$

Se uma proteína possui dois fluoróforos que tenham constantes de $\left(K_{l}+V_{i}\right)$ que sejam diferentes por um fator de 4 ou mais, os gráficos de $F_{0} / F$ vs [Q] podem aparecer com uma curvatura para baixo (ver Eftink e Ghiron, 1976).

\subsection{Usos da supressão de fluorescência no estudo de interações protéicas e no mapeamento de interações entre proteínas}

Reações de supressão de fluorescência são muito úteis na obtenção de informações relacionadas com aspectos topográficos e de interação entre superfícies protéicas.

A utilização de supressores não carregados pode fornecer informações sobre o grau de exposição de resíduos fluorescentes em proteínas. Assim, por exemplo, a realização de experimentos de supressão de fluorescência com supressores não carregados como a acrilamida podem revelar a variação no grau de exposição de um determinado resíduo fluorescente em situações diversas como na presença e na ausência de um ligante ou na presença e ausência de interação com outra proteína. Eftink e Ghiron (1976) realizaram uma análise interessante da variação da constante de supressão bimolecular pelo supressor acrilamida para diferentes graus de exposição do triptofano em diferentes proteínas. $O$ uso de supressores carregados como o iodeto permite ainda uma avaliação do microambiente eletrostático próximo à sonda fluorescente pela análise da dependência que a reação de supressão tem da força iônica (Ando e Asai, 1980; Ando et al., 1980). Estes resultados podem ser muito úteis para o mapeamento de interações entre proteínas pois permitem, no primeiro caso, uma medida direta do efeito da ligação sobre o grau de exposição do resíduo fluorescente 
e, no segundo caso, o efeito provocado sobre o ambiente eletrostático na região da sonda. Se se dispõe de um número suficientemente grande de mutantes fluorescentes numa determinada região da proteina, é teoricamente possível um verdadeiro mapeamento da superfície de interação entre esta e uma outra proteína qualquer à qual ela se ligue. Assim, pela análise da variação no grau de exposição dos resíduos fluorescentes e/ou variações no microambiente eletrostático ao redor das sondas na ausência e presença da segunda proteína, pode-se, em princípio, avaliar que regiões estão envolvidas na superfície de interação entre estas duas proteínas. Este projeto, em particular, fez uso extensivo destas possibilidades e utilizou a supressão de fluorescência no estudo das superfícies de interação entre proteínas do filamento fino muscular e no estudo de aspectos funcionais da regulação do processo de contração muscular. 
MATERIAIS E MÉTODOS

\section{Soluções gerais}

Tampão de fluorescência (FB)

MOPS $25 \mathrm{mM} \mathrm{pH} 7.0, \mathrm{NaCl} 50 \mathrm{mM}, \mathrm{MgCl}_{2} 5 \mathrm{mM}$ e DTT $1 \mathrm{mM}$

Tampão de dicroísmo circular (CDB)

$\mathrm{NaH}_{2} \mathrm{PO}_{4} 5.73 \mathrm{mM} \mathrm{pH} 7.0, \mathrm{NaCl} 50 \mathrm{mM}, \mathrm{MgCl}_{2}$ e DTT $1 \mathrm{mM}$

Notar que FB e CDB têm forças iônicas equivalentes ${ }^{3}$.

$5 X S B$ (tampão de amostra)

$260 \mathrm{mM}$ Tris. $\mathrm{HCl} \mathrm{pH} \mathrm{6.8,} 10 \%$ SDS, $0.5 \%$ azul de bromofenol, $50 \%$ glicerol, $50 \mu \mathrm{L} / \mathrm{mL} \beta$-mercaptoetanol.

\footnotetext{
${ }^{3}$ Calculo da equivalência da força iônica entre $F B$ e $C D B$. O cálculo da força iônica do meio pode ser realizado através da equação $\mid=1 / 2 \sum c_{i} z_{i}^{2}$, onde $c_{i}$ é a concentração da espécie i e $z_{i}$ é a carga da espécie i. Para o FB: A concentração de MOPS no FB é de 25 $\mathrm{mM}$. Como seu $\mathrm{pK}=7.15$, podemos calcular a concentração da espécie carregada a partir da equação de Henderson-Hasselbalch a $\mathrm{pH}=7.0: \mathrm{pH}=\mathrm{pK}+\log ([\mathrm{A}] /[\mathrm{HA}]) \rightarrow[\mathrm{HA}]=$ 1.412 $\left[\mathrm{A}^{-}\right]$. Como $[\mathrm{HA}]+\left[\mathrm{A}^{-}\right]=25 \mathrm{mM} \rightarrow\left[\mathrm{A}^{-}\right]=10.36 \mathrm{mM}$. Assim, substituindo as concentrações das espécies carregadas na equação da força iônica temos: $\mid(F B)=75.36$ mM. Para o CDB: Queremos um tampão cuja força iônica seja de l $(C D B)=$ l $(F B)=75.36$ $\mathrm{mM}$. Assim, substituindo os valores conhecidos na equação da força iônica teremos [A] $=$ $3.45 \mathrm{mM}$. Utilizando a equação de Henderson-Hasselbalch (para o fosfato monobásico de sódio o $\mathrm{pK}_{2}=6.82$ ) temos que $\left[\mathrm{A}^{-}\right]=1.51^{\star}[\mathrm{HA}]$ a $\mathrm{pH}=7.0$. Substituindo o valor de $\left[\mathrm{A}^{-}\right]$, temos que $[\mathrm{HA}]=2.28 \mathrm{mM}$. Assim $[\mathrm{HA}]+\left[\mathrm{A}^{\dagger}\right]=5.73 \mathrm{mM}$ que é a concentração de $\mathrm{NaH}_{2} \mathrm{PO}_{4}$ que deve ser utilizada para termos equivalência de froças iônicas entre os dois tampões. Assim, a $\mathrm{pH}=7.0,25 \mathrm{mM}$ MOPS $\equiv 5.73 \mathrm{mM} \mathrm{NaH}_{2} \mathrm{PO}_{4}$ em termos de força iônica.
} 
Soluções para supressão da ATPase (AAM) (Heinonen e Lahti, 1981)

1:1:2 $\mathrm{V}$ de molibdato de amônio $10 \mathrm{mM}: \mathrm{H}_{2} \mathrm{SO}_{4} 2.5 \mathrm{M}$ : acetona

$1 \mathrm{M}$ ácido cítrico

\section{Purificação das proteínas}

\subsection{Tropomiosinas recombinantes}

As tropomiosinas recombinantes de músculo esquelético de galinha com triptofanos nas posições 90, 94, 101, 107, 111, 122, 185, 276 e 278 foram construidas por Chuck Farah; as tropomiosinas recombinantes 261 , 263 e 269 foram construídas durante o doutorado da aluna Aurea D. de Souza. Todas as tropomiosinas produzidas continham a fusão de alaninaserina inicial. A tropomiosina expressa em bactéria precisa de uma fusão $\mathrm{N}$ terminal de Ala-Ser para conseguir polimerizar (ASTm), simulando a acetilação encontrada no $\mathrm{N}$-terminal da tropomiosina expressa em eucariotos (Monteiro et al., 1994). O mapa de restrição dos plasmídeos utilizados pode ser vizualizado na figura 24.

A figura 25 indica a sequência primária da tropomiosina e o resíduo original (em vermelho e sublinhado) que foi substituído pelo resíduo fluorescente 5-hidroxitriptofano (incorporado durante a expressão da proteína em bactéria em lugar do triptofano) nos vários mutantes. 

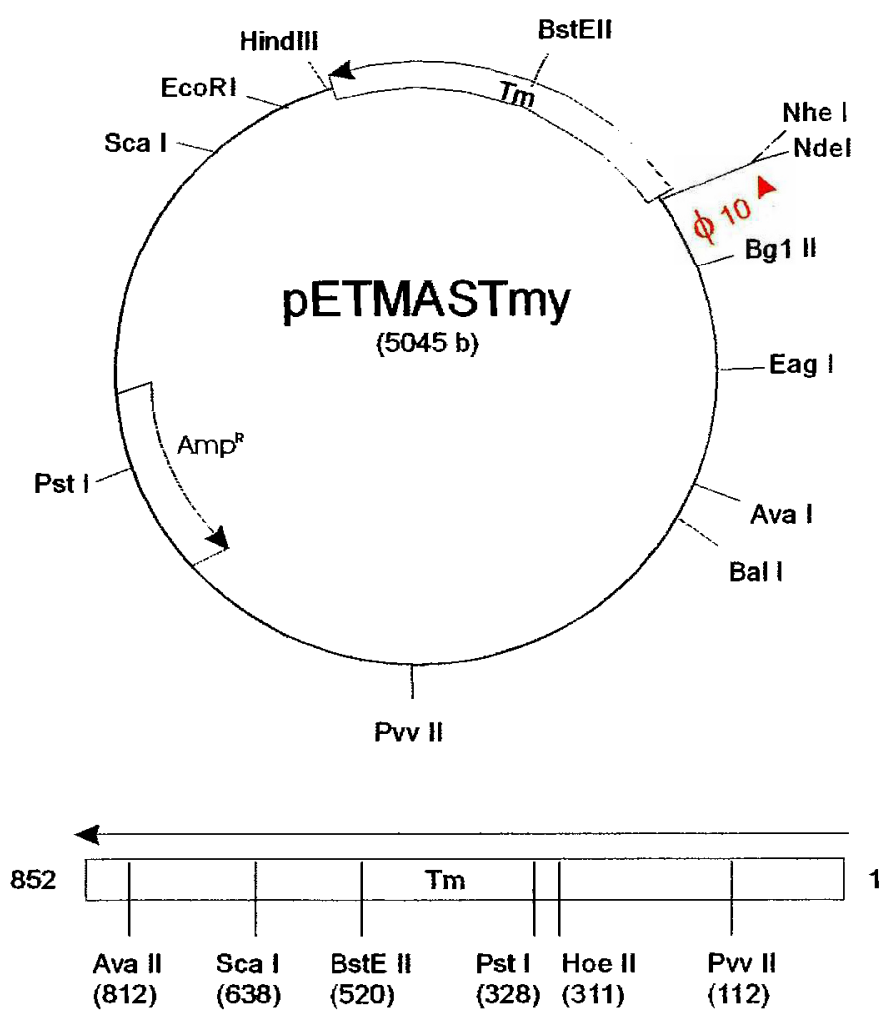

Figura 24. Mapa de restrição do pET-MASTm (Monteiro et al., 1994). Ф10: Promotor $\Phi 10$ do bacteriófago $T 7$.

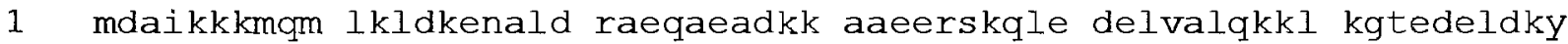

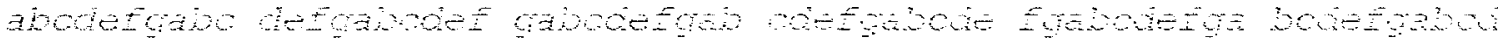

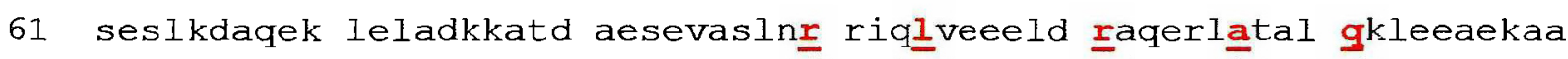

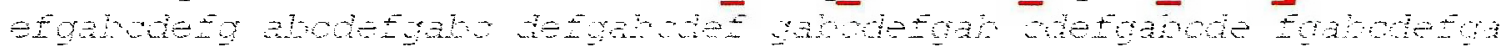

121 desergmkvi enraqkdeek meiqeiqlke akhiaeeadr kyeeaarklv iiegdlerae

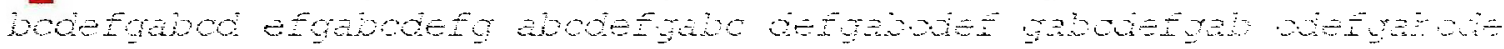

181 eraelseskc aeleeelktv tnnlksleaq aekysqkedk yeeeikvltd klkeaetrae

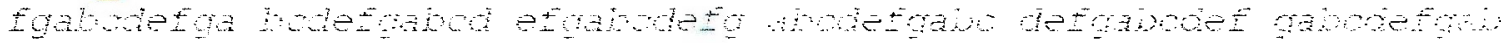

241 faersvtkle ksiddledel yagklkykai seeldhalnd mtsi

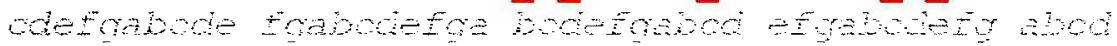

Figura 25. Sequência primária da cadeia a da tropomiosina de músculo esquelético de galinha (Gooding et al., 1987) indicando os resíduos mutados para triptofano (vermelho, sublinhado). Sob cada linha da sequência está indicado em cinza e itálico a posição na repetição heptapeptídica. 
As tropomiosinas recombinantes foram expressas com incorporação de 5-hidroxitriptofano em cepa de E. coli auxotrófica para triptofano Cy(DE3)pLysS (Drapeau et al., 1968) conforme descrito em Farah e Reinach (1999). O clone pET-ASTm de interesse foi transformado (Mandel e Higa, 1970) nesta cepa auxotrófica, repicado em placa com meio TyE com antibiótico adequado e incubado durante a noite a $37^{\circ} \mathrm{C} .50 \mathrm{~mL}$ de $2 x T y(16$ $\mathrm{g} / \mathrm{L}$ triptona, $10 \mathrm{~g} / \mathrm{L}$ extrato de levedura, $5 \mathrm{~g} / \mathrm{L} \mathrm{NaCl}, \mathrm{pH}$ 7.4) com $100 \mu \mathrm{g} / \mathrm{mL}$ de carbenicilina e cloranfenicol foram inoculados com cultura da placa e incubados por $3 \mathrm{~h}$ e $250 \mathrm{rpm}\left(37^{\circ} \mathrm{C}\right) .8 \times 500 \mathrm{~mL}$ de meio mínimo (para cada litro de meio: $6 \mathrm{~g}$ de $\mathrm{Na}_{2} \mathrm{HPO}_{4}$ anidro, $3 \mathrm{~g}$ de $\mathrm{KH}_{2} \mathrm{PO}_{4}, 0.5 \mathrm{~g}$ de $\mathrm{NaCl}, 1 \mathrm{~g}$ de $\mathrm{NH}_{4} \mathrm{Cl}, 812 \mu \mathrm{LgSO}_{4} 1 \mathrm{M}, 10 \mathrm{~mL}$ glicose $200 \mathrm{~g} / \mathrm{L}, 680 \mu \mathrm{L} \mathrm{CaCl} 200 \mathrm{~g} / \mathrm{L}, 1$ $\mathrm{mL}$ carbenicilina $200 \mathrm{mg} / \mathrm{mL}, 1 \mathrm{~mL}$ cloranfenicol $200 \mathrm{mg} / \mathrm{mL}$ e $10 \mu \mathrm{L}$ tiamina $100 \mathrm{mg} / \mathrm{mL}$ ) com $10 \mathrm{~mL} / \mathrm{L}$ do aminoácido triptofano $(10 \mathrm{mg} / \mathrm{mL}$ ) foram inoculados com a cultura anterior, incubados até densidade óptica 0.8 a 250 rpm $\left(37^{\circ} \mathrm{C}\right)$. Os meios foram centrifugados $4500 \times \mathrm{g}$ por $5 \mathrm{~min}\left(4{ }^{\circ} \mathrm{C}\right)$, o precipitado ressuspenso em meio mínimo na ausência de triptofano e induzidos com IPTG (0.4 mM finais). Após $15 \mathrm{~min} 40 \mathrm{~mL} / \mathrm{L}$ de 5hidroxitriptofano $(5 \mathrm{mg} / \mathrm{mL})$ foram adicionados. Após $3 \mathrm{~h}$ de indução a 250 $\mathrm{rpm}\left(37^{\circ} \mathrm{C}\right)$ e centrifugação a $4500 \times \mathrm{g}$ por $10 \mathrm{~min}\left(4{ }^{\circ} \mathrm{C}\right)$ o precipitado foi guardado a $-20^{\circ} \mathrm{C}$.

A purificação dos mutantes da tropomiosina com o aminoácido fluorescente 5-hidroxitriptofano foi realizada segundo descrito por Monteiro et al. (1994) com modificações (Farah e Reinach, 1999). Após a indução em larga escala (ver acima) as células foram ressuspensas em tampão de lise (50 mM Tris. $\mathrm{HCl} \mathrm{pH} \mathrm{8.0,} 25$ \% sacarose, $1 \mathrm{mM}$ EDTA), lisado por três passagens em 'French Press' a 16000 psi, centrifugado a 10000 x g por 20 $\min \left(4{ }^{\circ} \mathrm{C}\right)$ e o sobrenadante foi precipitado por $3 \mathrm{~V}$ de etanol $100 \% \mathrm{em}$ geladeira. Após centrifugação a $10000 \times \mathrm{g}$ por $20 \mathrm{~min}\left(4^{\circ} \mathrm{C}\right)$ o precipitado foi ressuspenso em $4 \mathrm{~V}$ de etanol $70 \%$, novamente centrifugado a $10000 \times$ g por $20 \min \left(4^{\circ} \mathrm{C}\right)$ e seco durante a noite. Adicionou-se ao precipitado seco 200 $\mathrm{mL}$ de tampão (50 mM Tris- $\mathrm{HCl} \mathrm{pH} 7.5$ e $1 \mathrm{M} \mathrm{KCl}$ ), ajustou-se $0 \mathrm{pH}$ rapidamente para $7.0 \mathrm{com} \mathrm{HCl} 1 \mathrm{M}$, extraiu-se por $4 \mathrm{~h}$ em gelo, sob agitação, e centrifugou-se $10000 \times \mathrm{g}$ por $20 \mathrm{~min}\left(4{ }^{\circ} \mathrm{C}\right)$. $\mathrm{O}$ sobrenadante teve $\mathrm{o}$ seu $\mathrm{pH}$ 
abaixado para $4.6 \mathrm{com} \mathrm{HCl} 0.25 \mathrm{M}$ (em gelo, sob agitação suave). Após centrifugação a $8000 \times \mathrm{g}$ por $15 \mathrm{~min}\left(4^{\circ} \mathrm{C}\right)$ o precipitado foi ressuspenso em $50 \mathrm{~mL}$ de tampão (50 mM Tris- $\mathrm{HCl}$ pH 8.0, EDTA $1 \mathrm{mM}$ e $\beta$-mercaptoetanol $14 \mathrm{mM}$ ) e dialisado contra este tampão. Uréia foi adicionada ao sobrenadante até $8 \mathrm{M}$ e a solução foi aplicada em coluna de DEAE-celulose equilibrada com o mesmo tampão. Após lavagem com este mesmo tampão com $20 \mathrm{mM} \mathrm{NaCl}$, eluimos a amostra com um gradiente de 20 a 140 mM num fluxo de $0.8 \mathrm{~mL} / \mathrm{min}$. As frações com a proteína de interesse foram reunidas, dialisadas $3 \times$ contra $50 \mathrm{mM}$ Tris. $\mathrm{HCl} \mathrm{pH} 8.0,0.5 \mathrm{mM}$ EDTA e $5 \mathrm{mM} \beta$ mercaptoetanol e $2 X$ contra $25 \mathrm{mM}$ MOPS pH 7.0, $50 \mathrm{mM} \mathrm{NaCl}, 5 \mathrm{mM} \mathrm{MgCl} 2$ e $1 \mathrm{mM}$ DTT (FB) e estocadas a $-20^{\circ} \mathrm{C}$.

\subsection{Complexo troponina}

Subunidades recombinantes da troponina

Indução em larga-escala

O clone de interesse (da TnC, Tnl ou TnT) foi transformado (Mandel e Higa, 1970) em cepa de E. Coli BL21(DE3)pLysS (Studier et al., 1990), repicado em placa com meio TyE com antibiótico adequado e incubado durante a noite a $37{ }^{\circ} \mathrm{C} .50 \mathrm{~mL}$ de $2 x T y$ contendo o antibiótico foram inoculados com cultura da placa e incubados por $3 \mathrm{~h}$ e $250 \mathrm{rpm}\left(37^{\circ} \mathrm{C}\right) .8 \mathrm{X}$ $500 \mathrm{~mL}$ de $2 x T y$ contendo o antibiótico foram inoculados com a cultura anterior, incubados até densidade óptica 0.8 a $250 \mathrm{rpm}\left(37^{\circ} \mathrm{C}\right)$ e induzidos com IPTG (0.4 mM finais). Após $3 \mathrm{~h}$ de indução a $250 \mathrm{rpm}\left(37^{\circ} \mathrm{C}\right) \mathrm{e}$ centrifugação a $4500 \times \mathrm{g}$ por $10 \min \left(4^{\circ} \mathrm{C}\right)$ o precipitado foi guardado a -20 ${ }^{\circ} \mathrm{C}$. 
A TnC recombinante de músculo de galinha foi purificada segundo Fujimori et al. (1990). Após indução indicada acima, o precipitado de bactérias de cada litro de cultura foi ressuspenso em $40 \mathrm{~mL}$ por litro de cultura de tampão (50 mM Tris. $\mathrm{HCl} \mathrm{pH} \mathrm{8.0,} 25 \%$ sacarose, 1 mM EDTA) e lisado por três passagens em 'French Press' a 16000 psi. O lisado foi clarificado a $27000 \times \mathrm{g}$ por $30 \mathrm{~min}$, o volume de sobrenadante foi aumentado para $50 \mathrm{~mL}$ por litro de cultura e TCA (ácido tricloroacético) foi adicionado até uma concentração final de $5 \%$, a solução foi centrifugada a $1500 \times$ g por 10 $\min \left(4{ }^{\circ} \mathrm{C}\right)$ e o precipitado solubilizado em $90 \mathrm{~mL}$ de $25 \mathrm{mM}$ Tris. $\mathrm{HCl} \mathrm{pH} \mathrm{8.0,1}$ $\mathrm{mM} \mathrm{MgCl} 2$ e $1 \mathrm{mM} \beta$-mercaptoetanol e dialisado contra três trocas desta solução. Após centrifugação a $110000 \times \mathrm{g}$ por $30 \mathrm{~min}\left(4{ }^{\circ} \mathrm{C}\right)$, uréia foi adicionada ao sobrenadante até $8 \mathrm{M}$ e a solução foi aplicada em coluna de DEAE-sepharose fast-flow equilibrada com o mesmo tampão. Após lavagem com este mesmo tampão com $60 \mathrm{mM} \mathrm{NaCl}$, eluimos a amostra com um gradiente de 60 a $400 \mathrm{mM}$ num fluxo de $200 \mathrm{~mL} / \mathrm{h}$. As frações com a proteína de interesse foram reunidas, dialisadas contra $25 \mathrm{mM}$ Tris. $\mathrm{HCl} \mathrm{pH} \mathrm{8.0,1} \mathrm{mM}$ $\mathrm{MgCl}_{2}$ e $1 \mathrm{mM} \beta$-mercaptoetanol e estocadas a $-20^{\circ} \mathrm{C}$.

$T n l$

A purificação da $\mathrm{Tnl}$ recombinante de músculo esquelético de galinha foi realizada segundo descrito em Quaggio et al. (1993). O precipitado da indução em larga escala (ver acima) foi solubilizado em potter em $40 \mathrm{~mL}$ por litro de cultura em tampão contendo $50 \mathrm{mM}$ Tris-HCl pH 7.0, EDTA $1 \mathrm{mM}, \beta-$ mercaptoetanol $10 \mathrm{mM}$ e PMSF $1 \mathrm{mM}$, congelado $\left(15 \mathrm{~min},-70{ }^{\circ} \mathrm{C}\right.$ ) e descongelado rapidamente, e lisado por três passagens em 'French Press' a 16000 psi. O lisado foi centrifugado a $110000 \times \mathrm{g}$, o precipitado ressuspenso em $50 \mathrm{mM}$ Tris. $\mathrm{HCl} \mathrm{pH} \mathrm{7.0,1} \mathrm{mM} \mathrm{EDTA} \mathrm{e} 10 \mathrm{mM} \beta$-mercaptoetanol com $8 \mathrm{M}$ uréia e a solução aplicada em coluna cromatográfica CM-sepharose fast-flow equilibrada com o mesmo tampão. Após lavagem com este mesmo tampão com $50 \mathrm{mM} \mathrm{NaCl}$, a amostra foi eluida com um gradiente de 50 a $280 \mathrm{mM}$ 
num fluxo de $180 \mathrm{~mL} / \mathrm{h}$. As frações com a proteína de interesse foram reunidas, dialisadas $5 \times$ contra $25 \mathrm{mM}$ Tris. $\mathrm{HCl} \mathrm{pH} \mathrm{7.0,500} \mathrm{mM} \mathrm{NaCl}$ e $5 \mathrm{mM}$ $\beta$-mercaptoetanol e estocadas a $-20^{\circ} \mathrm{C}$.

$\operatorname{Tn} T$

A purificação da $\mathrm{TnT}$ recombinante de músculo esquelético de galinha foi realizada conforme descrito em Farah et al. (1994). As células bacterianas obtidas pela indução em larga escala (ver acima) foram ressuspensas em 40 $\mathrm{mL}$ por litro de cultura em tampão contendo $50 \mathrm{mM}$ Tris. $\mathrm{HCl} \mathrm{pH} \mathrm{8.0,1} \mathrm{mM}$ EDTA, $10 \mathrm{mM} \beta$-mercaptoetanol e $6 \mathrm{M}$ uréia e lisadas por três passagens em 'French Press' a 16000 psi. O lisado foi centrifugado a $110000 \times \mathrm{g}$ por $1 \mathrm{~h} \mathrm{(4}$ ${ }^{\circ} \mathrm{C}$ ), o precipitado ressuspenso em $50 \mathrm{mM}$ Tris. $\mathrm{HCl} \mathrm{pH} \mathrm{8.0,1} \mathrm{mM} \mathrm{EDTA} \mathrm{e} 10$ mM $\beta$-mercaptoetanol com $8 \mathrm{M}$ uréia e a solução aplicada em coluna cromatográfica DEAE-sepharose fast-flow equilibrada com o mesmo tampão. Após lavagem a amostra foi eluida com um gradiente de 0 a 600 mM num fluxo de $180 \mathrm{~mL} / \mathrm{h}$. As frações contendo a proteína de interesse são reunidas e dialisadas contra $6 \mathrm{M}$ uréia, $50 \mathrm{mM}$ acetato de sódio $\mathrm{pH}$ 5.0, $1 \mathrm{mM}$ EDTA e $1.4 \mathrm{mM}$ ß-mercaptoetanol e aplicadas em coluna cromatográfica CMsepharose fast-flow equilibrada com o mesmo tampão. Após lavagem a amostra foi eluida com um gradiente de 0 a $600 \mathrm{mM}$ num fluxo de $180 \mathrm{~mL} / \mathrm{h}$. As frações com a proteína de interesse foram reunidas, dialisadas $3 \times$ contra $50 \mathrm{mM}$ Tris. $\mathrm{HCl} \mathrm{pH} 8.0,1 \mathrm{mM}$ EDTA, $1 \mathrm{M} \mathrm{KCl}$ e $1 \mathrm{mM}$ DTT e estocadas a $20^{\circ} \mathrm{C}$.

Montagem do compexo troponina

A montagem do complexo troponina a partir das subunidades recombinantes está descrito com detalhes em Farah et al. (1994).

O complexo (TnC-Tnl-TnT) foi reconstituido por meio da adição

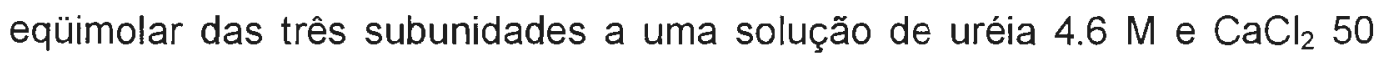


mM seguida de diálises contra : A) Uréia $4.6 \mathrm{M}, \mathrm{KCl} 1 \mathrm{M}$, Tris- $\mathrm{HCl} \mathrm{pH} 8.050$ $\mathrm{mM}, \mathrm{CaCl}_{2} 50 \mathrm{mM}, \beta$-mercaptoetanol $10 \mathrm{mM}$; B) Uréia $2 \mathrm{M}, \mathrm{KCl} 1 \mathrm{M}$, Tris- $\mathrm{HCl}$ $\mathrm{pH} 8.050 \mathrm{mM}, \mathrm{CaCl}_{2} 50 \mathrm{mM}, \beta$-mercaptoetanol $10 \mathrm{mM}$; C) $\mathrm{KCl} 1 \mathrm{M}$, MOPS $\mathrm{pH} 7.020 \mathrm{mM}, \mathrm{CaCl}_{2} 50 \mathrm{mM}, \beta$-mercaptoetanol $10 \mathrm{mM}$; D) $\mathrm{KCl} 100 \mathrm{mM}$, MOPS pH $7.020 \mathrm{mM}, \mathrm{CaCl}_{2} 50 \mathrm{mM}, \beta$-mercaptoetanol $10 \mathrm{mM}$; E) $\mathrm{KCl} 6.5$ mM, MOPS pH 7.025 mM, MgCl 3.5 mM, DTT 1 mM; F) KCl 6.5 mM, MOPS pH 7.025 mM, MgCl 3.5 mM, DTT 1 mM. Após centrifugação a $12000 \times \mathrm{g}$ durante 5 min para retirar qualquer $\operatorname{Tnl}$ ou $\operatorname{TnT}$ não complexadas, adiciona-se DTT $5 \mathrm{mM}$. Antes da adição de DTT uma alíquota deve ser retirada para dosagem de proteína pelo método de Hartree (Hartree, 1972) pois altas concentrações de DTT interferem na dosagem. O complexo é estocado a $20^{\circ} \mathrm{C}$.

\subsection{Actina}

A actina foi purificada a partir dos músculos pectoralis major e minor de galinha, previamente extraídos e congelados, segundo o protocolo de Pardee \& Spudich (1982) com modificações:

\section{Obtenção do pó cetônico}

Para a obtenção do pó cetônico, aproximadamente $350 \mathrm{~g}$ de músculo pectoralis major e minor congelado de galinha é moído e sujeito a uma série de extrações a $4{ }^{\circ} \mathrm{C}$ : A) 10 minutos com $1 \mathrm{~L}$ de solução $0.1 \mathrm{M} \mathrm{KCl}, 0.15 \mathrm{M}$ $\mathrm{K}_{2} \mathrm{HPO}_{4} \mathrm{pH} 6.5$ seguida por filtração em gaze, dobrada para evitar perdas, previamente fervida com EDTA; B) 10 minutos com $2 \mathrm{~L}$ de solução $0.05 \mathrm{M}$ $\mathrm{NaHCO}_{3}$ seguida por filtração em gaze; C) 10 minutos em solução $1 \mathrm{mM}$ NaEDTA pH 7.0 seguida de filtração em gaze; D) $2 \times 5$ minutos com $2 \mathrm{~L}$ de $\mathrm{H}_{2} \mathrm{O}$ seguida de filtração em gaze; E) $5 \times 10$ minutos com $1 \mathrm{~L}$ de acetona à temperatura ambiente seguida de filtração em gaze 
O resíduo é deixado secar até o dia seguinte à temperatura ambiente e então guardado $\mathrm{a}-20^{\circ} \mathrm{C}$ até o uso.

Obtenção da actina a partir do pó cetônico.

A actina é extraída de cerca de $2-3 \mathrm{~g}$ de pó cetônico, em gelo, sob agitação lenta, por $3 \times 10$ minutos com $3 \times 50 \mathrm{~mL}$ do seguinte tampão: Tris. $\mathrm{HCl}$ pH $8.02 .5 \mathrm{mM}, \mathrm{CaCl}_{2} 0.2 \mathrm{mM}$, ATP $0.2 \mathrm{mM}$ e DTT $1 \mathrm{mM}$. Os sobrenadantes combinados foram decantados e filtrados à vácuo e $\mathrm{NaCl} 50$ $\mathrm{mM}, \mathrm{MgCl}_{2} 0.7 \mathrm{mM}$, ATP $0.8 \mathrm{mM}$ e Tris. $\mathrm{HCl} \mathrm{pH} 7.5 \mathrm{mM}$ são adicionados. A solução é mantida a temperatura ambiente sob agitação lenta por 2 horas. Após este intervalo de tempo, a força iônica do meio é aumentada pela adição de $\mathrm{NaCl}$ até $600 \mathrm{mM}$. Após a solução ser lentamente agitada por mais 30 minutos a amostra é ultracentrifugada em ultracentrífuga Himac CP80 $\beta$ da Hitachi Koki Co. Ltd. por 2 horas a $160000 \times g\left(4^{\circ} \mathrm{C}\right)$ e o 'pellet' ressuspenso até o dia seguinte com cerca de $0.4 \mathrm{~mL} /$ tubo de tampão de fluorescência (MOPS $25 \mathrm{mM} \mathrm{pH} 7.0, \mathrm{NaCl} 50 \mathrm{mM}, \mathrm{MgCl}_{2} 5 \mathrm{mM}$ e DTT $1 \mathrm{mM}$ ).

A forma purificada é estocada no gelo em tampão de fluorescência por não mais que duas semanas. A concentração da actina purificada é obtida através de seu coeficiente de extinção por espectrofotometria (concentração $($ actina $)=(\operatorname{Abs}(290 \mathrm{~nm})-\operatorname{Abs}(320 \mathrm{~nm})) / 0.608^{\star} 42000$, onde 0.608 é o coeficiente de extinção da actina em $\mathrm{M}^{-1} \mathrm{~cm}^{-1}$ e 42000 é a massa molecular da actina em $\mathrm{gmol}^{-1}$ ).

\subsection{Fragmento $\mathrm{S} 1$ da miosina}

A miosina foi purificada durante o doutorado da aluna Áurea D. de Sousa a partir dos músculos pectoralis major e minor de galinha através do método modificado descrito em Reinach et al. (1982). O fragmento S1 (após digestão da miosina com quimiotripsina) foi purificado por Áurea D. de Sousa segundo o método de Margossian e Lowey (1982). 
A concentração da solução de S1 é obtida por meio de seu coeficiente de extinção (concentração $(\mathrm{S} 1)=(\mathrm{Abs}(280 \mathrm{~nm})-\mathrm{Abs}(330 \mathrm{~nm}))$ $0.800^{*} 110000$ onde $0.800 \mathrm{M}^{-1} \mathrm{~cm}^{-1}$ é o coeficiente de extinção da $\mathrm{S} 1$ a $280 \mathrm{~nm}$ e $110000 \mathrm{~g} \cdot \mathrm{mol}^{-1}$ é a massa molecular da S1.

\section{Ensaios de co-sedimentação com actina}

Os ensaios de co-sedimentação com actina baseiam-se no fato de que a F-actina sedimenta quando ultracentrifugada e que arrasta consigo para o pellet outras proteínas que se liguem a ela. Estas proteínas - tropomiosina e troponina - não sedimentam na ausência de actina nas condições utilizadas na ultracentrifugação. Assim, este ensaio permite verificar se os mutantes da tropomiosina construídos estão realmente se ligando a actina nas diversas condições estudadas.

Para os ensaios de co-sedimentação preparamos inicialmente $100 \mu \mathrm{L}$ da mistura de interesse (preparamos quatro misturas diferentes para cada um dos mutantes e para a tropomiosina tipo selvagem (ASTm): (1) Tropomiosina e Actina; (2) Tropomiosina, Actina e Troponina (1 mM EGTA); (3) Tropomiosina, Actina, Troponina e ions cálcio (1 mM) e (4) Tropomiosina e Actina na presença de $500 \mathrm{mM}$ de acrilamida) no mesmo tampão usado para os ensaios de fluorescência $(F B)$. As proteínas utilizadas estavam nas seguintes concentrações: actina $7 \mu \mathrm{M}$, tropomiosina $1 \mu \mathrm{M}$ e complexo troponina $1 \mu \mathrm{M}$.

Em seguida $25 \mu \mathrm{L}$ da mistura foram separados e misturados com 6.25 $\mu \mathrm{L}$ de $5 \mathrm{XSB}$ (tampão de amostra $5 \mathrm{X}$ concentrado) para posterior análise por SDS-PAGE. Os $75 \mu \mathrm{L}$ restantes foram então ultracentrifugados a $230000 \times \mathrm{g}$ durante 30 minutos a $25{ }^{\circ} \mathrm{C}$ em uma ultracentrífuga Beckman de mesa Optima TLX. Aos $75 \mu \mathrm{L}$ de sobrenadante adicionou-se $18.75 \mu \mathrm{L}$ de $5 \mathrm{XSB}$. Ao pellet adicionou-se $75 \mu \mathrm{L}$ de $\mathrm{FB}$ e $18.75 \mu \mathrm{L}$ de 5 XSB. 
Desta forma, cada amostra gerou 3 amostras (volumes equivalentes) para serem analisadas por SDS-PAGE: M - mistura inicial não ultracentrifugada; S - sobrenadante após ultracentrifugação; e P - pellet após a ultracentrifugação. A presença de tropomiosina em $P$ indica que ocorreu ligação à F-actina.

\section{Regulação da $\mathbf{M g}^{2+}$-ATPase da miosina $\mathbf{S 1}$ por filamentos finos reconstituidos contendo tropomiosinas mutantes}

Para os ensaios de regulação da atividade $\mathrm{Mg}^{2+}$-ATPásica da miosina S1 combinou-se $14 \mu \mathrm{M}$ actina, $0.5 \mu \mathrm{M}$ S1, $2 \mu \mathrm{M}$ tropomiosina e $2 \mu \mathrm{M}$ troponina em FB. $1 \mathrm{mM}$ EGTA foram adicionados às soluções contendo troponina na ausência de cálcio; $\mathrm{CaCl}_{2}$ foram adicionados a $1 \mathrm{mM}$. A reação foi iniciada pela adição de $2 \mathrm{mM}$ ATP. Após 1 h de reação determinou-se o fosfato inorgânico liberado (Heinonen e Lahti, 1981).

O tempo de reação de $1 \mathrm{~h}$ a partir da primeira adição de ATP foi estabelecido a partir da análise da variação na atividade ATPásica em função do tempo de reação a partir da adição de 2 mM ATP (Figura 26). Este tempo de reação para nosso ensaios de atividade ATPásica permitiram obter o maior sinal possivel em condições em que a velocidade de reação é razoavelmente constante. Nestas condições $\sim 22 \%$ do ATP adicionado inicialmente foi hidrolisado após $1 \mathrm{~h}$ de reação. A atividade ATPásica de acto$\mathrm{S} 1$ é aproximadamente $0.24 \mathrm{~s}^{-1}$. 


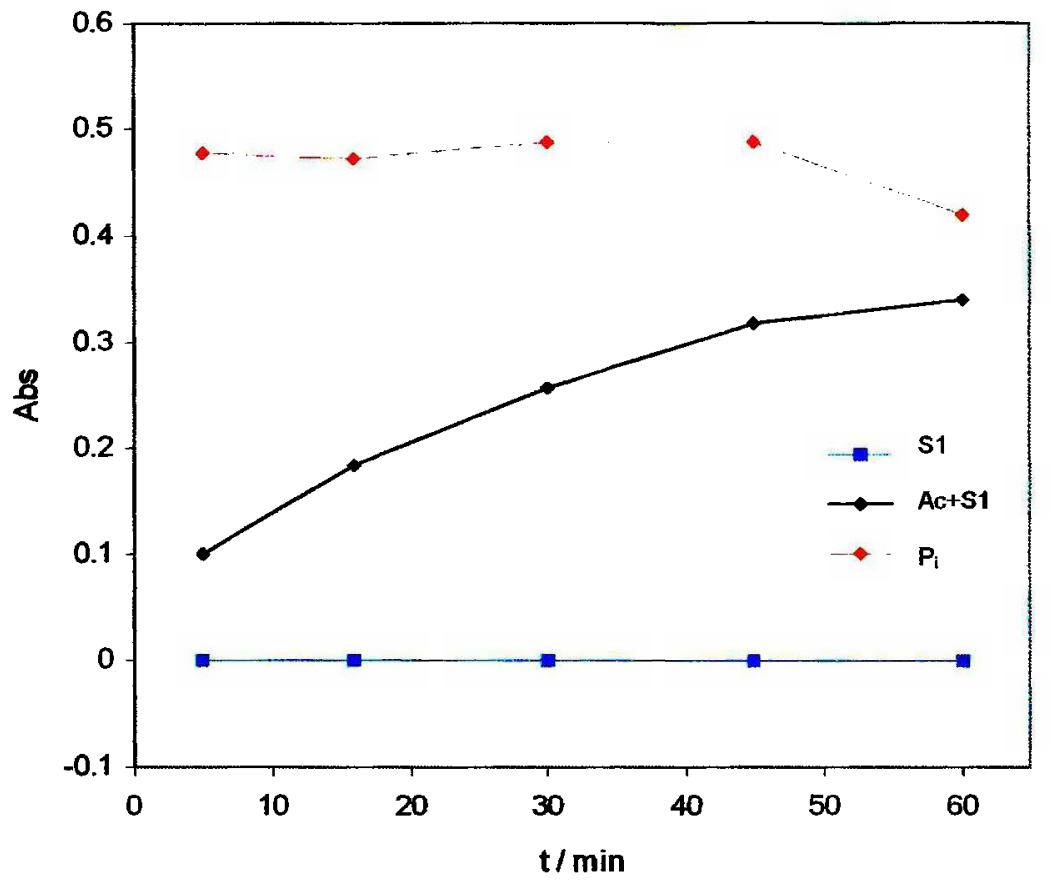

Figura 26. Estudo da variação na absorbância da reação de ATPase em função de tempo de reação normalizado para $S 1$ (branco contendo apenas S1 e ATP, i.e., relacionado com a baixa atividade ATPásica intrínsica da cabeça S1 da miosina). Ac+S1 - contendo actina, S1 e ATP; Pi - contendo $0.5 \mathrm{mM}$ de fosfato inorgânico, além de actina e ATP, na ausência de S1).

\section{Ensaios de estabilidade}

Espectros de dicroísmo circular

Os experimentos de desnaturação por temperatura acompanhadas por dicroísmo circular (CD) foram realizados num espectropolarímetro JASCO J810 no Laboratório Nacional de Luz Sincrotron (LNLS - Campinas). Antes de cada desnaturação por temperatura foi obtido um espectro de dicroísmo circular a $4{ }^{\circ} \mathrm{C}$ entre 190 e $260 \mathrm{~nm}$. Os espectros foram obtidos a uma velocidade de $50 \mathrm{~nm} / \mathrm{min}$ com um tempo de resposta de $4 \mathrm{~s}$. A fenda utilizada foi de $1 \mathrm{~nm}$. Cada espectro é a média de dois experimentos com 4 
acumulações cada. As concentrações foram corrigidas pelo ponto isodicróico como descrito em Holtzer e Holtzer (1992).

Desnaturações por temperatura seguida por dicroísmo circular

Utilizou-se o espectropolarimetro JASCO J-810 do Laboratório Nacional de Luz Sincrotron (LNLS - Campinas) para realização dos experimentos de desnaturação por temperatura acompanhadas por dicroísmo circular (CD) entre 4 e $80^{\circ} \mathrm{C}$ a $222 \mathrm{~nm}$. O tampão utilizado foi o CDB (ver 5. Soluções gerais). O tampão de fluorescência (FB) utilizado para os ensaios de supressão de fluorescência (seção 9. Ensaios de supressão de fluorescência) não pode ser utilizado aqui devido à absorção do MOPS em comprimentos de onda menores que $230 \mathrm{~nm}$ (especialmente na região próxima à $200 \mathrm{~nm}$ ). $\mathrm{O} C \mathrm{CDB}$ utilizado, entretanto, possuia o mesmo $\mathrm{pH}$ e a mesma força iônica do FB (75.36 mM) (ver seção 1. Soluções gerais para detalhes do cálculo da força iônica). O tratamento dos dados experimentais foi realizado como sugerido por Pace e Scholtz (1997) e encontra-se descrito com detalhes na seção de RESULTADOS.

Desnaturações por uréia seguida por fluorescência

A variação no sinal de fluorescência em função da concentração de agente caotrópico (uréia) foi obtida num espectrofluorímetro modelo ATF 105 da AVIV Instruments. As amostras a $25^{\circ} \mathrm{C}$ foram excitadas em $302 \mathrm{~nm}$ e a fluorescência emitida foi detectada a $337 \mathrm{~nm}$. As fendas de excitação e emissão utilizadas foram de 1 e $5 \mathrm{~nm}$ respectivamente.

O tampão utilizado nestes ensaios foi o FB (ver 1. Soluções gerais). Uréia preparada na hora foi adicionada até uma concentração de $8 \mathrm{M}$. A concentração foi conferida com refratômetro da maneira descrita a seguir. Calculamos inicialmente a concentração da uréia pelo valor obtido pelo 
cálculo da densidade relativa da solução de uréia através da equação $d / d_{0}=$ $1+0.2658 w+0.0330 w^{2}$, onde $w=M_{U} / M_{S}$. A concentração $C$ pode ser calculada pela equação $C=M_{U} /\left(60.06^{*} \mathrm{~V}\right)$ onde $M_{U}=$ massa de uréia obtida pela diferença $m$ (tubo+uréia) $-m\left(\right.$ tubo) e $V=M_{S} /\left(d / d_{0}\right)$ onde $M_{s}$ é a massa da solução obtida pela diferença $m$ (tubo+uréia+solução) - $m$ (tubo). Este valor foi então comparando com a concentração obtida pela medição em refratômetro através da equação $C=117.66 \Delta \mathrm{N}+29.753(\Delta \mathrm{N})^{2}+$ 185.56( $(\Delta N)^{3}$, onde $\Delta N=N_{U}-N_{0}$ é a diferença entre os índices de refração da solução de uréia $\left(\mathrm{N}_{U}\right)$ e do tampão $\left(\mathrm{N}_{0}\right)$. Um erro menor que $1 \%$ entre estes valores é aceitável.

A linha base do sinal espectroscópico é geralmente inclinada devido a variação aproximadamente linear do sinal dos estados desnaturado e nativo com a concentração de desnaturante. Portanto, estas dependências lineares devem ser incorporados na análise da curva (Santoro e Bolen, 1988). Este problema foi resolvido pela regressão linear da curva na linha base e introdução destes fatores na equação do cálculo de fração desenovelada. Os cálculos da fração desenovelada e dos parâmetros da desnaturação estão descritos na seção RESULTADOS.

\section{Ensaios de supressão de fluorescência.}

\section{Supressão por iodeto}

Os ensaios de quenching de fluorescência pelo supressor extrínsico negativamente carregado iodeto foram realizados num espectrofotômetro de fluorescência F-4500 da Hitachi. As amostras foram excitadas a 312 nm, que é um comprimento de onda de excitação seletivo ao 5-hidróxitriptofano, e o espectro de emissão foi registrado de 320 a $380 \mathrm{~nm}$. O tampão utilizado nestes ensaios foi o FB (ver 1. Soluções gerais). EGTA $1 \mathrm{mM}$ ou $\mathrm{CaCl}_{2} 1 \mathrm{mM}$ foram adicionados quando analisamos o quenching na presença de troponina (na ausência ou na presença de íons cálcio respectivamente). Os ensaios 
com iodeto foram inicialmenete realizados a quatro forças iônicas diferentes $(30,70,100$ e $160 \mathrm{mM})$ e o iodeto foi adicionado até atingir a forção iônica máxima em cada caso. A variação na força iônica devida à adição do iodeto foi corrigida a um valor constante com uma solução estoque tamponada de $\mathrm{NaCl} 5 \mathrm{M}$. Uma pequena quantidade de $\mathrm{S}_{2} \mathrm{O}_{3}^{-}\left(\sim 10^{-3} \mathrm{M}\right)$ foi adicionada à solução estoque de $\mathrm{Nal}$ (99.999 \% da Aldrich) para evitar a formação de $\mathrm{I}_{3}$. Esta adição é necessária porque $0 \mathrm{I}_{3}{ }^{-}$absorve na região de comprimento de onda do triptofanil (efeito filtro) e devido a possibilidade de reação química (Lehrer, 1971).

Devemos ressaltar que a interpretação dos dados de supressão pelo iodeto é bastante dificultada pelos motivos expostos a seguir:

1- O erro associado à medição do sinal de fluorescência é elevado devido ao fato de que para podermos manter a força iônica constante nas diversas concentrações de iodeto precisamos para cada ponto montar uma mistura protéica diferente a partir de uma solução estoque comum e corrigir a força iônica com uma solução de $\mathrm{NaCl}$ tamponado. Desta forma, pequenas variações na concentração de proteina de um tubo para o outro gera uma variação significativa em relação ao efeito da supressão na intensidade de fluorescência observada.

2- Uma outra fonte de erro reside no fato de que o uso de concentrações relativamente baixas de iodeto (no ponto mais concentrado aproximadamente $160 \mathrm{mM}$ ) resulta uma variação relativamente pequena em Fo/F (a variação obtida para os experimentos com acrilamida são muito maiores que as obtidas com iodeto). Esta restrição é devida ao fato de que um aumento na concentração de iodeto implicaria num aumento proporcional na força iônica do meio gerando variações indesejáveis mais pronunciadas no grau de interação entre as proteínas do sistema e na conformação destas proteínas. Essas limitações experimentais fazem com que as curvas obtidas para a supressão por iodeto à força iônica $30 \mathrm{mM}$ (que implica numa concentração máxima de iodeto de $30 \mathrm{mM}$ ) fiquem prejudicadas pelo fato de que a variação observada na fluorescência do sistema é bastante pequena 
(os experimentos haviam sido realizados a quatro forças iônicas diferentes: $30,70,100$ e $160 \mathrm{mM}$, mas devido aos problemas expostos neste item nos restringimos à análise das curvas obtidas a 100 e 160 mM).

3- Além disso, para vários dos sitemas estudados, uma outra complicação surge, em maior ou menor grau, para concentrações mais elevadas de supressor. As curvas obtidas passam a apresentar uma 'curvatura para baixo' típica para a supressão de sistemas com dois triptofanos em microambientes diferentes (ou duas conformações diferentes para os triptofanos). Este fator complica bastante a análise das curvas de supressão de fluorescência por iodeto porque aumenta o número de variáveis a serem ajustadas (de 1 (na ausência de supressão estática) ou 2 parâmetros (na presença desta), no caso de ambientes idênticos, para 3 (ausência de supressão estática) ou até 5 parâmetros (presença desta) no caso de ambientes diferentes; ver equação 5 da seção 3.3 Supressão de fluorescência da PARTE II da INTRODUÇÃO).

Para minimizar os erros indicados acima resolvemos analizar qualitativamente a variação na inclinação das curvas obtidas por supressão da fluorescência dos mutantes por iodeto entre os dados obtidos nas forças iônicas 100 mM e 160 mM ao invés de calcular valores para os parâmetros. Em alguns casos, em que obtivemos curvas de Stern-Volmer lineares, calculamos os valores de $\mathrm{K}_{\mathrm{SV}}$ como descrito abaixo para a supressão por acrilamida.

\section{Supressão por acilamida}

A fluorescência do análogo do triptofano 5-hidroxitriptofano pode ser excitada seletivamente a $312 \mathrm{~nm}$, permitindo a resolução do espectro de fluorescência da tropomiosina dos devido às outras proteínas contendo triptofano no filamento fino (Farah \& Reinach, 1999). Os ensaios de fluorescência foram realizados em um espectrofotômetro ATF 105 da AVIV Instruments. As fendas de excitação e emissão utilizadas foram 
respectivamente 1.0 e $5.0 \mathrm{~nm}$ e os comprimentos de onda de excitação e emissão 312 e $337 \mathrm{~nm}$ respectivamente. Tropomiosina $(1 \mu \mathrm{M})$, actina $(7 \mu \mathrm{M})$ e o complexo troponina $(2 \mu \mathrm{M})$ foram combinadas em FB (ver 1. Soluções gerais) e ou $1 \mathrm{mM}$ EGTA ou $1 \mathrm{mM} \mathrm{CaCl}_{2}$. Acrilamida foi adicionada até 0.5 M. A ausência de curvatura para baixo nos gráficos de Stern-Volmer (e portanto ausência de fluoróforos em sistemas heterogêneos) permitiu a análise dos dados utilizando-se a relação de Stern-Volmer modificada para supressão colisional e estática (ver PARTE II da INTRODUÇÃo, seção 3.3. Supressão de fluorescência):

$$
F_{0} / F=\left(1+K_{s V}[Q]\right) \exp (V[Q])
$$

onde $F_{0}$ é a fluorescência da amostra na ausência do supressor, $F$ é a fluorescência em função da concentração de acrilamida [Q], Ksv é a constante de Stern-Volmer ou de supressão dinâmica e $V$ é a constante de supressão estática (Lehrer \& Leavis, 1978; Eftink, 1991a; Eftink 1991b; Eftink \& Ghiron, 1981).

Sabe-se que o supressor extrínsico neutro acrilamida, um supressor eficiente que opera tanto pelo mecanismo colisional quanto pelo estático (Eftink e Ghiron, 1976), pode ser responsável, devido à sua absorção, por um artefato em análises por supressão de fluorescência conhecido como efeito do filtro interno. Para garantirmos que nosso sistema não tivesse este efeito indesejável, analisamos a variação na absorção de concentrações crescentes de acrilamida (até $2 \mathrm{M}$ ) em função do comprimento de onda de excitação (Figura 27). 


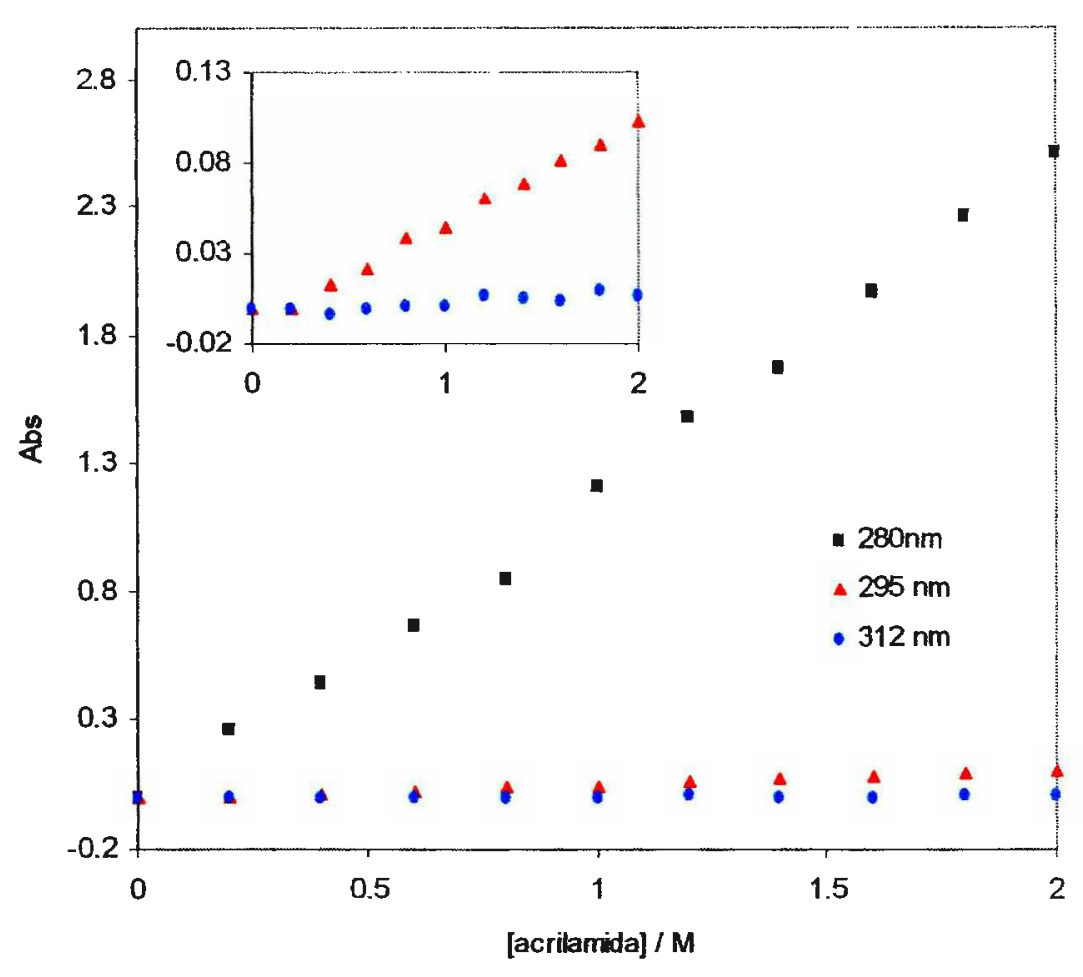

Figura 27. Análise da absorção da acrilamida em função da força iônica. Como pode ser visto no inserto, a absorção da acrilamida a comprimentos de onda maiores que $300 \mathrm{~nm}$ é praticamente nula mesmo a concentrações muito elevadas de acrilamida ( $2 \mathrm{M}$, nos ensaios de supressão a concentração máxima de acrilamida utilizada foi de $0.5 \mathrm{M}$ ).

Assim, a comprimentos de onda maiores que $312 \mathrm{~nm}$ a absorção pelo supressor acrilamida é desprezível. 


\section{RESULTADOS}

Nesta tese caracterizamos as interações entre vários mutantes recombinantes da tropomiosina e o filamento fino. Todos estes mutantes têm sondas fluorescentes de 5-hidroxitriptofano localizadas em várias posições ao longo da molécula (Figura 15). Todos estes mutantes são derivados da ASTm, uma a-tropomiosina recombinante de músculo esquelético de galinha que possui uma fusão Ala-Ser no seu amino-terminal (Monteiro et al., 1994). Esta fusão mimetiza a acetilação a-amino encontrada na proteína nativa e é necessária para a tropomiosina recombinante ligar a actina e regular a atividade $\mathrm{Mg}^{2+}$-ATPásica da actomiosina de forma equivalente à proteína muscular (Monteiro et al., 1994).

\section{Ligação da tropomiosina à actina: ensaios de co-sedimentação}

Os resultados obtidos por co-sedimentação (230000 x g, 30 minutos), que podem ser observados na figura 28 , mostraram que todos os mutantes da tropomiosina utilizados neste projeto (5-hidroxitriptofano inseridos nas posições $90,94,101,107,111,122,185,261,263,269,276$ e 278) ligam-se à actina +/- troponina +/- cálcio no tampão e temperatura utilizados para todos os ensaios. A presença de altas concentrações de acrilamida (500 mM) não altera esta ligação à actina para todos os mutantes exceto o $50 \mathrm{H} 90 \mathrm{~W}$, que tem sua ligação um pouco reduzida e o $50 \mathrm{H} 185 \mathrm{~W}$ que praticamente não liga actina nesta concentração de acrilamida (Figura 28). Entretanto, como pode ser visto na figura 29 , na presença de troponina $+/-\mathrm{Ca}^{2+}$ a ligação do mutante $5 \mathrm{OH} 90 \mathrm{~W}$ à actina é restaurada. Não testamos se a troponina restaura a ligação de $50 \mathrm{H} 185 \mathrm{~W}$ à actina na presença de $500 \mathrm{mM}$ acrilamida. 


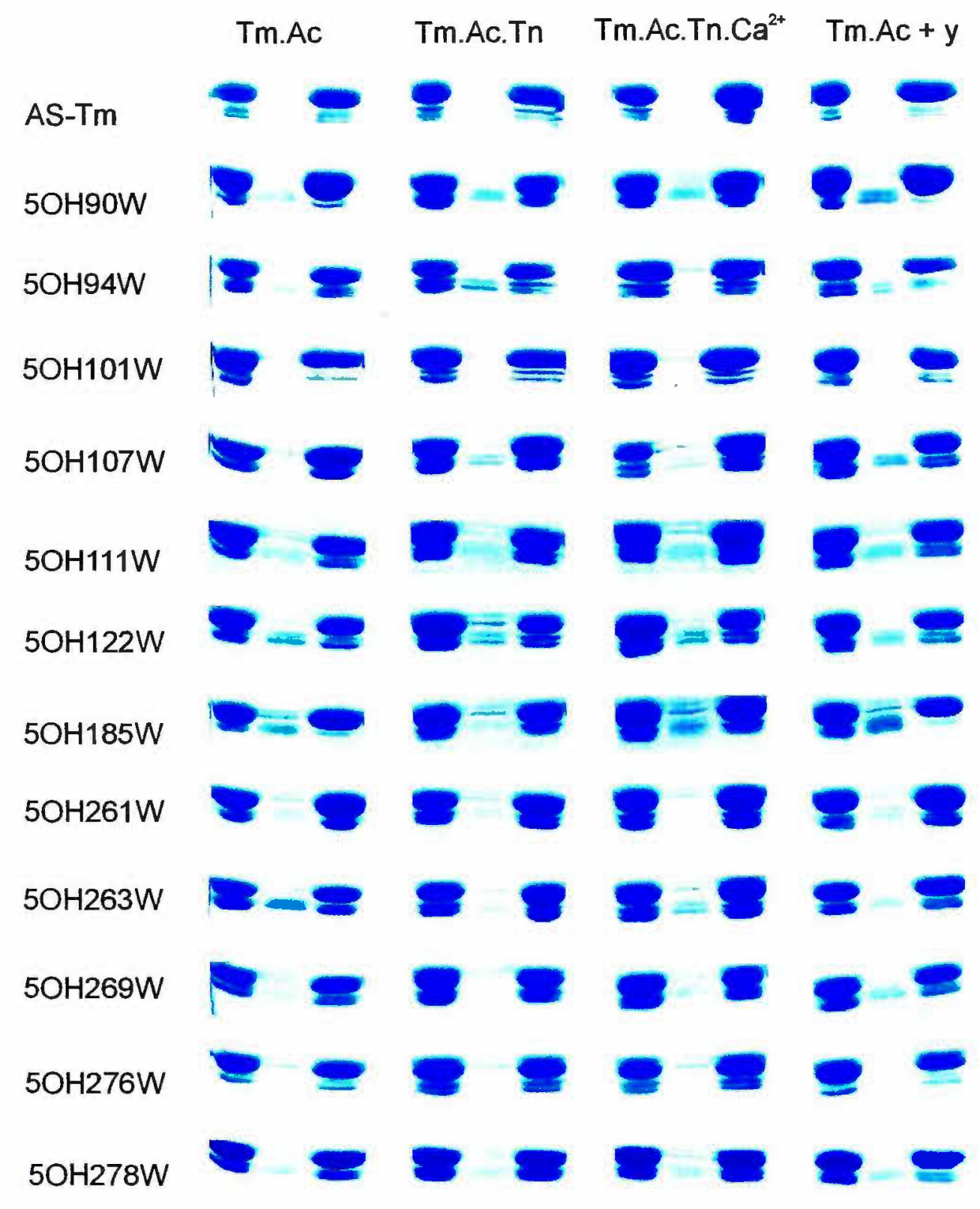

Figura 28. Resumo dos resultados obtidos dos ensaios de co-sedimentação em MOPS $25 \mathrm{mM}$ pH 7.0, NaCl $50 \mathrm{mM}, \mathrm{MgCl}_{2} 5 \mathrm{mM}$ e DTT $1 \mathrm{mM}$. Tm.Ac Tropomiosina e actina; Tm.Ac.Tn - Tropomiosina, actina e troponina; Tm.Ac.Tn.Ca ${ }^{2+}$ - Tropomiosina, actina, troponina e íns cálcio; Tm.Ac + y Tropomiosina e actina na presença de $500 \mathrm{mM}$ acrilamida. Concentrações das proteinas: actina $7 \mu \mathrm{M}$, tropomiosina $1 \mu \mathrm{M}$ e complexo troponina $1 \mu \mathrm{M}$. As três pistas estão apresentadas na seguinte ordem: mistura, sobrenadante e pellet, como descrito em materiais e métodos. A banda superior em cada gel refere-se à actina e a inferior à tropomiosina (nos ensaios com troponina a banda referente à $\mathrm{TnT}$ encontra-se ligeiramente acima da tropomiosina). 


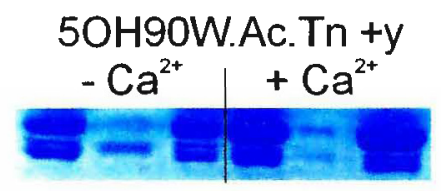

Figura 29. Ensaios de co-sedimentação para o mutante $5 \mathrm{OH} 90 \mathrm{~W}$ em MOPS $25 \mathrm{mM} \mathrm{pH} 7.0, \mathrm{NaCl} 50 \mathrm{mM}, \mathrm{MgCl}_{2} 5 \mathrm{mM}$ e DTT $1 \mathrm{mM}$ na presença de troponina na ausência $\left(-\mathrm{Ca}^{2+}\right)$ e na presença de ions cálcio $\left(+\mathrm{Ca}^{2+}\right)$ na presença de $0.5 \mathrm{M}$ acrilamida. Concentraçōes das proteínas: actina $7 \mu \mathrm{M}$, tropomiosina $1 \mu \mathrm{M}$ e complexo troponina $1 \mu \mathrm{M}$. As três pistas estão apresentadas na seguinte ordem: mistura, sobrenadante e pellet, como descrito em materiais e métodos. A banda superior em cada gel refere-se à actina e a inferior à tropomiosina (nos ensaios com troponina a banda referente à $T n T$ encontra-se ligeiramente acima da tropomiosina).

11. Regulação da $\mathbf{M g}^{2+}$-ATPase da miosina $\mathbf{S 1}$ por filamentos finos reconstituidos contendo tropomiosinas mutantes

Os ensaios realizados de atividade $\mathrm{Mg}^{2+}$-ATPásica da acto-S1 miosina para os mutantes de tropomiosina com as sondas 5-hidroxitriptofano introduzidas nas posições 90, 94, 101, 107, 111, 122, 185, 261, 263, 269, 276 e 278 da tropomiosina e com a ASTm na ausência e na presença de 500 mM acrilamida estão indicados na figura 30 . 

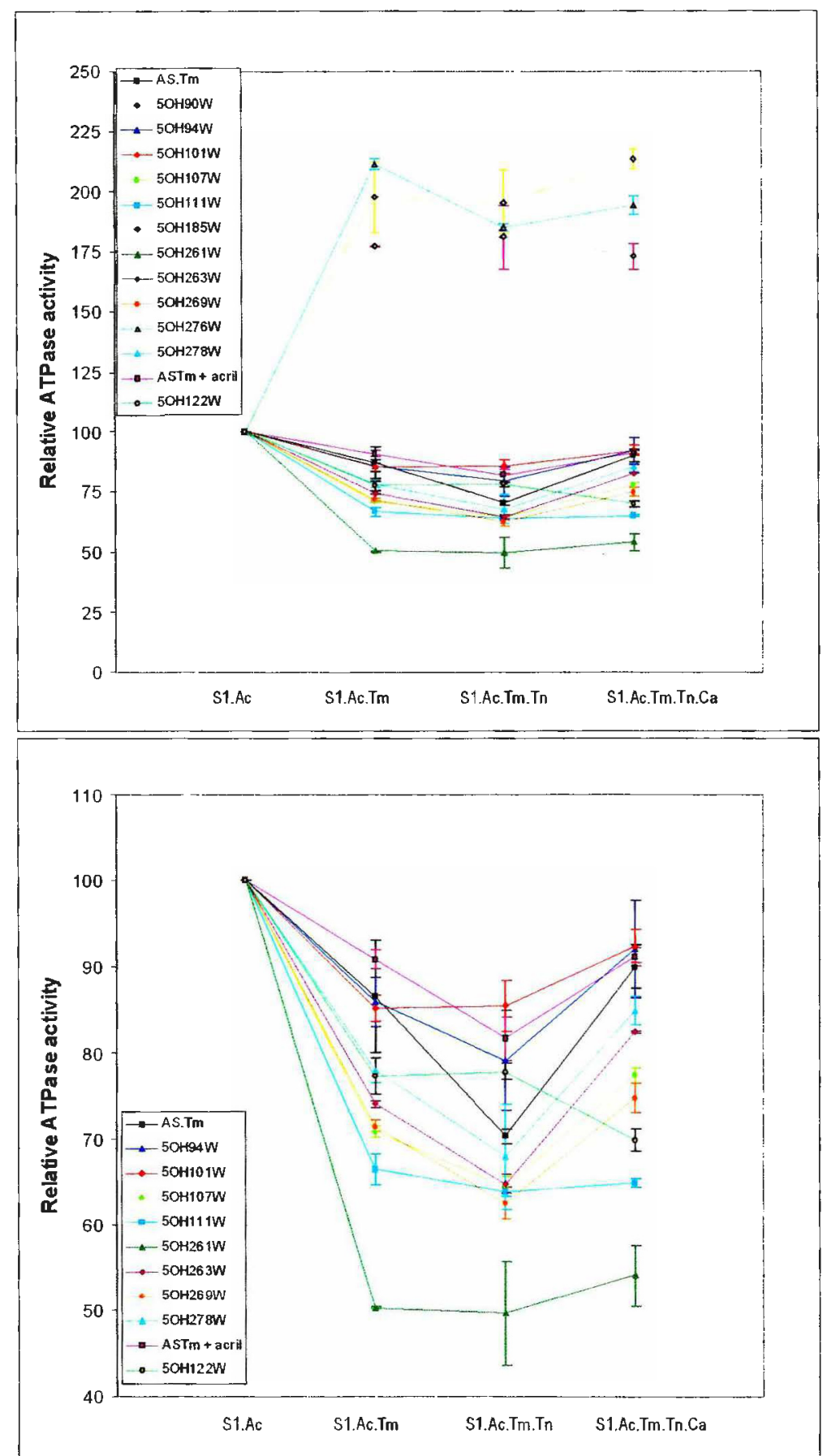

Figura 30. Ensaios de atividade $\mathrm{Mg}^{2+}$-ATPásica para todos os mutantes indicados, bem como da ASTm (AS.Tm) e da ASTm na presença de $500 \mathrm{mM}$ acrilamida (AS.Tm + acril) em MOPS $25 \mathrm{mM} \mathrm{pH} \mathrm{7.0,} \mathrm{NaCl} 50 \mathrm{mM}, \mathrm{MgCl}_{2} 5 \mathrm{mM}$ e DTT $1 \mathrm{mM}$ a $25{ }^{\circ} \mathrm{C}$. No painel superior temos a atividade ATPásica relativa para todos os mutantes em função da condição utilizada (S1.Ac - apenas actina e S1; S1.Ac. Tm S1, actina e tropmiosina (ASTm ou mutante, como indicado para cada curva); S1.Ac.Tm.Tn - igual ao anterior mas na presença do complexo troponina; S1.Ac.Tm.Tn.Ca - igual ao anterior mas na presença de íons cálcio. O painel inferior mostra um detalhe do painel superior ressaltando o efeito sobre a atividade $\mathrm{Mg}^{2+}$ ATPásica dos mutantes que não causam o efeito anômalo de aumentar a atividade $\mathrm{Mg}^{2+}$-ATPásica inicialmente (observado para os mutantes com sonda nas posições 90,185 e 276). Concentrações: $14 \mu \mathrm{M}$ actịna, $0.5 \mu \mathrm{M} \mathrm{S1}, 2 \mu \mathrm{M}$ tropomiosina e $2 \mu \mathrm{M}$ troponina. Os pontos estão unidos por linhas para facilitar a visualização. 
A maioria dos mutantes testados comportou-se de forma semelhante à ASTm: (a) a introdução da tropomiosina mutante na ausência de troponina e $\mathrm{Ca}^{2+}$ inibiu a atividade $\mathrm{Mg}^{2+}$-ATPásica da acto-S1 miosina; (b) a introdução de troponina na ausência de íons cálcio ao sistema ou causou uma inibição ainda maior na atividade $\mathrm{Mg}^{2+}$-ATPásica da acto-S1 miosina (5OH94W, $5 \mathrm{OH} 107 \mathrm{~W}, 5 \mathrm{OH} 263 \mathrm{~W}, 5 \mathrm{OH} 269 \mathrm{~W}$ e $5 \mathrm{OH} 278 \mathrm{~W}$ ) ou manteve a inibição constante $(5 \mathrm{OH} 101 \mathrm{~W}, 5 \mathrm{OH} 111 \mathrm{~W}, 5 \mathrm{OH} 122 \mathrm{~W}$ e $5 \mathrm{OH} 261 \mathrm{~W})$; (c) a introdução de troponina na presença de íons cálcio causou um aumento na atividade $\mathrm{Mg}^{2+}$-ATPásica da acto-S1 miosina na presença de tropomiosina; (d) a presença de uma concentração alta de acrilamida também não afetou a atividade da ASTm.

Quatro mutantes comportaram-se de maneira anômala em ensaios de regulação da atividade ATPásica da acto-S1 miosina. Os mutantes com a sonda nas posições 90, 185 e 276 causaram um aumento na atividade ATPásica per se, independente da presença de $\mathrm{Tn}+/-\mathrm{Ca}^{2+}$. Entretanto, apesar de estarem sempre ativando a atividade $\mathrm{Mg}^{2+}$-ATPásica da acto-S1 miosina, tanto o $5 \mathrm{OH} 185 \mathrm{~W}$ quanto $\mathrm{O} 5 \mathrm{OH} 276 \mathrm{~W}$ parecem regular esta atividade de maneira esperada na presença de troponina $+/-\mathrm{Ca}^{2+}$, ou seja, a presença de troponina diminui $(5 \mathrm{OH} 276 \mathrm{~W})$ ou mantém $(5 \mathrm{OH} 185 \mathrm{~W})$ a atividade e a presença de ions cálcio aumenta esta atividade. Por fim, o mutante $5 \mathrm{OH} 122 \mathrm{~W}$ comportou-se de maneira anômala em resposta ao $\mathrm{Ca}^{2+}$ : a adição de $\mathrm{Ca}^{2+}$ causou uma diminuição inesperada da atividade ATPásica (Figura 30).

\section{Ensaios de estabilidade}

Espectros de dicroísmo circular

A figura 31 apresenta os espectros de dicroísmo circular obtidos para a ASTm e para os mutantes da tropomiosina 5OH90W, 5OH94W, 50H101W, $5 \mathrm{OH} 107 \mathrm{~W}, 5 \mathrm{OH} 111 \mathrm{~W}, 5 \mathrm{OH} 122 \mathrm{~W}, 5 \mathrm{OH} 261 \mathrm{~W}, 5 \mathrm{OH} 276 \mathrm{~W}$ e $5 \mathrm{OH} 278 \mathrm{~W}$. 


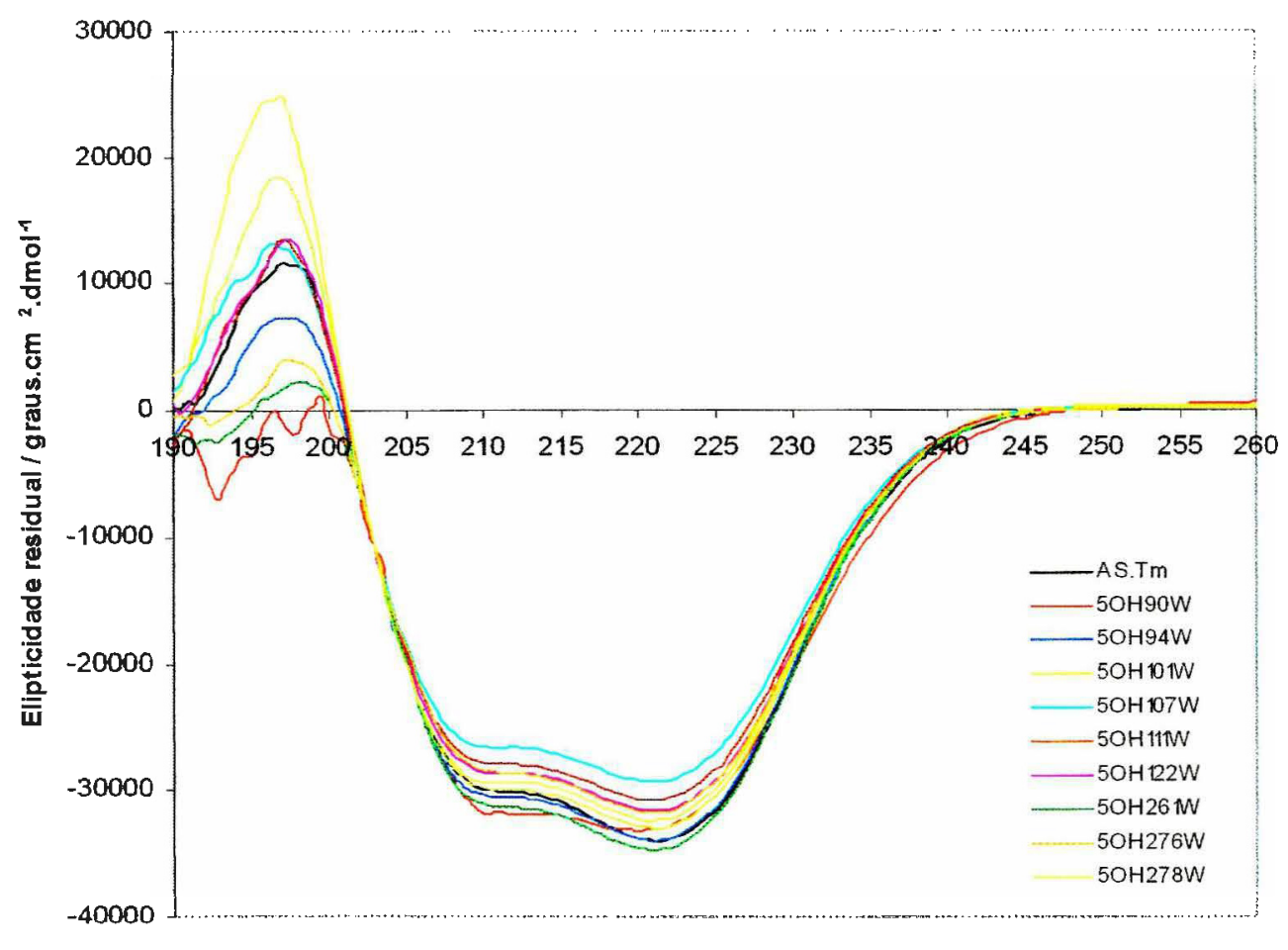

Figura 31. Espectros de dicroísmo circular a $4{ }^{\circ} \mathrm{C}$ para a ASTm e mutantes da tropomiosina em $\mathrm{NaH}_{2} \mathrm{PO}_{4} 5.73 \mathrm{mM} \mathrm{pH} 7.0, \mathrm{NaCl} 50 \mathrm{mM}, \mathrm{MgCl}_{2}$ e DTT 1 $\mathrm{mM}$. Concentração das proteínas: ASTm $10.0 \mu \mathrm{M}$, 5OH9OW $3.5 \mu \mathrm{M}$, 5OH94W $12.2 \mu \mathrm{M}, 5 \mathrm{OH} 101 \mathrm{~W} 7.4 \mu \mathrm{M}, 50 \mathrm{H} 107 \mathrm{~W} 9.6 \mu \mathrm{M}, 5 \mathrm{OH} 111 \mathrm{~W} 10.5 \mu \mathrm{M}$, $5 \mathrm{OH} 122 \mathrm{~W} 11.0 \mu \mathrm{M}, 5 \mathrm{OH} 261 \mathrm{~W} 13.7 \mu \mathrm{M}, 5 \mathrm{OH} 276 \mathrm{~W} 16.2 \mu \mathrm{M}, 5 \mathrm{OH} 278 \mathrm{~W} 10.2$ $\mu \mathrm{M}$. Elipticidades (graus. $\mathrm{cm}^{2} . \mathrm{dmol}^{-1}$ ) a $222 \mathrm{~nm}$ : ASTm -33780, 5OH9OW $32741,5 \mathrm{OH} 94 \mathrm{~W}-33691,5 \mathrm{OH} 101 \mathrm{~W}-32181,5 \mathrm{OH} 107 \mathrm{~W}-29120,5 \mathrm{OH} 111 \mathrm{~W}-$ $30595,5 \mathrm{OH} 122 \mathrm{~W}-31408,5 \mathrm{OH} 261 \mathrm{~W}-34449,5 \mathrm{OH} 276 \mathrm{~W}-31579,5 \mathrm{OH} 278 \mathrm{~W}$ 32778 .

Como pode ser observado pela inspeção da figura 31, apesar das diferenças nas concentrações das proteínas, o que dificulta a análise, todos os mutantes analisados (5OH9OW, 5OH94W, 5OH101W, 5OH107W, $5 \mathrm{OH} 111 \mathrm{~W}, 5 \mathrm{OH} 122 \mathrm{~W}, 5 \mathrm{OH} 261 \mathrm{~W}, 5 \mathrm{OH} 276 \mathrm{~W}$ e 5OH278W) possuem estrutura semelhante. As mutações analisadas parecem não estar causando uma desestabilização muito grande na estrutura da molécula. As bandas negativas a 208 e 222 nm observadas para nossas proteinas são características de estrutura a-hélice (mínimos em 208 e 222 nm) (Fasman, 1996). A utilização no experimento de cubeta com caminho óptico de $1 \mathrm{~mm}$ faz com que o sinal a comprimentos de onda menores que $200 \mathrm{~nm}$ estourem o fundo de escala e, portanto, percam sensibilidade. Este resultado é complementado pela análise da desnaturação térmica descrita a seguir. 
Desnaturação por temperatura acompanhada por dicroísmo circular

Para determinarmos o efeito que a introdução da sonda fluorescente 5-hidroxitriptofano têm sobre a estabilidade global dos mutantes de tropomiosina realizamos desnaturações por temperatura seguida por dicroísmo circular.

Na figura 32 podemos observar os gráficos de desnaturação térmica para os mutantes de Tm e da ASTm. Representamos a fração desenovelada vs temperatura obtidos a partir da desnaturação térmica dos mutantes 5OH94W, 5OH101W, 5OH107W, 5OH111W, 5OH122W, 5OH261W, $5 \mathrm{OH} 276 \mathrm{~W}$ e $5 \mathrm{OH} 278 \mathrm{~W}$ de tropomiosina e da ASTm.

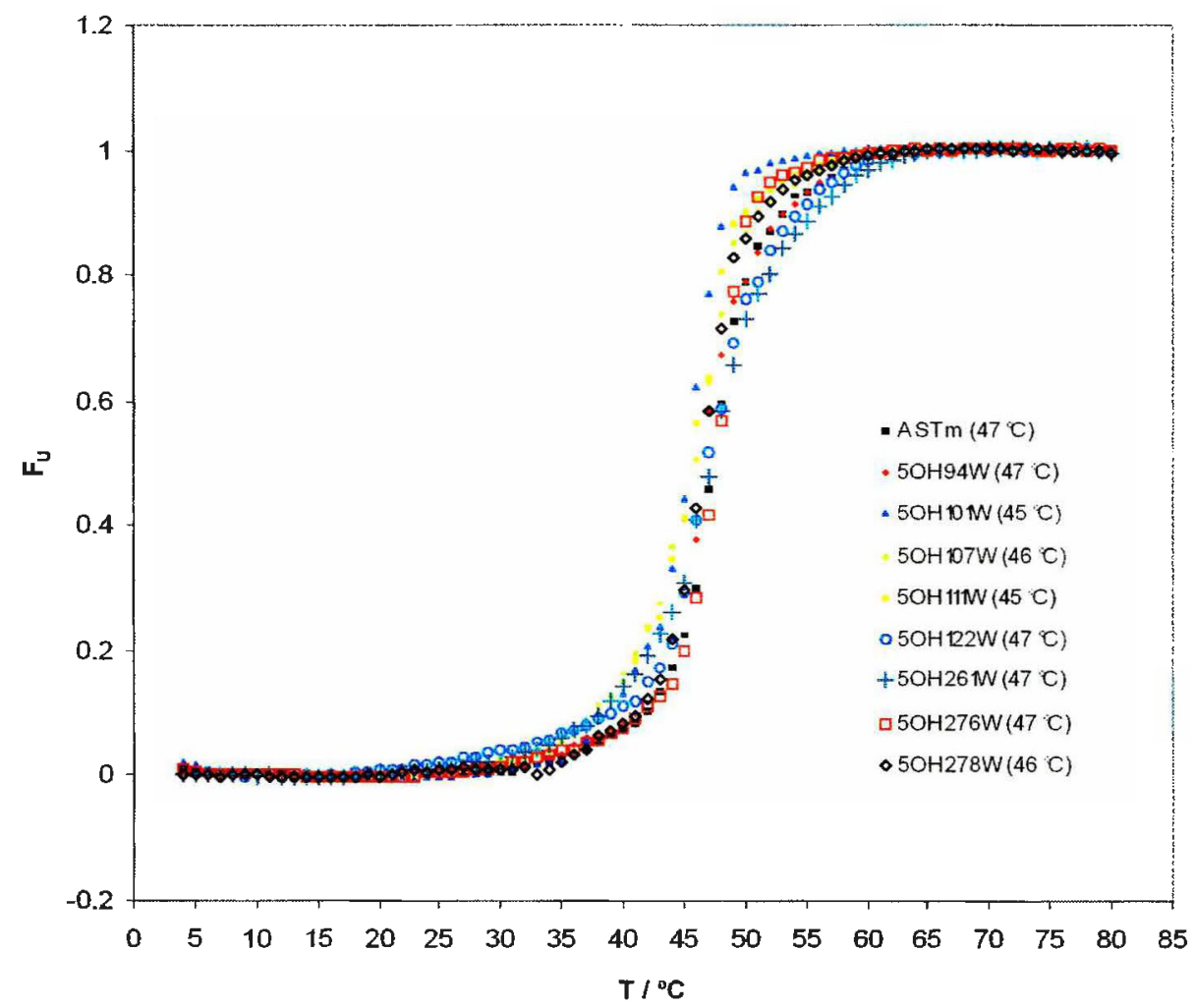

Figura 32. Fração desenovelada vs temperatura obtido pela desnaturação seguida por dicroísmo circular a $222 \mathrm{~nm}$ em $\mathrm{NaH}_{2} \mathrm{PO}_{4} 5.73 \mathrm{mM} \mathrm{pH} 7.0, \mathrm{NaCl}$ $50 \mathrm{mM}, \mathrm{MgCl}_{2}$ e DTT $1 \mathrm{mM}$. Os valores de $T_{m}$ estão indicados no gráfico. Concentração das proteínas: ASTm $10.0 \mu \mathrm{M}, 5 \mathrm{OH} 94 \mathrm{~W} 12.2 \mu \mathrm{M}, 5 \mathrm{OH} 101 \mathrm{~W}$ $7.4 \mu \mathrm{M}, 5 \mathrm{OH} 107 \mathrm{~W} 9.6 \mu \mathrm{M}, 5 \mathrm{OH} 111 \mathrm{~W} 10.5 \mu \mathrm{M}, 5 \mathrm{OH} 122 \mathrm{~W} 11.0 \mu \mathrm{M}$, $5 \mathrm{OH} 261 \mathrm{~W} 13.7 \mu \mathrm{M}, 5 \mathrm{OH} 276 \mathrm{~W} 16.2 \mu \mathrm{M}, 5 \mathrm{OH} 278 \mathrm{~W} 10.2 \mu \mathrm{M}$. 
0 $\quad 5 \quad 10152025303540 \quad 455055 \quad 60 \quad 65 \quad 7075 \quad 80 \quad 85$

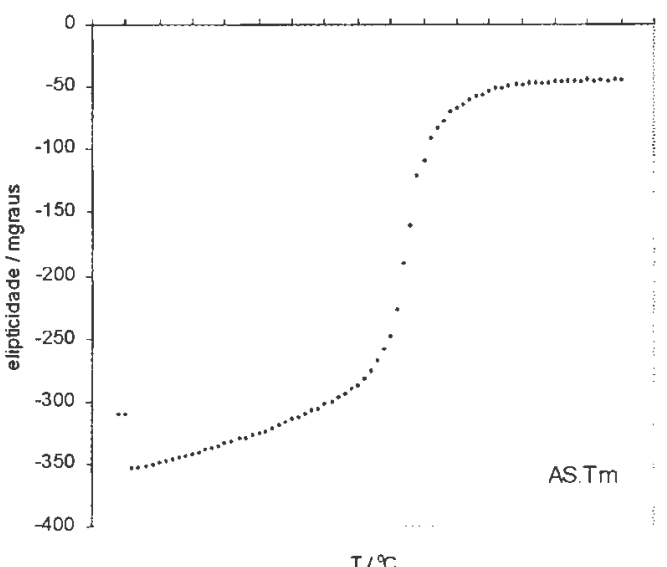

$T / \infty$
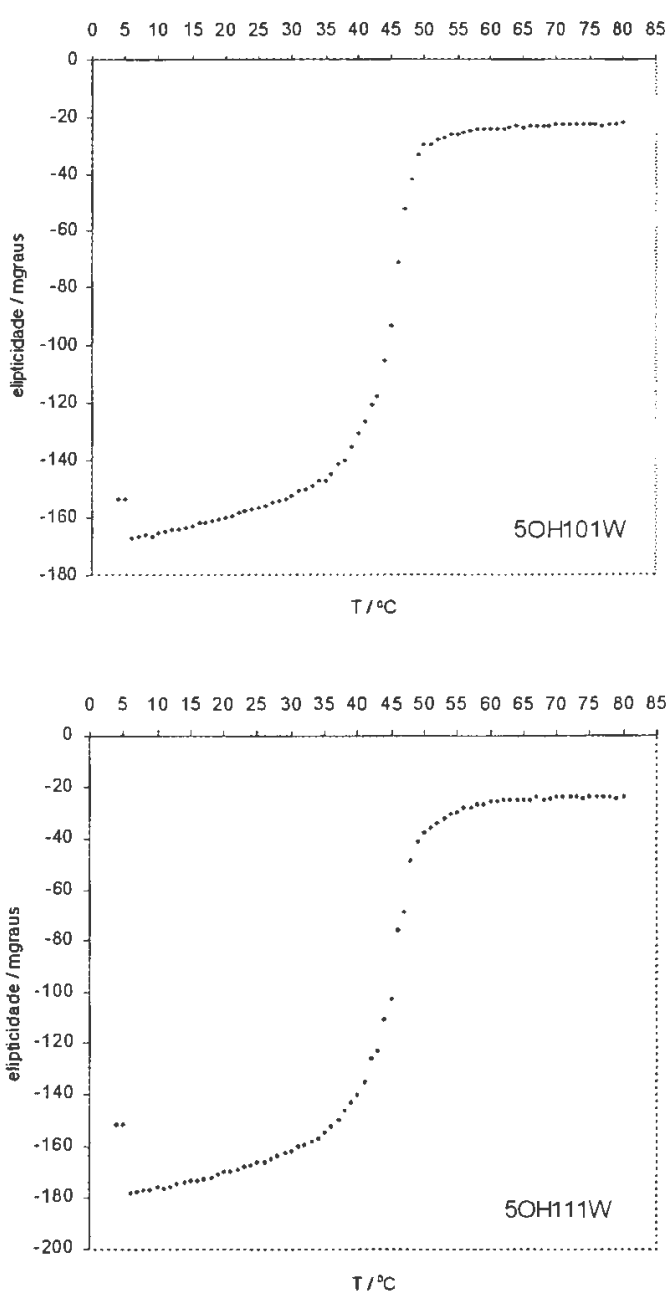

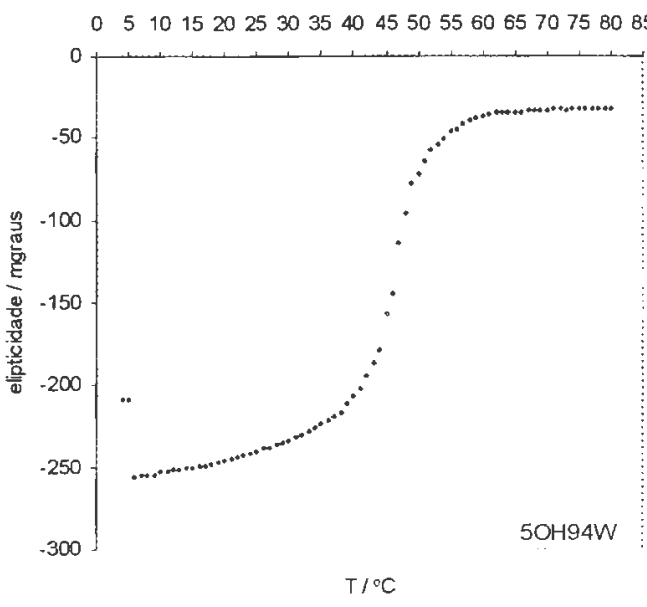

O $\quad 5 \quad 10 \quad 152025 \quad 30 \quad 35 \quad 40 \quad 45505560 \quad 65 \quad 7075 \quad 8085$

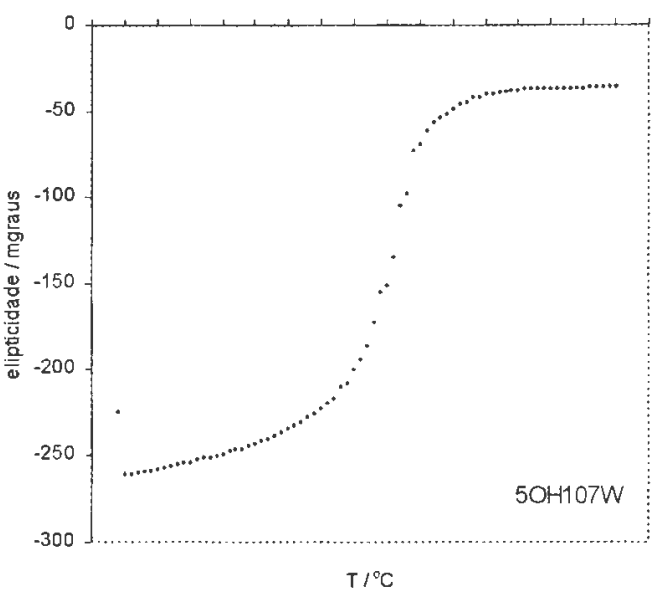

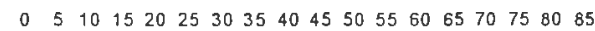

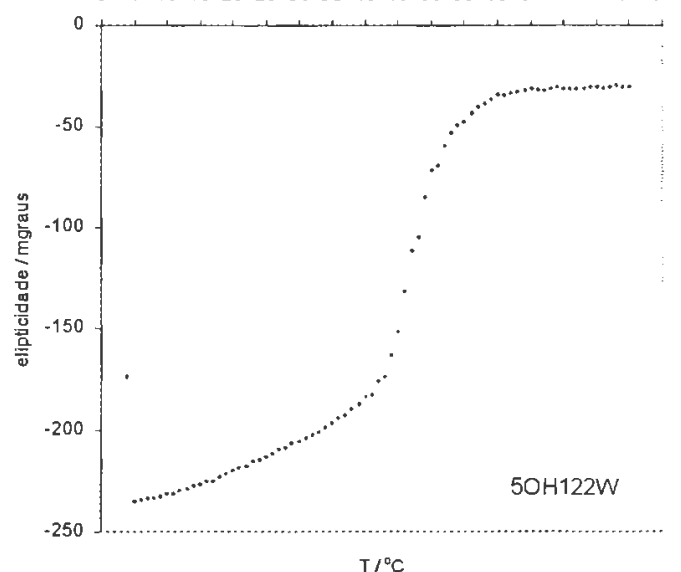



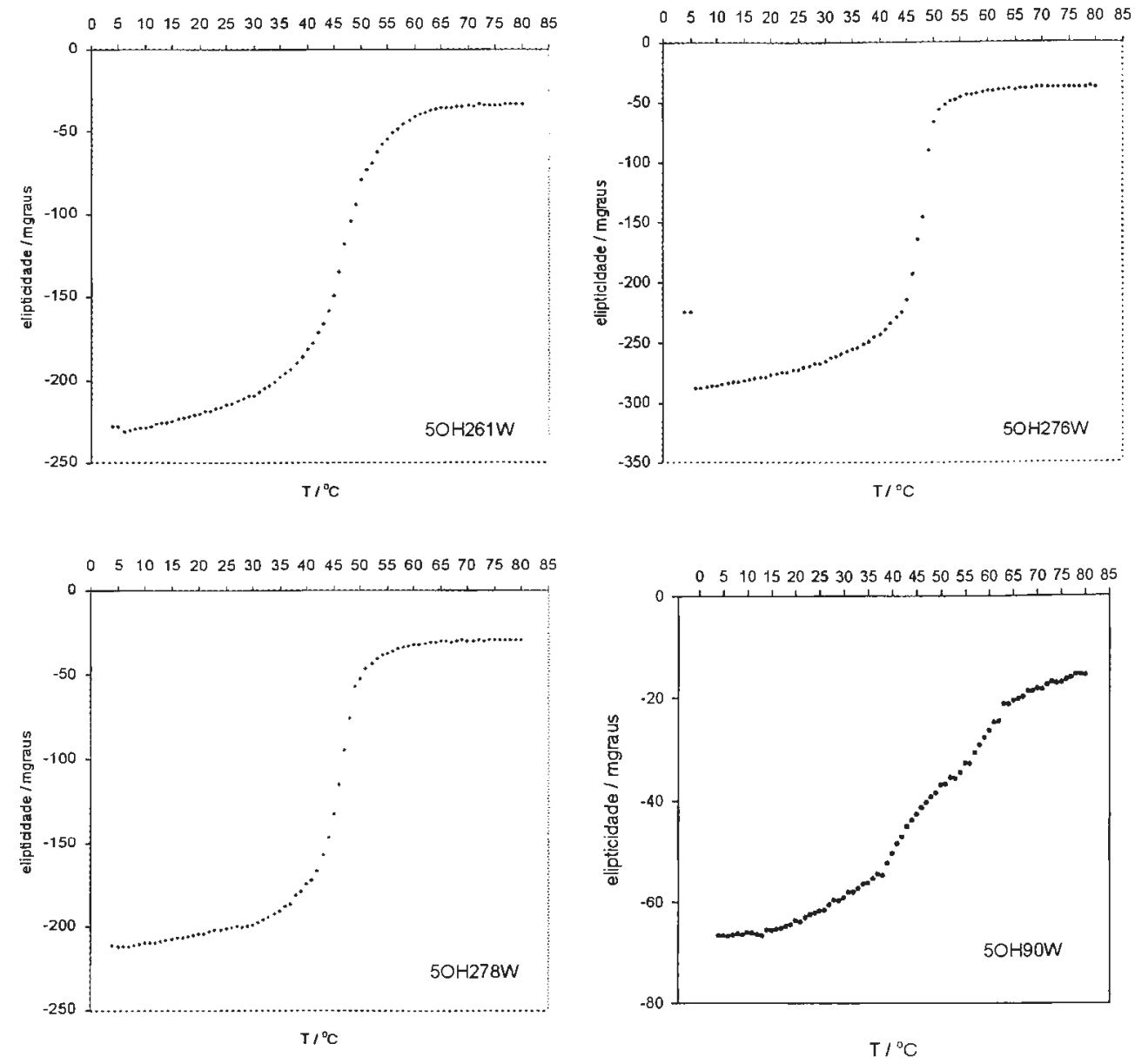

Figura 33. Curvas de desnaturação por temperatura acompanhada por dicroísmo circular a $222 \mathrm{~nm}$ obtida para a ASTm e para os mutantes 5OH94W, 50H101W, $5 \mathrm{OH} 107 \mathrm{~W}, 5 \mathrm{OH} 111 \mathrm{~W}$ e $5 \mathrm{OH} 122 \mathrm{~W}$ (página anterior) e $5 \mathrm{OH} 261 \mathrm{~W}, 5 \mathrm{OH} 276 \mathrm{~W}$, $50 \mathrm{H} 278 \mathrm{~W}$ e $5 \mathrm{OH} 90 \mathrm{~W}$ (nesta página) em $\mathrm{NaH}_{2} \mathrm{PO}_{4} 5.73 \mathrm{mM} \mathrm{pH} 7.0, \mathrm{NaCl} 50 \mathrm{mM}$, $\mathrm{MgCl}_{2}$ e DTT $1 \mathrm{mM}$. Concentração das proteínas: ASTm $10.0 \mu \mathrm{M}, 5 \mathrm{OH} 90 \mathrm{~W} 3.5 \mu \mathrm{M}$, $5 \mathrm{OH} 94 \mathrm{~W} 12.2 \mu \mathrm{M}, 50 \mathrm{H} 101 \mathrm{~W} 7.4 \mu \mathrm{M}, 5 \mathrm{OH} 107 \mathrm{~W} 9.6 \mu \mathrm{M}, 5 \mathrm{OH} 111 \mathrm{~W} 10.5 \mu \mathrm{M}$, $5 \mathrm{OH} 122 \mathrm{~W} 11.0 \mu \mathrm{M}, 5 \mathrm{OH} 261 \mathrm{~W} 13.7 \mu \mathrm{M}, 5 \mathrm{OH} 276 \mathrm{~W} 16.2 \mu \mathrm{M}, 5 \mathrm{OH} 278 \mathrm{~W} 10.2 \mu \mathrm{M}$.

Para o mutante $50 \mathrm{H} 90 \mathrm{~W}$ obtivemos uma curva semelhante à obtida para os outros mutantes a temperaturas menores que $45{ }^{\circ} \mathrm{C}$ (Figura 33). Acima desta temperatura ocorre a agregação deste mutante. Esta agregação é visível a olho nú, a solução dentro da cubeta fica bastante turva.

A figura 33 apresenta as curvas de elipticidade vs temperatura obtidas pela desnaturação térmica da ASTm e de vários mutantes da tropomiosina (5OH94W, 5OH101W, 50H107W, 50H111W, 5OH122W, 5OH261W, $5 \mathrm{OH} 276 \mathrm{~W}, 5 \mathrm{OH} 278 \mathrm{~W}$ e $5 \mathrm{OH} 90 \mathrm{~W})$. A reversibilidade da desnaturação foi analisada apenas para os mutantes $50 \mathrm{H} 261 \mathrm{~W}$ e $5 \mathrm{OH} 276 \mathrm{~W}$. A fração de 
proteína desenovelada nas curvas da figura 32 foi calculada a partir dos dados apresentados na figura 33 da forma indicada abaixo.

A fração desenovelada em cada temperatura foi calculada a partir da elipticidade em cada ponto a partir da regressão linear dos patamares (regiões da curva onde não há variação no grau de enovelamento) pré- e pós-transição (Santoro e Bolen, 1988). Por este método temos que a fração desenovelada $F_{U}=\left(y_{F}-y\right) /\left(y_{F}-y_{U}\right.$ ), onde $y_{F}$ é o sinal observado (por CD ou fluorescência, etc) no patamar pré-transição, yu é o sinal observado no patamar pós-transição e y é o sinal obtido em cada ponto da curva. A fração desenovelada $F_{U}$ pode então ser utilizada para o cálculo da constante de equilíbrio $\left(K_{\text {eq }}\right)$ em cada temperatura.

Se assumirmos que a desnaturação da tropomiosina pode ser descrita por uma desnaturação simples de dois estados na qual a maior parte da mudança conformacional ocorre antes da separação das duas cadeias, então

$$
\mathrm{K}_{\mathrm{eq}}=[\mathrm{U}] /[\mathrm{F}]=(\text { fração desenovelada }) /(\text { fração enovelada })=\mathrm{F}_{U} / \mathrm{F}_{F}
$$

onde [F] é a concentração da espécie enovelada e [U] é a concentração da espécie desenovelada e $F_{F}=1-F_{U}$. Notar que, neste caso, no meio da transição, quando $F_{F}=F_{U}=0.5, K_{\text {eq }}=1$ e $\Delta G^{\circ}=0$. $O$ valor de $\Delta G^{\circ}$ de desenovelamento a cada temperatura é encontrado a partir de

$$
\Delta G^{\circ}=-R T \ln K_{e q}
$$

A inclinação do gráfico de $\Delta G^{\circ}$ vs $T$ na região de transição fornece 0 valor de $\Delta S_{m}$ (Pace e Scholtz, 1997). O valor da $T_{m}$ é numericamente igual ao valor da temperatura quando $\Delta \mathrm{G}^{\circ}=0$, ou seja, no intercepto da curva $\Delta \mathrm{G}^{\circ}$ vs T com o eixo $\times$. Como $\Delta \mathrm{G}^{\circ}=0$ na $\mathrm{T}_{m}$, temos que $\Delta \mathrm{H}_{m}=\mathrm{T}_{m} \times \Delta \mathrm{S}_{m}$.

$\Delta \mathrm{G}^{\circ}$ a $25^{\circ} \mathrm{C}$, assumindo-se $\Delta \mathrm{C}_{\mathrm{p}}=0$, pode ser calculado resolvendo-se a seguinte equação, fazendo-se $\mathrm{T}=25^{\circ} \mathrm{C}$ : 


$$
\Delta G^{\circ}(T)=\Delta H_{m}\left(1-T / T_{m}\right)
$$

Se, por outro lado, a desnaturação da tropomiosina como refletida nas mudanças na sua elipticidade é acompanhada simultaneamente pela dissociação de suas cadeias, devemos considerar o equilíbrio

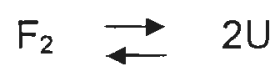

onde $F_{2}$ é o dímero enovelado e $U$ é o monômero desenovelado onde a constante de equilíbrio é $\mathrm{K}_{\mathrm{eq}}=[\mathrm{U}]^{2} /\left[\mathrm{F}_{2}\right]$.

Assim, as frações enovelada $\left(F_{F}\right)$ e desenovelada $\left(F_{U}\right)$ podem ser expressas por: $F_{F}=\left[F_{2}\right] / C_{T}$ e $F_{U}=\left[F_{2}\right]_{\text {des }} / C_{T}=([U] / 2) / C_{T}$.

Logo, $\left[F_{2}\right]=F_{F}^{*} C_{T}$ e $[U]=2 F_{U}{ }^{*} C_{T}$ onde $C_{T}$ é a concentração total de proteína. Assim, $\mathrm{K}_{\mathrm{eq}}=\left(4 \mathrm{~F}_{\mathrm{U}}{ }^{2} \mathrm{C}_{\mathrm{T}}\right) / \mathrm{F}_{\mathrm{F}}$.

Notar que, diferentemente do caso anterior, no meio da transição para uma determinada $\mathrm{C}_{\mathrm{T}}\left(\mathrm{F}_{\mathrm{F}}=\mathrm{F}_{\mathrm{U}}=0.5\right), \mathrm{K}_{\text {eq }}=2 \mathrm{C}_{\mathrm{T}}$. Esta observação reflete simplesmente a dependência da concentração para reações bimoleculares.

Agora, $\Delta G^{\circ}\left(25^{\circ} \mathrm{C}\right)$ para o processo de segunda ordem ou bimolecular, assumindo-se $\Delta C_{p}=0$, pode ser calculado resolvendo-se a seguinte equação (Privalov e Potekhin, 1986; Dragan e Privalov, 2002):

$$
\Delta G^{\circ}(T)=\Delta H_{m}\left(1-T / T_{m}\right)-R T \ln \left(2 C_{T}\right)
$$

As análises das curvas de desnaturação por temperatura seguida por dicroísmo circular para os dois tipos de desnaturação descritos acima (uni- e bimolecular) podem ser observadas nas figuras 34 a 42 . Uma discussão sobre a relevência destes modelos para a desnaturação da tropomiosina e a comparação entre suas respectivas análises pode ser encontrada na DISCUSSÃO. 

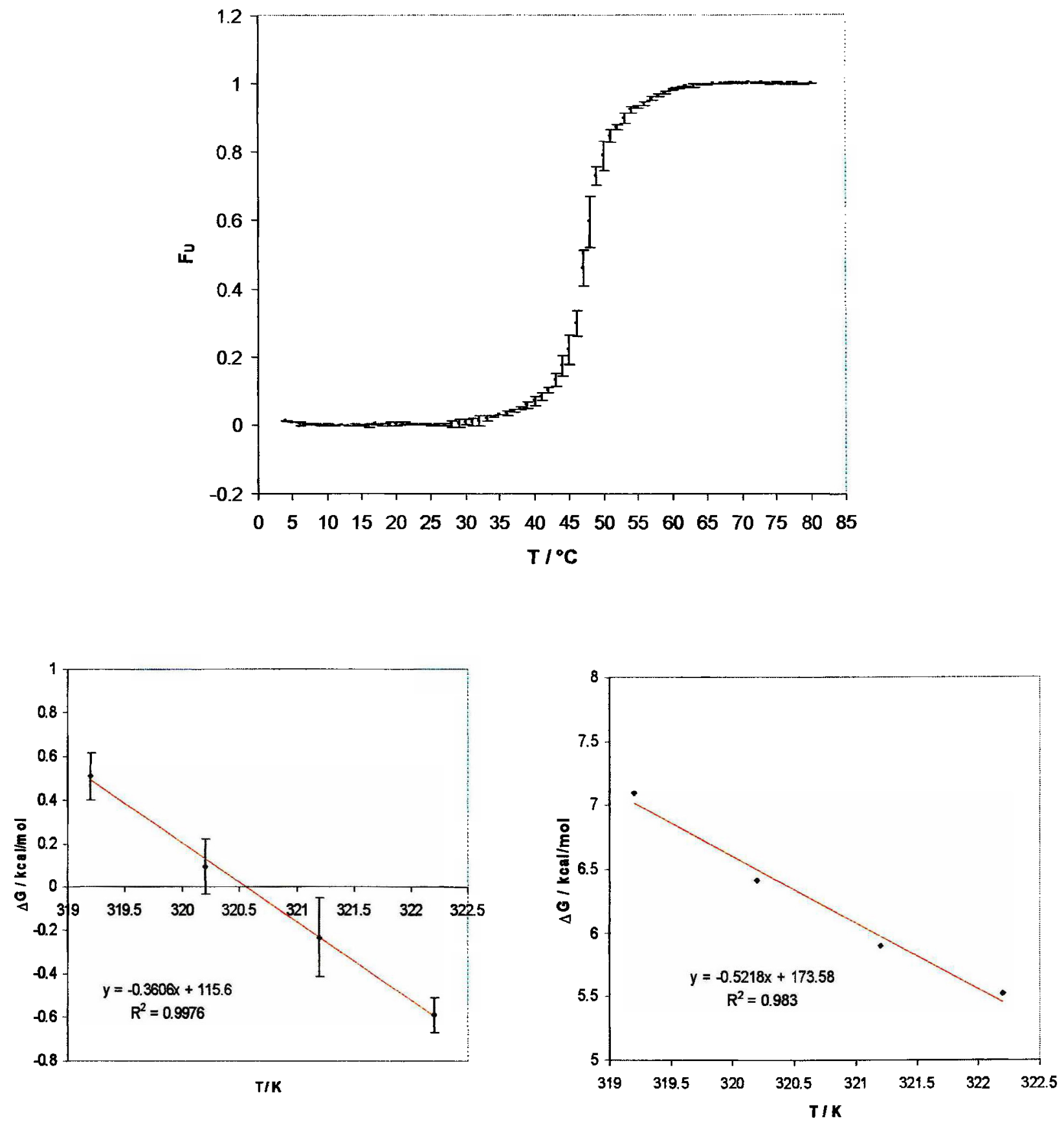

unimolecular

bimolecular

\begin{tabular}{|c|c|c|c|c|c|}
\hline $\mathrm{T} /{ }^{\circ} \mathrm{C}$ & $\mathrm{Fu}_{\mathrm{U}}$ & $\mathrm{K}(\mathrm{uni})$ & $\begin{array}{c}\Delta \mathrm{G}^{\circ}(\mathrm{uni}) \\
(\mathrm{cal} / \mathrm{mol})\end{array}$ & $\mathrm{K}(\mathrm{bi})$ & $\begin{array}{c}\Delta \mathrm{G}^{\circ}(\mathrm{bi}) \\
(\mathrm{cal} / \mathrm{mol})\end{array}$ \\
\hline 46 & 0.298 & 0.426 & 508 & $6.28 \mathrm{E}-06$ & 7092 \\
\hline 47 & 0.460 & 0.854 & 94 & $1.97 \mathrm{E}-05$ & 6415 \\
\hline 48 & 0.595 & 1.468 & -229 & $4.73 \mathrm{E}-05$ & 5896 \\
\hline 49 & 0.729 & 2.686 & -586 & $8.85 \mathrm{E}-05$ & 5526 \\
\hline
\end{tabular}

Figura 34. Análise da curva de desnaturação por temperatura para a ASTm e apresentação dos valores de $F_{u}, K\left(\right.$ uni) e $\Delta G^{\circ}$ (uni) para o processo unimolecular e $\mathrm{K}(\mathrm{bi})$ e $\Delta \mathrm{G}^{\circ}$ (bi) para o processo bimolecular. Condições: $\mathrm{NaH}_{2} \mathrm{PO}_{4} 5.73 \mathrm{mM} \mathrm{pH} 7.0, \mathrm{NaCl} 50 \mathrm{mM}, \mathrm{MgCl}_{2}$ e DTT $1 \mathrm{mM}$. $\mathrm{C}_{\mathrm{T}}=10.0 \mu \mathrm{M}$. 

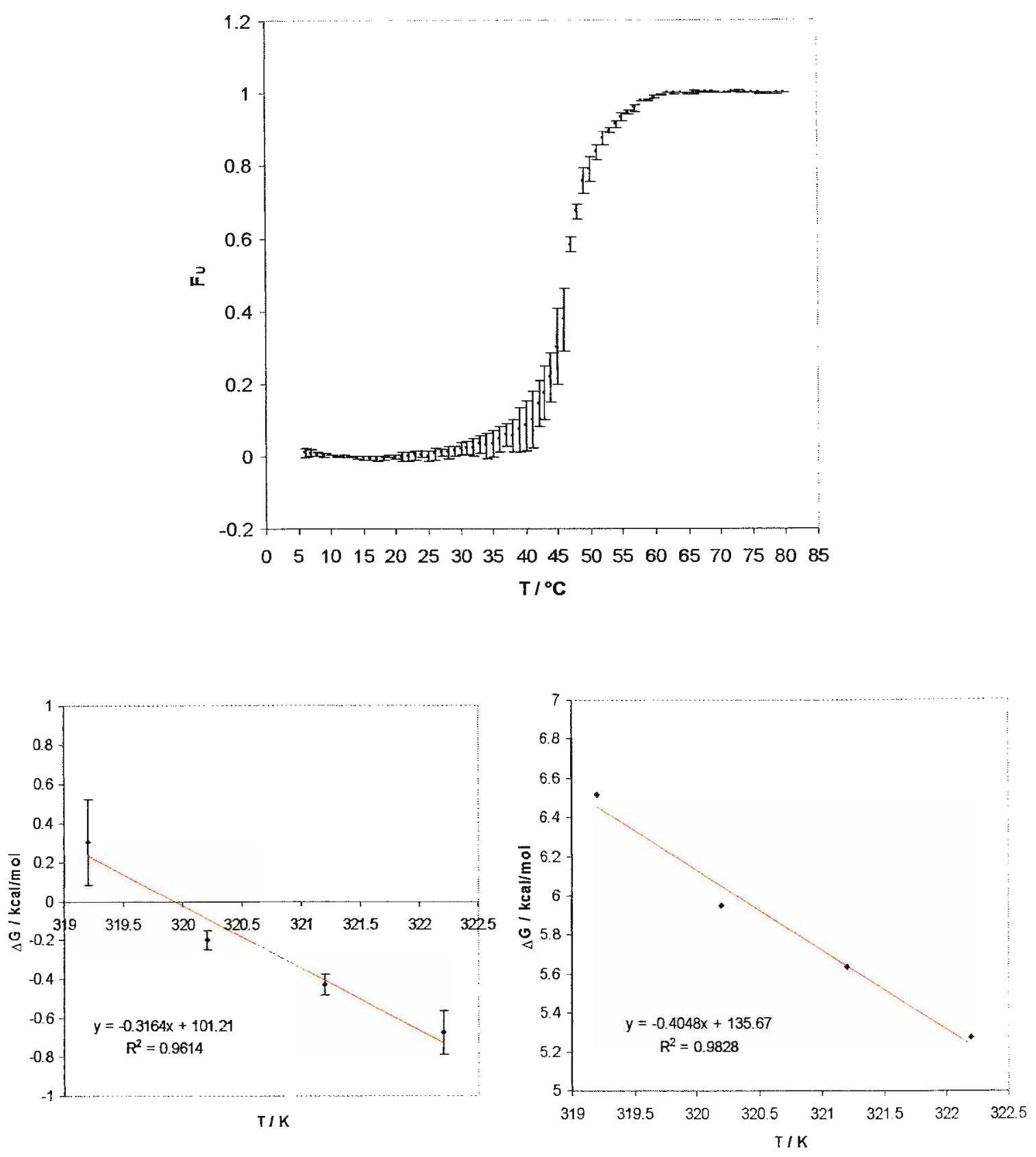

unimolecular

bimolecular

\begin{tabular}{|c|c|c|c|c|c|}
\hline $\mathrm{T} /{ }^{\circ} \mathrm{C}$ & $\mathrm{Fu}_{\mathrm{u}}$ & $\mathrm{K}(\mathrm{uni})$ & $\begin{array}{c}\Delta \mathrm{G}^{\circ} \text { (uni) } \\
\text { (cal/mol) }\end{array}$ & $\mathrm{K}(\mathrm{bi})$ & $\begin{array}{c}\Delta \mathrm{G}^{\circ}(\mathrm{bi}) \\
(\mathrm{call} / \mathrm{mol})\end{array}$ \\
\hline 46 & 0.377 & 0.605 & 303 & $3.21 \mathrm{E}-06$ & 7490 \\
\hline 47 & 0.582 & 1.394 & -197 & $7.11 \mathrm{E}-06$ & 7019 \\
\hline 48 & 0.673 & 2.061 & -428 & $3.63 \mathrm{E}-05$ & 6053 \\
\hline 49 & 0.757 & 3.111 & -675 & $6.22 \mathrm{E}-05$ & 5735 \\
\hline
\end{tabular}

Figura 35. Análise da curva de desnaturação por temperatura para o mutante $50 H 94 \mathrm{~W}$ e apresentação dos valores de $F_{u}, K$ (uni) e $\Delta G^{\circ}$ (uni) para 0 processo unimolecular e $\mathrm{K}(\mathrm{bi})$ e $\Delta \mathrm{G}^{\circ}$ (bi) para o processo bimolecular. Condições: $\mathrm{NaH}_{2} \mathrm{PO}_{4} 5.73 \mathrm{mM} \mathrm{pH} 7.0, \mathrm{NaCl} 50 \mathrm{mM}, \mathrm{MgCl}_{2}$ e DTT $1 \mathrm{mM}$. C $=12.2 \mu \mathrm{M}$. 

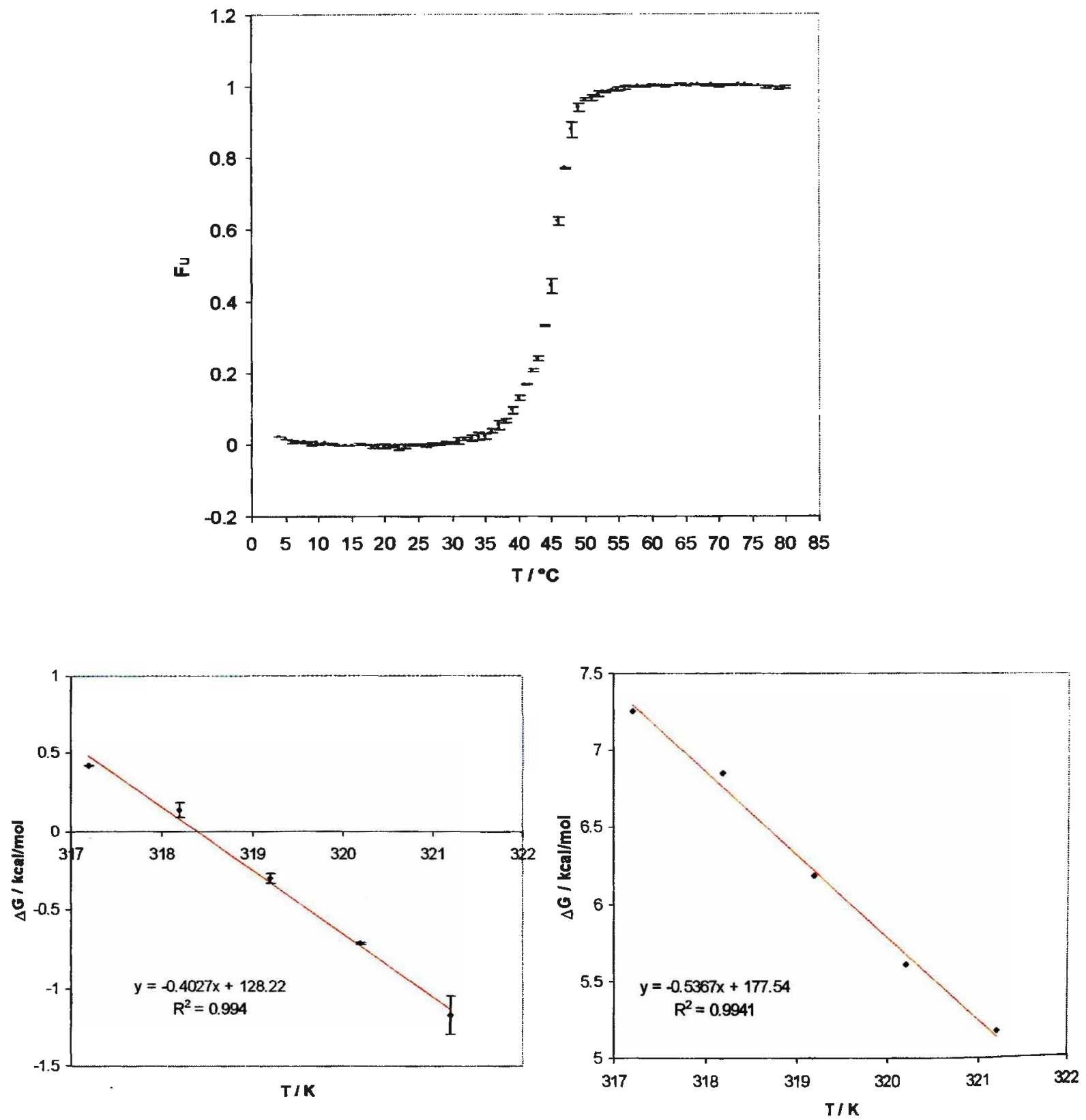

unimolecular

bimolecular

\begin{tabular}{|c|c|c|c|c|c|}
\hline $\mathrm{T} /{ }^{\circ} \mathrm{C}$ & $\mathrm{F}_{\mathrm{u}}$ & $\mathrm{K}(\mathrm{uni})$ & $\begin{array}{c}\Delta \mathrm{G}^{\circ}(\mathrm{uni}) \\
(\mathrm{cal} / \mathrm{mol})\end{array}$ & $\mathrm{K}(\mathrm{bi})$ & $\begin{array}{c}\Delta \mathrm{G}^{\circ}(\mathrm{bi}) \\
(\mathrm{cal} / \mathrm{mol})\end{array}$ \\
\hline 44 & 0.330 & 0.493 & 419 & $4.84 \mathrm{E}-06$ & 7246 \\
\hline 45 & 0.443 & 0.795 & 136 & $9.52 \mathrm{E}-06$ & 6846 \\
\hline 46 & 0.623 & 1.656 & -299 & $2.91 \mathrm{E}-05$ & 6184 \\
\hline 47 & 0.769 & 3.323 & -711 & $7.63 \mathrm{E}-05$ & 5613 \\
\hline 48 & 0.878 & 7.170 & -1171 & 0.000159 & 5178 \\
\hline
\end{tabular}

Figura 36. Análise da curva de desnaturação por temperatura para o mutante $5 \mathrm{OH} 101 \mathrm{~W}$ e apresentação dos valores de $F_{u}, \mathrm{~K}$ (uni) e $\Delta \mathrm{G}^{\circ}$ (uni) para 0 processo unimolecular e $\mathrm{K}(\mathrm{bi})$ e $\Delta \mathrm{G}^{\circ}$ (bi) para o processo bimolecular. Condiçōes: $\mathrm{NaH}_{2} \mathrm{PO}_{4} 5.73 \mathrm{mM} \mathrm{pH} 7.0, \mathrm{NaCl} 50 \mathrm{mM}, \mathrm{MgCl}_{2}$ e DTT $1 \mathrm{mM}$. CT $=7.4 \mu \mathrm{M}$. 


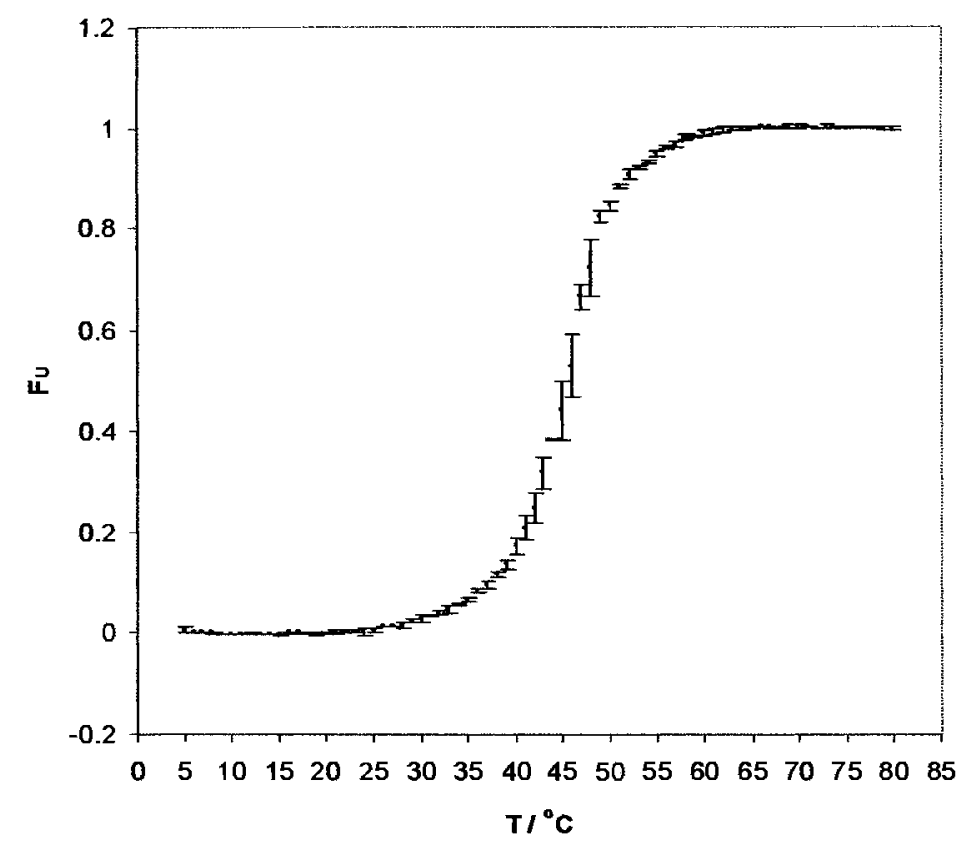

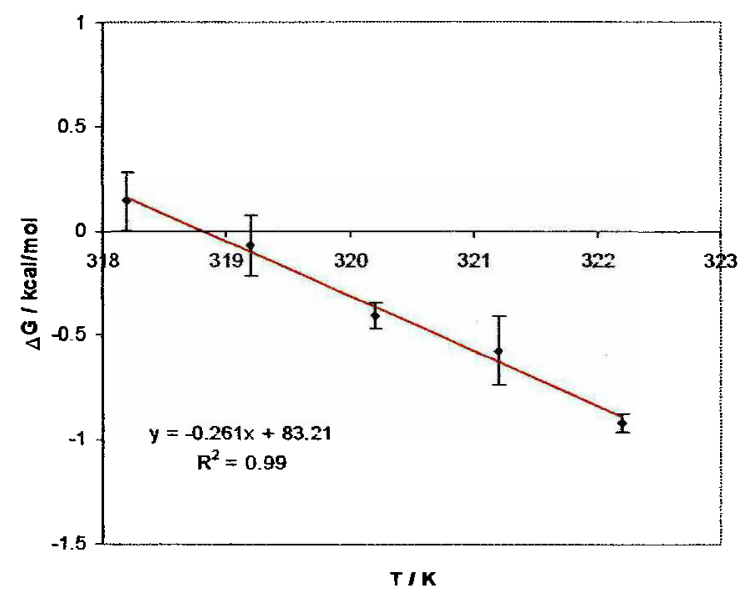

unimolecular

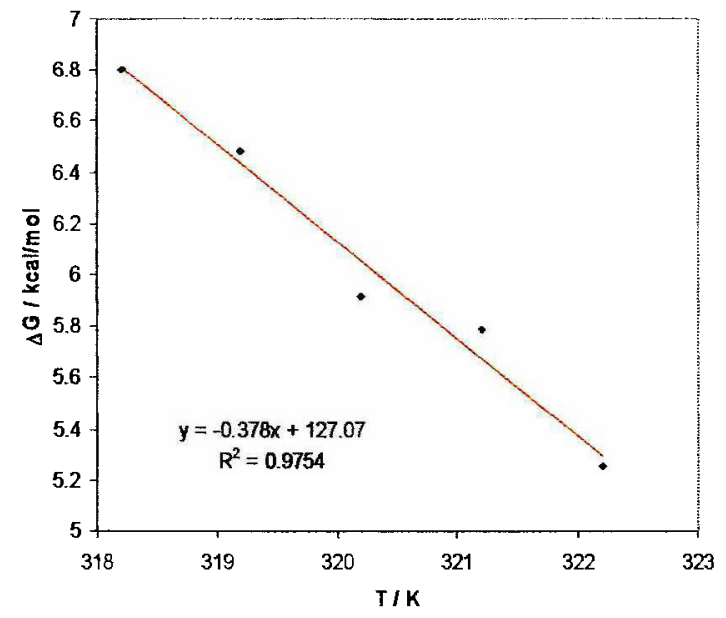

bimolecular

\begin{tabular}{|c|c|c|c|c|c|}
\hline $\mathrm{T} /{ }^{\circ} \mathrm{C}$ & $\mathrm{FU}_{\mathrm{U}}$ & $\mathrm{K}(\mathrm{uni})$ & $\begin{array}{c}\Delta \mathrm{G}^{\circ}(\mathrm{uni}) \\
(\mathrm{cal} / \mathrm{mol})\end{array}$ & $\mathrm{K}(\mathrm{bi})$ & $\begin{array}{c}\Delta \mathrm{G}^{\circ}(\mathrm{bi}) \\
(\mathrm{cal} / \mathrm{mol})\end{array}$ \\
\hline 45 & 0.409 & 0.693 & 141 & $1.02 \mathrm{E}-05$ & 6802 \\
\hline 46 & 0.504 & 1.017 & -71 & $1.77 \mathrm{E}-05$ & 6480 \\
\hline 47 & 0.631 & 1.709 & -406 & $4.58 \mathrm{E}-05$ & 5915 \\
\hline 48 & 0.737 & 2.804 & -570 & $5.67 \mathrm{E}-05$ & 5789 \\
\hline 49 & 0.852 & 5.760 & -915 & $1.39 \mathrm{E}-04$ & 5258 \\
\hline
\end{tabular}

Figura 37. Análise da curva de desnaturação por temperatura para o mutante $50 \mathrm{H} 107 \mathrm{~W}$ e apresentação dos valores de $\mathrm{F}_{\mathrm{u}}, \mathrm{K}$ (uni) e $\Delta \mathrm{G}^{\mathrm{O}}$ (uni) para 0 processo unimolecular e $\mathrm{K}(\mathrm{bi})$ e $\Delta \mathrm{G}^{\circ}$ (bi) para o processo bimolecular: Condições: $\mathrm{NaH}_{2} \mathrm{PO}_{4} 5.73 \mathrm{mM} \mathrm{pH} 7.0, \mathrm{NaCl} 50 \mathrm{mM}, \mathrm{MgCl}_{2}$ e DTT $1 \mathrm{mM}$. $\mathrm{C}_{\mathrm{T}}$ $=9.6 \mu \mathrm{M}$. 


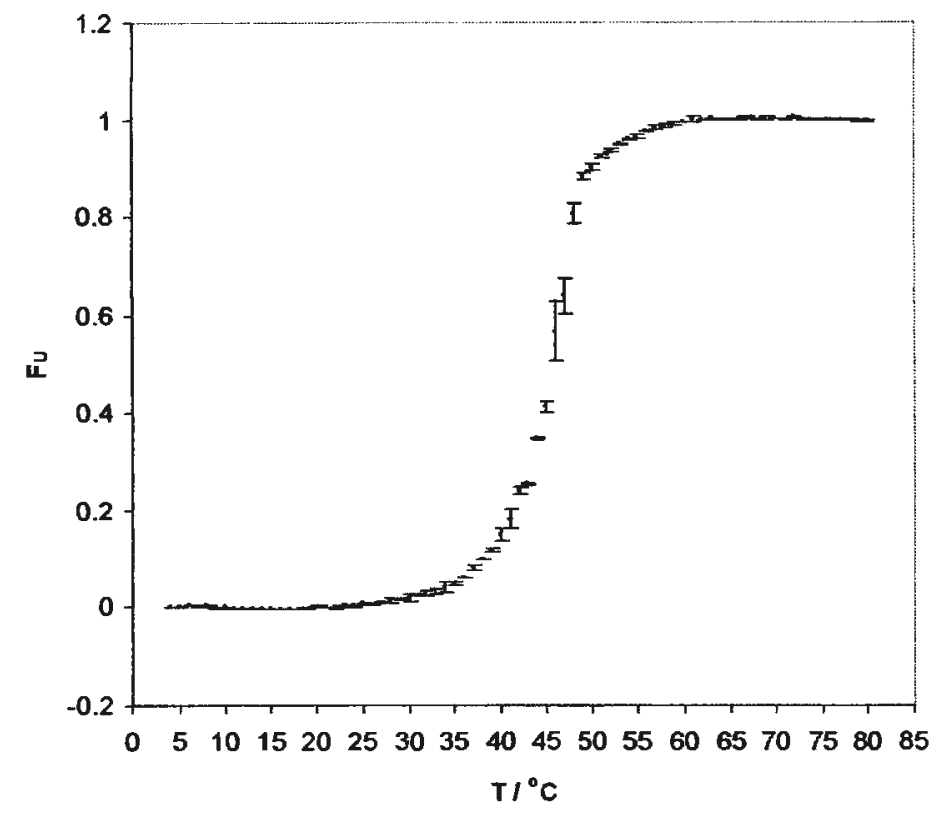

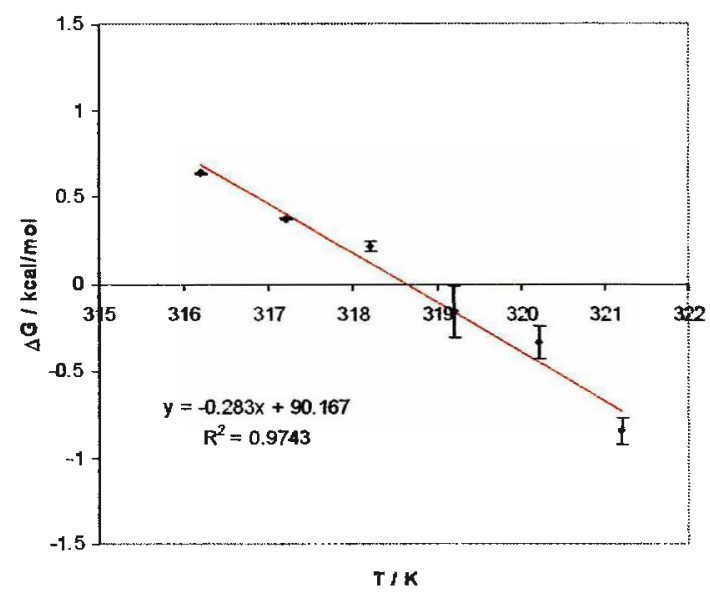

unimolecular

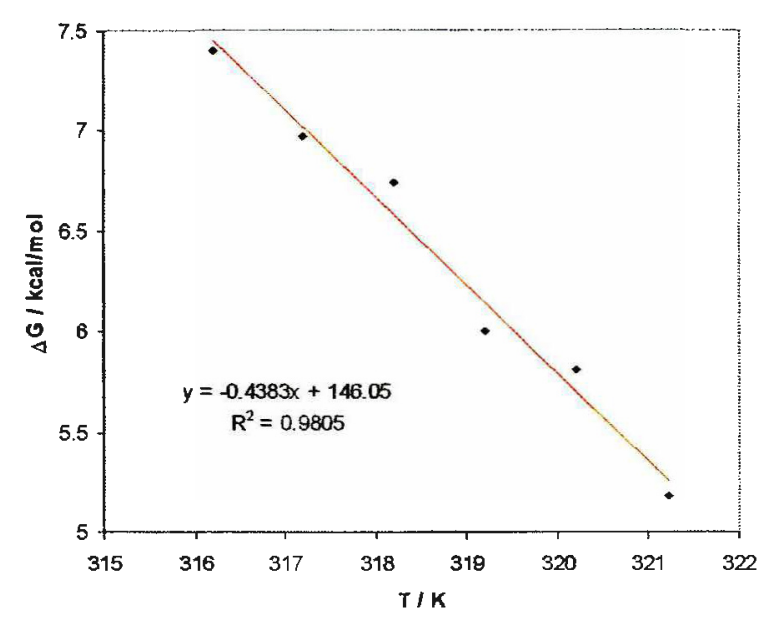

bimolecular

\begin{tabular}{|c|c|c|c|c|c|}
\hline $\mathrm{T} /{ }^{\circ} \mathrm{C}$ & $\mathrm{F}_{U}$ & $\mathrm{~K}$ (uni) & $\begin{array}{c}\Delta \mathrm{G}^{\mathrm{o}} \text { (uni) } \\
(\mathrm{cal} / \mathrm{mol})\end{array}$ & $\mathrm{K}(\mathrm{bi})$ & $\begin{array}{c}\Delta \mathrm{G}^{\circ}(\mathrm{bi}) \\
(\mathrm{call} / \mathrm{mol})\end{array}$ \\
\hline 43 & 0.255 & 0.342 & 636 & $3.71 \mathrm{E}-06$ & 7404 \\
\hline 44 & 0.347 & 0.532 & 374 & $7.68 \mathrm{E}-06$ & 6973 \\
\hline 45 & 0.411 & 0.698 & 213 & $1.15 \mathrm{E}-05$ & 6736 \\
\hline 46 & 0.566 & 1.303 & -158 & $3.99 \mathrm{E}-05$ & 5998 \\
\hline 47 & 0.639 & 1.767 & -338 & $5.5 \mathrm{E}-05$ & 5807 \\
\hline 48 & 0.806 & 4.147 & -844 & 0.000158 & 5183 \\
\hline
\end{tabular}

Figura 38. Análise da curva de desnaturação por temperatura para o mutante $50 H 111 W$ e apresentação dos valores de $F_{u}, K$ (uni) e $\Delta G^{\circ}$ (uni) para o processo unimolecular e $\mathrm{K}(\mathrm{bi})$ e $\Delta \mathrm{G}^{\circ}$ (bi) para o processo bimolecular. Condições: $\mathrm{NaH}_{2} \mathrm{PO}_{4} 5.73 \mathrm{mM} \mathrm{pH} 7.0, \mathrm{NaCl} 50 \mathrm{mM}, \mathrm{MgCl}_{2}$ e DTT $1 \mathrm{mM}$. $\mathrm{C}_{\mathrm{T}}$ $=10.5 \mu \mathrm{M}$. 


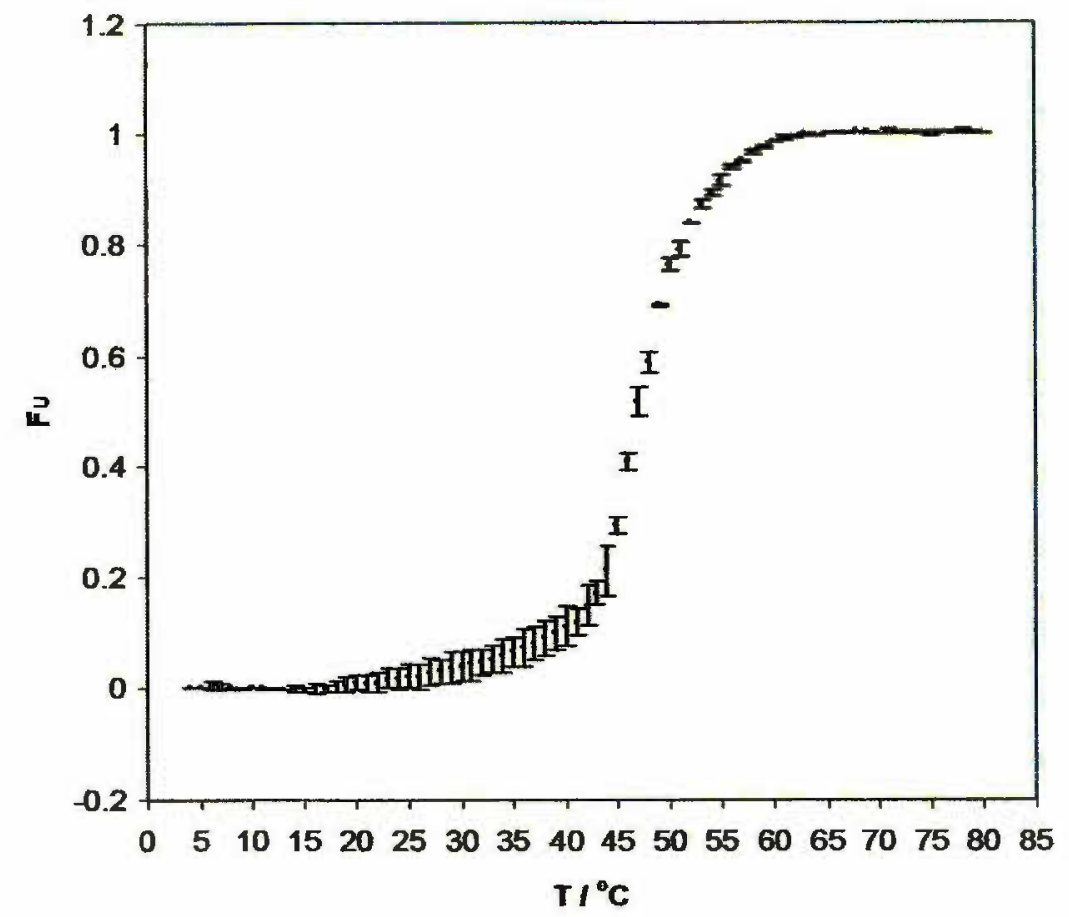

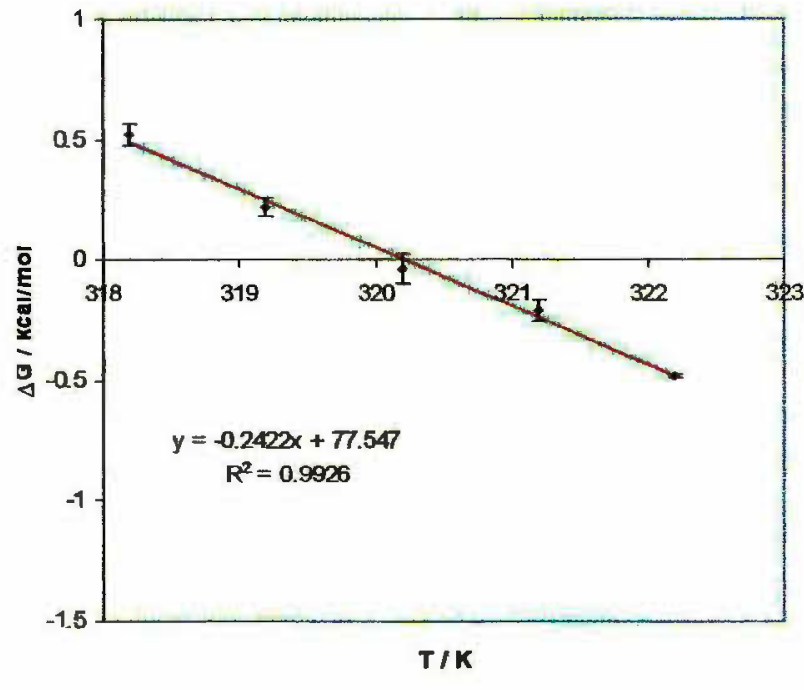

unimolecular

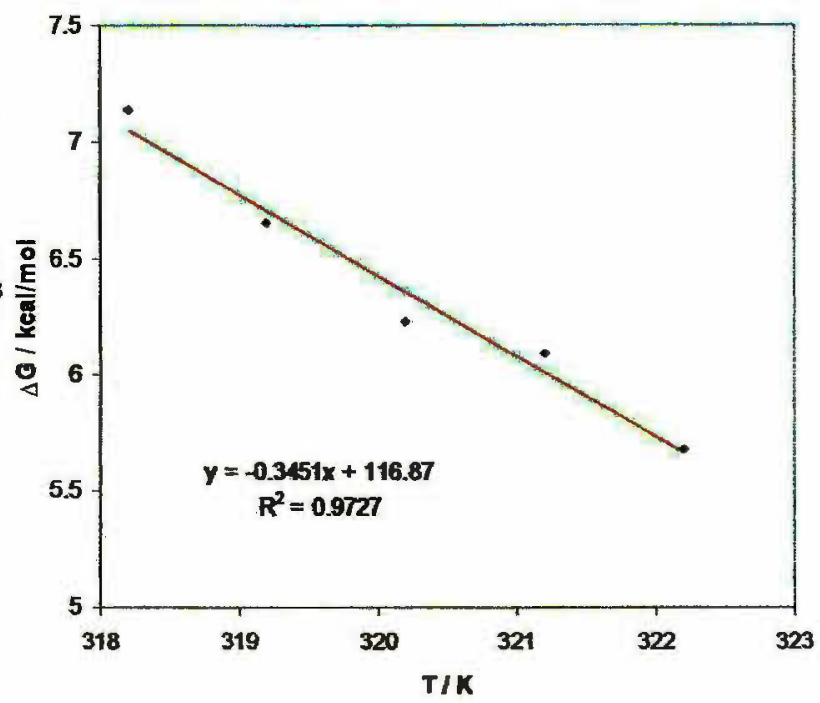

bimolecular

\begin{tabular}{|c|c|c|c|c|c|}
\hline $\mathrm{T} /{ }^{\circ} \mathrm{C}$ & $\mathrm{Fu}_{\mathrm{u}}$ & $\mathrm{K}(\mathrm{uni})$ & $\begin{array}{c}\Delta \mathrm{G}^{\circ}(\mathrm{uni}) \\
(\mathrm{cal} / \mathrm{mol})\end{array}$ & $\mathrm{K}(\mathrm{bi})$ & $\begin{array}{c}\Delta \mathrm{G}^{\circ}(\mathrm{bi}) \\
(\mathrm{cal} / \mathrm{mol})\end{array}$ \\
\hline 45 & 0.294 & 0.416 & 0.520 & $5.88 \mathrm{E}-06$ & 7131 \\
\hline 46 & 0.408 & 0.690 & 0.220 & $1.33 \mathrm{E}-05$ & 6647 \\
\hline 47 & 0.515 & 1.064 & -0.037 & $2.7 \mathrm{E}-05$ & 6228 \\
\hline 48 & 0.586 & 1.417 & -0.206 & $3.4 \mathrm{E}-05$ & 6093 \\
\hline 49 & 0.691 & 2.240 & -0.478 & $6.78 \mathrm{E}-05$ & 5683 \\
\hline
\end{tabular}

Figura 39. Análise da curva de desnaturação por temperatura para o mutante $50 \mathrm{H} 122 \mathrm{~W}$ e apresentação dos valores de $F_{u}, K$ (uni) e $\Delta G^{\circ}$ (uni) para o processo unimolecular e $\mathrm{K}(\mathrm{bi})$ e $\Delta \mathrm{G}^{\circ}(\mathrm{bi})$ para o processo bimolecular. Condiçōes: $\mathrm{NaH}_{2} \mathrm{PO}_{4} 5.73 \mathrm{mM}$ pH 7.0, NaCl $50 \mathrm{mM}, \mathrm{MgCl}_{2}$ e DTT $1 \mathrm{mM}$. $\mathrm{C}_{\mathrm{T}}$ $=11.0 \mu \mathrm{M}$. 

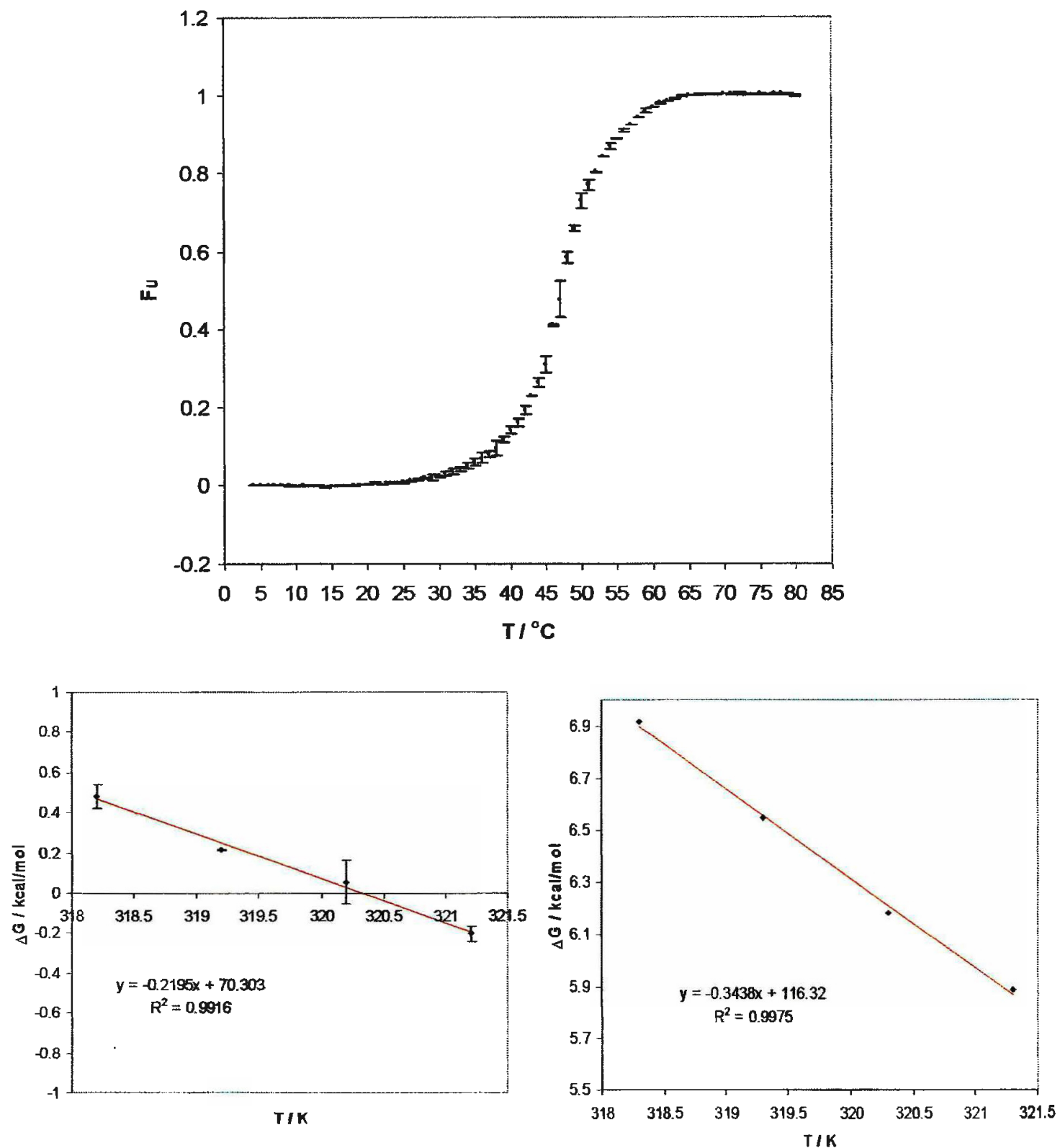

unimolecular

bimolecular

\begin{tabular}{|c|c|c|c|c|c|}
\hline $\mathrm{T} /{ }^{\circ} \mathrm{C}$ & $\mathrm{Fu}_{\mathrm{U}}$ & $\mathrm{K}$ (uni) & $\begin{array}{c}\Delta \mathrm{G}^{\circ} \text { (uni) } \\
\text { (cal/mol) }\end{array}$ & $\mathrm{K}(\mathrm{bi})$ & $\begin{array}{c}\Delta \mathrm{G}^{\circ}(\mathrm{bi}) \\
(\mathrm{cal} / \mathrm{mol})\end{array}$ \\
\hline 45 & 0.308 & 0.446 & 479 & $8.47 \mathrm{E}-06$ & 6915 \\
\hline 46 & 0.411 & 0.697 & 214 & $1.58 \mathrm{E}-05$ & 6547 \\
\hline 47 & 0.477 & 0.913 & 54 & $2.9 \mathrm{E}-05$ & 6185 \\
\hline 48 & 0.583 & 1.401 & 200 & $4.79 \mathrm{E}-05$ & 5889 \\
\hline
\end{tabular}

Figura 40. Análise da curva de desnaturação por temperatura para o mutante $5 \mathrm{OH} 261 \mathrm{~W}$ e apresentação dos valores de $F_{\mathrm{u}}, \mathrm{K}$ (uni) e $\Delta \mathrm{G}^{\circ}$ (uni) para o processo unimolecular e $\mathrm{K}(\mathrm{bi})$ e $\Delta \mathrm{G}^{\circ}$ (bi) para o processo bimolecular. Condições: $\mathrm{NaH}_{2} \mathrm{PO}_{4} 5.73 \mathrm{mM}$ pH 7.0, $\mathrm{NaCl} 50 \mathrm{mM}, \mathrm{MgCl}_{2}$ e DTT $1 \mathrm{mM}$. C $=13.7 \mu \mathrm{M}$. 

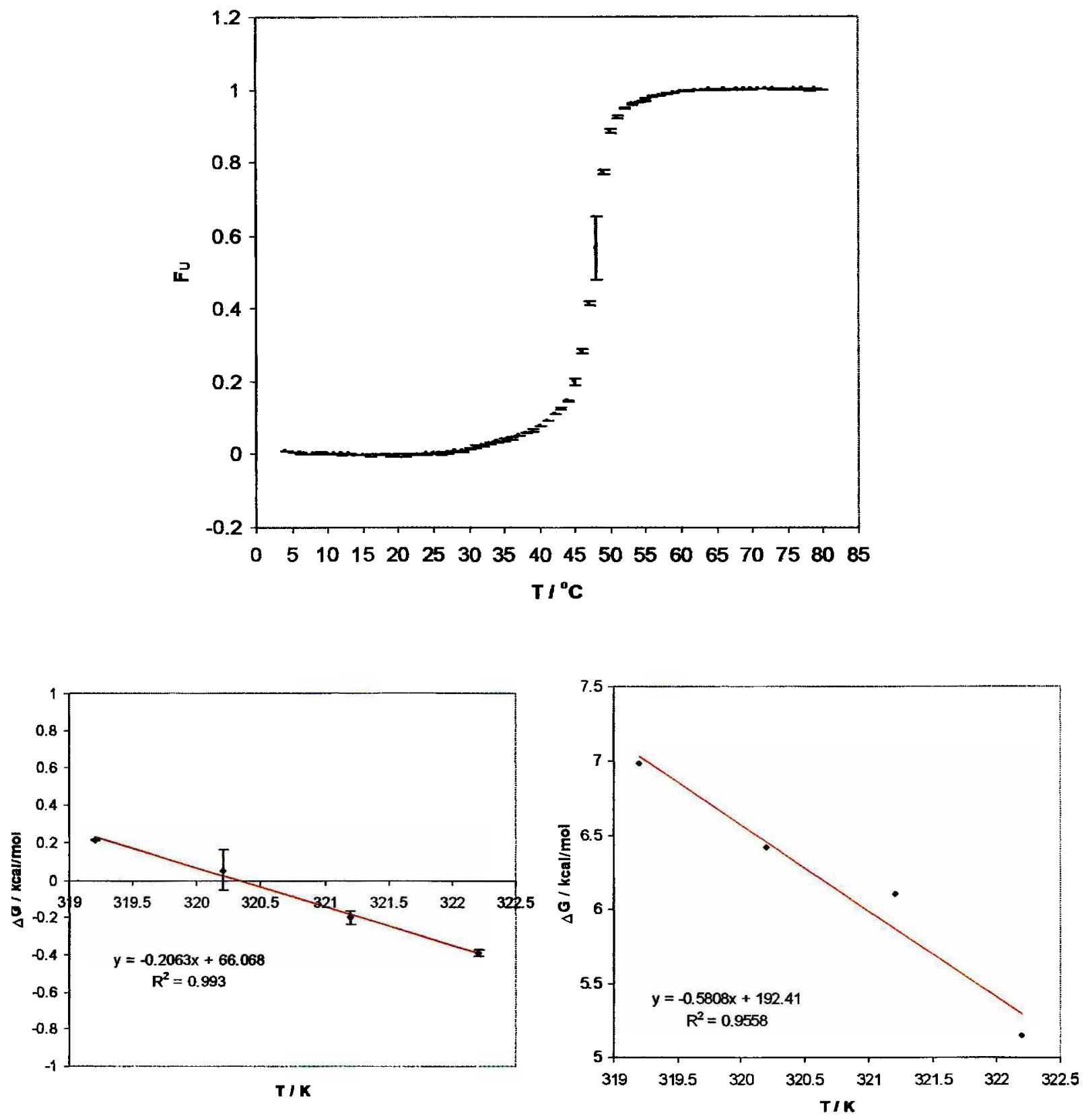

unimolecular

bimolecular

\begin{tabular}{|c|c|c|c|c|c|}
\hline $\mathrm{T} /{ }^{\circ} \mathrm{C}$ & $\mathrm{F}_{U}$ & $\mathrm{~K}$ (uni) & $\begin{array}{c}\Delta \mathrm{G}^{\circ}(\mathrm{uni}) \\
(\mathrm{cal} / \mathrm{mol})\end{array}$ & $\mathrm{K}(\mathrm{bi})$ & $\begin{array}{c}\Delta \mathrm{G}^{\circ}(\mathrm{bi}) \\
(\mathrm{cal} / \mathrm{mol})\end{array}$ \\
\hline 46 & 0.284 & 0.397 & 214 & $7.58 \mathrm{E}-06$ & 6981 \\
\hline 47 & 0.416 & 0.711 & 54 & $1.97 \mathrm{E}-05$ & 6416 \\
\hline 48 & 0.566 & 1.304 & -200 & $3.34 \mathrm{E}-05$ & 6103 \\
\hline 49 & 0.774 & 3.425 & -389 & 0.000167 & 5149 \\
\hline
\end{tabular}

Figura 41. Análise da curva de desnaturação por uréia para o mutante $50 H 276 W$ e apresentação dos valores de $F_{u}, K$ (uni) e $\Delta G^{\circ}$ (uni) para o processo unimolecular e $\mathrm{K}$ (bi) e $\Delta \mathrm{G}^{\circ}$ (bi) para o processo bimolecular. Condiçōes: $\mathrm{NaH}_{2} \mathrm{PO}_{4} 5.73 \mathrm{mM} \mathrm{pH} 7.0, \mathrm{NaCl} 50 \mathrm{mM}, \mathrm{MgCl}_{2}$ e DTT $1 \mathrm{mM}$. $\mathrm{C}_{\mathrm{T}}$ $=16.2 \mu \mathrm{M}$. 


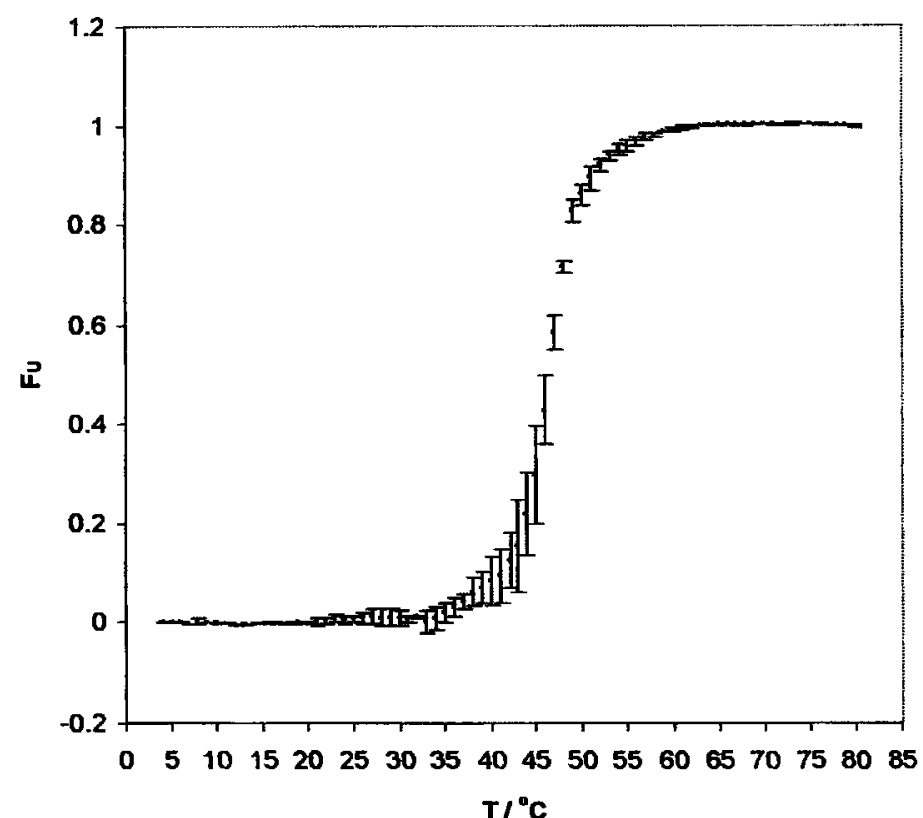

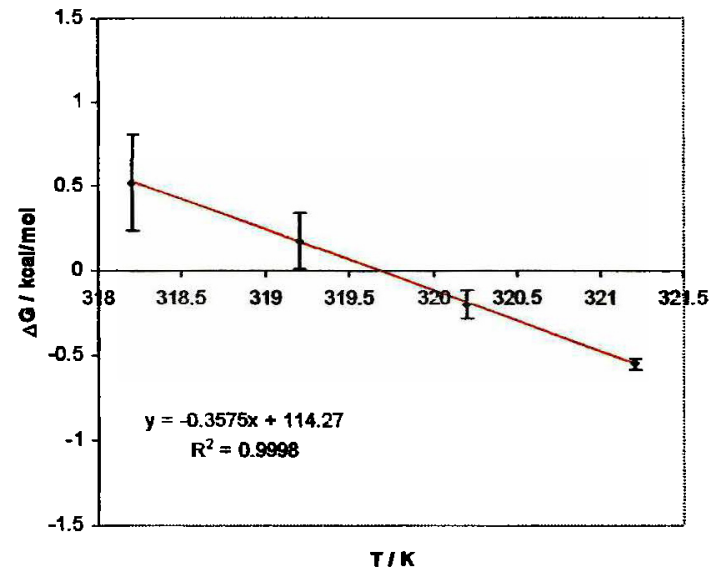

unimolecular

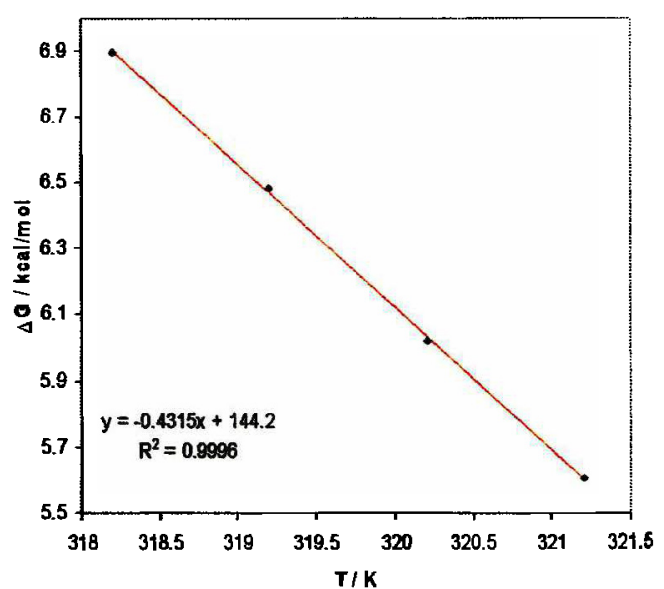

bimolecular

\begin{tabular}{|c|c|c|c|c|c|}
\hline $\mathrm{T} /{ }^{\circ} \mathrm{C}$ & $\mathrm{FU}_{\mathrm{U}}$ & $\mathrm{K}(\mathrm{uni})$ & $\begin{array}{c}\Delta \mathrm{G}^{\circ} \text { (uni) } \\
(\mathrm{cal} / \mathrm{mol})\end{array}$ & $\mathrm{K}(\mathrm{bi})$ & $\begin{array}{c}\Delta \mathrm{G}^{\circ}(\mathrm{bi}) \\
(\mathrm{cal} / \mathrm{mol})\end{array}$ \\
\hline 45 & 0.298 & 0.425 & 521 & $8.79 \mathrm{E}-06$ & 6893 \\
\hline 46 & 0.428 & 0.748 & 173 & $1.77 \mathrm{E}-05$ & 6479 \\
\hline 47 & 0.583 & 1.398 & -199 & $3.83 \mathrm{E}-05$ & 6021 \\
\hline 48 & 0.716 & 2.517 & -547 & $7.71 \mathrm{E}-05$ & 5607 \\
\hline
\end{tabular}

Figura 42. Análise da curva de desnaturação por temperatura para o mutante $50 \mathrm{H} 278 \mathrm{~W}$ e apresentação dos valores de $\mathrm{F}_{\mathrm{u}}, \mathrm{K}$ (uni) e $\Delta \mathrm{G}^{\circ}$ (uni) para 0 processo unimolecular e $\mathrm{K}(\mathrm{bi})$ e $\Delta \mathrm{G}^{\circ}$ (bi) para o processo bimolecular. Condições: $\mathrm{NaH}_{2} \mathrm{PO}_{4} 5.73 \mathrm{mM} \mathrm{pH} 7.0, \mathrm{NaCl} 50 \mathrm{mM}, \mathrm{MgCl}_{2}$ e DTT $1 \mathrm{mM}$. C $=10.2 \mu \mathrm{M}$. 
Os valores calculados para $T_{m}, \Delta H_{m}$ e $\Delta G^{\circ}\left(25^{\circ} \mathrm{C}\right)$ a partir dos dados obtidos nas figuras 34 a 42 podem ser vistos na tabela 2.

Tabela 2. Valores calculados para $T_{m}$ e $\Delta G^{\circ}\left(25^{\circ} \mathrm{C}\right)$ assumindo $\Delta C_{p}=0$ para - processo uni- e bimolecular obtidos a partir dos experimentos de desnaturação por temperatura acompanhada por dicroísmo circular. A concentração inicial de cada proteína $\left(\mathrm{C}_{\mathrm{T}}\right)$ também está indicada.

\begin{tabular}{|c|c|c|c|c|}
\hline tropomiosina & $\mathrm{T}_{m} /{ }^{\circ} \mathrm{C}$ & $\mathrm{C}_{\mathrm{T}} / \mu \mathrm{M}$ & $\begin{array}{c}\Delta \mathrm{G}^{\circ}\left(25^{\circ} \mathrm{C}\right) / \\
\mathrm{kcalmol}^{-1} \\
\text { unimolecular })^{\prime}\end{array}$ & $\begin{array}{c}\Delta \mathrm{G}^{\circ}\left(25^{\circ} \mathrm{C}\right) / \\
\mathrm{kcalmol}^{-1} \\
\text { (bimolecular) }^{\prime}\end{array}$ \\
\hline $\mathrm{ASTm}$ & 47 & 10.0 & 8.1 & 18.5 \\
\hline $5 \mathrm{OH} 94 \mathrm{~W}$ & 47 & 12.2 & 6.9 & 15.5 \\
\hline $5 \mathrm{OH} 101 \mathrm{~W}$ & 45 & 7.4 & 8.1 & 17.9 \\
\hline $5 \mathrm{OH} 107 \mathrm{~W}$ & 46 & 9.6 & 5.4 & 14.7 \\
\hline $5 \mathrm{OH} 111 \mathrm{~W}$ & 45 & 10.5 & 5.8 & 15.8 \\
\hline $5 \mathrm{OH} 122 \mathrm{~W}$ & 47 & 11.0 & 5.3 & 14.4 \\
\hline $5 \mathrm{OH} 261 \mathrm{~W}$ & 47 & 13.7 & 4.8 & 14.2 \\
\hline $5 \mathrm{OH} 276 \mathrm{~W}$ & 47 & 16.2 & 4.6 & 19.4 \\
\hline $5 \mathrm{OH} 278 \mathrm{~W}$ & 46 & 10.2 & 7.7 & 16.1 \\
\hline
\end{tabular}

Podemos observar da tabela 2 e da figura 32 que os valores obtidos para a $T_{m}$ para todas as tropomiosinas analisadas são muito próximos entre si, variando em apenas $2{ }^{\circ} \mathrm{C}$ entre o valor mínimo $\left(45^{\circ} \mathrm{C}\right)$ e o valor máximo $\left(47^{\circ} \mathrm{C}\right)$, indicando que a introdução da sonda fluorescente 5-hidroxitriptofano nestas posições da molécula não estão causando um grande efeito na estabilidade global da molécula. A variação observada para $\Delta \mathrm{G}^{\circ}\left(25^{\circ} \mathrm{C}\right)$ provavelmente está mais relacionada com a imprecisão no cálculo desta constante do que com diferenças reais na estabilidade das diversas tropomiosinas. Podemos notar que a ordem das tropomiosinas em termos de estabilidade refletida em termos de $T_{m}, \Delta G^{\circ}$ (unimolecular) e $\Delta G^{\circ}$ (bimolecular) são diferentes. Isso é devido às diferenças nas cooperatividades das transições que se traduzem em diferenças na extrapolação até $\mathrm{T}=25^{\circ} \mathrm{C}$ (298K). Uma comparação entre os valores para os processos uni- e bimolecular pode ser encontrada na DISCUSSÃo. 
Se utilizarmos o método de Myers et al. (1995) para estimarmos o $\Delta \mathrm{C}_{\mathrm{p}}$ a partir da sequência primária da tropomiosina obtemos:

Considerando $\Delta \mathrm{C}_{\mathrm{P}} \sim 172+17.6 \times \mathrm{N}-164 \times \mathrm{SS}=10.2392 \mathrm{kcal} / \mathrm{mol} . \mathrm{K}$

onde $\mathrm{N}$ é o número de resíduos $(286 \times 2)$ e $\mathrm{SS}$ é o número de pontes dissulfeto (zero). Desta maneira (Privalov e Potekhin, 1986; Dragan e Privalov, 2002), podemos recalcular os valores de $\Delta \mathrm{G}^{\circ}\left(25^{\circ} \mathrm{C}\right)$ para o processo unimolecular a partir da equação:

$$
\Delta G^{\circ}(T)=\Delta H_{m}\left(1-T / T_{m}\right)-\Delta C_{p}\left[\left(T_{m}-T\right)+T \ln \left(T / T_{m}\right)\right]
$$

e, para o processo bimolecular, a partir da equação:

$$
\Delta G^{0}(T)=\Delta H_{m}\left(1-T / T_{m}\right)-R T \ln \left(2 C_{T}\right)-\Delta C_{p}\left[\left(T_{m}-T\right)+T \ln \left(T / T_{m}\right)\right]
$$

onde $\mathrm{T}=25^{\circ} \mathrm{C}$. Os $\Delta \mathrm{G}^{\circ}\left(25^{\circ} \mathrm{C}\right)$. Os valores obtidos para $\Delta \mathrm{G}^{\circ}$ para o processo unimolecular está entre -3.4 e $1.4 \mathrm{kcal} / \mathrm{mol}$, o que não é compativel com o valor positivo esperado para $\Delta \mathrm{G}^{\circ}\left(25^{\circ} \mathrm{C}\right)$. Para o processo bimolecular, entretanto, utilizando $o$ valor de $\Delta \mathrm{C}_{\mathrm{P}}$ calculado acima, obtemos valores positivos para o $\Delta \mathrm{G}^{\circ}\left(25^{\circ} \mathrm{C}\right)$ (Tabela 3$)$.

Tabela 3. Valores para $\circ \Delta G^{\circ}\left(25^{\circ} \mathrm{C}\right)$ para o processo bimolecular utilizando $\Delta \mathrm{C}_{\mathrm{P}}$ diferente de zero.

\begin{tabular}{|c|c|c|}
\hline tropomiosina & $\begin{array}{c}\Delta \mathrm{G}^{\circ}\left(25^{\circ} \mathrm{C}\right) \\
/ \mathrm{kcal} \mathrm{mol}^{-1} \\
\text { (unimolecular) }\end{array}$ & $\begin{array}{c}\Delta \mathrm{G}^{\circ}\left(25^{\circ} \mathrm{C}\right) \\
/ \mathrm{kcal} \mathrm{mol}^{-1} \\
(\text { bimolecular })\end{array}$ \\
\hline ASTm & -0.1 & 10.4 \\
\hline $5 \mathrm{OH} 94 \mathrm{~W}$ & -0.8 & 7.8 \\
\hline $5 \mathrm{OH} 101 \mathrm{~W}$ & 1.4 & 11.2 \\
\hline $5 \mathrm{OH} 107 \mathrm{~W}$ & -1.6 & 7.7 \\
\hline $5 \mathrm{OH} 111 \mathrm{~W}$ & -1.1 & 8.9 \\
\hline $5 \mathrm{OH} 122 \mathrm{~W}$ & -2.6 & 6.5 \\
\hline $5 \mathrm{OH} 261 \mathrm{~W}$ & -3.1 & 6.3 \\
\hline $5 \mathrm{OH} 276 \mathrm{~W}$ & -3.4 & 11.4 \\
\hline $5 \mathrm{OH} 278 \mathrm{~W}$ & 0.1 & 8.5 \\
\hline
\end{tabular}


Estes resultados estão analisados na seção DISCUSSÃO.

Desnaturação por uréia seguida por fluorescência

A desnaturação por uréia acompanhada por variação na fluorescência é um método conveniente de se estudar a estabilidade local, próxima a região da sonda fluorescente, de proteinas.

A figura 43 apresenta as curvas de desnaturação por uréia seguida por fluorescência para os mutantes de tropomiosina com a sonda fluorescente inserida nas posições 90, 94, 101, 107, 111, 122, 185, 261, 263, 269, 276 e 278. A figura 44A apresenta uma comparação das curvas obtidas por desnaturação por uréia seguida por fluorescência para todos os mutantes testados. A figura 44B mostra apenas as curvas para os mutantes que apresentaram transições definidas. Os resultados obtidos por estes ensaios estão resumidos na tabela 4 . É interessante notar que dos 12 mutantes analisados por esta técnica todos os 5 mutantes que possuem a sonda fluorescente dentro de uma banda a mostraram transições definidas ao passo que todos os 7 mutantes com a sonda dentro de uma banda $\beta$ não apresentaram transição definida (Figuras 43 e 44) (ver DISCUSSÃO).

Uma comparação das curvas da fração desenovelada dos mutantes $50 H 90 \mathrm{~W}, 5 \mathrm{OH} 94 \mathrm{~W}, 5 \mathrm{OH} 101 \mathrm{~W}, 5 \mathrm{OH} 261 \mathrm{~W}$ e $5 \mathrm{OH} 263 \mathrm{~W}$ em função da concentração de uréia pode ser observada na figura 45 . A tabela 4 resume os resultados obtidos através da desnaturação destes mutantes por uréia seguida por fluorescência. Os mutantes com as sondas nas posições 90, 94, 101, 261 e 263 forneceram curvas de desnaturação com transição relativamente bem definida e puderam ter suas constantes de equilíbrio calculadas para as concentrações de uréia no meio da transição cooperativa (figura 43). Uma comparação entre os resultados de desnaturação local (fluorescência) e desnaturação global da molécula de tropomiosina (dicroísmo circular) pode ser encontrada na DISCUSSÃo. 
Tabela 4. Valores de $U_{1 / 2}, m$ e $\Delta G^{\circ}\left(H_{2} \mathrm{O}\right)$ obtidos a partir dos experimentos de desnaturação por uréia acompanhada por fluorescência. Os volores de $\Delta \mathrm{G}^{\circ}\left(\mathrm{H}_{2} \mathrm{O}\right)$ para o processo bimolecular também estão indicados para comparação. A concentração inicial de cada proteina $\left(C_{T}\right)$ é de $1 \mu \mathrm{M}$.

\begin{tabular}{|c|c|c|c|c|c|}
\hline Mutante & $U_{1 / 2} / \mathrm{M}^{*}$ & $\begin{array}{c}\mathrm{U}_{1 / 2}=\Delta \mathrm{G}^{\circ}\left(\mathrm{H}_{2} \mathrm{O}\right) / \\
m / \mathrm{M}^{*}\end{array}$ & $\begin{array}{c}\mathrm{m} / \\
\mathrm{kcalmol}^{-1} \mathrm{M}^{-1}\end{array}$ & $\begin{array}{c}\Delta \mathrm{G}^{\circ}\left(\mathrm{H}_{2} \mathrm{O}\right) / \\
\mathrm{kcal} \text { mol }^{-1} \dagger \\
\text { unimolecular })\end{array}$ & $\begin{array}{c}\Delta \mathrm{G}^{\circ}\left(\mathrm{H}_{2} \mathrm{O}\right) / \\
\mathrm{kcal} \mathrm{mol}^{-1}{ }^{\prime} \\
\text { (bimolecular })\end{array}$ \\
\hline $5 \mathrm{OH} 90 \mathrm{~W}$ & 2.9 & 2.9 & 1.7 & 4.9 & 15.4 \\
\hline $5 \mathrm{OH} 94 \mathrm{~W}$ & 2.6 & 2.7 & 1.9 & 5.1 & 15.6 \\
\hline $5 \mathrm{OH} 101 \mathrm{~W}$ & 2.4 & 2.4 & 2.3 & 5.6 & 16.1 \\
\hline $5 \mathrm{OH} 107 \mathrm{~W}$ & n.d. & - & - & - & - \\
\hline $5 \mathrm{OH} 111 \mathrm{~W}$ & n.d. & - & - & - & - \\
\hline $5 \mathrm{OH} 122 \mathrm{~W}$ & n.d. & - & - & - & - \\
\hline $5 \mathrm{OH} 185 \mathrm{~W}$ & n.d. & - & - & - & - \\
\hline $5 \mathrm{OH} 261 \mathrm{~W}$ & 2.2 & 2.4 & 2.6 & 6.1 & 16.4 \\
\hline $5 \mathrm{OH} 263 \mathrm{~W}$ & 2.7 & 2.7 & 2.4 & 6.6 & 17.6 \\
\hline $5 \mathrm{OH} 269 \mathrm{~W}$ & n.d. & - & - & - & - \\
\hline $5 \mathrm{OH} 276 \mathrm{~W}$ & n.d. & - & - & - & - \\
\hline $5 \mathrm{OH} 278 \mathrm{~W}$ & n.d. & - & - & - & - \\
\hline
\end{tabular}

* Obtido a partir do ajuste direto da curva de intensidade de fluorescência para a equação $y=\left\{\left(y_{F}+m_{F}{ }^{*}[U]\right)+\left(y_{U}+m_{U}{ }^{*}[U]\right)^{*} \exp \left(m^{*}\left([U]-[U]_{1 / 2}\right) / R T\right)\right\} /\{1+$ $\left.\exp \left(m^{*}\left([U]-[U]_{1 / 2}\right) / R T\right)\right\}$, onde $y_{F}$ e $m_{F}$ são os coeficientes linear e angular do patamar pré-transição, $y_{\cup}$ e $m_{\cup}$ os do patamar pós-transição, [U] é a concentração de desnaturante.

\# Obtido a partir dos valores de $m$ e de $\Delta \mathrm{G}^{\circ}\left(\mathrm{H}_{2} \mathrm{O}\right)$ calculados como indicado no final desta seção $\left(U_{1 / 2}=\Delta G^{\circ}\left(H_{2} \mathrm{O}\right) / m\right)$.

† Determinado a partir da desnaturação por uréia seguida por fluorescência. 

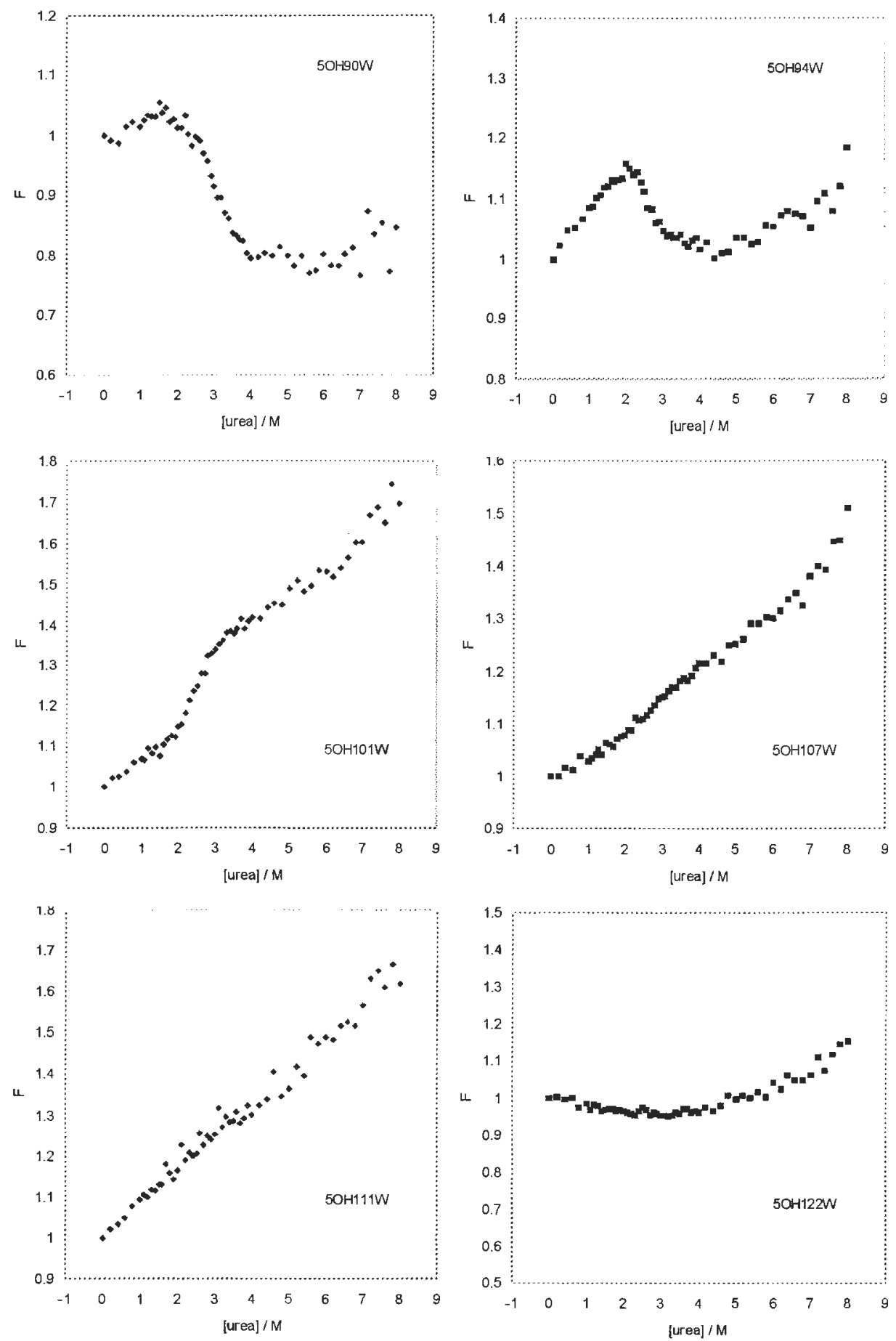

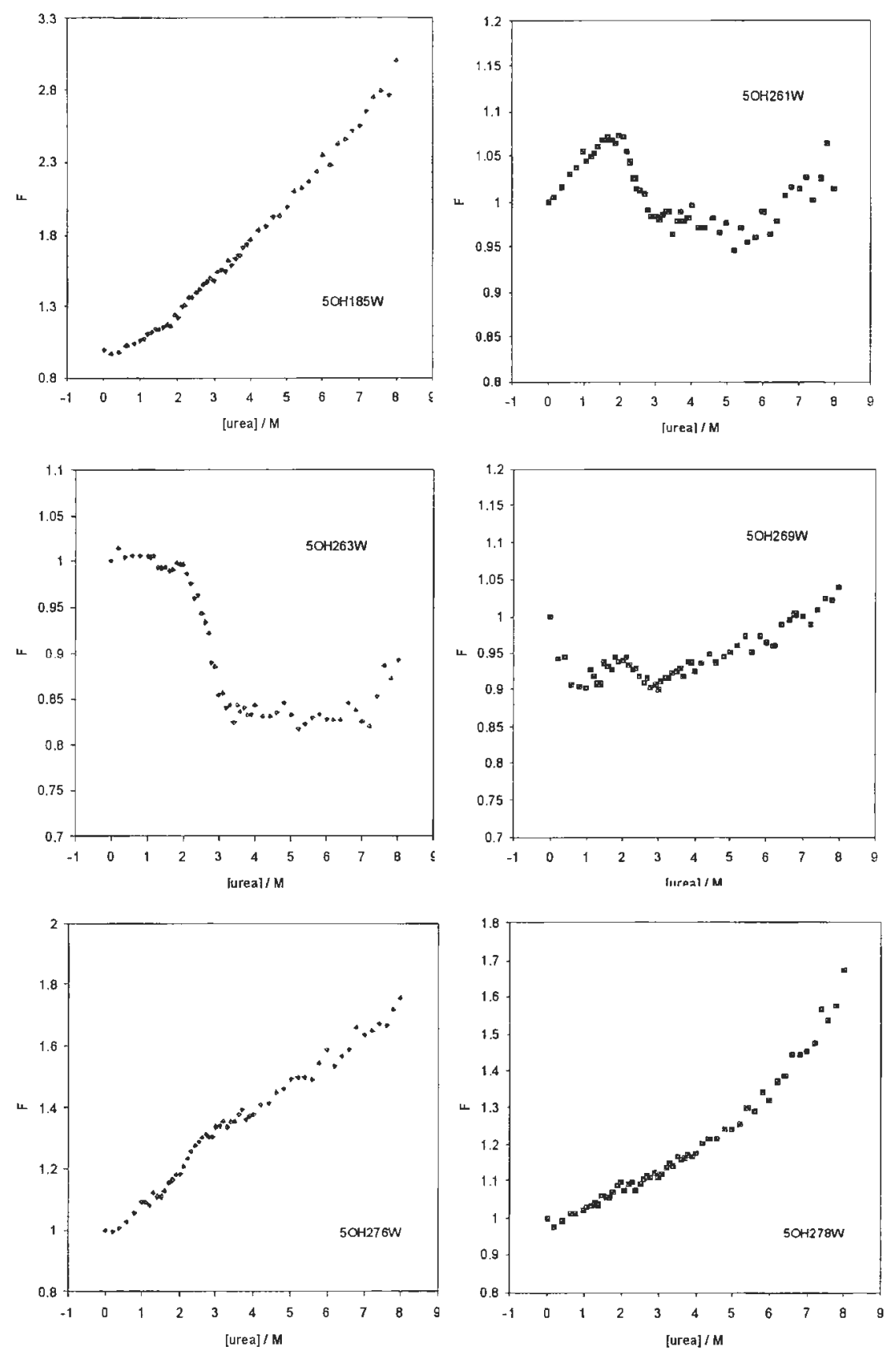

Figura 43. Curvas de desnaturação por uréia acompanhada por fluorescência obtida para os mutantes 5OH90W, 5OH94W, 5OH101W, $5 \mathrm{OH} 107 \mathrm{~W}, 5 \mathrm{OH} 111 \mathrm{~W}$ e $5 \mathrm{OH} 122 \mathrm{~W}$ (página anterior) e 5OH185W, 5OH261W, $5 \mathrm{OH} 263 \mathrm{~W}, 5 \mathrm{OH} 269 \mathrm{~W}, 5 \mathrm{OH} 276 \mathrm{~W}$ e $5 \mathrm{OH} 278 \mathrm{~W}$ (nesta página). Cada experimento continha $1 \mu \mathrm{M}$ de proteína em MOPS $25 \mathrm{mM} \mathrm{pH} 7.0, \mathrm{NaCl} 50$ $\mathrm{mM}, \mathrm{MgCl}_{2} 5 \mathrm{mM}$ e DTT $1 \mathrm{mM}$ a $25^{\circ} \mathrm{C}$. 

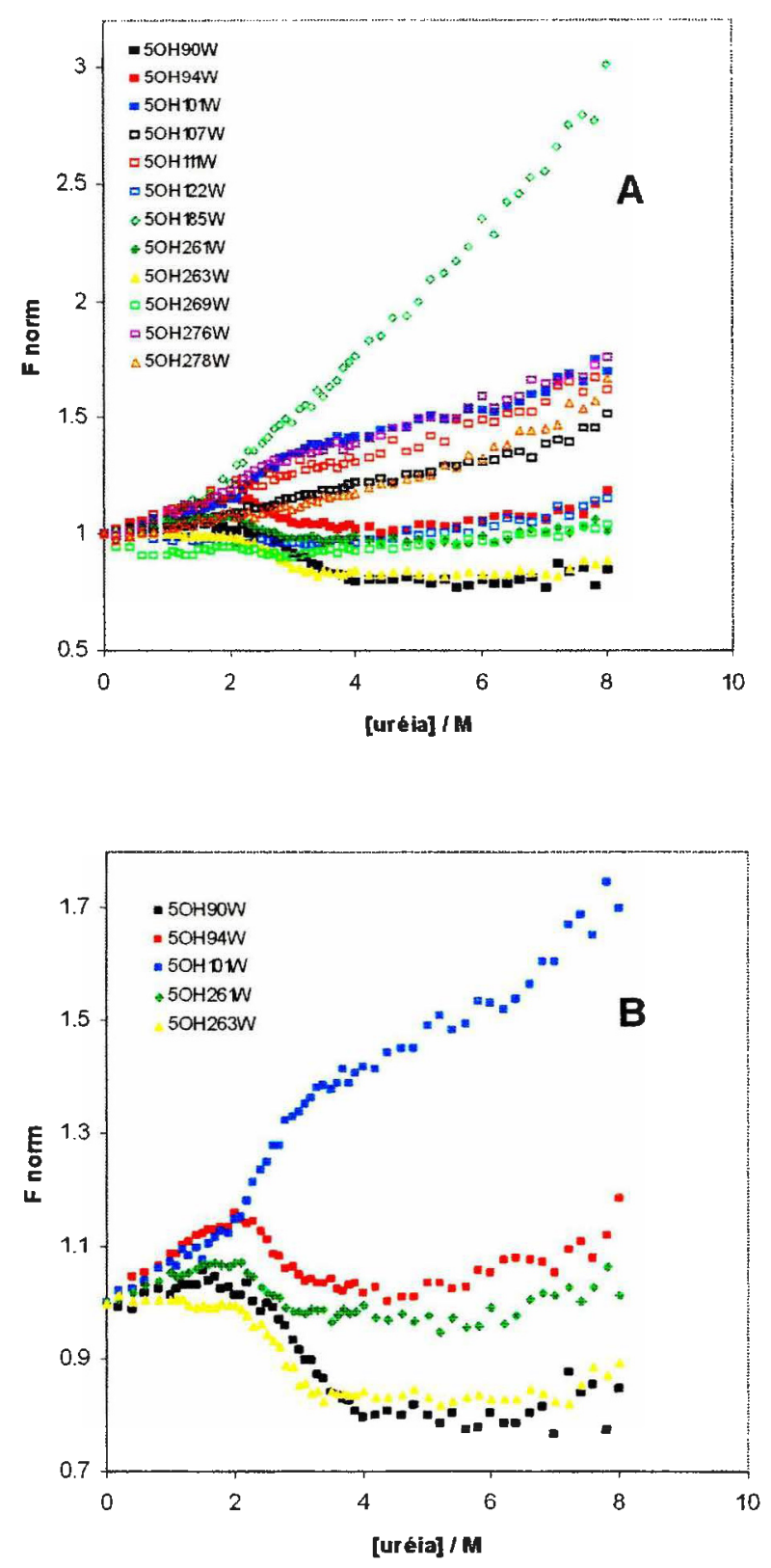

Figura 44. Comparação das curvas de desnaturação por uréia de $1 \mu \mathrm{M}$ de cada proteína em MOPS $25 \mathrm{mM} \mathrm{pH} \mathrm{7.0,} \mathrm{NaCl} 50 \mathrm{mM}, \mathrm{MgCl}_{2} 5 \mathrm{mM}$ e DTT 1 mM a $25^{\circ} \mathrm{C}$ seguida por fluorescência. $\mathrm{O}$ painel $\mathrm{A}$ apresenta num mesmo gráfico todos os mutantes testados. O painel B apresenta apenas os mutantes que apresentaram uma transição identificável. 


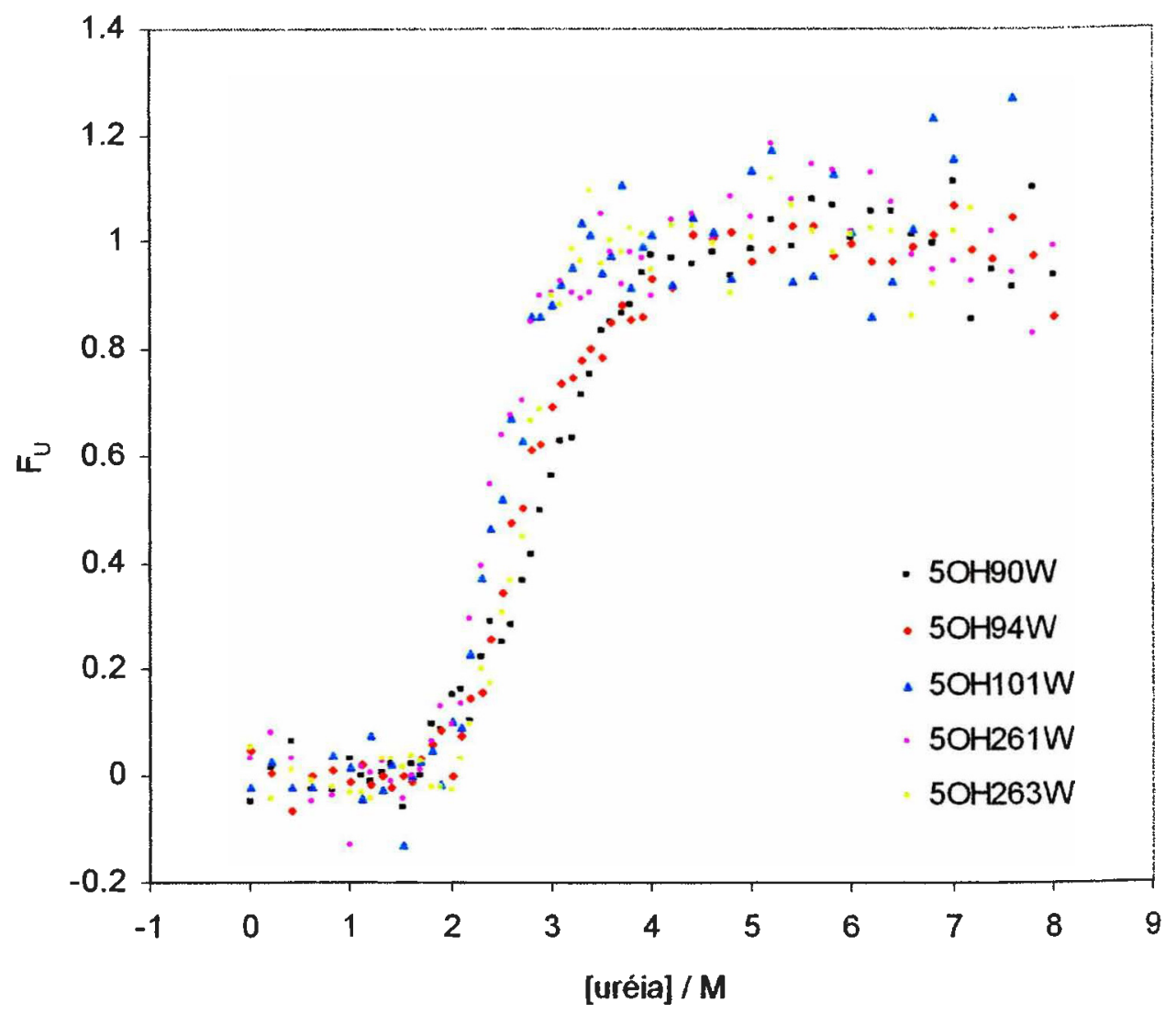

Figura 45. Comparação das curvas da fração desenovelada dos mutantes $5 \mathrm{OH} 90 \mathrm{~W}, 5 \mathrm{OH} 94 \mathrm{~W}, 5 \mathrm{OH} 101 \mathrm{~W}, 5 \mathrm{OH} 261 \mathrm{~W}$ e 5OH263W em MOPS $25 \mathrm{mM}$ $\mathrm{pH} 7.0, \mathrm{NaCl} 50 \mathrm{mM}, \mathrm{MgCl}_{2} 5 \mathrm{mM}$ e DTT $1 \mathrm{mM}$ a $25^{\circ} \mathrm{C}$ em função da concentração de uréia. As proteinas estavam presentes a $1 \mu \mathrm{M}$.

Os valores de $\mathrm{Fu}_{\mathrm{U}}, \mathrm{K}_{\text {eq }}$ e $\Delta \mathrm{G}^{\circ}\left(\mathrm{H}_{2} \mathrm{O}\right)$ foram obtidos segundo o tratamento descrito em Pace e Scholtz (1997) baseado na observação de que $\circ \Delta G^{\circ}$ de desnaturação de uma proteína é linearmente proporcional à concentração do desnaturante. Para estimar-se a estabilidade conformacional na ausência de uréia, $\Delta \mathrm{G}^{\circ}\left(\mathrm{H}_{2} \mathrm{O}\right)$, assume-se que a dependência linear continua até [uréia] = 0 e ajustar os dados à seguinte equação (Santoro e Bolen, 1988 e Bolen e Santoro, 1988):

$$
\Delta G^{\circ}=\Delta G^{\circ}\left(H_{2} \mathrm{O}\right)-m[\mathrm{U}]
$$


onde $m$ é uma medida da dependência de $\Delta G^{\circ}$ pela concentração de desnaturante, [U]. A concentração de desnaturante no ponto médio da curva de desnaturação, $U_{1 / 2}$ é igual a razão $\Delta G^{\circ}\left(H_{2} O\right) / m$ (Pace e Scholtz, 1997).

As análises das curvas com transição identificável podem ser observadas nas figuras 46 a 50 . Como indicado acima, destas análises podemos obter os valores de $U_{1 / 2}$ (concentração de uréia quando $F_{U}=0.5$ ), $\Delta G^{\circ}\left(\mathrm{H}_{2} \mathrm{O}\right)$ (a partir da extrapolação linear até o eixo y), e de $m$ (coeficiente angular da curva).

Uma discussão dos resultados de desnaturação por uréia seguida por fluorescência pode ser encontrada na seção DISCUSSÃO. 


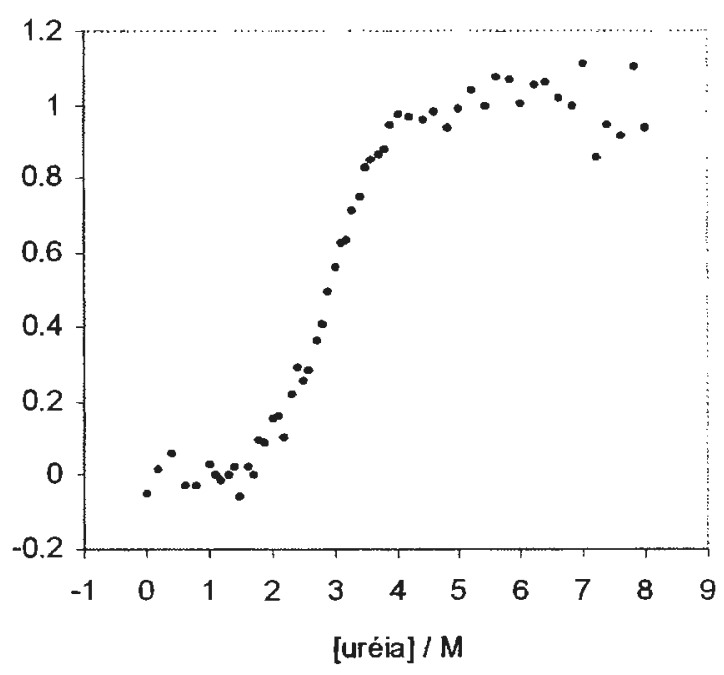

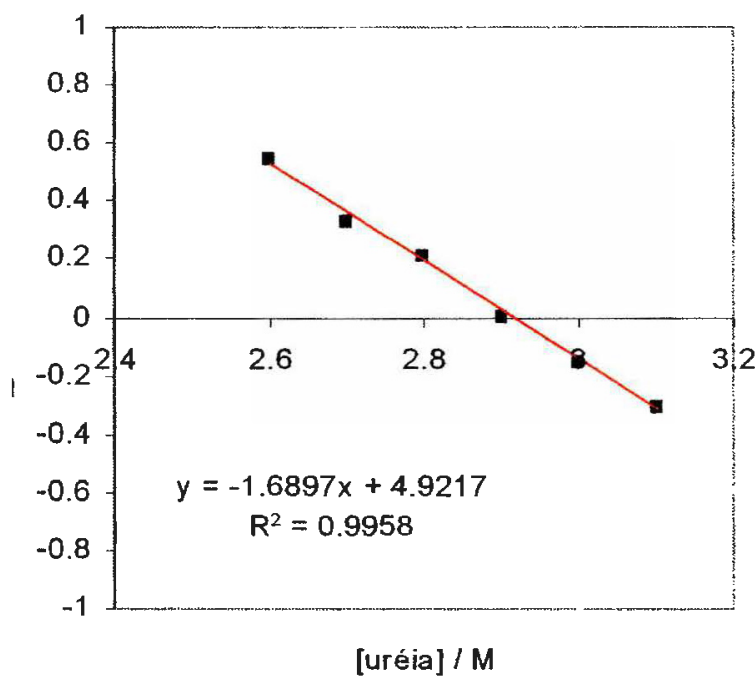

unimolecular

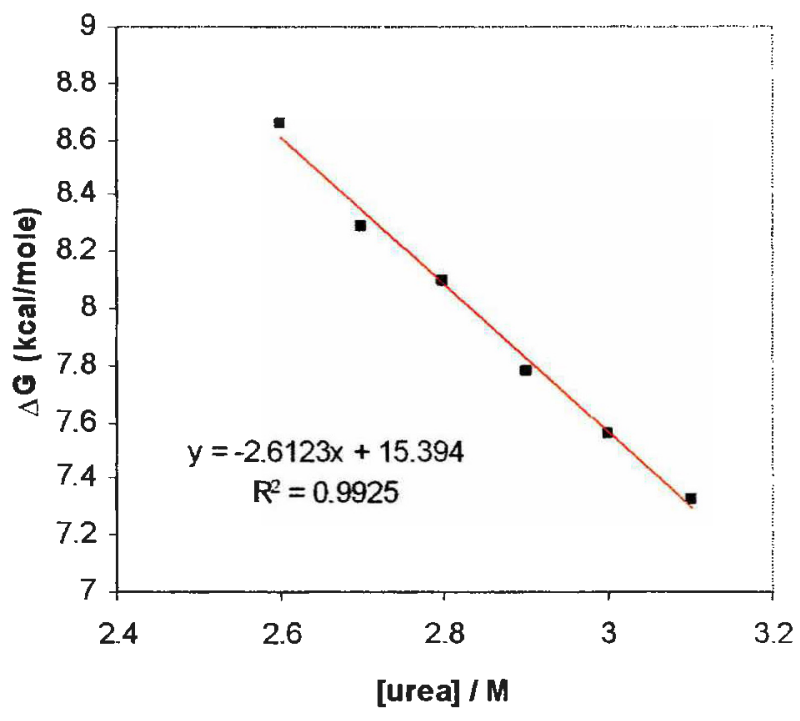

bimolecular

\begin{tabular}{|c|c|c|c|c|c|}
\hline [uréia] / M & $F_{U}$ & $\mathrm{~K}(\mathrm{uni})$ & $\begin{array}{c}\Delta \mathrm{G}^{\circ}(\mathrm{uni}) \\
(\mathrm{cal} / \mathrm{mol})\end{array}$ & $\mathrm{K}(\mathrm{bi})$ & $\begin{array}{c}\Delta \mathrm{G}^{\circ}(\mathrm{bi}) \\
(\mathrm{cal} / \mathrm{mol})\end{array}$ \\
\hline 2.6 & 0.283 & 0.395 & 549 & $4.48 \mathrm{E}-07$ & 8655 \\
\hline 2.7 & 0.365 & 0.575 & 328 & $8.39 \mathrm{E}-07$ & 8284 \\
\hline 2.8 & 0.413 & 0.703 & 208 & $1.16 \mathrm{E}-06$ & 8091 \\
\hline 2.9 & 0.498 & 0.992 & 5 & $1.98 \mathrm{E}-06$ & 7776 \\
\hline 3 & 0.562 & 1.282 & -147 & $2.88 \mathrm{E}-06$ & 7553 \\
\hline 3.1 & 0.627 & 1.681 & -307 & $4.21 \mathrm{E}-06$ & 7328 \\
\hline
\end{tabular}

Figura 46 Análise da curva de desnaturação por uréia para o mutante $50 \mathrm{H} 90 \mathrm{~W}$ e apresentação dos valores de $\mathrm{F}_{\mathrm{u}}$, $\mathrm{K}$ (uni) e $\Delta \mathrm{G}^{\circ}$ (uni) para o processo unimolecular e $\mathrm{K}(\mathrm{bi})$ e $\Delta \mathrm{G}^{\circ}(\mathrm{bi})$ para o processo bimolecular. Condições: $1 \mu \mathrm{M}$ de proteína em MOPS $25 \mathrm{mM}$ pH 7.0, $\mathrm{NaCl} 50 \mathrm{mM}, \mathrm{MgCl}_{2} 5$ mM e DTT $1 \mathrm{mM}$ a $25^{\circ} \mathrm{C}$. 


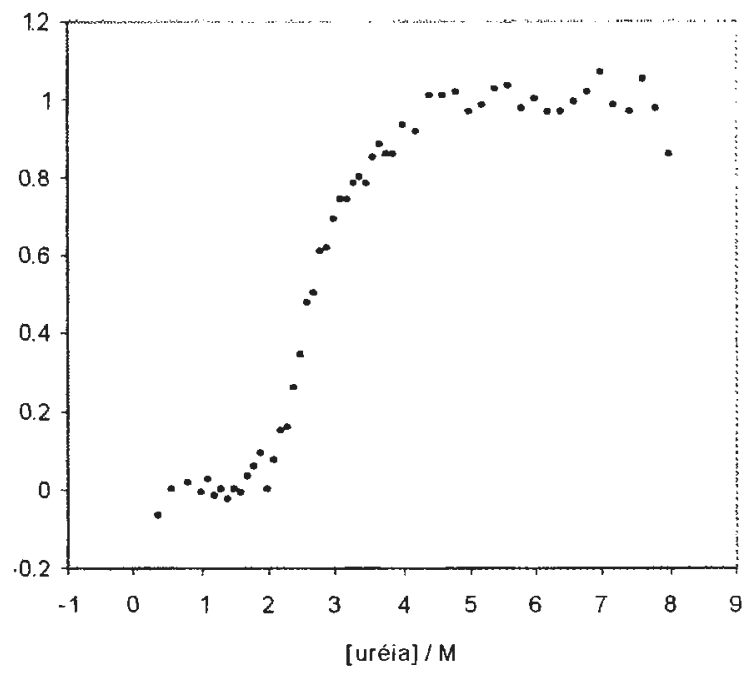

B I B L I O TE C A INSTITUTO DE QUIMICA Universidade de São Paulo

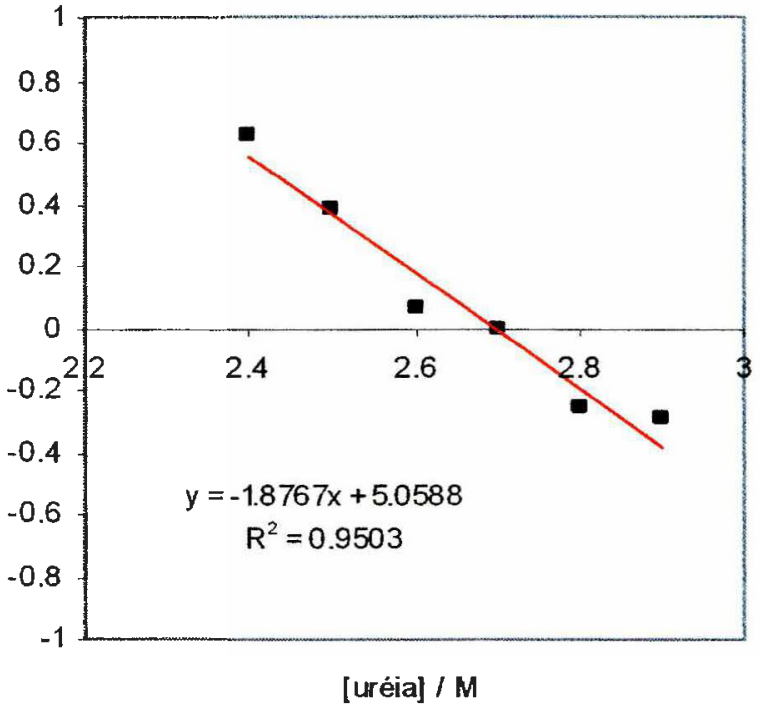

unimolecular

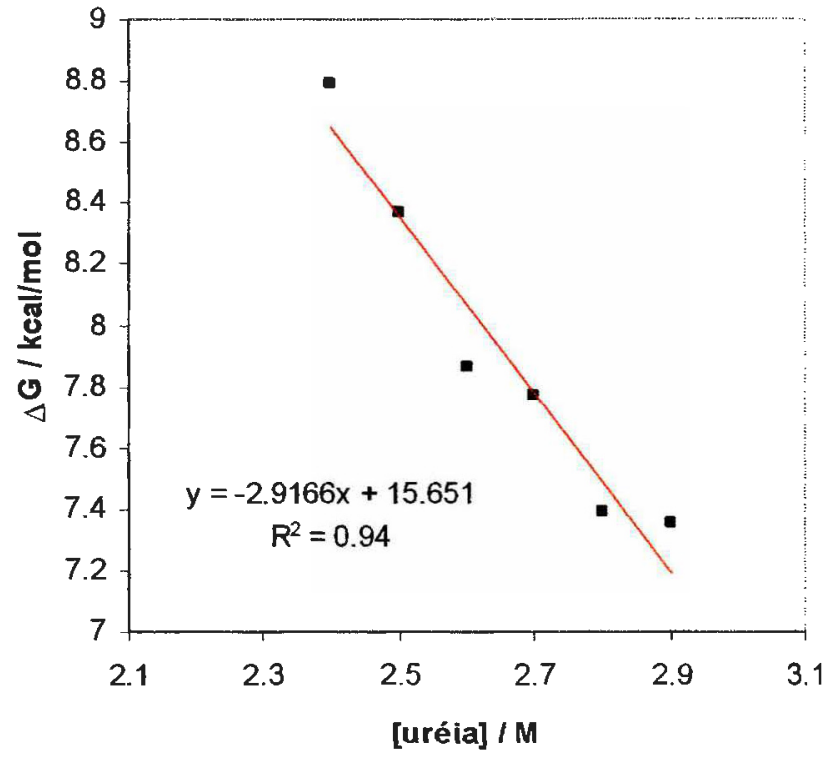

bimolecular

\begin{tabular}{|c|c|c|c|c|c|}
\hline [uréia] $/ \mathrm{M}$ & $\mathrm{F}_{\mathrm{U}}$ & $\mathrm{K}($ uni) & $\begin{array}{c}\Delta \mathrm{G}^{\circ} \text { (uni) } \\
\text { (cal/mol) }\end{array}$ & $\mathrm{K}(\mathrm{bi})$ & $\begin{array}{c}\Delta \mathrm{G}^{\circ}(\mathrm{bi}) \\
(\mathrm{cal} / \mathrm{mol})\end{array}$ \\
\hline 2.4 & 0.258 & 0.347 & 626 & $3.58 \mathrm{E}-07$ & 8788 \\
\hline 2.5 & 0.345 & 0.527 & 379 & $7.28 \mathrm{E}-07$ & 8368 \\
\hline 2.6 & 0.474 & 0.902 & 61 & $1.71 \mathrm{E}-06$ & 7862 \\
\hline 2.7 & 0.501 & 1.004 & -2 & $2.01 \mathrm{E}-06$ & 7766 \\
\hline 2.8 & 0.609 & 1.555 & -261 & $3.79 \mathrm{E}-06$ & 7392 \\
\hline 2.9 & 0.620 & 1.633 & -290 & $4.05 \mathrm{E}-06$ & 7352 \\
\hline
\end{tabular}

Figura 47 Análise da curva de desnaturação por uréia para o mutante $50 H 94 \mathrm{~W}$ e apresentação dos valores de $\mathrm{F}_{\mathrm{u}}, \mathrm{K}$ (uni) e $\Delta \mathrm{G}^{\circ}$ (uni) para o processo unimolecular e $\mathrm{K}(\mathrm{bi})$ e $\Delta \mathrm{G}^{\circ}$ (bi) para o processo bimolecular. Condições: $1 \mu \mathrm{M}$ de proteina em MOPS $25 \mathrm{mM} \mathrm{pH} 7.0, \mathrm{NaCl} 50 \mathrm{mM}, \mathrm{MgCl}_{2} 5$ $\mathrm{mM}$ e DTT $1 \mathrm{mM}$ a $25^{\circ} \mathrm{C}$. 


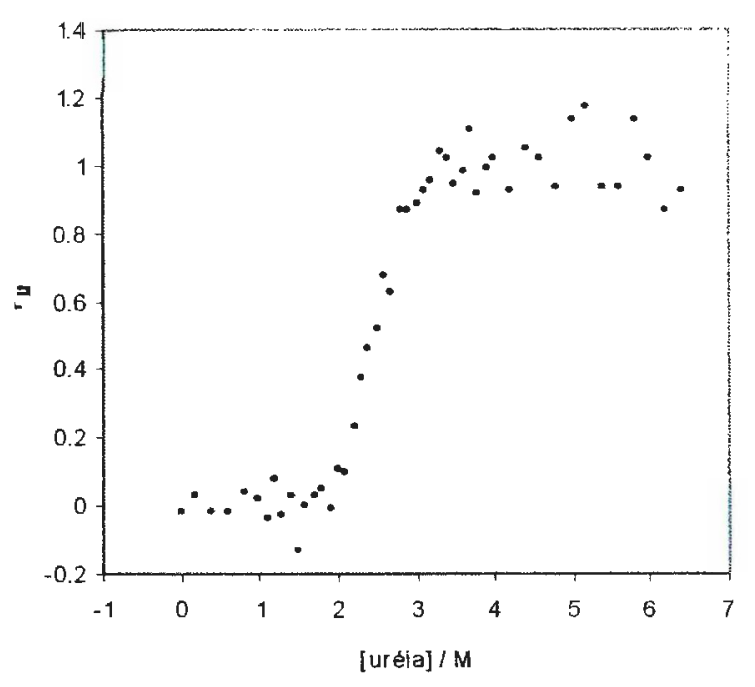

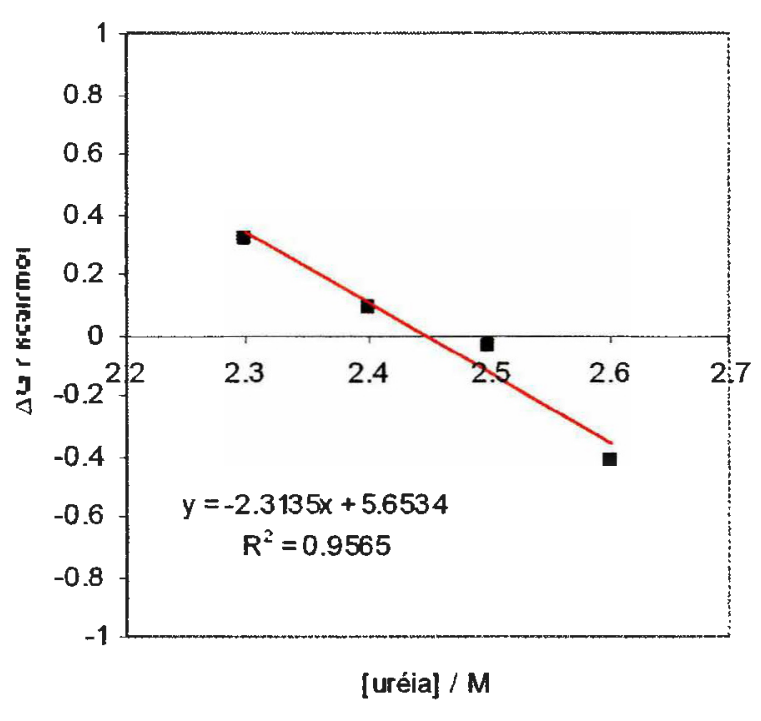

unimolecular

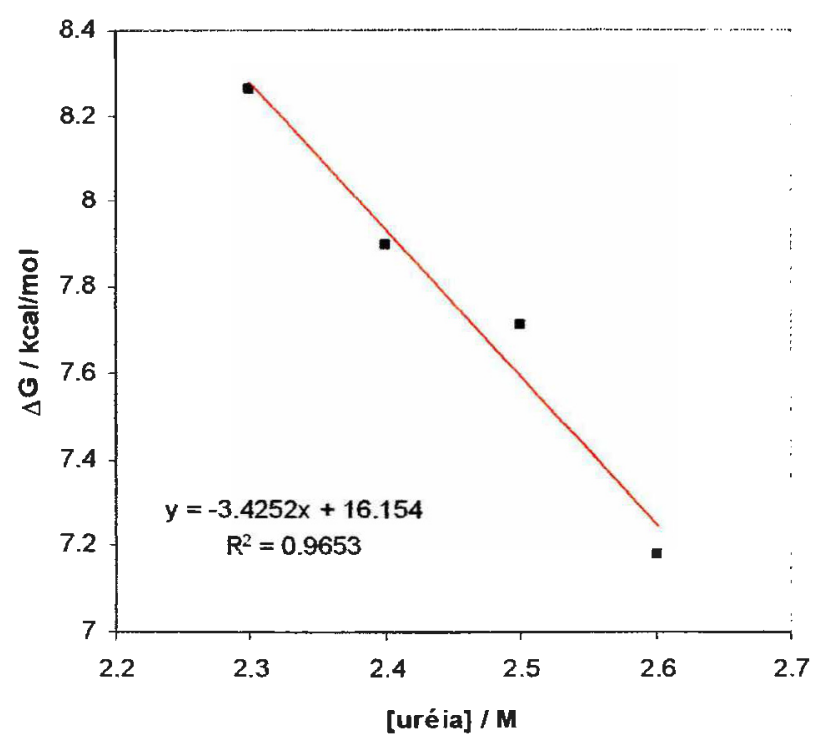

bimolecular

\begin{tabular}{|c|c|c|c|c|c|}
\hline [uréia] $/ \mathrm{M}$ & $\mathrm{Fu}_{\mathrm{U}}$ & $\mathrm{K}($ uni) & $\begin{array}{c}\Delta \mathrm{G}^{\circ}(\mathrm{uni}) \\
(\mathrm{call} / \mathrm{mol})\end{array}$ & $\mathrm{K}(\mathrm{bi})$ & $\begin{array}{c}\Delta \mathrm{G}^{\circ}(\mathrm{bi}) \\
(\mathrm{cal} / \mathrm{mol})\end{array}$ \\
\hline 2.3 & 0.371 & 0.589 & 314 & $8.72 \mathrm{E}-07$ & 8261 \\
\hline 2.4 & 0.465 & 0.870 & 83 & $1.62 \mathrm{E}-06$ & 7895 \\
\hline 2.5 & 0.516 & 1.067 & -39 & $2.2 \mathrm{E}-06$ & 7712 \\
\hline 2.6 & 0.669 & 2.022 & -417 & $5.41 \mathrm{E}-06$ & 7180 \\
\hline
\end{tabular}

Figura 48. Análise da curva de desnaturação por uréia para o mutante $5 \mathrm{OH} 101 \mathrm{~W}$ e apresentação dos valores de $\mathrm{F}_{\mathrm{u}}, \mathrm{K}$ (uni) e $\Delta \mathrm{G}^{\circ}$ (uni) para o processo unimolecular e $\mathrm{K}(\mathrm{bi})$ e $\Delta \mathrm{G}^{\circ}$ (bi) para o processo bimolecular. Condições: $1 \mu \mathrm{M}$ de proteína em MOPS $25 \mathrm{mM} \mathrm{pH} 7.0, \mathrm{NaCl} 50 \mathrm{mM}, \mathrm{MgCl}_{2} 5$ $\mathrm{mM}$ e DTT $1 \mathrm{mM}$ a $25^{\circ} \mathrm{C}$. 

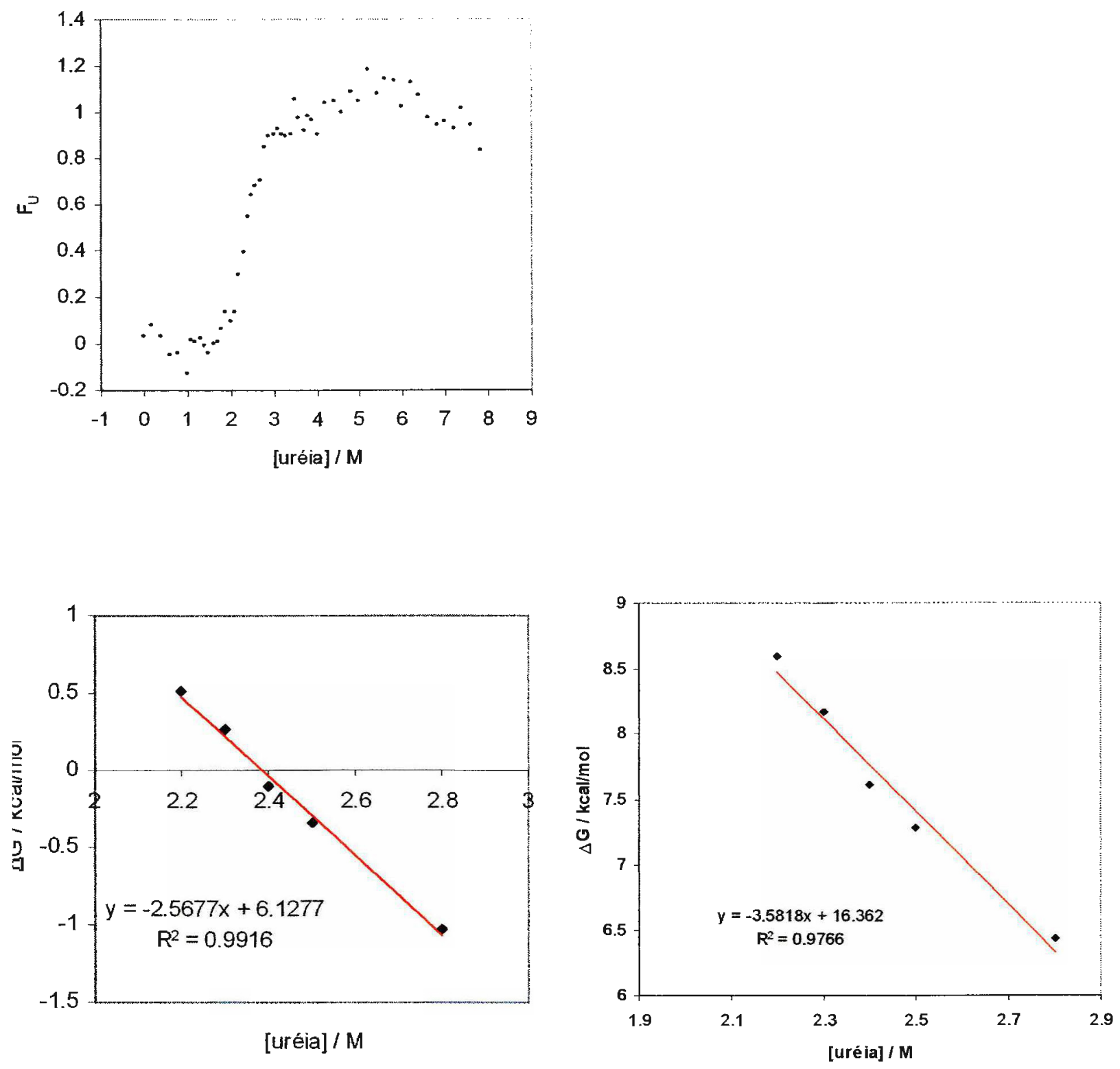

unimolecular

bimolecular

\begin{tabular}{|c|c|c|c|c|c|}
\hline [uréia] / M & $F_{U}$ & $\mathrm{~K}($ uni) & $\begin{array}{c}\Delta \mathrm{G}^{\circ} \text { (uni) } \\
\text { (cal/mol) }\end{array}$ & $\mathrm{K}(\mathrm{bi})$ & $\begin{array}{c}\Delta \mathrm{G}^{\circ}(\mathrm{bi}) \\
(\mathrm{cal} / \mathrm{mol})\end{array}$ \\
\hline 2.2 & 0.294 & 0.417 & 518 & $4.91 \mathrm{E}-07$ & 8601 \\
\hline 2.3 & 0.392 & 0.645 & 260 & $1.01 \mathrm{E}-06$ & 8173 \\
\hline 2.4 & 0.544 & 1.194 & -105 & $2.60 \mathrm{E}-06$ & 7614 \\
\hline 2.5 & 0.639 & 1.773 & -339 & $4.54 \mathrm{E}-06$ & 7285 \\
\hline 2.8 & 0.849 & 5.609 & -1021 & $5.66 \mathrm{E}-06$ & 7154 \\
\hline
\end{tabular}

Figura 49. Análise da curva de desnaturação por uréia para o mutante $50 \mathrm{H} 261 \mathrm{~W}$ e apresentação dos valores de $F_{\mathrm{u}}, \mathrm{K}$ (uni) e $\Delta \mathrm{G}^{\circ}$ (uni) para o processo unimolecular e $\mathrm{K}(\mathrm{bi})$ e $\Delta \mathrm{G}^{\circ}$ (bi) para o processo bimolecular. Condições: $1 \mu \mathrm{M}$ de proteína em MOPS $25 \mathrm{mM} \mathrm{pH} 7.0, \mathrm{NaCl} 50 \mathrm{mM}, \mathrm{MgCl}_{2} 5$ $\mathrm{mM}$ e DTT $1 \mathrm{mM}$ a $25^{\circ} \mathrm{C}$. 


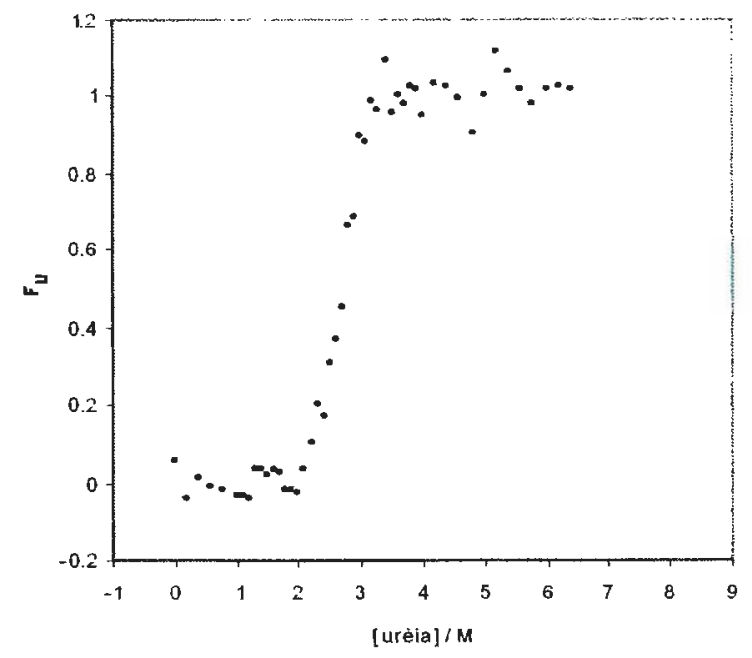

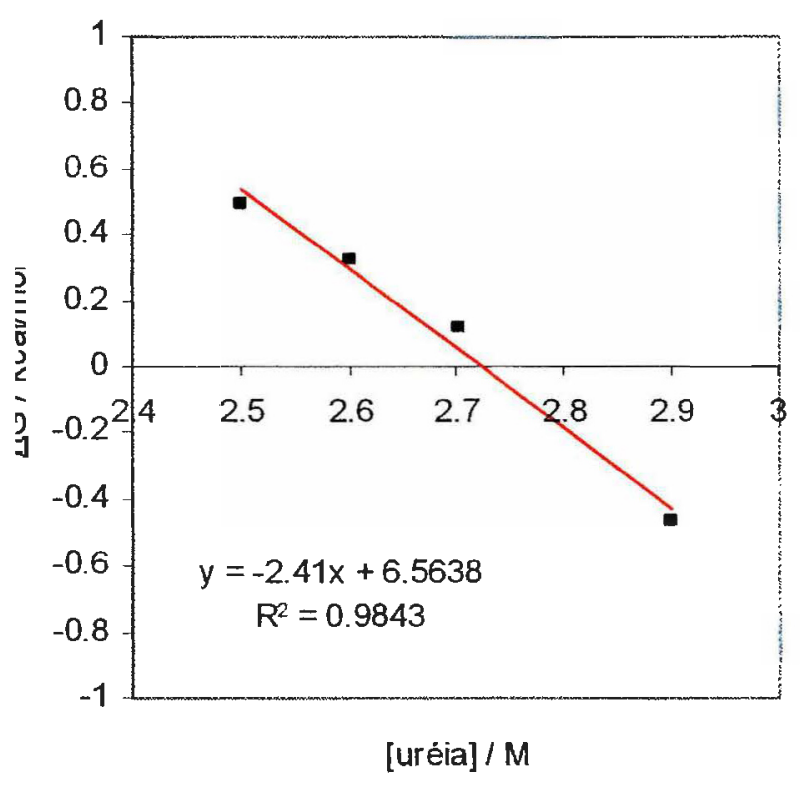

unimolecular

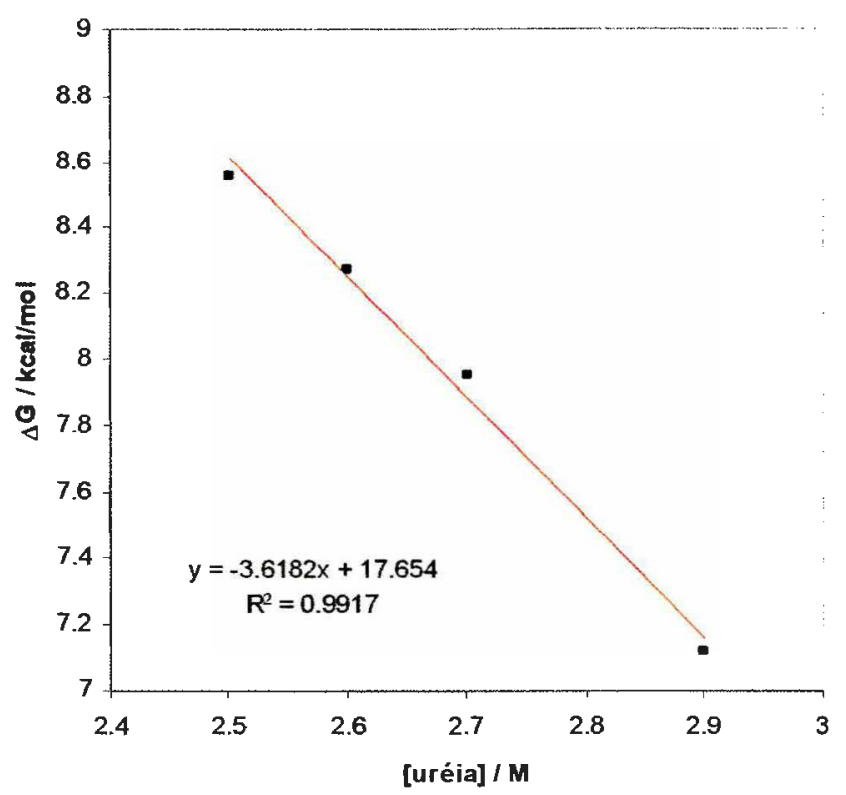

bimolecular

\begin{tabular}{|c|c|c|c|c|c|}
\hline [uréia] $/ \mathrm{M}$ & $\mathrm{F}_{\mathrm{U}}$ & $\mathrm{K}$ (uni) & $\begin{array}{c}\Delta \mathrm{G}^{\mathrm{o}} \text { (uni) } \\
\text { (cal/mol) }\end{array}$ & $\mathrm{K}(\mathrm{bi})$ & $\begin{array}{c}\Delta \mathrm{G}^{\circ}(\mathrm{bi}) \\
(\mathrm{call} / \mathrm{mol})\end{array}$ \\
\hline 2.5 & 0.304 & 0.436 & 491 & $5.3 \mathrm{E}-07$ & 8556 \\
\hline 2.6 & 0.368 & 0.583 & 319 & $8.59 \mathrm{E}-07$ & 8270 \\
\hline 2.7 & 0.450 & 0.817 & 120 & $1.47 \mathrm{E}-06$ & 7952 \\
\hline 2.9 & 0.686 & 2.183 & -462 & $5.99 \mathrm{E}-06$ & 7120 \\
\hline
\end{tabular}

Figura 50. Análise da curva de desnaturação por uréia para o mutante $50 H 263 W$ e apresentação dos valores de $F_{u}, K$ (uni) e $\Delta G^{\circ}$ (uni) para o processo unimolecular e $\mathrm{K}(\mathrm{bi})$ e $\Delta \mathrm{G}^{\circ}$ (bi) para o processo bimolecular. Condições: $1 \mu \mathrm{M}$ de proteína em MOPS $25 \mathrm{mM} \mathrm{pH} 7.0, \mathrm{NaCl} 50 \mathrm{mM}, \mathrm{MgCl}_{2} 5$ $\mathrm{mM}$ e DTT $1 \mathrm{mM}$ a $25^{\circ} \mathrm{C}$. 


\section{Ensaios de supressão de fluorescência}

\section{Supressão por iodeto}

Os gráficos obtidos para a análise por supressão de fluorescência por iodeto dos mutantes da tropomiosina 5OH90W, 5OH101W, 50H111W e $5 \mathrm{OH} 122 \mathrm{~W}$ podem ser observados nas figuras 51 a 54 .
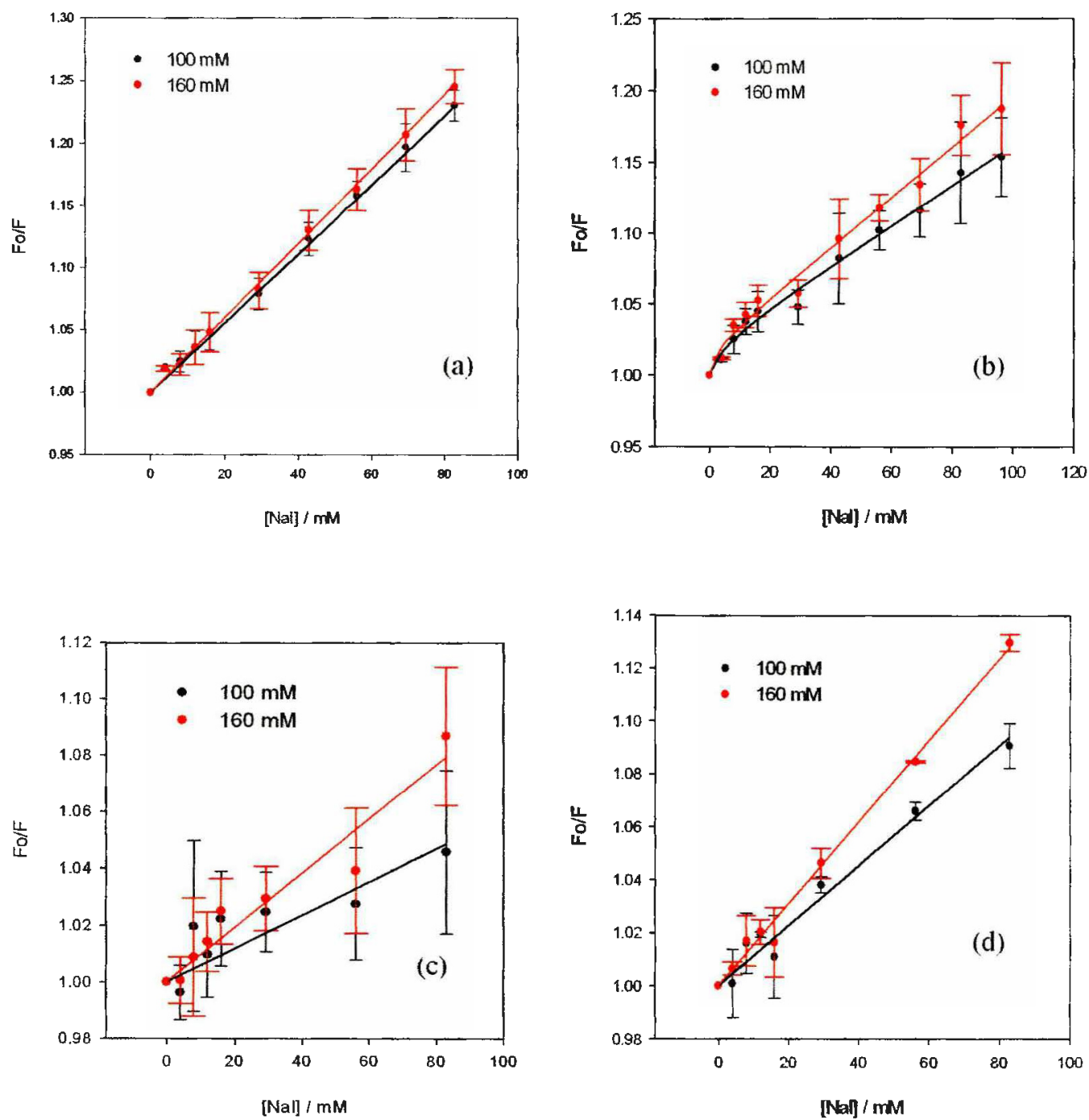

Figura 51. Comparação da supressão da fluorescência pelo iodeto nas forças iônicas constantes de 100 e $160 \mathrm{mM}$ (corrigidas com $\mathrm{NaCl}$ ) para o mutante 5OH9OW em MOPS $25 \mathrm{mM}$ pH 7.0, $\mathrm{MgCl}_{2} 5 \mathrm{mM}$ e DTT $1 \mathrm{mM}$ (25 ${ }^{\circ} \mathrm{C}$ ): (a) $50 \mathrm{H} 90 \mathrm{~W}$; (b) $50 \mathrm{H} 90 \mathrm{~W}+\mathrm{Ac}$; (c) $50 \mathrm{H} 90 \mathrm{~W}+\mathrm{Ac}+\mathrm{Tn}$; (c) $50 \mathrm{H} 90 \mathrm{~W}+$ $\mathrm{Ac}+\mathrm{Tn}+\mathrm{Ca}^{2+}$. Concentrações das proteinas: actina $7 \mu \mathrm{M}$, tropomiosina 1 $\mu \mathrm{M}$ e complexo troponina $1 \mu \mathrm{M}$. 

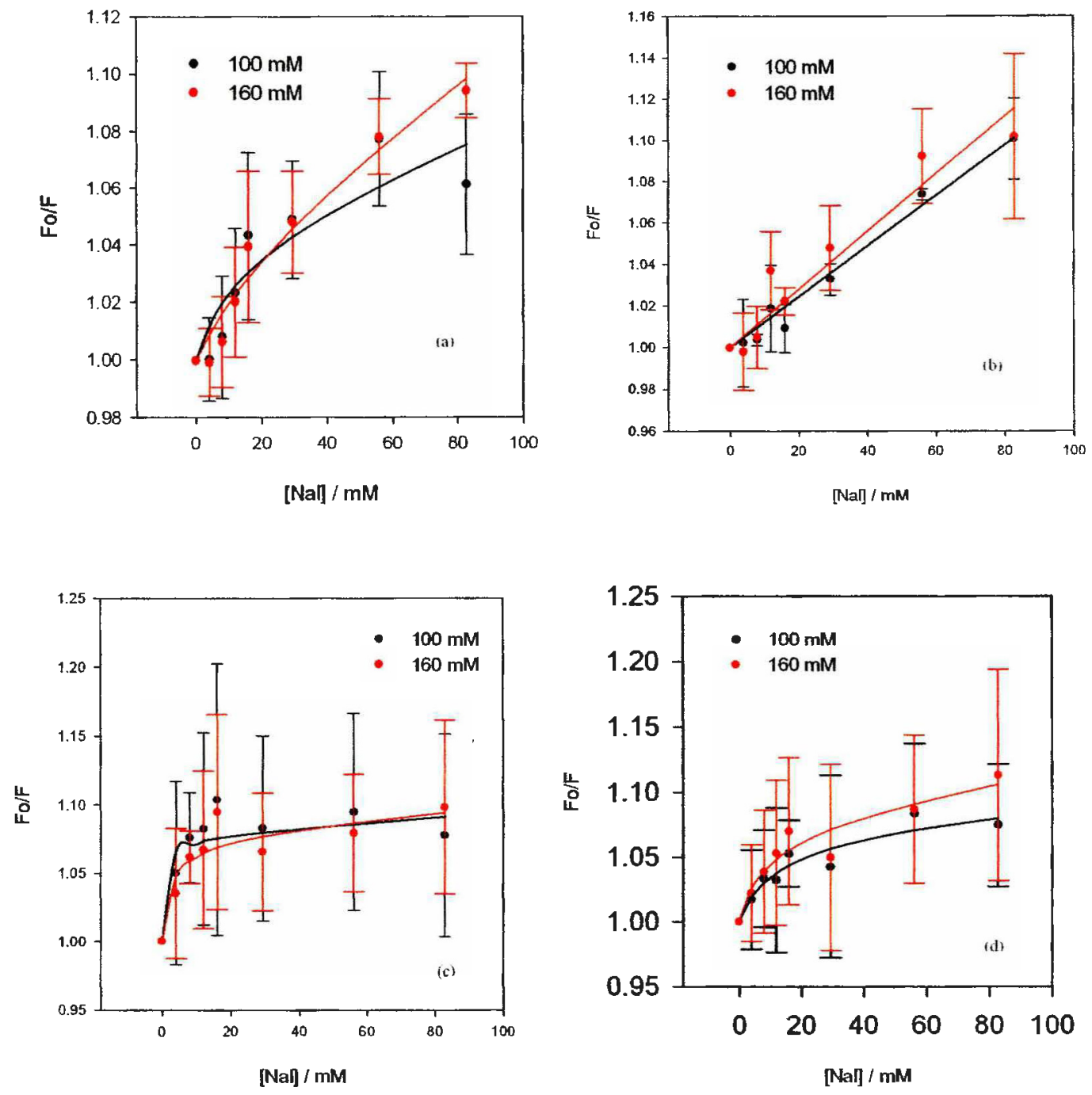

Figura 52. Comparação da supressão da fluorescência pelo iodeto nas forças iônicas constantes de 100 e $160 \mathrm{mM}$ (corrigidas com NaCl) para o mutante $5 \mathrm{OH} 101 \mathrm{~W}$ em MOPS $25 \mathrm{mM}$ pH 7.0, $\mathrm{MgCl}_{2} 5 \mathrm{mM}$ e DTT $1 \mathrm{mM}\left(25^{\circ} \mathrm{C}\right)$ : (a) $5 \mathrm{OH} 101 \mathrm{~W}$; (b) $5 \mathrm{OH} 101 \mathrm{~W}+\mathrm{Ac}$; (c) $5 \mathrm{OH} 101 \mathrm{~W}+\mathrm{Ac}+\mathrm{Tn}$; (c) $5 \mathrm{OH} 101 \mathrm{~W}+\mathrm{Ac}$ $+\mathrm{Tn}+\mathrm{Ca}^{2+}$. Concentrações das proteínas: actina $7 \mu \mathrm{M}$, tropomiosina $1 \mu \mathrm{Me}$ complexo troponina $1 \mu \mathrm{M}$. 

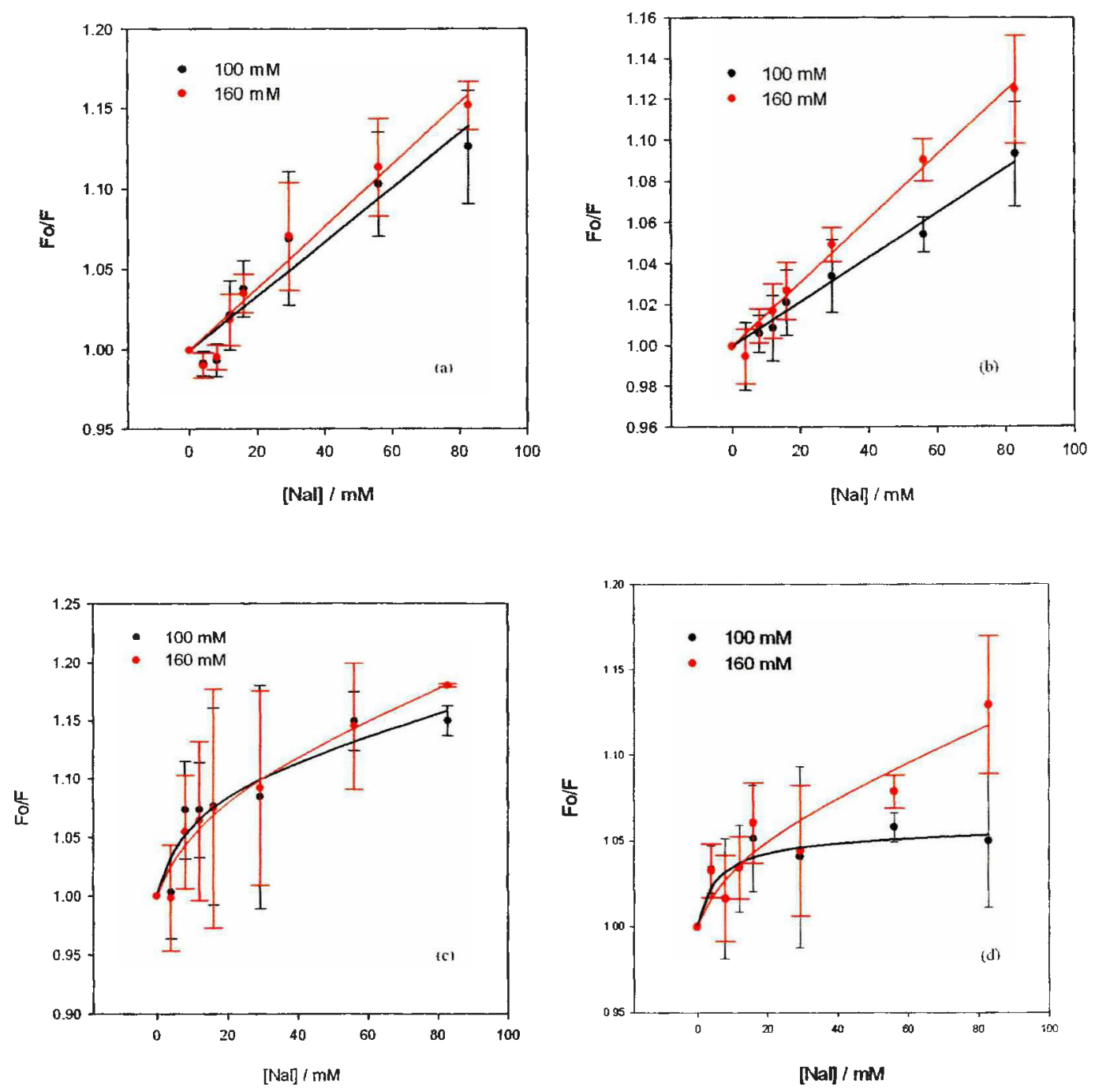

Figura 53. Comparação da supressão da fluorescência pelo iodeto nas forças iônicas constantes de 100 e $160 \mathrm{mM}$ (corrigidas com NaCl) para o mutante $50 \mathrm{OH} 111 \mathrm{~W}$ em MOPS $25 \mathrm{mM}$ pH $7.0, \mathrm{MgCl}_{2} 5 \mathrm{mM}$ e DTT $1 \mathrm{mM}\left(25^{\circ} \mathrm{C}\right)$ : (a) $5 \mathrm{OH} 111 \mathrm{~W}$; (b) $5 \mathrm{OH} 111 \mathrm{~W}+\mathrm{Ac}$; (c) $5 \mathrm{OH} 111 \mathrm{~W}+\mathrm{Ac}+\mathrm{Tn}$; (c) $5 \mathrm{OH} 111 \mathrm{~W}+\mathrm{Ac}$ $+\mathrm{Tn}+\mathrm{Ca}^{2+}$. Concentrações das proteinas: actina $7 \mu \mathrm{M}$, tropomiosina $1 \mu \mathrm{M}$ e complexo troponina $1 \mu \mathrm{M}$. 

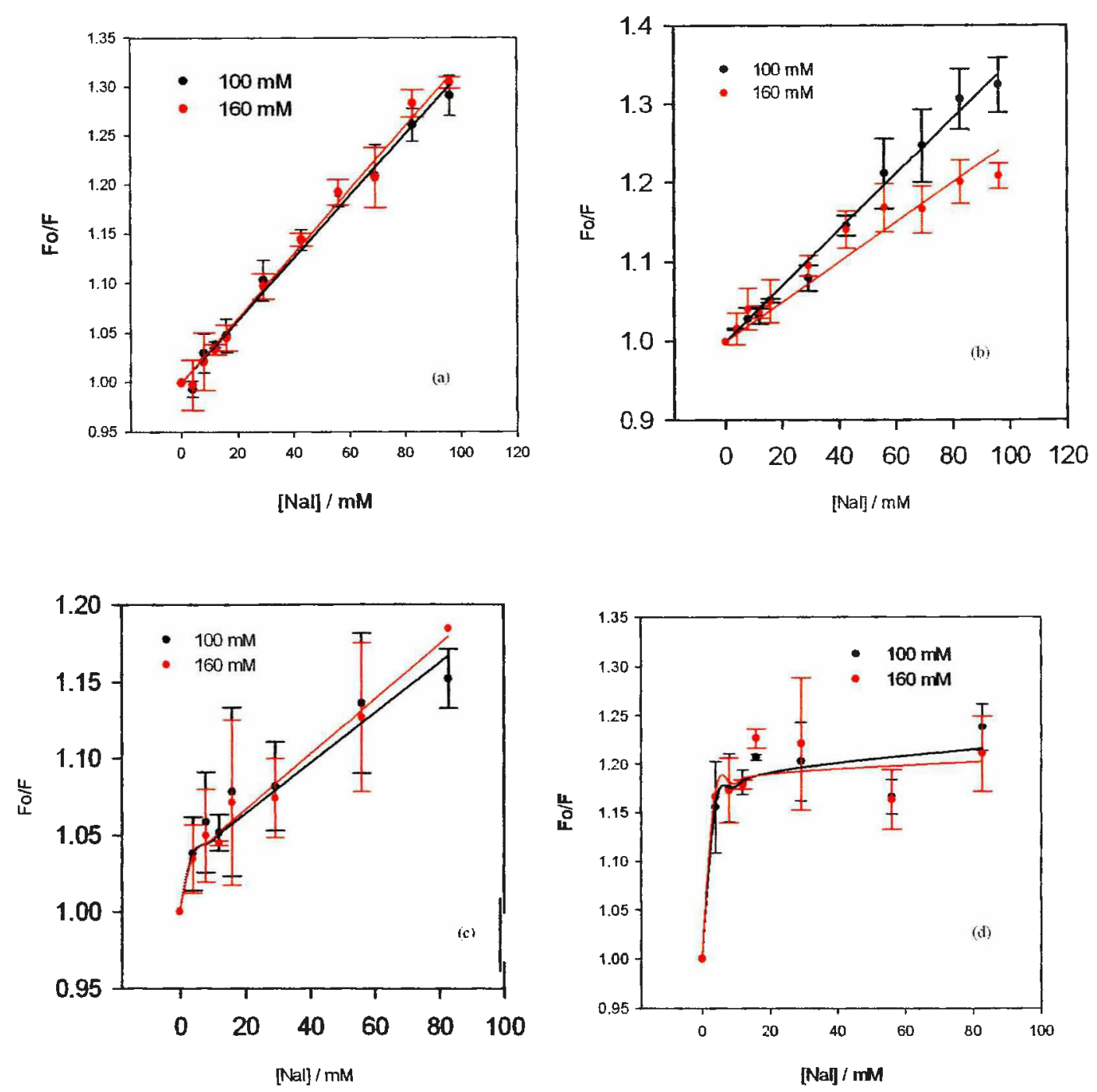

Figura 54. Comparação da supressão da fluorescência pelo iodeto nas forças iônicas constantes de 100 e $160 \mathrm{mM}$ (corrigidas com NaCl) para o mutante $5 \mathrm{OH} 122 \mathrm{~W}$ em MOPS $25 \mathrm{mM}$ pH 7.0, $\mathrm{MgCl}_{2} 5 \mathrm{mM}$ e DTT $1 \mathrm{mM}\left(25^{\circ} \mathrm{C}\right.$ ): (a) $5 \mathrm{OH} 122 \mathrm{~W}$; (b) $5 \mathrm{OH} 122 \mathrm{~W}+\mathrm{Ac}$; (c) $5 \mathrm{OH} 122 \mathrm{~W}+\mathrm{Ac}+\mathrm{Tn}$; (c) $5 \mathrm{OH} 122 \mathrm{~W}+\mathrm{Ac}$ $+\mathrm{Tn}+\mathrm{Ca}^{2+}$. Concentrações das proteínas: actina $7 \mu \mathrm{M}$, tropomiosina $1 \mu \mathrm{M} \mathrm{e}$ complexo troponina $1 \mu \mathrm{M}$.

Para algumas situações, como explicado, os valores de $\mathrm{K}_{\mathrm{sv}}$ não puderam ser obtidos devido a acentuada curvatura para baixo nos gráficos de Stern-Volmer. Esta curvatura aumenta o número de parâmetros a serem ajustados o que causa um grande aumento no erro para o valor destes parâmetros (de fato, o erro obtido é maior que o próprio valor do parâmetro). Os valores de $\mathrm{K}_{\text {sv }}$ para as curvas que não apresentaram curvatura para baixo e que, portanto, podem ser analisadas pela equação de Stern-Volmer simplificada $\left(F_{0} / F=1+K_{s v}[Q]\right)$, ou seja, assumindo apenas um 
microambiente e $V=0$, foram calculados e estão mostrados na tabela 5 . Note que a magnitude dos valores obtidos é bem menor do que a obtida para as constantes de Stern-Volmer pela supressão por acrilamida (seção seguinte) devido à supressão bem menor na intensidade de fluorescência obtida com o supressor iodeto quando comparada àquela obtida pelo supressor acrilamida.

Tabela 5. Calculo de $\mathrm{K}_{\mathrm{s}}$ para as situações que não apresentaram curvatura para baixo no gráfico da Stern-Volmer. Os erros estão apresentados entre parêntesis.

\begin{tabular}{|c|c|c|c|c|c|}
\hline Mutante & Força iônica & $\begin{array}{c}\text { Sozinha } \\
\left(10^{-3} \mathrm{M}^{-1}\right)\end{array}$ & $\begin{array}{c}+\mathrm{Ac} \\
\left(10^{-3} \mathrm{M}^{-1}\right)\end{array}$ & $\begin{array}{c}+\mathrm{Ac}+\mathrm{Tn} \\
\left(10^{-3} \mathrm{M}^{-1}\right)\end{array}$ & $\begin{array}{c}+\mathrm{Ac}+\mathrm{Tn} \\
+\mathrm{Ca}^{2+} \\
\left(10^{-3} \mathrm{M}^{-1}\right)\end{array}$ \\
\hline \multirow{2}{*}{$5 \mathrm{OH} 90 \mathrm{~W}$} & $100 \mathrm{mM}$ & $2.82(0.03)$ & $1.72(0.06)$ & $0.59(0.08)$ & $1.13(0.05)$ \\
\cline { 2 - 6 } & $160 \mathrm{mM}$ & $2.96(0.03)$ & $2.06(0.07)$ & $0.96(0.07)$ & $1.54(0.04)$ \\
\hline \multirow{2}{*}{$5 \mathrm{OH} 101 \mathrm{~W}$} & $100 \mathrm{mM}$ & - & $1.22(0.05)$ & - & - \\
\cline { 2 - 6 } & $160 \mathrm{mM}$ & - & $1.40(0.11)$ & - & - \\
\hline \multirow{2}{*}{$5 \mathrm{OH} 111 \mathrm{~W}$} & $100 \mathrm{mM}$ & $1.68(0.13)$ & $1.08(0.05)$ & - & - \\
\cline { 2 - 6 } & $160 \mathrm{mM}$ & $1.92(0.11)$ & $1.55(0.05)$ & - & - \\
\hline $50 \mathrm{H} 122 \mathrm{~W}$ & $100 \mathrm{mM}$ & $3.14(0.06)$ & $3.51(0.07)$ & - & - \\
& $160 \mathrm{mM}$ & $3.24(0.06)$ & $2.50(0.12)$ & - & - \\
\hline
\end{tabular}

Um resumo dos resultados dispostos na tabela 5 em conjunto com a análise das curvas indicadas nas figuras 51 a 54 pode ser visualizado na tabela 6 . O raciocínio para a análise qualitativa dos gráficos apresentados nas figuras 51 a 54 baseia-se na análise da variação do ambiente eletrostático observado pelo supressor a forças iônicas diferentes (Ando e Asai, 1980; Ando et al., 1980). Devido à sua carga negativa, o iodeto apresenta uma maior tendência a suprimir a fluorescência de sondas que estejam localizadas em ambientes mais positivos em detrimento àquelas que estejam localizadas em ambientes mais negativos. Podemos chegar à conclusão do tipo de microambiente eletrostático que a sonda experimenta utilizando o seguinte artifício: se aumentarmos a força iônica do meio teremos um efeito de mascaramento das cargas na solução. Desta forma, se nosso supressor estivesse suprimindo uma sonda localizada num ambiente positivo, 
um aumento na força iônica do meio diminuiria a atração entre a sonda e o supressor diminuindo a eficiência da supressão. Isto se traduziria numa diminuição na inclinação da curva de Stern-Volmer (menor $\mathrm{K}_{\mathrm{sV}}$ ) com relação à situação de força iônica mais baixa. Por outro lado, se o ambiente que estivesse sendo suprimido fosse negativo, um aumento na força iônica do meio reduziria a repulsão entre as cargas do supressor e do microambiente da sonda fazendo com que a eficiência da supressão aumentasse. Este efeito se traduz num aumento na inclinação da curva de Stern-Volmer com relação à situação de força iônica mais baixa. Se observarmos que o valor de $\mathrm{K}_{\mathrm{sv}}$ é insensivel à força iônica, podemos concluir que a sonda encontra-se num microambiente neutro. Desta forma, a inspeção dos gráficos apresentados nas figuras 51 a 54 e análise dos resultados dispostos na tabela 5 sugere os seguintes microambientes eletrostáticos para a região próxima à sonda fluorescente (tabela 6):

Tabela 6. Ambientes eletrostáticos na vizinhança das sondas fluorescentes inferidos pelos ensaios de supressão de fluorescência pelo supressor extrínsico negativamente carregado iodeto.

\begin{tabular}{|c|c|c|c|c|}
\hline & sozinha & $+\mathrm{Ac}$ & $+\mathrm{Ac}+\mathrm{Tn}$ & $+\mathrm{Ac}+\mathrm{Tn}+\mathrm{Ca}^{2+}$ \\
\hline & & & & \\
\hline $5 \mathrm{OH} 90 \mathrm{~W}$ & neutro & negativo & negativo & negativo \\
\hline $5 \mathrm{OH} 101 \mathrm{~W}$ & $?$ & neutro & neutro & neutro \\
\hline $5 \mathrm{OH} 111 \mathrm{~W}$ & neutro & negativo & neutro & negativo \\
\hline $5 \mathrm{OH} 122 \mathrm{~W}$ & neutro & positivo & neutro & neutro \\
\hline
\end{tabular}

É interessante notar que a sonda muda seu ambiente eletrostático em resposta a cálcio em apenas uma das quatro posições testadas (posição 111, neste caso mudando de um ambiente "neutro" para um ambiente mais negativo). 
Como a intensidade de fluorescência é diretamente proporcional ao tempo de vida e como não temos medidas de tempo de vida precisamos analisar a variação na intensidade de fluorescência devida à adição das outras proteínas (e de íons cálcio) às nossas tropomiosinas fluorescentes.
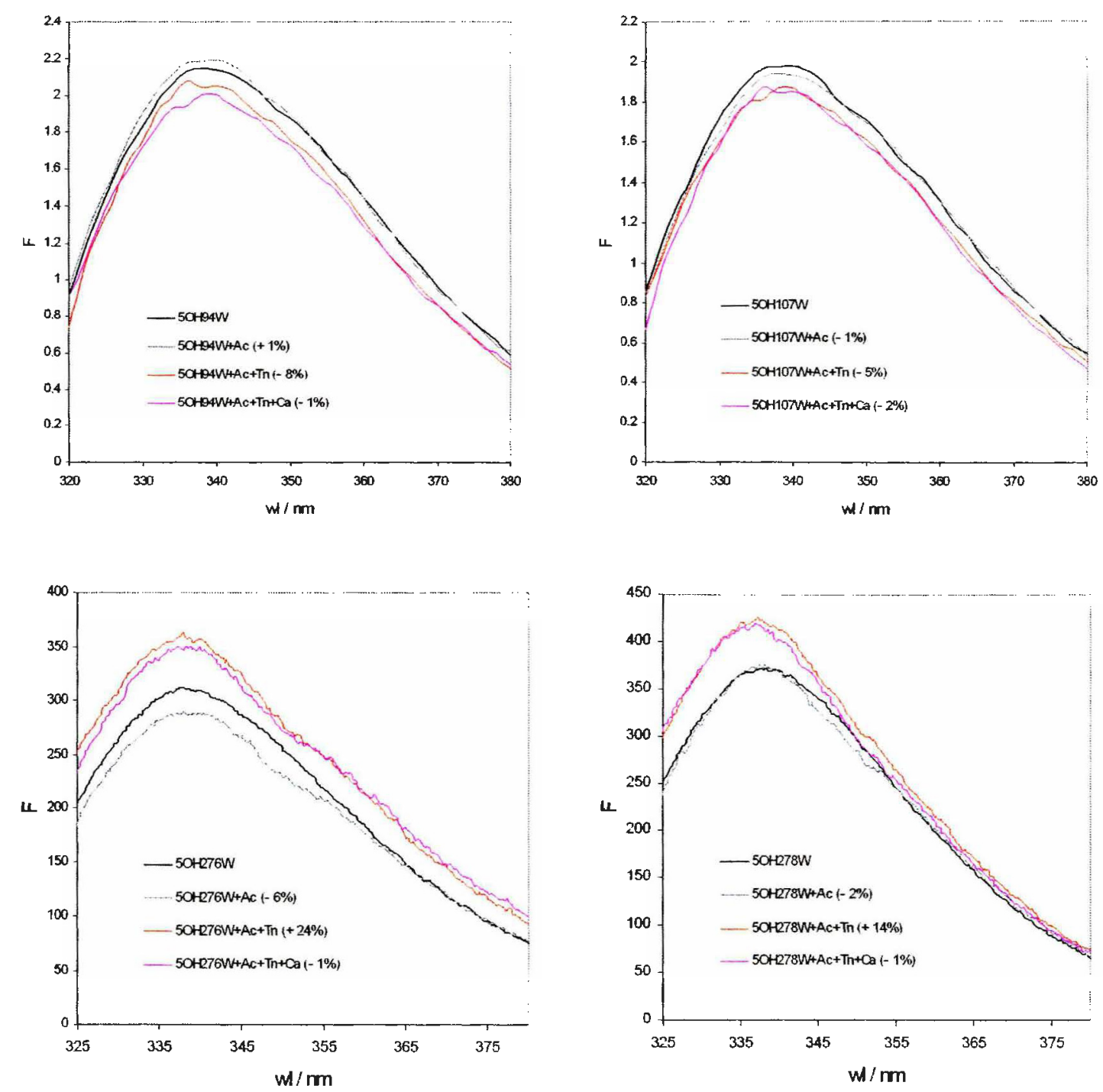

Figura 55. Variação na intensidade de fluorescência devido à adição de actina e de actina e troponina na presença e ausência de íns cálcio para os mutantes de tropomiosina 50H94W, 50H107W, 5OH276W e 5OH278W em MOPS $25 \mathrm{mM} \mathrm{pH} \mathrm{7.0,} \mathrm{NaCl} 50 \mathrm{mM}, \mathrm{MgCl}_{2} 5 \mathrm{mM}$ e DTT $1 \mathrm{mM} 25^{\circ} \mathrm{C}$. As variações porcentuais na intensidade estão indicadas nas figuras. Concentrações das proteínas: actina $7 \mu \mathrm{M}$, tropomiosina $1 \mu \mathrm{M}$ e complexo troponina $1 \mu \mathrm{M}$. 
A figura 55 indica as variações na intensidade de fluorescência das sondas 5-hidroxitriptofano inseridas nas posições 94, 107, 276 e 278 da molécula de tropomiosina em função da adição seqüencial de actina, troponina e íons cálcio. Como pode ser observado na figura, para os mutantes $5 \mathrm{OH} 94 \mathrm{~W}$ e $5 \mathrm{OH} 107 \mathrm{~W}$, estas variações foram em todos os casos menores ou iguais a $8 \%$. Para os mutantes $5 \mathrm{OH} 276 \mathrm{~W}$ e $5 \mathrm{OH} 278 \mathrm{~W}$, entretanto, mudanças significantes na intensidade de fluorescência foram observadas para a adição de troponina: um aumento de $\sim 24 \%$ na intensidade de fluorescência para a adição de troponina ao mutante $5 \mathrm{OH} 276 \mathrm{~W}$ na presença de actina e um aumento de $\sim 14 \%$ para a adição de troponina ao mutante $5 \mathrm{OH} 278 \mathrm{~W}$ na presença de actina. Esta sensibilidade da intensidade de fluorescência à ligação de troponina está relacionada ao fato de que estes dois mutantes C-terminais possuem suas sondas fluorescentes numa região de interação direta com a troponina (embora, como pode ser visto abaixo para o mutante $5 \mathrm{OH} 122 \mathrm{~W}$ que é sensivel à ligação de íons cálcio à troponina (Farah e Reinach, 1999), mudanças na intensidade de fluorescência podem ser sentidas em posições bem afastadas do sítio direto de interação entre proteínas através da transmissão do sinal por mudanças conformacionais mais abrangentes).

A sensibilidade dos outros mutantes da tropomiosina à adição de actina e troponina $+/$ - ions cálcio foi determinada por outros membros do laboratório (Farah e Reinach, 1999; Sousa e Farah, 2002; Sousa, 2002, dissertação de tese de doutorado). Como pode ser apreciado na tabela 7, a adição de actina e actina e troponina $\left(+/-\mathrm{Ca}^{2+}\right)$ não causa qualquer efeito significante (maior que $10 \%$ ) sobre a intensidade de fluorescência dos mutantes 50H9OW (Farah e Reinach, 1999), 50H94W (figura 55), 50H101W (Farah e Reinach, 1999), 50H107W (figura 55) e 50H111W (Farah e Reinach, 1999). Como mostrado por Farah e Reinach (1999), o mutante $5 \mathrm{OH} 122 \mathrm{~W}$ é sensível à ligação de actina (aumento de $40 \%$ na intensidade de fluorescência) e à ligação de íons cálcio à troponina (aumento de $15 \%$ na intensidade de fluorescência) (tabela 7). Mostrou-se que o mutante $5 \mathrm{OH} 261 \mathrm{~W}$ tem um decréscimo acentuado na sua intensidade de fluorescência (25\%) quando actina é adicionada ao sistema mas não sofre 
nenhuma variação adicional com a adição de troponina ou de íons cálcio (Sousa, A. D., dissertação de doutorado) (ver tabela 7 para um resumo destes dados).

Estudos de supressão de fluorescência por acrilamida (que foi variada entre 0 e $500 \mathrm{mM}$ ) foram realizados com nove mutantes de tropomiosina (5OH9OW, 5OH94W, 5OH101W, 5OH107W, 5OH111W, 5OH122W, $50 \mathrm{H} 261 \mathrm{~W}, 5 \mathrm{OH} 276 \mathrm{~W}$ e $5 \mathrm{OH} 278 \mathrm{~W}$ ) em quatro condições diferentes: tropomiosina $(\mathrm{Tm})$ sozinha, $\mathrm{Tm}+$ actina, $\mathrm{Tm}+$ actina + troponina $-\mathrm{Ca}^{2+}$ e $\mathrm{Tm}$ + actina + troponina $+\mathrm{Ca}^{2+}$. Os valores das constantes de supressão dinâmica (KSV) e estática (V) (Lehrer \& Leavis, 1978; Eftink, 1991a; Eftink, 1991b; Eftink \& Ghiron, 1981) obtidas para todos os nove mutantes em cada condição estão apresentados na tabela 7 .

A figura 56 mostra os gráficos obtidos para a supressão de fluorescência por acrilamida para todos os mutantes analisados. 
Tabela 7. Constantes de supressão dinâmica (Ksv) e estática (V) para as sondas 5-hidroxitriptofano em posições específicas da estrutura da tropomiosina em diversas condições. O efeito da ligação à actina e à actina $e$ troponina $\left(+/-\mathrm{Ca}^{2+}\right)$ na intensidade de fluorescência do mutante pode ser observado na tabela (só foram consideradas significantes variações maiores que $10 \%)$.

\begin{tabular}{|c|c|c|c|c|c|c|c|}
\hline Condiẹão & $\mathrm{K}_{\mathrm{sV}} / \mathrm{M}^{-1}$ & $V / M^{-1}$ & $\begin{array}{l}\text { Efeito da } \\
\text { ligação }\end{array}$ & Condição & $\mathrm{K}_{\mathrm{SV}} / \mathrm{M}^{-1}$ & $\mathrm{~V} / \mathrm{M}^{-1}$ & $\begin{array}{c}\text { Efeito } \\
\text { da } \\
\text { ligação }\end{array}$ \\
\hline $90(\mathrm{~d} / \mathrm{f})^{*}$ & $10.1(0.4) \#$ & $1.21(0.09)$ & - & $122(\overline{\beta / C})$ & $6.4(0.1)$ & $1.41(0.03)$ & - \\
\hline +actina & $8.3(0.1)$ & $1.76(0.04)$ & - & +actina & $5.0(0.2)$ & $0.81(0.07)$ & $+40 \%$ \\
\hline$+\mathrm{Th}$ & $8.0(0.1)$ & - & - & $+\mathrm{Tn}$ & $5.6(0.3)$ & $0.60(0.12)$ & - \\
\hline$+\mathrm{Ca}^{2+}$ & $8.7(0.3)$ & $1.77(0.10)$ & - & $+\mathrm{Ca}^{2+}$ & $4.8(0.4)$ & $0.43(0.23)$ & $+15 \%$ \\
\hline $94(a / c)$ & $7.0(0.2)$ & $0.67(0.05)$ & - & $261(a / b)$ & $8.7(0.2)$ & $0.46(0.03)$ & - \\
\hline tactina & $5.6(0.1)$ & $0.43(0.04)$ & - & +actina & $6.3(0.1)$ & $0.53(0.03)$ & $-25 \%$ \\
\hline$+T_{n}$ & $4.3(0.2)$ & $1.63(0.07)$ & - & $+\operatorname{Tn}$ & $3.5(0.3)$ & $1.67(0.11)$ & - \\
\hline$+\mathrm{Ca}^{2+}$ & $5.3(0.1)$ & $0.89(0.03)$ & - & $+\mathrm{Ca}^{2+}$ & $6.1(0.1)$ & $0.15(0.04)$ & - \\
\hline & & & & & & & \\
\hline $101(a / c)$ & $4.6(0.1)$ & $0.76(0.01)$ & - & $276(\beta / c)$ & $6.3(0.1)$ & $1.04(0.04)$ & - \\
\hline +actina & $3.1(0.1)$ & $1.07(0.03)$ & - & +actina & $3.8(0.1)$ & $0.67(0.05)$ & - \\
\hline$+T n$ & $3 . \overline{1(0.1)}$ & $0.56(0.05)$ & - & $+\operatorname{Tn}$ & $4.3(0.2)$ & $0.17(0.04)$ & $+24 \%$ \\
\hline$+\mathrm{Ca}^{2+}$ & $4.9(0.1)$ & $0.83(0.04)$ & - & $+\mathrm{Ca}^{2+}$ & $4.1(0.6)$ & $0.30(0.07)$ & - \\
\hline $107(\beta / b)$ & $5.8(0.1)$ & $1.00(0.03)$ & - & $278(\beta / e)$ & $5.6(0.1)$ & $1.14(0.03)$ & - \\
\hline +actina & $3.5(0.1)$ & $0.87(0.04)$ & - & +actina & $3.2(0.2)$ & $1.03(0.07)$ & - \\
\hline$+T n$ & $5.4(0.2)$ & $0.60(0.06)$ & - & $+\operatorname{Tn}$ & $3.4(0.5)$ & $0.19(0.15)$ & $+14 \%$ \\
\hline$+\mathrm{Ca}^{2+}$ & $5.2(0.1)$ & $0.47(0.03)$ & - & $+\mathrm{Ca}^{2+}$ & $2.6(0.3)$ & $0.29(0.20)$ & - \\
\hline $111(\beta / f)$ & $5.3(0.2)$ & $0.65(0.05)$ & - & & & & \\
\hline tactina & $3.7(0.1)$ & $0.82(0.03)$ & - & & & & \\
\hline$+\mathrm{Tn}$ & $5.4(0.1)$ & $0.92(0.04)$ & - & & & & \\
\hline$+\mathrm{Ca}^{2+}$ & $4.9(0.4)$ & $0.98(0.14)$ & - & & & & \\
\hline & & & & & & & \\
\hline
\end{tabular}

*Posição da sonda 5-hidroxitriptofano na sequência primária da tropomiosina. Localização dentro de uma banda $\alpha$ ou $\beta$ e posição dentro da repetição heptapeptídica (abcdefg) estão indicadas entre parêntesis: (banda $\alpha$ ou $\beta /$ posição na repetição heptapeptídica).

\#Valores (+/- erro) obtidos para as constantes de supressão $K_{S V}$ e $V$ para cada um dos mutantes sozinho, na presença de actina (+actina), na presença de actina e troponina $(+T n)$ e na presença de actina, troponina e ions cálcio $\left(+\mathrm{Ca}^{2+}\right)$. 

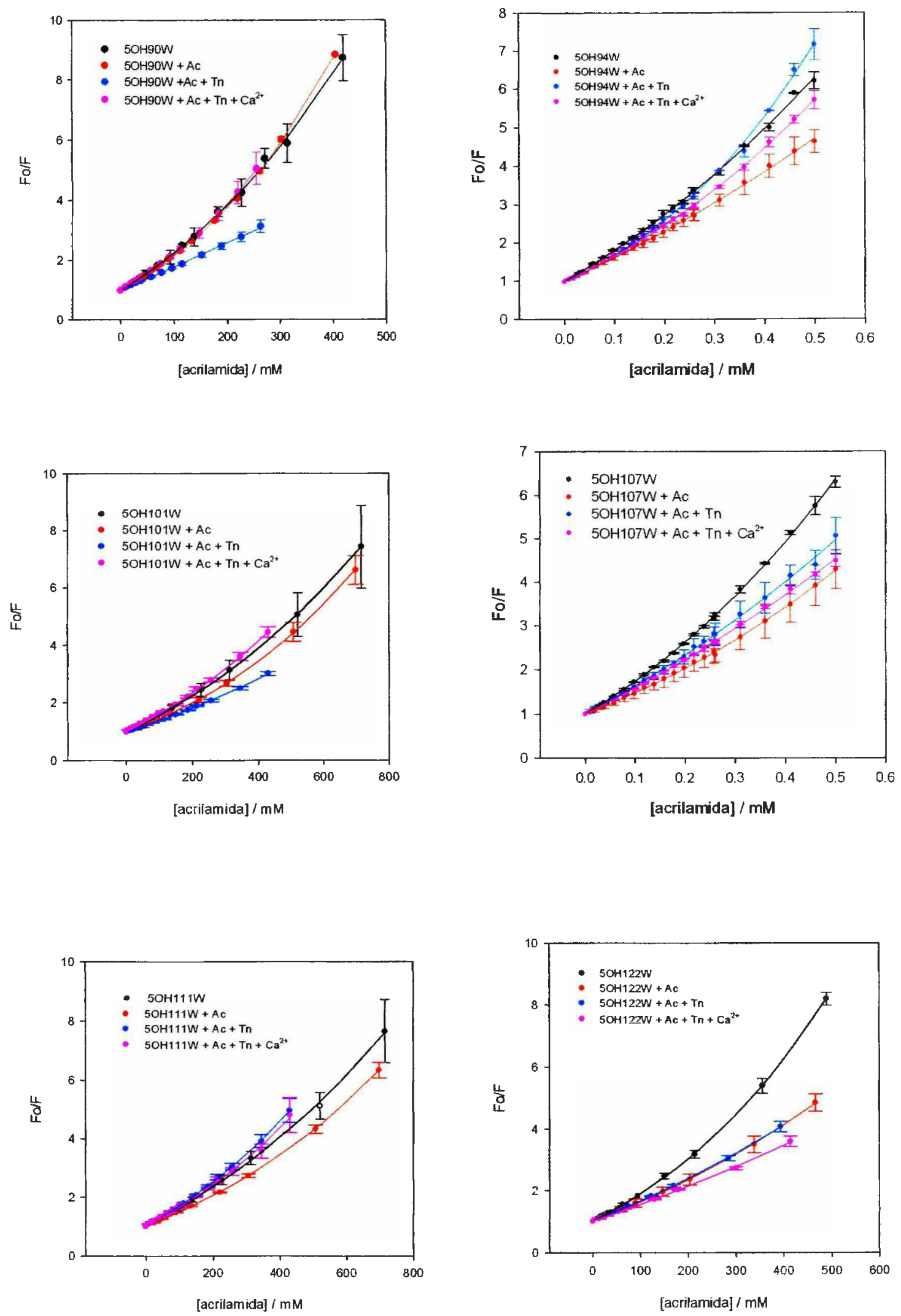

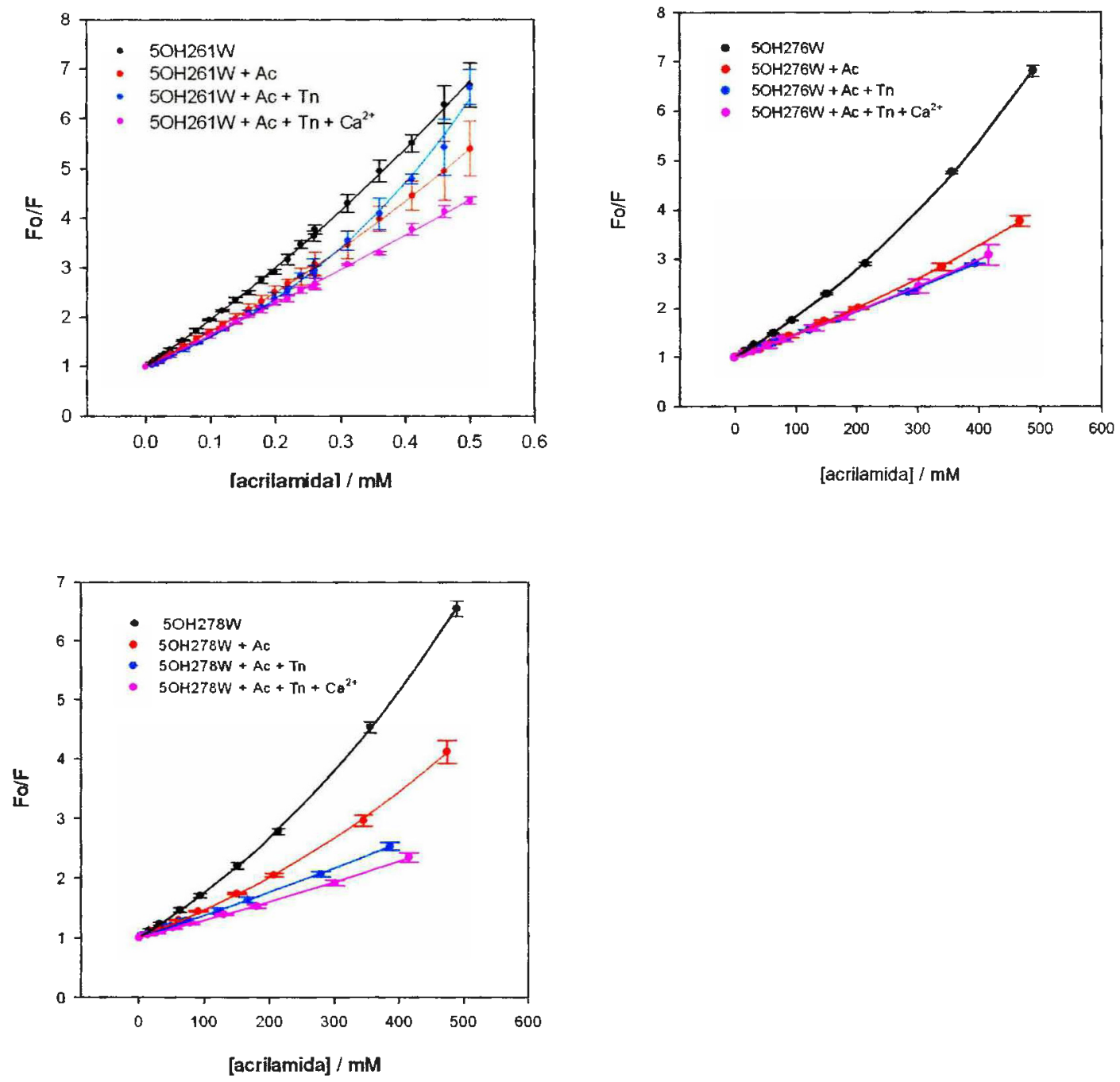

Figura 56. Supressão da fluorescência através do supressor extrinsico neutro acrilamida para os mutantes de tropomiosina 50H90W, 50H94W, $5 \mathrm{OH} 101 \mathrm{~W}, 5 \mathrm{OH} 107 \mathrm{~W}, 5 \mathrm{OH} 111 \mathrm{~W}$ e $5 \mathrm{OH} 122 \mathrm{~W}$ (página anterior) e 5OH261W, $5 \mathrm{OH} 276 \mathrm{~W}$ e $5 \mathrm{OH} 278 \mathrm{~W}$ (nesta página) em MOPS $25 \mathrm{mM} \mathrm{pH} \mathrm{7.0,} \mathrm{NaCl} 50$ $\mathrm{mM}, \mathrm{MgCl}_{2} 5 \mathrm{mM}$ e DTT $1 \mathrm{mM}$ a $25^{\circ} \mathrm{C}$. Concentrações das proteínas: actina $7 \mu \mathrm{M}$, tropomiosina $1 \mu \mathrm{M}$ e complexo troponina $2 \mu \mathrm{M}$.

As variações nas intensidades de fluorescência devido à adição de actina, troponina e íons cálcio, como indicadas na tabela 7, permitem a avaliação das variações obtidas nos valores de $\mathrm{K}_{\text {sv }}$ para cada mutante mesmo na ausência de medições dos tempos de vida. Como será analisado 
em detalhes na seção DISCUSSÃO, da tabela 7 podemos ver que um padrão geral pode ser inferido para o grau de exposição de cada sonda fluorescente com relação à presença de íons cálcio no sistema. Para todas as sondas localizadas dentro de bandas a da tropomiosina $(50 \mathrm{H} 90 \mathrm{~W}, 5 \mathrm{OH} 94 \mathrm{~W}$, $5 \mathrm{OH} 101 \mathrm{~W}$ e $5 \mathrm{OH} 261 \mathrm{~W}$ ) dá-se um aumento na constante de Stern-Volmer com a adição de íons cálcio, indicando que, conforme estes ions são adicionados ao sistema, as sondas estão sendo afastadas da actina. Por outro lado, todas as sondas localizadas dentro de bandas $\beta(50 \mathrm{H} 107 \mathrm{~W}$, $5 \mathrm{OH} 111 \mathrm{~W}, 5 \mathrm{OH} 122 \mathrm{~W}, 5 \mathrm{OH} 276 \mathrm{~W}$ e $5 \mathrm{OH} 278 \mathrm{~W}$ ), dá-se o inverso: a adição de íons cálcio causa uma diminuição na constante de Stern-Volmer indicando que a sonda nestas posições está se tornando menos exposta, indicando uma aproximação ao filamento de actina. Uma discussão extensa deste resultado e uma análise de sua relevância para a regulação da contração muscular pode ser encontrado na DISCUSSÃO. 


\section{DISCUSSÃO}

\section{Ensaios de co-sedimentação}

A introdução das sondas fluorescentes 5-hidroxitriptofano nas diferentes posições da tropomiosina parecem não estar afetando a ligação da molécula ao filamento de actina. Todos os mutantes de tropomiosina testados ligaram-se à F-actina de forma comparável (em termos qualitativos) à ASTm (figura 28). Todas as tropomiosinas também ligaram-se à actina na presença do complexo troponina tanto na ausência quanto na presença de íons cálcio. Como os ensaios de supressão de fluorescência pelo quencher extrínsico acrilamida foram realizados na presença de concentrações de até $0.5 \mathrm{M}$ de acrilamida, os experimentos de co-sedimentação também foram realizados sob estas condições. Apenas os mutantes com a sonda 5-hidroxitriptofano localizada nas posições 90 e 185 tiveram sua ligação à F-actina significantemente reduzida na presença de $0.5 \mathrm{M}$ acrilamida. Entretanto, a ligação do mutante $50 \mathrm{H} 90 \mathrm{~W}$ é reestabelecida quando adicionamos troponina $+/-\mathrm{Ca}^{2+}$ mesmo nestas condições de alta concentração de acrilamida (figura 29).

\section{Regulação da $\mathrm{Mg}^{2+}$-ATPase da miosina $\mathbf{S 1}$ por filamentos finos reconstituidos contendo tropomiosinas mutantes}

As curvas representadas na figura 30 indicam que a maior parte dos mutantes utilizados está regulando a atividade $\mathrm{Mg}^{2+}$-ATPásica da maneira esperada: a atividade ATPásica é reduzida quando os mutantes de tropomiosinas são adicionados, esta atividade é reduzida ainda mais (ou pelo menos mantida) quando o complexo troponina é adicionado e esta atividade é novamente aumentada quando íons cálcio são adicionados ao sistema. Esta concordância para quase todos os mutantes $(50 \mathrm{H} 94 \mathrm{~W}, 5 \mathrm{OH} 101 \mathrm{~W}$, $50 \mathrm{H} 107 \mathrm{~W}, 5 \mathrm{OH} 111 \mathrm{~W}, 5 \mathrm{OH} 261 \mathrm{~W}, 5 \mathrm{OH} 263 \mathrm{~W}, 5 \mathrm{OH} 269 \mathrm{~W}$ e $50 \mathrm{H} 278 \mathrm{~W}$ ) somada aos resultados obtidos com os ensaios de co-sedimentação apresentados acima indica que as mutações realizadas na tropomiosina para 
a introdução das sondas fluorescentes não estão causando uma modificação inabilitante para a proteína. A presença de altas concentrações de acrilamida (500 mM) só foi testada para a ASTm. Neste caso, a presença desta concentração de acrilamida mantêm o perfil esperado para a regulação da atividade $\mathrm{Mg}^{2+}$-ATPásica da acto-S1 miosina.

Dos mutantes que se comportaram de forma anômala nos ensaios de regulação da atividade $\mathrm{Mg}^{2+}$-ATPásica dois já se comportaram de forma um pouco alterada nos ensaios de co-sedimentação com actina. São estes os mutantes $5 \mathrm{OH} 90 \mathrm{~W}$ e $5 \mathrm{OH} 185 \mathrm{~W}$ que tiveram o comportamento não esperado de causar um aumento considerável na atividade $\mathrm{Mg}^{2+}$-ATPásica da actomiosina mesmo na ausência de troponina $+/$ - ions cálcio. Este comportamento anômalo para o $50 \mathrm{H} 90 \mathrm{~W}$ na ausência de troponina já foi observado anteriormente (Farah e Reinach, 1999). Em adição a estes dois mutantes o mutante $50 \mathrm{H} 276 \mathrm{~W}$ também causou este efeito inesperado na atividade $\mathrm{Mg}^{2+}$-ATPásica. Estes três mutantes causaram a ativação da $\mathrm{Mg}^{2+}-$ ATPase da acto-S1 miosina a niveis aproximadamente $100 \%$ maiores que o observado na ausência de tropomiosina (figura 30A). Esta maior ativação é bastante interessante e pode ser devida a uma maior interação da S1 com a tropomiosina devido à mutação ou, ainda, a uma variação conformacional na actina devido à mutação que aumente a sua interação com a S1.

Um quarto mutante, o $5 \mathrm{OH} 122 \mathrm{~W}$, também apresentou um comportamento não convencional em ensaios da regulação da atividade da $\mathrm{Mg}^{2+}$-ATPase da acto-S1 miosina. Embora este mutante tenha causado a regulação da atividade $\mathrm{Mg}^{2+}$-ATPásica esperada quando sozinho e quando na presença do complexo troponina, íons de cálcio causaram uma diminuição na atividade $\mathrm{Mg}^{2+}$-ATPásica da actomiosina ao contrário do que seria esperado para a regulação da contração muscular. É interessante notar que uma mutação letal em tropomiosina de Drosophila, Asp121Asn (Kreuz et al., 1996), que foi testada in vitro por Hitchcock-DeGregori e colaboradores (2002) e que não altera a afinidade da tropomiosina pela actina na presença de troponina, inibe a ativação da atividade $\mathrm{Mg}^{2+}$-ATPásica da acto-S1 miosina na presença de $\mathrm{Ca}^{2+}$. Estes resultados sugerem que a região da 
tropomiosina que engloba as posições 121 e 122 deve ser particularmente importante para a atividade regulatória da tropomiosina.

\section{Ensaios de estabilidade conformacional das tropomiosinas mutantes}

Espectros de dicroísmo circular

A figura 31 mostra o espectro de dicroísmo circular a $4{ }^{\circ} \mathrm{C}$ entre $190 \mathrm{e}$ $260 \mathrm{~nm}$ em $\mathrm{NaH}_{2} \mathrm{PO}_{4} 5.73 \mathrm{mM}$ pH 7.0, $\mathrm{NaCl} 50 \mathrm{mM}, \mathrm{MgCl}_{2}$ e DTT $1 \mathrm{mM}$. para a ASTm e vários dos mutantes utilizados neste trabalho (50H90W, 5OH94W, 5OH101W, 5OH107W, 5OH111W, 5OH122W, 5OH261W, $5 \mathrm{OH} 276 \mathrm{~W}$ e $5 \mathrm{OH} 278 \mathrm{~W}$ ). Como pode ser observado da análise qualitativa dos espectros de dicroísmo circular, não há grandes variações em termos de estrutura entre os mutantes testados e a ASTm. Este resultado está mostrando que a introdução das sondas fluorescentes 5-hidroxitriptofano na tropomiosina nestas posições não deve estar causando uma desestabilização muito acentuada na estrutura da tropomiosina. Mesmo os mutantes que apresentaram resultados anômalos nos ensaios de co-sedimentação com actina $(5 \mathrm{OH} 90 \mathrm{~W})$ e de regulação da atividade $\mathrm{Mg}^{2+}$-ATPásica da acto-S1 miosina $(5 \mathrm{OH} 90 \mathrm{~W}, 5 \mathrm{OH} 122 \mathrm{~W}$ e $5 \mathrm{OH} 276 \mathrm{~W})$ parecem não possuir muitas diferenças em termos estruturais em comparação com a tropomiosina nativa (ASTm) nas condições deste ensaio. Este ensaio mostra que, nas condições testadas, todos os mutantes estão estruturados. $O$ ensaio descrito a seguir permite comparar as diferenças na estabilidade relativa entre os mutantes e a ASTm. Como será visto, não há diferenças significativas entre a estabilidade dos mutantes e da ASTm.

Desnaturação por temperatura acompanhada por dicroísmo circular

A desnaturação por temperatura acompanhada por dicroísmo circular mostrou claramente que todos os mutantes (exceto o $50 \mathrm{H} 90 \mathrm{~W}$, ver abaixo) testados (5OH94W, 5OH101W, 50H107W, 5OH111W, 50H122W, $50 \mathrm{H} 261 \mathrm{~W}, 5 \mathrm{OH} 276 \mathrm{~W}$ e $50 \mathrm{H} 278 \mathrm{~W}$ ) possuem estabilidade global similar 
(entre 45 e $47^{\circ} \mathrm{C}$ ) àquela observada para a ASTm (figura 32) nas condições deste ensaio. Este resultado indica que a sonda localizada nestas regiões não está afetando a estabilidade global da molécula de tropomiosina. Todas as tropomiosinas testadas possuem sondas 5-hidroxitriptofano em posições externas $(b, c, e, f$, ou $g)$ do coiled-coil da tropomiosina e, portanto, este arranjo não deve ser muito desestabilizante para a molécula. Na tabela 2 podemos observar os valores obtidos para a $T_{m}$ e para $\circ \Delta G^{\circ}\left(H_{2} \mathrm{O}\right)$ a $25^{\circ} \mathrm{C}$ obtidos dos experimentos de desnaturação por temperatura seguido por fluorescência para a ASTm e para os mutantes testados. A variação encontrada para $\circ \Delta G^{\circ}\left(25^{\circ} \mathrm{C}\right)$ dos mutantes da tropomiosina e da ASTm pode estar relacionada à imprecisão na determinação dos valores de $\Delta \mathrm{G}^{\circ}$.

O mutante $50 \mathrm{H} 90 \mathrm{~W}$ não pode ser analisado quantitativamente por desnaturação térmica seguida por dicroísmo circular porque este agregou repetitivamente à temperaturas superiores à $44^{\circ} \mathrm{C}$ nas condições testadas. Apesar disso, o perfil de desnaturação até esta temperatura mostrou-se similar aos das outras proteínas testadas (figura 33). Estes resultados indicam que apesar do fato de que esta mutação promove agregação da molécula a temperaturas mais altas, sua estabilidade a temperaturas mais baixas parece ser similar àquelas das outras moléculas de tropomiosina testadas.

Além das desnaturações por temperatura seguidas por dicroísmo circular tentamos realizar desnaturações por temperatura seguidas por fluorescência. Infelizmente, devido à extrema sensibilidade do sinal de fluorescência do aminoácido 5-hidroxitriptofano sozinho à temperatura, estes experimentos não forneceram resultados satisfatórios (a variação no sinal de fluorescência do aminoácido sozinho é maior do que a variação deste inserido na proteína, dado não mostrado).

\section{Desnaturação por uréia seguida por fluorescência}

Antes de iniciar uma discussão dos valores obtidos pela desnaturação por uréia acompanhada por fluorescência dos mutantes da tropomiosina 
indicados na tabela 4 devemos ressaltar que as variações sentidas pelas sondas fluorescentes refletem variações no microambiente das sondas em cada posição onde esta tenha sido introduzida. Assim, este método de estudo permite, em conjunto com os estudos de desestabilização global dos mutantes de tropomiosina citados acima, a avaliação da estabilidade local na região da sonda fluorescente da molécula analisada.

Outra questão a ser levantada é o fato de que dos 12 mutantes analisados por esta técnica todos os 5 mutantes que possuem a sonda fluorescente dentro de uma banda a $(50 \mathrm{H} 90 \mathrm{~W}$ - que na temperatura deste ensaio $\left(25^{\circ} \mathrm{C}\right)$ não apresentou o problema de agregação que encontramos à temperaturas mais altas nos ensaios de desnaturação térmica,$- 50 \mathrm{H} 94 \mathrm{~W}$, $50 \mathrm{H} 101 \mathrm{~W}, 5 \mathrm{OH} 261 \mathrm{~W}$ e $50 \mathrm{H} 263 \mathrm{~W}$ ) apresentaram transições definidas ao passo que todos os 7 mutantes com a sonda dentro de uma banda $\beta$ (5OH107W, 5OH111W, 5OH122W, 5OH185W, 5OH269W, 5OH276W e $50 \mathrm{H} 278 W$ ) não apresentaram transição definida. Este fato é inesperado e bastante curioso. É possível que a desnaturação da região das bandas $\alpha$ não ocorra da mesma forma que a desnaturação das bandas $\beta$. Poder-se-ia especular que os resíduos que se encontam em bandas $\alpha$ teriam um mecanismo de denaturação mais parecido com uma desnaturação de dois estados ao passo que as bandas $\beta$ poderiam estar tendo uma desnaturação mais gradual de diversos microestados, o que não forneceria uma transição bem definida (devido a microtransições quase que infinitesimais e não a uma única transição cooperativa). Estes dados podem ser analisados em conjunto com dados publicados para a desnaturação por pressão da tropomiosina (Suarez et al., 2001) onde reporta-se que a desnaturação por pressão (2.4 kbar) fornece uma tropomiosina com subdomínios desnaturados na qual subdomínios sem estrutura secundária estão ligados por pontos de nucleação que mantêm as cadeias unidas. Infelizmente os dados obtidos por Suarez et al. (2001) não permitem a identificação da localização e da quantidade destes pontos de nucleação. Talvez o que estamos observando nesta análise seja exatamente esta desnaturação de subdomínios onde os pontos de nucleação seriam as bandas $\alpha$ que se mantêm estruturados até 
uma certa concentração de uréia e finalmente desnaturam, enquanto que as bandas $\beta$ podem ser os subdomínios desnaturados que sofrem esta desnaturação lenta e contínua com o acréscimo de uréia.

Como pode ser visto na tabela 4 , os valores de $\Delta G^{\circ}\left(\mathrm{H}_{2} \mathrm{O}\right)$ aumentam claramente para os mutantes analisados em função da posição na sequência primária da tropomiosina. Assim a região da III banda $\alpha / \beta$ mostrou-se menos estável que a região $\mathrm{C}$-terminal (banda $\alpha / \beta$ VII). Este resultado está de acordo com dados obtidos anteriormente neste laboratório com fragmentos da tropomiosina (Paulucci et al., 2002) que indicou a importância da estabilidade da região C-terminal da molécula. Nossos dados sugerem uma maior flexibilidade da região central da molécula em comparação com o seu C-terminal. Esta maior flexibilidade deve ser importante para o processo de regulação da contração muscular.

Análise das curvas de desnaturação levando em consideração o equilíbrio monômero-dímero

Como apresentado anteriormente na seção RESULTADOS, analisamos as curvas assumindo-se que os dados de dicroísmo circular e fluorescência reflitam tanto um processo uni- como bimolecular. Neste ítem, discutiremos o processo de desenovelamento da molécula de tropomiosina com base em dados da literatura e faremos uma comparação entre os resultados obtidos para os mutantes da tropomiosina analisados neste projeto segundo os dois tipos de processos de desnaturação (uni- e bimolecular).

Como dito anteriormente, se a desnaturação da tropomiosina como medida pelo dicroísmo circular e fluorescência é acompanhada simultaneamente pela dissociação de suas cadeias, a equação para a constante de equilíbrio torna-se: $\mathrm{K}_{\mathrm{eq}}=\left(4 \mathrm{~F}_{\mathrm{U}}{ }^{2} \mathrm{C}_{\mathrm{T}}\right) / \mathrm{F}_{\mathrm{F}}$. 
Desta forma, resolvemos calcular os valores de $\Delta G^{\circ}$ para as desnaturações térmicas e por uréia considerando ambos os processos unimolecular e bimolecular. Estes valores, já apresentados em tabelas separadas nos resultados estão apresentados juntos na tabela 8.

Tabela 8. Comparação dos valores obtidos para $\Delta G^{\circ}\left(25^{\circ} \mathrm{C}\right)$ e para os valores obtidos para $\Delta G^{\circ}\left(\mathrm{H}_{2} \mathrm{O}\right)$ considerando os dois tipos de processos (uni- e bimolecular).

\begin{tabular}{|c|c|c|c|c|}
\hline tropomiosina & $\begin{array}{c}\Delta \mathrm{G}^{\circ}\left(25^{\circ} \mathrm{C}\right) / \\
\mathrm{kcal} \mathrm{mol}^{-1} \\
\text { (unimolecular) }\end{array}$ & $\begin{array}{c}\Delta \mathrm{G}^{\circ}\left(25^{\circ} \mathrm{C}\right) / \\
\mathrm{kcal} \mathrm{mol}^{-1} \\
\text { (bimolecular) }\end{array}$ & $\begin{array}{c}\Delta \mathrm{G}^{\circ}\left(\mathrm{H}_{2} \mathrm{O}\right) / \\
\mathrm{kcal} \mathrm{mol}^{-1} \\
\text { (unimolecular) }\end{array}$ & $\begin{array}{c}\Delta \mathrm{G}^{\circ}\left(\mathrm{H}_{2} \mathrm{O}\right){ }^{\prime} \mathrm{kcal} \mathrm{mol}^{-1} \\
\text { (bimolecular })\end{array}$ \\
\hline ASTm & 8.1 & 18.5 & - & - \\
\hline $5 \mathrm{OH} 90 \mathrm{~W}$ & - & - & 4.9 & 15.4 \\
\hline $5 \mathrm{OH} 94 \mathrm{~W}$ & 6.9 & 15.5 & 5.1 & 15.6 \\
\hline $5 \mathrm{OH} 101 \mathrm{~W}$ & 8.1 & 17.9 & 5.6 & 16.1 \\
\hline $5 \mathrm{OH} 107 \mathrm{~W}$ & 5.4 & 14.7 & - & - \\
\hline $5 \mathrm{OH} 111 \mathrm{~W}$ & 5.8 & 15.8 & - & - \\
\hline $5 \mathrm{OH} 122 \mathrm{~W}$ & 5.3 & 14.4 & - & - \\
\hline $5 \mathrm{OH} 261 \mathrm{~W}$ & 4.8 & 14.2 & 6.1 & 16.4 \\
\hline $5 \mathrm{OH} 263 \mathrm{~W}$ & - & - & 6.6 & 17.6 \\
\hline $5 \mathrm{OH} 276 \mathrm{~W}$ & 4.6 & 19.4 & - & - \\
\hline $50 \mathrm{H} 278 \mathrm{~W}$ & 7.7 & 16.1 & - & - \\
\hline
\end{tabular}

Notemos que os valores de $\Delta G^{\circ}\left(\mathrm{H}_{2} \mathrm{O}\right)$ obtidos para o processo bimolecular são maiores que os valores de $\Delta G^{\circ}\left(H_{2} \mathrm{O}\right)$ calculados para um processo unimolecular. Também devemos notar que os valores para $\Delta \mathrm{G}^{\circ}\left(25^{\circ} \mathrm{C}\right)$ e $\Delta \mathrm{G}^{\circ}\left(\mathrm{H}_{2} \mathrm{O}\right)$ calculados para um processo bimolecular são muito semelhantes entre si. Este fato indica que as sondas fluorescentes são sensiveis à mesma transição global medida por dicroísmo circular.

A equação para a constante de equilíbrio para um processo bimolecular prevê que no ponto médio da transição, onde $F_{U}=F_{F}=0.5$, a $K_{\text {eq }}$ $=2 C_{T}$. Podemos, portanto, esperar que um aumento na concentração total $\left(\mathrm{C}_{\mathrm{T}}\right)$ de proteína vai causar um deslocamento na curva de desnaturação de forma que o ponto médio da transição seja deslocado para valores maiores de desnaturante ou temperaturas mais altas (Pode-se mostrar que para um 
aumento de $10 \mathrm{X}$ em $\mathrm{C}_{T}$, teremos um decréscimo em $\mathrm{F}_{U}$ de 0.5 para 0.2). Esta propriedade fornece uma forma de testar se a desnaturação é ou não dependente da concentração pela realização de experimentos de desnaturação a diferentes valores de $C_{T}$. Apesar de não termos realizado estes experimentos com nossas tropomiosinas recombinantes, experimentos tanto com fragmentos da tropomiosina (Holtzer e Holtzer, 1990; Holtzer et al., 1995; Paulucci et al., 2002) como com a tropomiosina inteira (Isom et al., 1984; Skolnick e Holtzer, 1985) indicam que esta dependência realmente é observada. A verificação da troca entre dímeros $\alpha \alpha$ e $\beta \beta$ da tropomiosina gerando híbridos $\alpha \beta$ (Lehrer e Qian, 1990; Lehrer e Stafford, 1991; Orlov et al., 1998) após desnaturação e renaturação também sugere a monomerização da tropomiosina sob desnaturação.

Outra discussão relevante é a respeito do processo de desnaturação. A evidência apresentada acima indica que durante as desnaturações da tropomiosina o sinal de dicroísmo circular ou fluorescência está refletindo um processo que tem pelo menos um componente bimolecular. Entretanto, existem evidências na literatura que indicam que a desnaturação em coiledcoils em geral e da tropomiosina em particular não ocorre por um processo simples de dois estados, mas sim em várias etapas unimoleculares que precedem uma etapa de dissociação bimolecular final. Os próximos parágrafos consideram algumas destas evidências.

Um estudo recente de Dragan e Privalov (2002) analisa a desnaturação de um coiled-coil (o domínio de dimerização do GCN4, com duas fitas idênticas de 33 aminoácidos) e conclui que a desnaturação pode nem ser uma transição simples de dois estados. Sua análise calorimétrica sugere que uma primeira transição começa logo no início do aumento da temperatura, não depende da concentração de proteína e é sensível à modificação química do seu $\mathrm{N}$-terminal. Os autores associam esta transição à um desenovelamento ou abertura desta região do coiled-coil. A segunda transição, que ocorre a temperaturas maiores, é mais pronunciada que a primeira e também é unimolecular. Esta transição é sensivel a modificações em ambas as pontas da molécula e afeta as propriedades ópticas de um 
triptofano localizado na parte central do coiled-coil. Portanto, esta transição envolve a molécula inteira mas não resulta em dissociação. A esta segunda transição segue-se, a temperaturas maiores por uma separação/desenovelamento das duas fitas. Os autores sugerem que a entalpia e a entropia das mudanças estruturais induzidas por temperatura no coiled-coil que ocorrem antes de sua dissociação/desenovelamento são responsáveis por quase $40 \%$ da entalpia e entropia totais do desenovelamento do coiled-coil.

Estudos calorimétricos sugerem que o processo de desnaturação da tropomiosina pode ser resolvido em diversos componentes (Potekhin e Privalov, 1982; Sturtevant et al., 1991). Além disso, como discutido anteriormente um estudo de desnaturação da tropomiosina por pressão mostrou que a tropomiosina não desnatura de forma homogênea mas dá origem a pontos de nucleação que são resistentes a desnaturação Suarez et al. (2001). Nossos resultados de desnaturação por uréia podem ser interpretados assumindo este modelo sugerido por Suarez et al. (2001) (ver discussão da desnaturação por uréia seguida por fluorescência). Holtzer et al. (1989) sugerem ainda que o equilibrio de desenovelamento em coiled-coils em geral, e para a tropomiosina em particular, pode não seguir o modelo de desenovelamento "tudo-ou-nada" mas provavelmente é melhor descrito por um modelo onde se assume um "continuum-de-estados".

Por fim, experimentos de cinética realizados por Mo et al. (1990 e 1991) mostraram que a etapa limitante do processo de enovelamento da tropomiosina não é a dimerização e sim o enovelamento das cadeias polipeptídicas. Além disso, o re-enovelamento da molécula ocorre com cinéticas iguais tanto para a proteína menos como para a mais concentrada, mostrando que o processo cinético independe da concentração, e que portanto o mecanismo é unimolecular. 


\section{Ensaios de supressão de fluorescência}

Supressão por iodeto

A análise da supressão da fluorescência pelo supressor extrínsico negativamente carregado iodeto permitiu a análise do ambiente eletrostático ao redor da sonda fluorescente 5-hidroxitriptofano inserida nas posições 90 , 101, 111 e 122 da sequência primária da molécula de tropomiosina. Estes estudos foram realizados com os mutantes de tropomiosina sozinhos, na presença de actina, na presença de actina e troponina $\left(-\mathrm{Ca}^{2+}\right)$ e na presença de actina e troponina na presença de íons cálcio (tabela 5).

$\mathrm{Na}$ ausência de outras proteínas a sonda forneceu ambientes neutros para três dos quatro mutantes $(5 \mathrm{OH} 90 \mathrm{~W}, 5 \mathrm{OH} 111 \mathrm{~W}$ e $5 \mathrm{OH} 122 \mathrm{~W})$. Para o mutante $5 \mathrm{OH} 101 \mathrm{~W}$ este ambiente não pode ser determinado (Figura 52A). Este resultado indica que as cargas na tropomiosina na vizinhança das sondas não estão próximas o suficiente destas sondas para afetar a supressão por iodeto nas condições testadas.

A presença de actina afeta as sondas de modos diferentes. Os resultados obtidos a partir dos ensaios de supressão da fluorescência pelo iodeto sugerem que, na presença de actina, a sonda 5-hidroxitriptofano nas posições 90 e 111 estão inseridas em microambientes negativos. As posições 101 e 122, na presença de actina, encontram-se em ambientes neutro e positivo, respectivamente. É interessante notar que as posições 90 , e 122 são ocupadas, na proteína nativa, por resíduos de arginina (positivo) e glutamato (negativo) o que é coerente com os microambientes aos quais as sondas estão expostas na presença de actina, isto é, possíveis sítios de ligação na superfície da actina com campos eletricos de cargas opostas, negativo para a posição 90 e positivo para a 122. As posições 101 e 111 são ocupadas, na proteína nativa, por resíduos de arginina (positivo) e glutamina (neutro) e portanto não encontramos o mesmo tipo de correlação entre estes resíduos e seus microambientes na presença de actina. 
A adição de troponina, na presença de actina, não afeta o microambiente eletrostático observado pelas sondas fluorescentes nas posições 90 e 101. Ambas continuam a estar inseridas no mesmo tipo de ambiente eletrostático no qual se encontravam na presença de apenas actina (negativo para a posição 90 e neutro para a posição 101). Entretanto, a introdução de troponina dá origem a uma mudança no microambiente eletrostático envolvendo as sondas nas posições 111 e 122. Ambas passam a se inserir num ambiente eletrostaticamente neutro.

A introdução de íons cálcio neste sistema altera apenas um microambiente eletrostático com relação aqueles na presença de troponina ($\left.\mathrm{Ca}^{2+}\right)$ : a sonda fluorescente inserida na posição 111 passa a se encontrar num ambiente negativo. As outras três posições não têm seu microambiente eletrostático alterado, com relação à presença de troponina $\left(-\mathrm{Ca}^{2+}\right)$, em função da introdução de íons cálcio no sistema (as posições 90, 101 e 122 continuam inseridas, respectivamente, num microambiente negativo, neutro e neutro).

Uma extensão e comparação destes resultados com modelos moleculares do filamento fino podem auxiliar numa futura análise molecular da ligação entre a tropomiosina e a actina na ausência e na presença de troponina (+/- íons cálcio).

\section{Supressão por acrilamida}

Os experimentos de supressão da fluorescência pelo supressor extrínsico neutro acrilamida foram realizados com mutantes da tropomiosina contendo resíduos de 5-hidroxitriptofano em uma de nove posições ao longo da molécula: 90, 94, 101, 107, 111, 122, 261, 276 e 278. Todas estas posições são expostas ao solvente na repetição heptapeptídica do 'coiledcoil' (tabela 7, figura 57). As posições 90, 94, 101 e 261 pertencem à terceira e sétima banda $\alpha$, ao passo que as posições 107, 111, 122 e 261 pertencem à terceira ou sétima banda $\beta$ (tabela 7 , figura 57 ). Na figura 57 podem ser 
visualizados modelos moleculares dos segmentos do 'coiled-coil' da tropomiosina correspondentes aos terceiros e sétimos pares de bandas $\alpha$ e $\beta$.

Para facilitar-se a interpretação dos resultados de supressão de fluorescência devemos fazer algumas considerações com relação ao ambiente das sondas na tropomiosina e no filamento fino. Em primeiro lugar, devido à estrutura 'coiled-coil' paralela e em fase da molécula de tropomiosina, cada mutante possui dois resíduos de 5-hidroxitriptofano, um em cada cadeia polipeptídica, em posições diametralmente opostas na superfície do 'coiled-coil' (figura 57). Desta forma, na ausência de outras proteínas, os microambientes de cada sonda são equivalentes. Esta simetria é entretanto rompida quando da ligação à actina. Em segundo lugar, as sondas localizadas na terceira repetição $\alpha / \beta(90,94,101,107,111,122$; figura 57A e D) não estão em contato direto com o complexo troponina. Devido às simetrias rotacionais do filamento de actina e do 'coiled-coil' da tropomiosina, para estes seis mutantes é muito provável que uma das sondas encontre-se o tempo todo acessível ao supressor ao passo que a exposição da outra sonda deve ser uma função de seu grau de interação com a superfície da actina. Em terceiro lugar, como a troponina interage com a metade C-terminal da tropomiosina, os três mutantes com as sondas na repetição $\alpha / \beta$ C-terminal VII (261, 276 e 278; figura 57B e E), podem teoricamente ter ambas as suas sondas parcialmente enterradas, uma pela actina e a outra pela troponina (especificamente o domínio N-terminal da troponina $T$ (White et al., 1987)). Finalmente, é de se esperar que as posições 276 e 278 sejam ainda menos acessiveis ao supressor em filamentos reconstituídos por localizarem-se na região de sobreposição cabeça-cauda onde ocorrem interações complexas, embora até o presente não caracterizadas estruturalmente, envolvendo os dois dímeros de tropomiosina, o filamento de actina e a troponina T (Sousa e Farah, 2002; White et al., 1987; McLachlan e Stewart, 1975). Note que na estrutura cristalina recentemente determinada de um fragmento C-terminal da tropomiosina de músculo esquelético os 22 resíduos C-terminais abrem-se devido à formação de um dímero cauda-cauda com uma molécula de simetria 
relacionada ( $\mathrm{Li}$ et al., 2002) (figura 57C e F). Esta abertura da estrutura coiled-coil no C-terminal da tropomiosina também foi evidenciada na estrutura (RMN) em solução de um fragmento contendo resíduos 251-284 (Greenfield et al, 2003). A relevância fisiológica desta abertura ainda não é clara. Uma possibilidade é a de que esta abertura do C-terminal permita uma maximização das interações eletrostáticas entre as cargas negativas desta região da molécula com as cargas positivas do $\mathrm{N}$-terminal da molécula de tropomiosina vizinha permitindo a formação das interações que mantêm a estrutura cabeça-cauda.

Outro ponto que devemos considerar antes de iniciar a análise dos resultados obtidos pela supressão da fluorescência dos mutantes pela acrilamida é até que ponto mudanças no valor de $K_{\text {sv }}$ representam realmente mudanças na acessibilidade da sonda 5-hidroxitriptofano ao supressor. Como $\mathrm{K}_{\mathrm{sV}}=\mathrm{k}_{\mathrm{q}} \tau_{0}$ (ver INTRODUÇÃO PARTE II - Fluorescência ítem 3.3. Supressão de fluorescência), as diferenças nos valores de $K_{\text {sv }}$ podem estar refletindo, em parte, diferenças nos tempos de vida de fluorescência das sondas em diferentes posições na cadeia polipeptídica da tropomiosina. Os tempos de vida de fluorescência para as sondas nestes mutantes nas diversas condições em que eles foram estudados (sozinhos, na presença de actina e na presença de troponina (+/- íons cálcio) não foram determinados neste projeto devido à dificuldades técnicas envolvendo a complexidade das misturas proteicas e a baixa intensidade de fluorescência obtida pela excitação da amostra a $312 \mathrm{~nm}$. Entretanto, nós temos evidências de que os aumentos e diminuições observados nos valores de $K_{S V}$ causados pela actina, pela troponina ou pela ligação de $\mathrm{Ca}^{2+}$ a cada mutante refletem de fato aumentos e diminuições no grau de exposição da sonda fluorescente (ou seja, reflete aumentos e diminuições nos valores de $k_{q}$ ) ao invés de apenas modificações em $\tau_{0}$. Esta evidência está baseada no fato de que na ausência do supressor a intensidade de fluorescência é diretamente proporcional ao tempo de vida e, em nosso sistema, nós observamoes variações na intensidade de fluorescência induzidas pela actina, troponina ou ions cálcio em apenas alguns poucos casos específicos (tabela 7). Estes casos 
específicos são os seguintes: 1) A ligação de íons cálcio não resulta em mudanças significantes na intensidade de fluorescência em nenhum dos mutantes com exceção do 50H122W (tabela 7; Farah e Reinach, 1999). No caso do $5 \mathrm{OH} 122 \mathrm{~W}$, a ligação de íons cálcio ao filamento fino regulado causa um aumento de $\sim 15 \%$ na intensidade de fluorescência (tabela 7 ; Farah e Reinach, 1999), ao passo que os valores de $\mathrm{K}_{\text {sv }}$ para este mutante diminui de $5.6 \mathrm{M}^{-1}$ para $4.8 \mathrm{M}^{-1}$ (tabela 7). Assim, para $05 \mathrm{OH} 122 \mathrm{~W}$, a diminuição induzida por $\mathrm{Ca}^{2+}$ na exposição da sonda é até maior do que pode ser inferido apenas pela variação no valor de $K_{\text {sv. }}$ 2) O único mutante cuja intensidade de fluorescência é significantemente reduzida pela ligação à actina é o $5 \mathrm{OH} 261 \mathrm{~W}$ (tabela 7). Para este mutante a redução na intensidade de fluorescência está entre 20 e 25 \% (Sousa, 2002 (tese de doutorado)) que é uma diminuição um pouco menor que a redução no valor de $\mathrm{K}_{\mathrm{sv}}(28 \%)$. Logo, para este mutante a variação devida à introdução de actina deve ser bem menor do que o indicado pela variação no $K_{\text {sv }}$ (provavelmente uma diminuição de $\sim 5 \%$ no grau de exposição da sonda). Devemos notar, entretanto, que a introdução de troponina ou íons cálcio não causa nenhum efeito adicional na intensidade da fluorescência deste mutante (tabela 7). 0 único outro mutante que possui intensidade de fluorescência sensível à ligação à actina é o $50 \mathrm{H} 122 \mathrm{~W}$. A intensidade de fluorescência deste mutante aumenta em 40 \% com a ligação de actina (tabela 7; Farah e Reinach, 1999), ou seja, na direção oposta àquela observada para a mudança no $K_{s v}$ (tabela 7). Novamente, a mudança no valor de $K_{s v}$ indica corretamente a natureza da variação no $k_{q}$, mas subestima a extensão da mudança. $A$ intensidade de fluorescência de todos os outros mutantes não varia com a ligação de actina (tabela 7; Farah e Reinach, 1999). 3) As únicas sondas com intensidade de fluorescência sensível á ligação de troponina $\left(-\mathrm{Ca}^{2+}\right)$, na presença de actina, são aquelas situadas nas posições 276 e 278 (tabela 7 , figura 55) que encontram-se localizadas na região de interação cabeça-cauda e, portanto, interagem diretamente com a troponina T. Esses aumentos de 24 e $14 \%$ respectivamente são próximos aos valores observados para as variações no $K_{\text {sv }}$ indicando que a variação no valor destas constantes nestes casos é pequena (ver tabela 9). Portanto, o único caso em que há variação na intensidade no valor de $\mathrm{K}_{\mathrm{SV}}$ devido à adição de íons cálcio é para o 
mutante $5 \mathrm{OH} 122 \mathrm{~W}$ e, como visto esta mudança causa uma subestimação na variação verdadeira do $K_{s v}$ para este caso. A tabela 9 apresenta os valores corrigidos de $K_{s v}$ para estes casos. Por fim, devemos notar que como cada mutante provavelmente possui tempos de vida de fluorescência diferentes, a comparação dos valores de $K_{\text {sv }}$ entre os mutantes não é tão importante quanto as mudanças no valor de $\mathrm{K}_{\mathrm{sv}}$ para cada mutante como resultado de mudanças conformacionais induzidas pela ligação de outras proteínas (actina ou troponina) e $\mathrm{Ca}^{2+}$

Tabela 9. Correção dos valores de $K_{\text {sv }}$ para os mutantes que apresentaram variação na intensidade de fluorescência associada à adição de actina, troponina ou íons cálcio.

\begin{tabular}{|c|c|c|c|c|c|c|c|}
\hline Condição & $\mathrm{K}_{\mathrm{sV}}$ & $\begin{array}{c}\text { Variação } \\
\text { na inten- } \\
\text { sidade }\end{array}$ & $\begin{array}{c}\mathrm{K}_{\mathrm{sV}} \\
\text { corrigido }\end{array}$ & Condição & $\mathrm{K}_{\text {sV }}$ & $\begin{array}{c}\text { Variação } \\
\text { na inten- } \\
\text { sidade }\end{array}$ & $\begin{array}{c}\mathrm{K}_{\text {sV }} \\
\text { corrigido }\end{array}$ \\
\hline $5 \mathrm{OH} 122 \mathrm{~W}$ & 6.4 & - & 6.4 & $5 \mathrm{H} 276 \mathrm{~W}$ & 6.3 & - & 6.3 \\
\hline$+\mathrm{Ac}$ & 5.0 & $+40 \%$ & 3.6 & $+\mathrm{Ac}$ & 3.8 & - & 3.8 \\
\hline$+\mathrm{Tn}$ & 5.6 & - & 4.0 & $+\mathrm{Tn}$ & 4.3 & $+24 \%$ & 3.5 \\
\hline$+\mathrm{Ca}^{2+}$ & 4.8 & $+15 \%$ & 3.0 & $+\mathrm{Ca}^{2+}$ & 4.1 & - & 3.3 \\
\hline & & & & & & & \\
\hline $5 \mathrm{OH} 261 \mathrm{~W}$ & 8.7 & - & 8.7 & $50 \mathrm{H} 278 \mathrm{~W}$ & 5.6 & - & 5.6 \\
\hline$+\mathrm{Ac}$ & 6.3 & $-25 \%$ & 8.4 & $+\mathrm{Ac}$ & 3.2 & - & 3.2 \\
\hline$+\mathrm{Tn}$ & 3.5 & - & 4.7 & $+\mathrm{Tn}$ & 3.4 & $+14 \%$ & 3.0 \\
\hline$+\mathrm{Ca}^{2+}$ & 6.1 & - & 8.2 & $+\mathrm{Ca}^{2+}$ & 2.6 & - & 2.3 \\
\hline
\end{tabular}



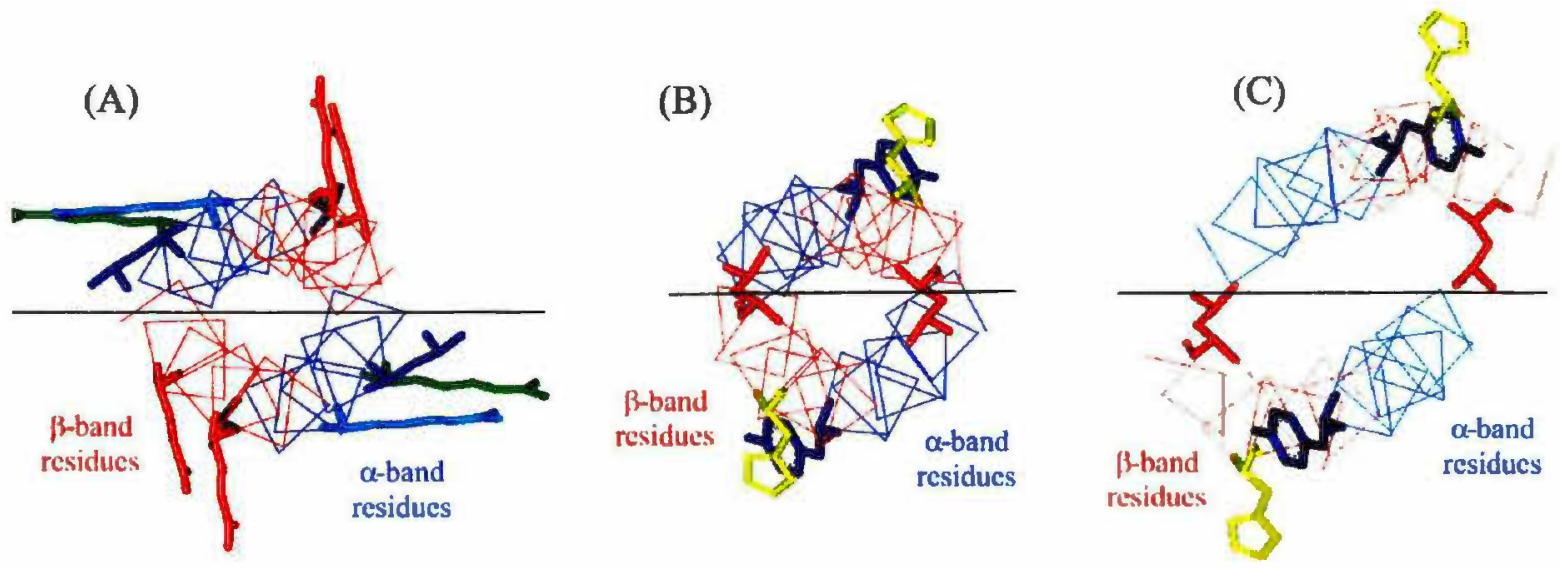

(D)

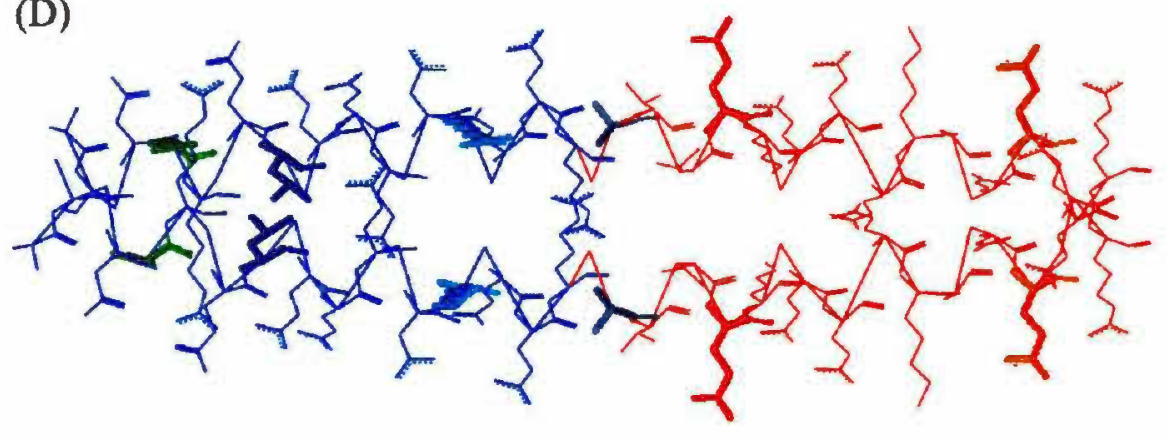

(E)

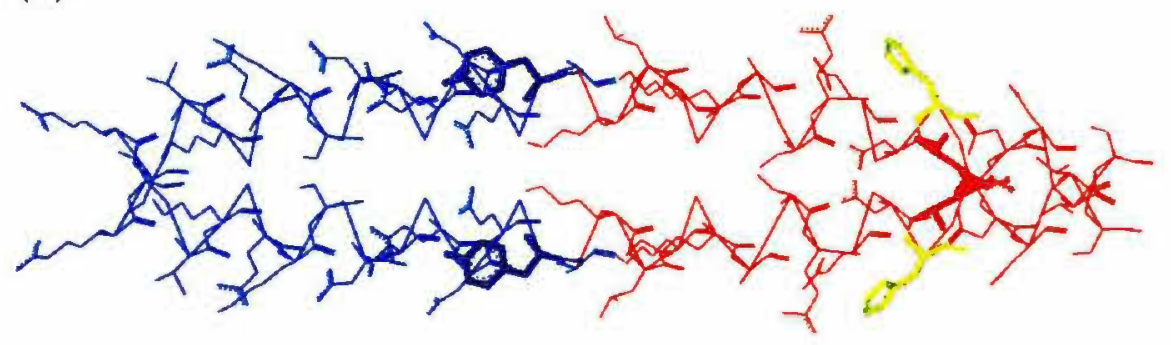

(F)

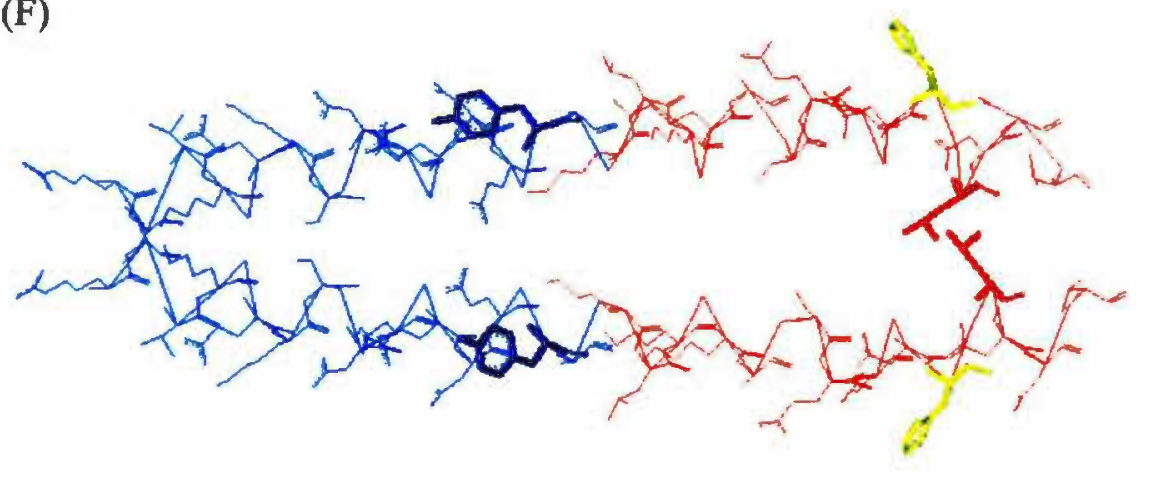


Figura 57 (na página anterior). Modelos moleculares para as repetições $\alpha / \beta$ III e VII da tropomiosina. As cadeias laterais são mostradas na conformação extendida toda-trans e os esqueletos polipeptídicos são baseados no descrito anteriormente para a repetição III (Whitby e Phillips, 2000). As bandas $\alpha$ e $\beta$ estão mostradas respectivamente em azul e vermelho e estão relacionadas por rotações de $90^{\circ}$ da super-hélice do 'coiled-coil'. A e B, vistas axiais pelo C-terminal da III e VII repetição $\alpha / \beta$ (resíduos 86 a 125 e 244 a 283 respectivamente) (Huxley, 1972) mostrando as cadeias laterais dos resíduos R90 (verde claro), L94 (azul), R101 (azul claro), A107 (cinza), Q111 (vermelho), E122 (laranja), Y261 (azul escuro), H276 (amarelo) e L278 (salmon). As linhas horizontais representam um plano separando as duas ahélices do 'coiled-coil'. Como a Y261 está a apenas dois resíduos do início de uma banda $\beta$, uma pequena sobreposição azimutal é observada com o $\mathrm{H} 276$ quando observamos a molécula axialmente. C e D, vistas longitudinais da III e VII repetição $\alpha / \beta$. Todas as cadeias laterais estão mostradas exceto as posições internas a e $d$ da repetição heptapeptídica. Os residuos estão mostrados nas mesmas cores que nas partes A e B. E e F são o mesmo que B e D mas utilizando como modelo as coordenadas do backbone da estrutura cristalina recentemente determinada de um fragmento C-terminal da tropomiosina de músculo esquelético (Li et al., 2002).

Para facilitar a comparação entre os nove mutantes nas quatro condições, os valores de $K_{s v}$ da tabela 7 estão apresentados num formato gráfico nas figuras $58 \mathrm{~A}$ e $58 \mathrm{C}$ enquanto nas figuras $58 \mathrm{~B}$ e $58 \mathrm{D}$ estão representadas as constantes de supressão dinâmicas normalizadas para cada mutante na ausência de outras proteínas. A figura 59A e B mostra os valores de $K_{s v}$ corrigidos para o efeito da variação na intensidade de fluorescência.

Como esperado, a actina diminuiu a acessibilidade da sonda ao supressor para todos os mutantes, indicando que a ligação ao filamento de actina resulta no enterramento parcial de uma das sondas. As sondas nas posições 276 e 278 mostraram o maior decréscimo proporcional na acessibilidade (figura 58). Isto pode ser devido à localização destes resíduos C-terminais na região de sobreposição cabeça-cauda a qual inclui os primeiros e últimos 9-11 resíduos da tropomiosina (McLachlan e Stewart, 1975). Nas condições utilizadas, espera-se que menos da metade dos Cterminais da tropomiosina estejam envolvidos em interações cabeça-cauda na ausência de actina (Sousa e Farah, 2002). A ligação à actina 
provavelmente aumenta esta fração e, portanto, é provável que o enterramento relativamente grande observado para as sondas nas posições 276 e 278 deva-se à uma combinação de interações tanto com a actina como com o $\mathrm{N}$-terminal de uma molécula vizinha de tropomiosina.
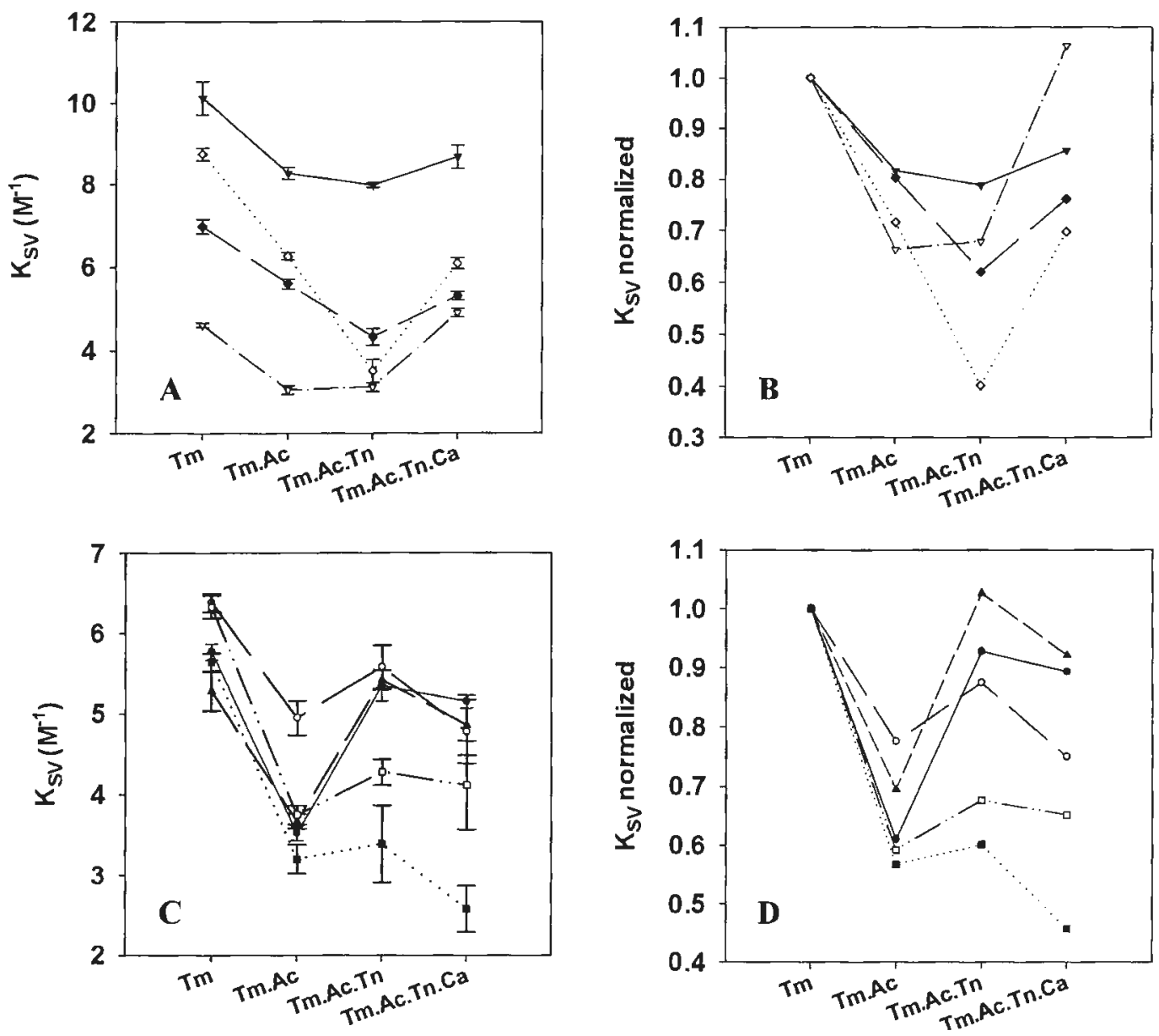

Figura 58. Constantes de Stern-Volmer (Ksv) para a supressão por acrilamida da fluorescência das sondas 5-hidroxitriptofano inseridas nas tropomiosinas mutantes em função do sistema analisado. A e $\mathbf{B}$, resíduos em bandas $\alpha ; C$ e $D$, resíduos em bandas $\beta$. Os valores absolutos de $K_{s v}(A, C)$ e os valores normalizados para os valores de $K_{\text {sv }}$ para a tropomiosina sozinha (B, D) estão mostrados. Símbolos: A, B: 50H90W, ( $)$; 50H94W,

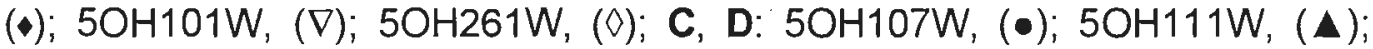
$5 \mathrm{OH} 122 \mathrm{~W},(\mathrm{O}) ; 5 \mathrm{OH} 276 \mathrm{~W}$, (口); 5OH278W, (घ). Condições: MOPS $25 \mathrm{mM} \mathrm{pH}$ 7.0, $\mathrm{NaCl} 50 \mathrm{mM}, \mathrm{MgCl}_{2} 5 \mathrm{mM}$ e DTT $1 \mathrm{mM}\left(25^{\circ} \mathrm{C}\right)$. 

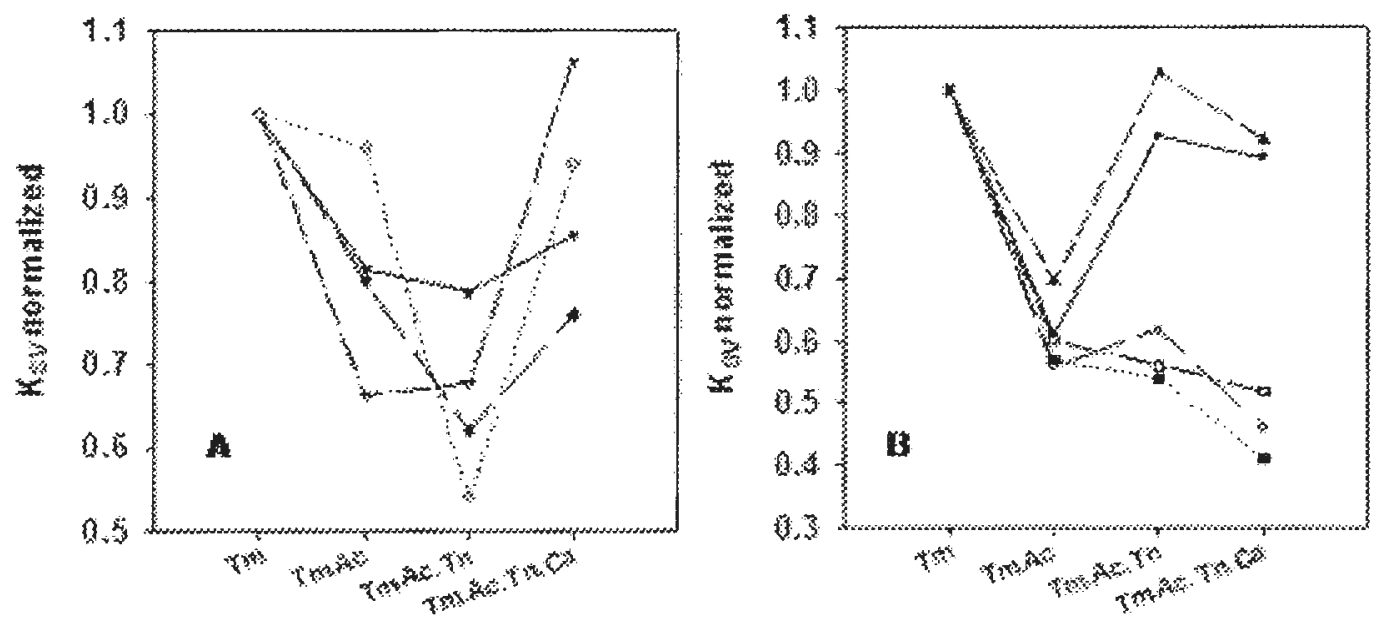

Figura 59. Constantes de Stern-Volmer ( $K_{s v}$ ) corrigidas e normalizadas para a supressão por acrilamida da fluorescência das sondas 5-hidroxitriptofano inseridas nas tropomiosinas mutantes em função do sistema analisado. A: resíduos em bandas $\alpha$; $\mathbf{B}$ : resíduos em bandas $\beta$. Símbolos: $\mathbf{A}$ : $50 \mathrm{H} 90 \mathrm{~W}$, $(\nabla) ; 50 H 94 \mathrm{~W},(\bullet) ; 50 \mathrm{OH} 101 \mathrm{~W},(\nabla) ; 50 \mathrm{H} 261 \mathrm{~W},(\diamond) ; \mathbf{B}: 50 \mathrm{H} 107 \mathrm{~W},(\bullet)$; $5 \mathrm{OH} 111 \mathrm{~W},(\mathbf{\Lambda}) ; 5 \mathrm{OH} 122 \mathrm{~W},(0) ; 5 \mathrm{OH} 276 \mathrm{~W}$, (口); 5OH278W, (ロ). Condições: MOPS $25 \mathrm{mM} \mathrm{pH} 7.0, \mathrm{NaCl} 50 \mathrm{mM}, \mathrm{MgCl}_{2} 5 \mathrm{mM}$ e DTT $1 \mathrm{mM}\left(25^{\circ} \mathrm{C}\right)$.

A adição de troponina na ausência de cálcio afeta o grau de acessibilidade das sondas fluorescentes de forma dependente da posição em que elas se encontram. A acessibilidade das sondas nas bandas $\alpha$ ou permaneceu inalterada (posições 90 e 101) ou sofreu uma redução significativa (posição 94 e 261) devido à presença de troponina na ausência de íons cálcio (figura 59A). Em contraste, as sondas posicionadas em bandas $\beta$ ou permaneceram inalteradas (posições 122, 276 e 278) ou tornaram-se mais acessiveis (posições 107 e 111) pela adição de troponina na ausência de íons cálcio (figura 59B). Estes resultados enfatizam o papel da troponina de fixar a tropomiosina em sua posição na ausência de cálcio, aproximando do filamento de actina os resíduos das bandas $\alpha$ enquanto ao mesmo tempo afastando aqueles das bandas $\beta$.

A adição de íons cálcio à tropomiosina-actina-troponina resulta em mudanças dramáticas na acessibilidade do 5-hidroxitriptofano e, como antes, 
a natureza das mudanças depende da localização das sondas em bandas $\alpha$ ou $\beta$. A ligação de cálcio à troponina faz com que todas as sondas testadas localizadas em bandas $\alpha$ tornem-se mais acessíveis à supressão por acrilamida enquanto ao mesmo tempo faz com que todas as sondas localizadas em bandas $\beta$ tornem-se menos acessíveis ao supressor (figuras 58 e 59, Tabela 7). Estes resultados ilustram poderosamente o mecanismo pelo qual a troponina posiciona a molécula de tropomiosina sobre o filamento de actina de maneira dependente de $\mathrm{Ca}^{2+}$ e são consistentes com o modelo proposto por McLachlan e Stewart (McLachlan e Stewart, 1976) no qual as bandas $\alpha$ são usadas para a ligação à actina na ausência de íons cálcio e as bandas $\beta$ para a ligação à actina na presença de íons cálcio.

Os resultados apresentados acima indicam que as bandas $\alpha$ e $\beta$ originalmente identificadas com base na periodicidade encontrada na sequência primária da tropomiosina (Stewart e McLachlan, 1975; McLachlan e Stewart, 1976; Parry, 1974) estão realmente relacionadas à uma ligação diferencial desta molécula ao filamento de actina nos diferentes estados da contração do músculo esquelético. Nossos resultados sugerem que a introdução de íons cálcio ao filamento fino totalmente regulado faz com que os resíduos localizados dentro de bandas a afastem-se do filamento de actina ao passo que resíduos localizados dentro de bandas $\beta$ são aproximados do filamento de actina. Devemos ressaltar que os estados sem $\mathrm{Ca}^{2+}$ e com $\mathrm{Ca}^{2+}$ de filamento fino provavelmente não correspondem a duas conformações estáveis e específicas mas devem ser melhor descritas por diferentes misturas em equilibrio entre dois ou três estados cujas populações relativas são moduladas pela ligação de íons cálcio e/ou ligação do domínio motor da miosina (Squire e Morris, 1998; Ishii e Lehrer, 1993; Geeves e Lehrer, 1994; Maytum et al., 1999). Desta forma, nossos resultados de supressão por acrilamida são melhor interpretados em termos de deslocamentos neste equilíbrio disparados por cálcio ao invés de refletir características estruturais de estados conformacionais puros e distintos. 
O movimento da tropomiosina sobre a superfície da F-actina poderia, em princípio, ocorrer através de uma série de mecanismos. Dois mecanismos distintos e simples - 'deslizamento' e 'rolamento' - estão ilustrados na figura 60. Num mecanismo de deslizamento puro (figura 60A) o 'coiled-coil' da tropomiosina mantém sempre a mesma face direcionada ao eixo do filamento de actina conforme liga-se a diferentes sítios na superficie da actina. Este mecanismo prediria variações mínimas na exposição ao solvente dos resíduos da tropomiosina em resposta a íons cálcio, embora variações não sistemáticas e, portanto, dificilmente previsiveis, poderiam ser esperadas em sítios específicos. Por outro lado, num mecanismo de rolamento (figura 60B) o 'coiled-coil' da tropomiosina rodaria em torno de seu eixo e faces diferentes de sua superfície seriam utilizadas na interação com a actina. Nossos dados revelam mudanças sistemáticas na exposição ao solvente de regiões específicas na superfície da tropomiosina e são, portanto, consistentes com o mecanismo de rolamento. Com o número limitado de mutantes utilizados não podemos determinar precisamente a magnitude da rotação do 'coiled-coil' em resposta a íons cálcio mas o fato de que todas as nove posições testadas seguem o padrão previsto para uma rotação de $90^{\circ}$ sugere que esta pode ser uma boa primeira estimativa. A análise por supressão de fluorescência de um número maior de mutantes fluorescentes da tropomiosina poderia em princípio mapear a natureza periódica da interação tropomiosina-actina em maior detalhe e possivelmente poderia detectar descontinuidades nesta periodicidade tais como quebras ou torções. 

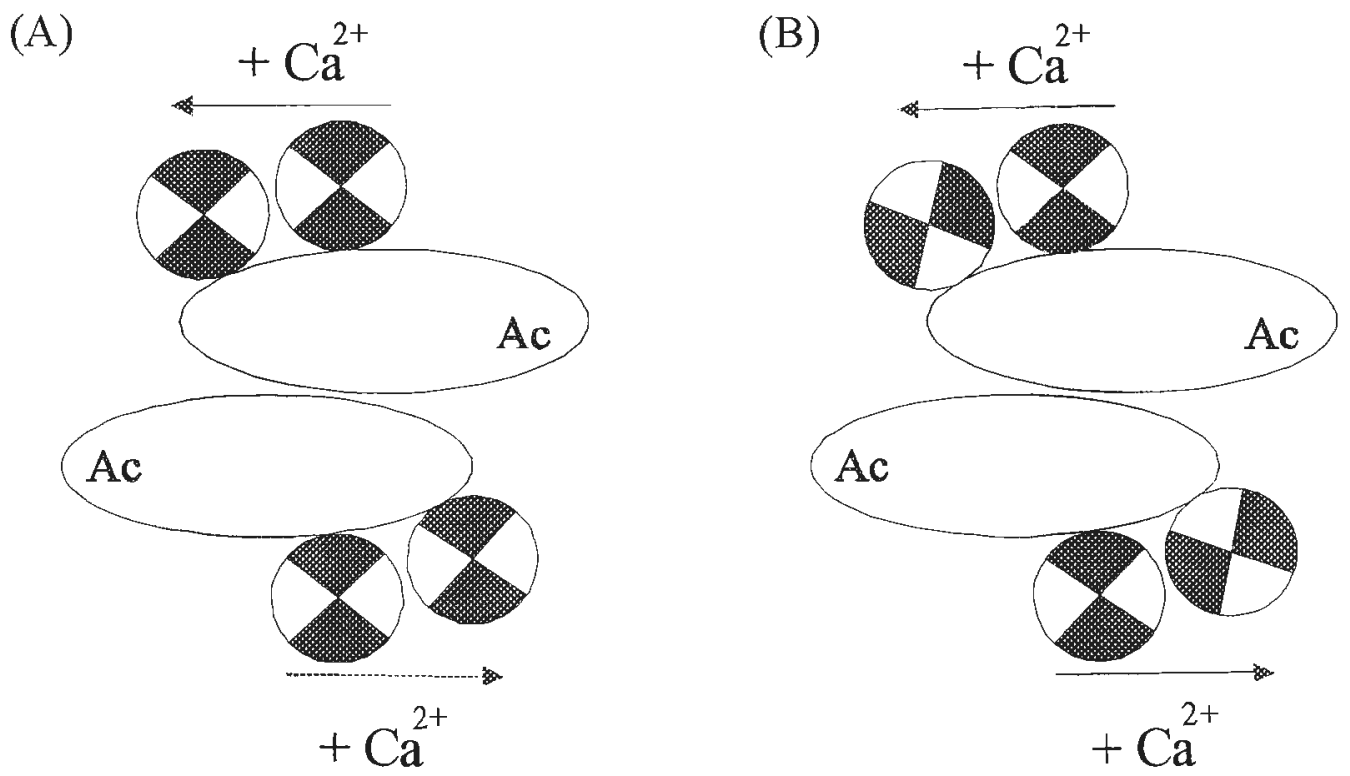

Figura 60. Mecanismos de deslizamento (A) e rolamento (B) para a translação azimutal dependente de $\mathrm{Ca}^{2+}$ da tropomiosina (círculos pequenos) na superfície da actina (AC). Os quadrantes negros dentro da molécula de tropomiosina representam superfícies dominadas por resíduos de bandas a enquanto os quadrantes brancos representam resíduos de bandas $\beta$. 0 complexo troponina não está mostrado. A, um mecanismo de deslizamento puro onde a mesma superficie da tropomiosina interage com a actina na ausência e na presença de $\mathrm{Ca}^{2+}$. $\mathbf{B}$, um mecanismo de rolamento onde a tropomiosina sofre uma rotação de $90^{\circ}$ e utiliza resíduos diferentes para interagir com a molécula de actina na ausência (residuos de bandas $\alpha$ ) e na presença (residuos de bandas $\beta$ ) de $\mathrm{Ca}^{2+}$.

Se analizarmos o fato de que as bandas $\alpha$ e $\beta$ estão deslocadas tanto azimutalmente como axialmente ao longo da estrutura da tropomiosina em conjunto com nossos resultados de supressão de fluorescência por acrilamida podemos inferir alguns aspectos estruturais interessantes. Devemos inicialmente lembrar que até o momento não se conseguiu determinar a fase da ligação da tropomiosina à actina; ou seja, se todos os resíduos numa repetição $\alpha / \beta$ (como definido (McLachlan e Stewart, 1976)) ligam-se a um único monômero de actina ("em fase") ou se a ligação é "defasada" (Lorenz et al., 1995) na qual uma banda $\alpha$ liga-se a um monômero 
e a banda $\beta$ seguinte liga-se a outro. Se considerarmos que todos os resíduos numa repetição $\alpha / \beta$ ligam-se a um único monômero de actina podemos utilizar os dados obtidos por Vibert et al. (1997) (figura 17) para inferir em que regiões da molécula de actina a tropomiosina deva estar se ligando: As bandas $\alpha$, responsáveis pela ligação na ausência de íons cálcio, ligar-se-iam a resíduos na actina localizados nos subdomínios I e III (figura 61A); com a introdução de íons cálcio no sistema a tropomiosina rolaria $\left(90^{\circ}\right)$ sobre o filamento de actina de modo a posicionar os resíduos das bandas $\beta$ para interação com resíduos do subdomínio IV da actina (figura 61B).

Alternativamente, se a ligação entre a tropomiosina e a actina for fora de fase, as bandas a ligar-se-iam à actina na ausência de íons cálcio no subdomínio II (figura 61C) e a as bandas $\beta$ ligar-se-iam à actina na presença de íons cálcio no subdomínio III (figura 61D).

Este raciocínio equivale a dizer que, se as repetições $\alpha / \beta$ da tropomiosina (como designadas por McLachlan e Stewart, 1976; Figura 15) encontram-se em fase com a actina, os resíduos da actina responsáveis pela ligação à tropomiosina na ausência de ions cálcio encontram-se nos subdomínios I e III (figura 61A). Quando íons cálcio são introduzidos ao sistema, os resíduos responsáveis pela ligação à tropomiosina encontram-se no subdomínio IV (figura 61B). Se a ligação a/ß-actina dá-se fora de fase, os resíduos da actina responsáveis pela ligação à tropomiosina na ausência de cálcio encontram-se no subdomínio II (figura 61C) e na presença de cálcio, os resíduos do subdomínio III da actina seriam os responsáveis pela ligação desta à tropomiosina (figura 61D). 
A

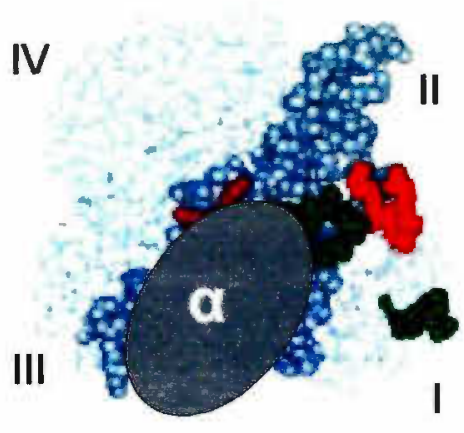

$$
-\mathrm{Ca}^{2+}
$$

C

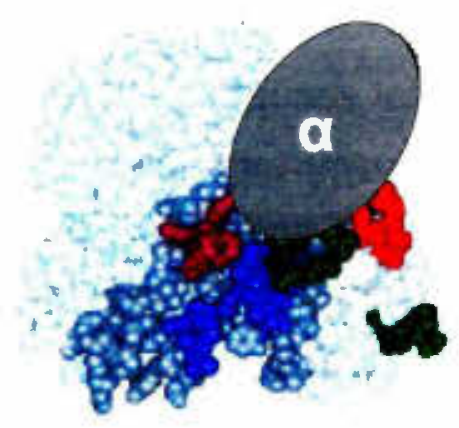

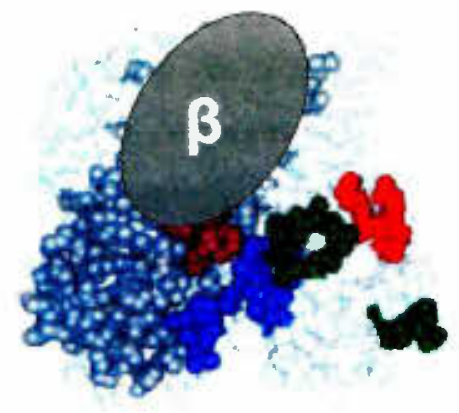

$+\mathrm{Ca}^{2+}$

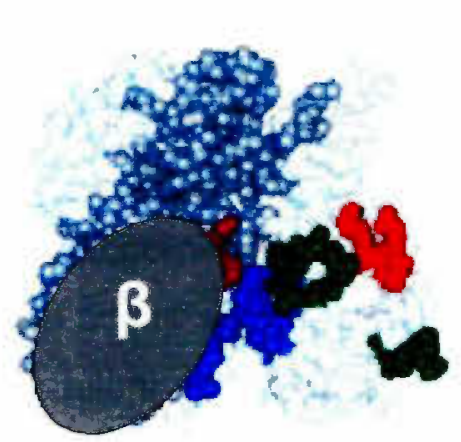

B

D

Figura 61. Modelo para a ligação da tropomiosina na actina combinando os resultados de Vibert et al. (1997) e os inferidos neste doutorado.Os círculos negros representam as regiōes de ligação da tropomiosina sobre a actina. (ver figura 17 para as outras cores). Os painéis $\mathbf{A}$ e $\mathbf{C}$ assumem ausência de íons cálcio e os painéis $B$ e $D$ presença de íons cálcio. (Os painéis A e B assumem que a tropomiosina esteja em fase com a actina (ver texto para detalhes); os painéis $C$ e $D$ assumem que a tropomiosina esteja fora de fase com a actina (ver texto para detalhes). Os subdomínios da actina (I a IV) estão indicados em A. A, na ausência de cálcio as bandas $\alpha$ são as responsáveis pela ligação da tropomiosina na actina (subdomínios I e III); B, na presença de cálcio a rotação da tropomiosina faz com que as bandas $\beta$ da tropomiosina interajam com o subdomínio IV da actina. C, As bandas $\alpha$ da tropomiosina, na ausência de íons cálcio, estariam ligando-se no subdomínio II da actina; D, a ligação de cálcio deslocaria a tropomiosina para uma posição em que suas bandas $\beta$ passem a interagir com o subdomínio III de uma actina acima. 
Devemos notar ainda que dados existentes na literatura (ver tabela I na INTRODUÇÃO - PARTE I - Sistema Muscular) vêm relacionando resíduos do subdomínio IV da actina como responsáveis pela ligação da tropomiosina à actina na presença de íons cálcio. Analisados em conjunto com nossos resultados podemos identificar esta situação como sendo a representada na figura $61 \mathrm{~B}$, favorecendo a ligação "em fase" da actina com a tropomiosina.

Devido à estrutura do coiled-coil da tropomiosina, a face do coiled-coil de maior "densidade" de cadeias laterais de resíduos em posições $\beta$ é onde existe a menor "densidade" de cadeias laterais de resíduos em posições $\alpha$. Este aspecto de sua estrutura terciária é melhor apreciado por uma visão ao longo do eixo da molécula (Figuras 57 e 62). Desta forma quando íons cálcio são adicionados ao sistema a rotação da tropomiosiona afasta a maior parte das cadeias laterais $\alpha$ da interação com a actina; nesta situação a região que se aproxima do filamento de actina na altura das bandas a é a fenda do coiled-coil. Da mesma forma, na ausência de íons cálcio, a maior parte das cadeias laterais dos resíduos das bandas $\beta$ não estão em contato com a superfície da actina; nesta situação a fenda do coiled-coil está sendo apresentada à actina nesta região. 

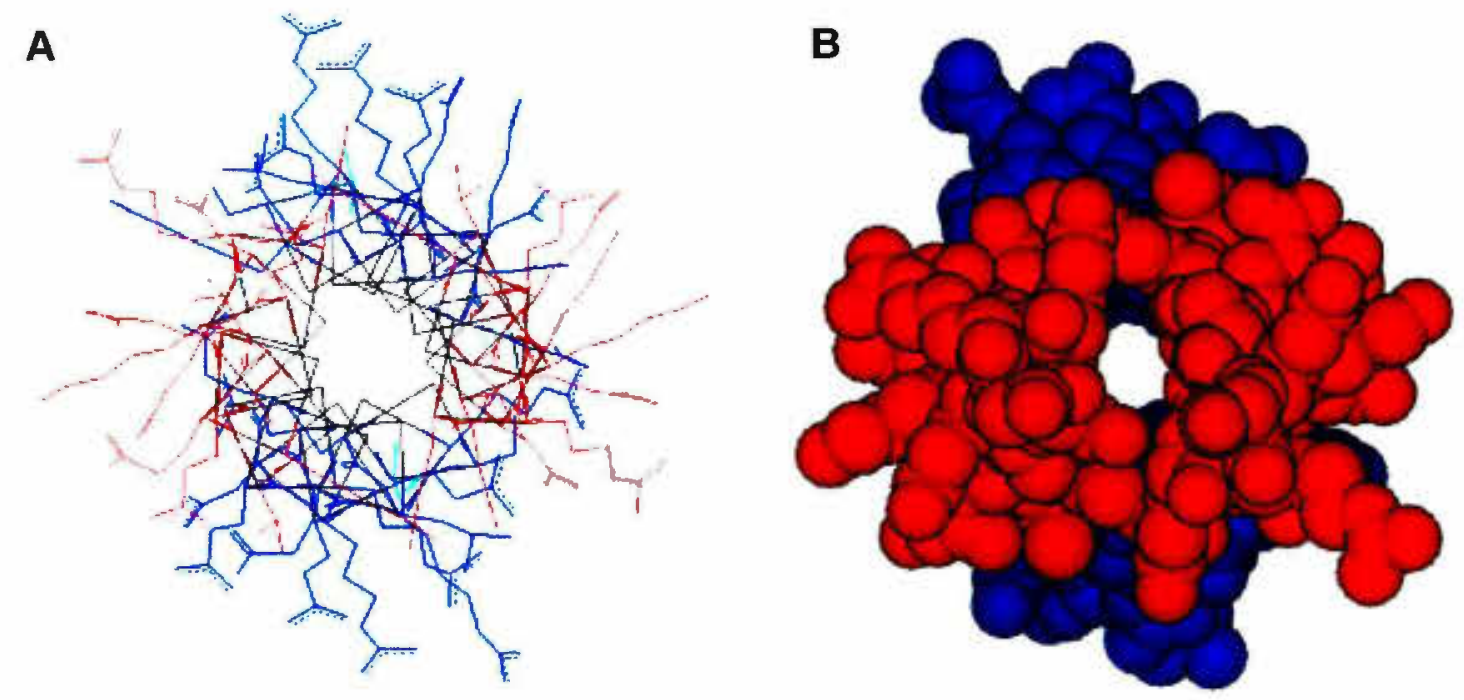

Figura 62. Vista axial da III repetição $\alpha / \beta$ (resíduos 86-125) do C- para o Nterminal (A, linhas; B, CPK) comparando a variação na "densidade" das cadeias laterais entre as bandas $\alpha$ (azul) e $\beta$ (vermelho).

A rotação da tropomiosina por si só não implica em rolamento: a tropomiosina poderia rodar sem mudar de posição (um deslizamento negativo ou 'escorregamento"). Como movimentos da tropomiosina induzidos por íons cálcio vêm sendo observados (Vibert et al., 1997; Lehman et al., 2001; Lehman et al., 1994; Huxley, 1972; Haselgrove, 1972; Parry e Squire, 1973; Xu et al., 1999), uma rotação que leve a um rolamento é fortemente favorecida. Como mencionado anteriormente, um modelo favorecendo o rolamento da tropomiosina foi recentemente proposto a partir de medidas de transferência de energia de fluorescência (Bacchiocchi e Lehrer, 2002). Se a tropomiosina realmente rolar na superfície do filamento de actina sem escorregar ou deslizar, então o ângulo de rotação $\left(\sim 90^{\circ}\right)$ e o raio do 'coiledcoil" (entre $\sim 9$ e $14 \AA$ ) podem ser usados para estimarmos uma translação entre 14 e $22 \AA$ s sobre a superficie de um monômero da actina. Estes valores são consistentes com modelos de desvios induzidos por íons cálcio na posição da tropomiosina em filamentos finos regulados (Squire e Morris, 1998; Vibert et al., 1997; Lehman et al., 2001; Lehman et al., 1994; Xu et al., 1999). 
Como a ligação de cálcio à troponina induz o rolamento da tropomiosina sobre a actina? Nossos dados favorecem um papel ativo para a troponina no posicionamento da molécula de tropomiosina tanto na ausência quanto na presença de íons cálcio já que os perfis de acessibilidade dos dois estados são significantemente diferentes daqueles observados para a tropomiosina + actina na ausência de troponina. Mudanças induzidas por íons cálcio no complexo troponina podem propiciar o rolamento da tropomiosina pela aplicação de um torque à metade $\mathrm{C}$-terminal da tropomiosina através do domínio helicoidal $\mathrm{N}$-terminal da troponina $\mathrm{T}$ e/ou pode ser influenciada por interações dependentes de cálcio com a troponina I e o domínio globular $\mathrm{N}$ terminal da troponina T (Farah e Reinach, 1995; Gordon et al., 2000; Squire e Morris, 1998; Lehman et al., 2000; White et al., 1987; Malnic et al., 1998). O mecanismo específico da transmissão do sinal da troponina para a tropomiosina ainda não foi elucidado. A resolução recente da estrutura do complexo ternário troponina (Takeda et al., 2003; ver INTRODUÇÃO, figuras 10 e 11) deve fornecer informações interessantes para a construção de um modelo de alta resolução entre as proteínas envolvidas na regulação da contração muscular. 


\section{CONCLUSÕES}

Estudamos aspectos moleculares da regulação da contração do músculo esquelético pela tropomiosina bem como aspectos da estabilidade desta molécula. Fizemos uso para estes estudos de mutantes da tropomiosina com a sonda fluorescente 5-hidroxitriptofano inserida em diversas posições da molécula. Estes mutantes foram caracterizados com relação à capacidade de ligar actina e de regular a atividade $\mathrm{Mg}^{2+}$-ATPásica da acto-S1 miosina. Ensaios de desnaturação térmica também foram realizados e a forma de análise destes resultados foi discutida em termos de mecanismos uni- e bimoleculares para o processo de desenovelamento da tropomiosina.

Numa outra série de estudos enfocamos a estabilidade local da tropomiosina por meio de desnaturações com uréia seguidas pela variação no sinal de fluorescência das sondas. Estes ensaios também foram analisados assumindo-se tanto um mecanismo uni- quanto bimolecular para o processo de desnaturação. Em ambos os casos sondas inseridas no Cterminal da molécula reportaram valores para $\Delta G^{\circ}$ mais altos do que sondas inseridas na região da III repetição $\alpha / \beta$, fornecendo uma comparação da estabilidade destas duas regiões da molécula. Além disso, notamos o fato curioso que apenas as sondas inseridas em regiões pertencentes a bandas $\alpha$ apresentaram uma transição clara segundo reportado pela variação no sinal de fluorescência. As sondas localizadas em bandas $\beta$ apresentaram uma variação linear no sinal de fluorescência com a desnaturação. Hipotetizamos que este fato pode estar relacionado com os pontos de nucleação observados por Suarez et al. (2001) para a desnaturação da tropomiosina por pressão.

Dados de supressão de fluorescência por iodeto permitiram a análise dos microambientes eletrostáticos ao redor das sondas fluorescentes para diversas situações: tropomiosina sozinha, presença de actina e presença de 
actina e troponina (+/- íons cálcio). Os resultados estão sumarizados na tabela 6.

Por fim, nossos dados de supressão da fluorescência por acrilamida permitiram a proposição de um modelo para a forma pela qual a tropomiosina regula a contração do músculo esquelético. Nossos resultados fornecem uma evidência experimental direta do movimento da tropomiosina sobre a superfície da actina em resposta à presença de íons cálcio: este movimento acoplaria um deslocamento da tropomiosina sobre a superficie do filamento de actina a uma rotação de $\sim 90^{\circ}$ da tropomiosina sobre seu próprio eixo. Nossos dados sugerem ainda que, na ausência de íons cálcio, os resíduos das bandas $\alpha$ seriam os responsáveis pela ligação da tropomiosina ao filamento de actina; na presença de íons cálcio, e com o conseqüente deslocamento da tropomiosina, as bandas $\beta$ passariam a ser as responsáveis pela ligação da tropomiosina ao filamento de actina. 


\section{REFERÊNCIAS BIBLIOGRÁFICAS}

1. al Khayat, H. A., Yagi, N., \& Squire, J. M. (1995). Structural changes in actin-tropomyosin during muscle regulation: computer modelling of low-angle X-ray diffraction data. J. Mol. Biol. 252, 611632.

2. Ando, T. \& Asai, H. (1980). Charge effects on the dynamic quenching of fluorescence of 1,N6ethenoadenosine oligophosphates by iodide, thallium (I) and acrylamide. J. Biochem. (Tokyo) 88, 255-264

3. Ando, T., Fujisaki, H., \& Asai, H. (1980). Electric-Potential at Regions Near the 2 Specific Thiols of Heavy-Meromyosin Determined by the Fluorescence Quenching Technique .1. Effect of Atp. Journal of Biochemistry 88, 265-276.

4. Aspenstrom, P., Lindberg, U., \& Karlsson, R. (1992). Site-specific amino-terminal mutants of yeast-expressed beta-actin. Characterization of the interaction with myosin and tropomyosin. FEBS Lett. 303, 59-63.

5. Bacchiocchi, C. \& Lehrer, S. S. (2002). Ca(2+)-induced movement of tropomyosin in skeletal muscle thin filaments observed by multi-site FRET. Biophys. J. 82, 1524-1536

6. Bolen, D. W. \& Santoro, M. M. (1988). Unfolding free energy changes determined by the linear extrapolation method. 2. Incorporation of delta $\mathrm{G}$ degrees $\mathrm{N}-\mathrm{U}$ values in a thermodynamic cycle. Biochemistry 27, 8069-8074.

7. Callis, P. R. (1997). 1La and 1Lb transitions of tryptophan: applications of theory and experimental observations to fluorescence of proteins. Methods Enzymol. 278, 113-150.

8. Cantor, C. R. \& Schimmel, P. R. (1998). Other optical techniques. In Biophysical Chemistry, pp. $409-480$, W. H. Freeman and Company, New York.

9. Cohen, C. \& Holmes, K. C. (1963). X-ray diffraction evidence for alpha-helical coiled-coils in native muscle. J. Mol. Biol. 6, 423-432.

10. Cooke, R. (1993). The actomyosin engine. FASEB J. 9, 636-642.

11. Cooke, R. (1997). Actomyosin interaction in striated muscle. Physiol Rev. 77, 671-697.

12. Crick, F. H. C. (1953). Acta Cryst. 6, 689-697.

13. da Silva, A. C. \& Reinach, F. C. (1991). Calcium binding induces conformational changes in muscle regulatory proteins. Trends Biochem. Sci. 16, 53-57.

14. Das, K, Ashby, K. D., Smirnov, A. V., Reinach, F. C., Petrich, J. W., \& Farah, C. S. (1999). Fluorescence properties of recombinant tropomyosin containing tryptophan, 5-hydroxytryptophan and 7-azatryptophan. Photochem. Photobiol. 70, 719-730.

15. Dragan, A. I. \& Privalov, P. L (2002). Unfolding of a leucine zipper is not a simple two-state transition. J. Mol. Biol. 321, 891-908.

16. Drapeau, G. R., Brammar, W. J., \& Yanofsky, C. (1968). Amino acid replacements of the glutamic acid residue at position 48 in the tryptophan synthetase A protein of escherichia coli. J. Mol. Biol. 35, 357-367.

17. Earley, J. J. (1991). Simple harmonic motion of tropomyosin: proposed mechanism for lengthdependent regulation of muscle active tension. Am. J. Physiol 261, C1184-C1195.

18. Ebashi, S., Endo, M., \& Otsuki, I. (1969). Control of muscle contraction. Q. Rev. Biophys. 2, 351384.

19. Ebashi, S., Wakabayashi, T., \& Ebashi, F. (1971). Troponin and its components. J. Biochem. 69, $441-445$ 
20. Eftink, M. R. \& Ghiron, C. A. (1976b). Exposure of tryptophanyl residues in proteins. Quantitative determination by fluorescence quenching studies. Biochemistry 15, 672-680.

21. Eftink, M. R. \& Ghiron, C. A. (1976a). Fluorescence quenching of indole and model micelle systems. J. Phys. Chem. 80, 486-493.

22. Eftink, M. R. \& Ghiron, C. A. (1981). Fluorescence quenching studies with proteins. Anal. Biochem. 114, 199-227.

23. Eftink, M. R. (1991a). Fluorescence quenching: theory and applications. In Principles (Lakowicz, J. R., ed), pp. 53-126, Plenum Press, New York.

24. Eftink, M. R. (1991b). Fluorescence techniques for studying protein structure. Methods Biochem. Anal. 35, 127-205.

25. El Saleh, S. C., Thieret, R., Johnson, P., \& Potter, J. D. (1984). Modification of Lys-237 on actin by 2,4-pentanedione. Alteration of the interaction of actin with tropomyosin. J. Biol. Chem 259. 11014-11021.

26. Farah, C. S., Miyamoto, C. A., Ramos, C. H., da Silva, A. C., Quaggio, R. B., Fujimori, K., Smillie, L. B., \& Reinach, F. C. (1994). Structural and regulatory functions of the NH2- and $\mathrm{COOH}-$ terminal regions of skeletal muscle troponin I. J. Biol. Chem 269, 5230-5240.

27. Farah, C. S. \& Reinach, F. C. (1995). The troponin complex and regulation of muscle contraction. FASEB J. 9, 755-767.

28. Farah, C. S. \& Reinach, F. C. (1999). Regulatory properties of recombinant tropomyosins containing 5-hydroxytryptophan: Ca2+-binding to troponin results in a conformational change in a region of tropomyosin outside the troponin binding site. Biochemistry 38, 10543-10551.

29. Fasman, G. D. (1996). Circular dichroism and the conformational analysis of biomolecules Plenum Press.

30. Fisher, A. J., Smith, C. A., Thoden, J. B., Smith, R., Sutoh, K., Holden, H. M., \& Rayment, I. (1995). X-ray structures of the myosin motor domain of Dictyostelium discoideum complexed with MgADP.BeFx and MgADP.AlF4-. Biochemistry 34, 8960-8972

31. Fujimori, K., Sorenson, M., Herzberg, O., Moult, J., \& Reinach, F. C. (1990). Probing the calciuminduced conformational transition of troponin $\mathrm{C}$ with site-directed mutants. Nature 345, 182-184.

32. Geeves, M. A. \& Lehrer, S. S. (1994). Dynamics of the muscle thin filament regulatory switch: the size of the cooperative unit. Biophys. J. 67, 273-282.

33. Geeves, M. A. \& Holmes, K. C. (1999). Structural mechanism of muscle contraction. Annu. Rev. Biochem. 68, 687-728.

34. Gooding, C., Reinach, F. C., \& MacLeod, A. R. (1987). Complete nucleotide sequence of the fasttwitch isoform of chicken skeletal muscle alpha-tropomyosin. Nucleic Acids Res. 15, 8105.

35. Gordon, A. M., Homsher, E., \& Regnier, M. (2000). Regulation of contraction in striated muscle. Physiol Rev. B0, 853-924.

36. Greaser, M. L. \& Gergely, J. (1971). Reconstitution of troponin activity from three protein components. J. Biol. Chem 246, 4226-4233.

37. Greaser, M. L. \& Gergely, J. (1973). Purification and properties of the components from troponin. J. Biol. Chem 248, 2125-2133.

38. Gulick, A. M., Bauer, C. B., Thoden, J. B., \& Rayment, I. (1997). X-ray structures of the MgADP, MgATPgammaS, and MgAMPPNP complexes of the Dictyostelium discoideum myosin motor domain. Biochemistry 36, 11619-11628.

39. Hanson, J. \& Lowy, J. (1963). The structure of F-actin and of actin filaments isolated from muscle. J. Mol. Biol. 6, 46-60. 
40. Hartree, E. F. (1972). Determination of protein: a modification of Lowry method that gives a linear photometric response. Analytical Biochemistry 48, 422-427.

41. Haselgrove, J. C. (1972). X-ray evidence for a conformational change in the actin-containing filaments of vertebrate striated muscle. Cold Spring Harbour Symp. Quant. Biol. 37, 341-352.

42. Heeley, D. H., Golosinska, K., \& Smillie, L. B. (1987). The effects of troponin T fragments T1 and $\mathrm{T} 2$ on the binding of nonpolymerizable tropomyosin to F-actin in the presence and absence of troponin I and troponin C. J. Biol. Chem 262, 9971-9978.

43. Heinonen, J. K. \& Lahti, R. J. (1981). A new and convenient colorimetric determination of inorganic orthophosphate and its application to the assay of inorganic pyrophosphatase. Anal. Biochem. 113, 313-317.

44. Herzberg, O. \& James, M. N. (1985). Structure of the calcium regulatory muscle protein troponin$\mathrm{C}$ at $2.8 \mathrm{~A}$ resolution. Nature $313,653-659$.

45. Herzberg, O., Moult, J., \& James, M. N. (1987). Molecular structure of troponin C and its implications for the Ca2+ triggering of muscle contraction. Methods Enzymol. 139, 610-632.

46. Hirono, M., Endoh, H., Okada, N., Numata, O., \& Watanabe, Y. (1987). Tetrahymena actin. Cloning and sequencing of the Tetrahymena actin gene and identification of its gene product. $J$. Mol. Biol. 194, 181-192.

47. Hirono, M., Tanaka, R., \& Watanabe, Y. (1990). Tetrahymena actin: copolymerization with skeletal muscle actin and interactions with muscle actin-binding proteins. J. Biochem. (Tokyo) $107,32-36$.

48. Hitchcock-DeGregori, S. E., Song, Y., \& Greenfield, N. J. (2002). Functions of tropomyosin's periodic repeats. Biochemistry 41, 15036-15044.

49. Hitchcock, S. E., Huxley, H. E., \& Szent-Gyorgyi, A. G. (1973). Calcium sensitive binding of troponin to actin-tropomyosin: a two-site model for troponin action. J. Mol. Biol. 80, 825-836.

50. Holmes, K. C., Popp, D., Gebhard, W., \& Kabsch, W. (1990). Atomic model of the actin filament. Nature 347, 44-49.

51. Holmes, K. C. (1995). The actomyosin interaction and its control by tropomyosin. Biophys. J. 68, 2S-5S.

52. Holtzer, M. E., Kumar, S., Holtzer, A., \& Crimmins, D. L. (1989). The CD of two-chain coiled coils: experiments on tropomyosin and tropomyosin segments in the tyrosine/disulfide spectral region. Biopolymers 28, 1597-1612.

53. Holtzer, M. E. \& Holtzer, A. (1990). Alpha-helix to random coil transitions of two-chain coiled coils: experiments on the thermal denaturation of isolated segments of alpha alpha-tropomyosin. Biopolymers 30, 985-993.

54. Holtzer, M. E. \& Holtzer, A. (1992). Alpha-helix to random coil transitions: determination of peptide concentration from the CD at the isodichroic point. Biopolymers 32, 1675-1677.

55. Holtzer, M. E., Crimmins, D. L., \& Holtzer, A. (1995). Structural stability of short subsequences of the tropomyosin chain. Biopolymers 35, 125-136.

56. Houdusse, A., Love, M. L., Dominguez, R., Grabarek, Z., \& Cohen, C. (1997). Structures of four Ca2+-bound troponin $\mathrm{C}$ at $2.0 \mathrm{~A}$ resolution: further insights into the $\mathrm{Ca2+-switch}$ in the calmodulin superfamily. Structure 5, 1695-1711.

57. Houdusse, A. \& Sweeney, H. L. (2001). Myosin motors: missing structures and hidden springs. Curr. Opin. Struct. Biol. 11, 182-194.

58. Huxley, H. E. (1972). Structural changes in the actin- and myosin-containing filaments during contraction. Cold Spring Harbour Symp. Quant. Biol. 37, 361-376. 
59. Ishii, Y. \& Lehrer, S. S. (1993). Kinetics of the "on-off" change in regulatory state of the muscle thin filament. Arch. Biochem. Biophys. 305, 193-196.

60. Isom, L. L., Holtzer, M. E., \& Holtzer, A. (1984). Alpha-Helix-To-Random-Coil Transition of 2Chain, Coiled Coils - Experiments on the Thermal-Denaturation of Alpha-Tropomyosin and BetaTropomyosin. Macromolecules 17, 2445-2447.

61. Johnson, F. \& Smillie, L. B. (1975). Rabbit skeletal alpha-tropomyosin chains are in register. Biochem. Biophys. Res. Commun. 64, 1316-1322.

62. Johnson, P. \& Blazyk, J. M. (1978). Involvement of an arginine residue of actin in tropomyosin binding. Biochem. Biophys. Res. Commun. 82, 1013-1018

63. Kabsch, W., Mannher, H. G., Suck, D., Pai, E. F., \& Holmes, K. C. (1990). Atomic structure of the actin:DNase I complex. Nature 347, 37-44.

64. Kabsch, W. \& Vandekerckhove, J. (1992). Structure and function of actin. Annu. Rev. Biophys. Biomol. Struct. 21, 49-76.

65. Kasha, M. (1950). Discuss. Faraday Soc. 9, 14

66. Kreuz, A. J., Simcox, A. \& Maughan, D. (1996). Alterations in flight muscle ultrastructure and function in Drosophila tropomyosin mutants. J. Cell Biol. 135, 673-687.

87. Lakowicz, J. R. (1983). Protein fluorescence. In Principles of fluorescence spectroscopy, pp. 342385, Plenum Press, New York and London.

68. Laws, W. R. \& Contino, P. B. (1992). Fluorescence quenching studies: analysis of nonlinear Stern-Volmer data. Methods Enzymol. 210, 448-463.

69. Lehman, W., Craig, R., \& Vibert, P. (1994). Ca(2+)-induced tropomyosin movement in Limulus thin filaments revealed by three-dimensional reconstruction. Nature 368, 65-67.

70. Lehman, W., Vibert, P., Uman, P., \& Craig, R. (1995). Steric-blocking by tropomyosin visualized in relaxed vertebrate muscle thin filaments. J. Mol. Biol. 251, 191-196.

71. Lehman, W., Hatch, V., Korman, V., Rosol, M., Thomas, L., Maytum, R., Geeves, M. A., Van Eyk, J. E., Tobacman, L. S., \& Craig, R. (2000). Tropomyosin and actin isoforms modulate the localization of tropomyosin strands on actin filaments. J. Mol. Biol. 302, 593-606.

72. Lehman, W., Rosol, M., Tobacman, L. S., \& Craig, R. (2001). Troponin organization on relaxed and activated thin filaments revealed by electron microscopy and three-dimensional reconstruction. J. Mol. Biol. 307, 739-744.

73. Lehrer, S. S. (1971). Solute perturbation of protein fluorescence. The quenching of the tryptophyl fluorescence of model compounds and of lysozyme by iodide ion. Biochemistry 10, 3254-3263.

74. Lehrer, S. S. \& Leavis, P. C. (1978). Solute quenching of protein fluorescence. Methods Enzymol. 49, 222-236.

75. Lehrer, S. S. \& Qian, Y. (1990). Unfolding/refolding studies of smooth muscle tropomyosin. Evidence for a chain exchange mechanism in the preferential assembly of the native heterodimer. J. Biol. Chem 265, 1134-1138.

76. Lehrer, S. S. \& Stafford, W. F., III (1991). Preferential assembly of the tropomyosin heterodimer: equilibrium studies. Biochemistry $30,5682-5688$.

77. Li, Y., Mui, S., Brown, J. H., Strand, J., Reshetnikova, L., Tobacman, L. S., \& Cohen, C. (2002). The crystal structure of the C-terminal fragment of striated-muscle alpha-tropomyosin reveals a key troporin T recognition site. Proc. Natl. Acad. Sci. U. S. A 99, 7378-7383.

78. Lorenz, M., Poole, K. J., Popp, D., Rosenbaum, G., \& Holmes, K. C. (1995). An atomic model of the unregulated thin filament obtained by $X$-ray fiber diffraction on oriented actin-tropomyosin gels. J. Mol. Biol. 246, 108-119. 
79. Lupas, A. (1996). Coiled coils: new structures and new functions. Trends Biochem. Sci. 21 , 375382.

80. Ma, Y. Z. \& Taylor, E. W. (1994). Kinetic mechanism of myofibril ATPase. Biophys. J. 66, 15421553.

81. Mak, A. S. \& Smillie, L. B. (1981). Non-polymerizable tropomyosin: preparation, some properties and F-actin binding. Biochem. Biophys. Res. Commun. 101, 208-214.

82. Malnic, B., Farah, C. S., \& Reinach, F. C. (1998). Regulatory properties of the NH2- and $\mathrm{COOH}_{-}$ terminal domains of troponin T. ATPase activation and binding to troponin 1 and troponin C. $J$. Biol. Chem 273, 10594-10601.

83. Mandel, M. \& Higa, A. (1970). Calcium-Dependent Bacteriophage Dna Infection. Journal of Molecular Biology 53, 159-\&.

84. Margossian, S. S. \& Lowey, S. (1982). Preparation of myosin and its subfragments from rabbit skeletal muscle. Methods Enzymol. 85 Pt B, 55-71.

85. Maytum, R., Lehrer, S. S., \& Geeves, M. A. (1999). Cooperativity and switching within the threestate model of muscle regulation. Biochemistry 38, 1102-1110.

86. McCubbin, W. D. \& Kay, C. M. (1969). Physicochemical studies on the aggregation of bovine cardiac tropomyosin with ionic strength. Can. J. Biochem. 47, 411-414.

87. McKillop, D. F. \& Geeves, M. A. (1993). Regulation of the interaction between actin and myosin subfragment 1: evidence for three states of the thin filament. Biophys. J. 65, 693-701.

88. McLachlan, A. D. \& Stewart, M. (1975). Tropomyosin coiled-coil interactions: evidence for an unstaggered structure. J. Mol. Biol. 98, 293-304.

89. McLachlan, A. D. \& Stewart, M. (1976). The 14-fold periodicity in alpha-tropomyosin and the interaction with actin. J. Mol. Biol. 103, 271-298.

90. Mejean, C., Lebart, M. C., Boyer, M., Roustan, C., \& Benyamin, Y. (1992). Localization and identification of actin structures involved in the filamin-actin interaction. Eur. J. Biochem. 209, $555-562$.

91. Miki, M. \& dos Remedios, C. G. (1988). Fluorescence quenching studies of fluorescein attached to Lys-61 or Cys-374 in actin: effects of polymerization, myosin subfragment-1 binding, and tropomyosin-troponin binding. J. Biochem. (Tokyo) 104, 232-235.

92. Miki, M., Miura, T., Sano, K., Kimura, H., Kondo, H., Ishida, H., \& Maeda, Y. (1998). Fluorescence resonance energy transfer between points on tropomyosin and actin in skeletal muscle thin filaments: does tropomyosin move? J. Biochem. (Tokyo) 123, 1104-1111.

93. Milligan, R. A. \& Flicker, P. F. (1987). Structural relationships of actin, myosin, and tropomyosin revealed by cryo-electron microscopy. J. Cell Biol. 105, 29-39.

94. Milligan, R. A, Whittaker, M., \& Safer, D. (1990). Molecular structure of F-actin and location of surface binding sites. Nature $348,217-221$.

95. Milligan, R. A. (1996). Protein-protein interactions in the rigor actomyosin complex. Proc. Natl. Acad. Sci. U. S. A 93, 21-26.

96. Mo, J. M., Holtzer, M. E., \& Holtzer, A. (1990). The thermal denaturation of nonpolymerizable alpha alpha-tropomyosin and its segments as a function of ionic strength. Biopolymers 30, 921927.

97. Mo, J. M., Holtzer, M. E., \& Holtzer, A. (1991). Kinetics of self-assembly of alpha alphatropomyosin coiled coils from unfolded chains. Proc. Natl. Acad. Sci. U. S. A 88, 916-920.

98. Moir, A. J. \& Levine, B. A. (1986). Protein cognitive sites on the surface of actin. A proton NMR study. J. Inorg. Biochem. 28, 271-278. 
99. Monteiro, P. B., Lataro, R. C., Ferro, J. A, \& Reinach, F. C. (1994). Functional alpha-tropomyosin produced in Escherichia coli. A dipeptide extension can substitute the amino-terminal acetyl group. J. Biol. Chem 269, 10461-10466.

100. Moore, P. B., Huxley, H. E., \& DeRosier, D. J. (1970). Three-dimensional reconstruction of Factin, thin filaments and decorated thin filaments. J. Mol. Biol. 50, 279-295.

101. Myers, J. K., Pace, C. N., \& Scholtz, J. M. (1995). Denaturant M-Values and Heat-Capacity Changes - Relation to Changes in Accessible Surface-Areas of Protein Unfolding. Protein Science 4, 2138-2148.

102. Narita, A., Yasunaga, T., Ishikawa, T., Mayanagi, K., \& Wakabayashi, T. (2001). Ca(2+)-induced switching of troponin and tropomyosin on actin filaments as revealed by electron cryomicroscopy. J. Mol. Biol. 308, 241-261.

103. O'Donoghue, S. I., Miki, M., \& dos Remedios, C. G. (1992). Removing the two C-terminal residues of actin affects the filament structure. Arch. Biochem. Biophys. 293, 110-116.

104. Ohtsuki, I. (1979). Molecular arrangement of troponin-T in the thin filament. J. Biochem. (Tokyo) $86,491-497$.

105. Ohtsuki, 1., Maruyama, K., \& Ebashi, S. (1986). Regulatory and cytoskeletal proteins of vertebrate skeletal muscle. Adv. Protein Chem 38, 1-67.

106. Orlov, V. N., Rostkova, E. V., Nikolaeva, O. P., Drachev, V. A., Gusev, N. B., \& Levitsky, D. I. (1998). Thermally induced chain exchange of smooth muscle tropomyosin dimers studied by differential scanning calorimetry. FEBS Lett. 433, 241-244.

107. Pace, C. N. \& Scholtz, J. M. (1997). Measuring the conformational stability of a protein. In Protein Structure (Creighton, T. E., ed), pp. 299-321, IRL Press, Oxford.

108. Pardee, J. D. \& Spudich, J. A (1982). Purification of muscle actin. Mothods Enzymol. 85 Pt B, 164-181.

109. Parry, D. A. \& Squire, J. M. (1973). Structural role of tropomyosin in muscle regulation: analysis of the x-ray diffraction patterns from relaxed and contracting muscles. J. Mol. Biol. 75, 33-55.

110. Parry, D. A. (1974). Structural studies on the tropomysin-troponin complex of vertebrate skeletal muscle. Biochem. Biophys. Res. Commun. 57, 216-224.

111. Pate, E. \& Cooke, R. (1989). Addition of phosphate to active muscle fibers probes actomyosin states within the powerstroke. Pflugers Arch. 414, 73-81.

112. Pauling, L. \& Corey, R. B. (1953). Nature 171, 59-61.

113. Paulucci, A. A., Hicks, L., Machado, A, Miranda, M. T., Kay, C. M., \& Farah, C. S. (2002). Specific Sequences Determine the Stability and Cooperativity of Folding of the C-terminal Half of Tropomyosin. J. Biol. Chem 277, 39574-39584.

114. Perry, S. V., Cole, H. A., Head, J. F., \& Wilson, F. J. (1972). Localization and mode of action of the inhibitory protein component of the troponin complex. Cold Spring Harbour Symp. Quant. Biol. 37, 251-262.

115. Phillips, G. N., Jr., Fillers, J. P., \& Cohen, C. (1986). Tropomyosin crystal structure and muscle regulation. J. Mol. Biol. 192, 111-131.

116. Poole, K. V., Holmes, K. C., Rayment, I., and Lorenz, M. Control of the actomyosin interaction. Biophys.J. 68, 348s. 1994.

117. Potekhin, S. A. \& Privalov, P. L. (1982). Co-operative blocks in tropomyosin. J. Mol. Biol. 159, 519-535.

118. Potter, J. D. \& Gergely, J. (1974). Troponin, tropomyosin, and actin interactions in the Ca2+ regulation of muscle contraction. Biochemistry 13, 2697-2703. 
119. Privalov, P. L. \& Potekhin, S. A. (1986). Scanning microcalorimetry in studying temperatureinduced changes in proteins. Methods Enzymol. 131, 4-51.

120. Quaggio, R. B., Ferro, J. A. Monteiro, P. B., \& Reinach, F. C. (1993). Cloning and expression of chicken skeletal muscle troponin I in Escherichia coli: the role of rare codons on the expression level. Protein Sci. 2, 1053-1056.

121. Rayment, I., Holden, H. M., Whittaker, M., Yohn, C. B., Lorenz, M., Holmes, K. C., \& Milligan, R A. (1993a). Structure of the actin-myosin complex and its implications for muscle contraction. Science 261, 58-65.

122. Rayment, I., Rypniewski, W. R., Schmidt-Base, K, Smith, R., Tomchick, D. R., Benning, M. M. Winkelmann, D. A., Wesenberg, G., \& Holden, H. M. (1993b). Three-dimensional structure of myosin subfragment-1: a molecular motor. Science 261, 50-58.

123. Rayment, I. \& Holden, H. M. (1993). Myosin subfragment-1: structure and function of a molecular motor. Curr. Opin. Struct. Biol. 3, 944-952.

124. Reinach, F. C., Farah, C. S., Monteiro, P. B., \& Malnic, B. (1997). Structural interactions responsible for the assembly of the troponin complex on the muscle thin filament. Cell Struct. Funct. 22, 219-223.

125. Ross, J. B., Szabo, A G., \& Hogue, C. W. (1997). Enhancement of protein spectra with tryptophan analogs: fluorescence spectroscopy of protein-protein and protein-nucleic acid interactions. Methods Enzymol. 278, 151-190.

126. Saeki, K., Sutoh, K., \& Wakabayashi, T. (1996). Tropomyosin-binding site(s) on the Dictyostelium actin surface as identified by site-directed mutagenesis. Biochemistry 35, 14465-14472.

127. Saeki, K., Yasunaga, T., Matsuura, Y., \& Wakabayashi, T. (2000). Role of residues 230 and 236 of actin in myosin-ATPase activation by actin-tropomyosin. Biochem. Biophys. Res. Commun. $275,428-433$.

128. Santoro, M. M. \& Bolen, D. W. (1988). Unfolding free energy changes determined by the linear extrapolation method. 1. Unfolding of phenylmethanesulfonyl alpha-chymotrypsin using different denaturants. Biochemistry 27, 8063-8068.

129. Sheterline, P., Clayton, J., \& Sparrow, J. C. (1998). Actin Oxford University Press.

130. Skolnick, J. \& Holtzer, A. (1985). Theory of Alpha-Helix-To-Random-Coil Transition of 2-Chain, Coiled Coils - Application of the Augmented Theory to Thermal-Denaturation of AlphaTropomyosin. Macromolecules 18, 1549-1559.

131. Smillie, L. B. (1979). Structure and functions of tropomyosins from musclee and non-muscle sources. Trends Biochem. Sci. july, 151-155.

132. Smith, C. A \& Rayment, I. (1996). X-ray structure of the magnesium(II).ADP.vanadate complex of the Dictyostelium discoideum myosin motor domain to $1.9 \mathrm{~A}$ resolution. Biochemistry 35 , 5404-5417.

133. Smith, D. A, Maytum, R., \& Geeves, M. A. (2003). Cooperative regulation of Myosin-actin interactions by a continuous flexible chain I: actin-tropomyosin systems. Biophys. J. 84, 31553167.

134. Smith, D. A. \& Geeves, M. A. (2003). Cooperative Regulation of Myosin-Actin Interactions by a Continuous Flexible Chain II: Actin-Tropomyosin-Troponin and Regulation by Calcium. Biophys. J. 84, 3168-3180.

135. Sousa, A. D. \& Farah, C. S. (2002). Quantitative analysis of tropomyosin linear polymerization equilibrium as a function of ionic strength. J. Biol. Chem 277, 2081-2088.

136. Squire, J. M. \& Morris, E. P. (1998). A new look at thin filament regulation in vertebrate skeletal muscle. FASEB J. 12, 761-771. 
137. Stewart, M. \& McLachlan, A. D. (1975). Fourteen actin-binding sites on tropomyosin? Nature 257, 331-333.

138. Stewart, M. (2001). Structural basis for bending tropomyosin around actin in muscle thin filaments. Proc. Natl. Acad. Sci. U. S. A 98, 8165-8166.

139. Straub, F. B. (1942). Studies. University of Szeged II, 3-15.

140. Studier, F. W., Rosenberg, A. H., Dunn, J. J., \& Dubendorff, J. W. (1990). Use of T7 RNA polymerase to direct expression of cloned genes. Methods Enzymol. 185, 60-89.

141. Sturtevant, J. M., Holtzer, M. E., \& Holtzer, A. (1991). A scanning calorimetric study of the thermally induced unfolding of various forms of tropomyosin. Biopolymers 31, 489-495.

142. Suarez, M. C., Lehrer, S. S., \& Silva, J. L. (2001). Local heterogeneity in the pressure denaturation of the coiled-coil tropomyosin because of subdomain folding units. Biochemistry $\mathbf{4 0}$, 1300-1307.

143. Sundaralingam, M., Bergstrom, R., Strasburg, G., Rao, S. T., Roychowdhury, P., Greaser, M., \& Wang, B. C. (1985). Molecular structure of troponin C from chicken skeletal muscle at 3angstrom resolution. Science $227,945-948$.

144. Syska, H., Wilkinson, J. M., Grand, R. J., \& Perry, S. V. (1976). The relationship between biological activity and primary structure of troponin I from white skeletal muscle of the rabbit. Biochem. J. 153, 375-387.

145. Szilagyi, L. \& Lu, R. C. (1982). Changes of lysine reactivities of actin in complex with myosin subfragment-1, tropomyosin and troponir. Biochim. Biophys. Acta 709, 204-211.

146. Takeda, S., Yamashita, A., Maeda, K., \& Maeda, Y. (2003). Structure of the core domain of human cardiac troponin in the $\mathrm{Ca}(2+)$-saturated form. Nature $424,35-41$.

147. Talbot, J. A. \& Hodges, R. S. (1981). Synthetic studies on the inhibitory region of rabbit skeletal troponin I. J. Biol. Chem. 256, 2798-2802.

148. Tanokura, M., Tawada, Y., Ono, A., \& Ohtsuki, I. (1983). Chymotryptic subfragments of troponin $\mathrm{T}$ from rabbit skeletal muscle. Interaction with tropomyosin, troponin I and troponin $\mathrm{C}$. $J$. Biochem. (Tokyo) 93, 331-337.

149. Tao, T., Lamkin, M., \& Lehrer, S. S. (1983). Exitation Energy Transfer Studies of the Proximity between Tropomyosin and Actin Reconstituted Skeletal Muscle Thin Filaments. American Chemical Society 22, 3059-3065.

150. Teale, F. W. J. \& Weber, G. (1957). Ultraviolet Fluorescence of the Aromatic Amino Acids. Biochemical Journal 65, 476-482.

151. Tobacman, L S. (1996). Thin filament-mediated regulation of cardiac contraction. Annu. Rev. Physiol 58, 447-481.

152. Vibert, P., Craig, R., \& Lehman, W. (1997). Steric-model for activation of muscle thin filaments. J. Mol. Biol. 266, 8-14.

153. Voet, D. \& Voet, J. G. (1995). Biochemistry John Wiley \& Sons, Inc..

154. Wetlaufer, D. B. (1962). Ultraviolet Spectra of Proteins and Amino Acids. Advances in Protein Chemistry 17, 303-390.

155. Whitby, F. G. \& Phillips, G. N., Jr. (2000). Crystal structure of tropomyosin at 7 Angstroms resolution. Proteins 38, 49-59.

156. White, H. D. \& Taylor, E. W. (1976). Energetics and mechanism of actomyosin adenosine triphosphatase. Biochemistry 15, 5818-5826. 
157. White, H. D., Belknap, B., \& Webb, M. R. (1997). Kinetics of nucleoside triphosphate cleavage and phosphate release steps by associated rabbit skeletal actomyosin, measured using a novel fluorescent probe for phosphate. Biochemistry 36, 11828-11836.

158. White, S. P., Cohen, C., \& Phillips, G. N., Jr. (1987). Structure of co-crystals of tropomyosin and troponin. Nature 325, 826-828.

159. Xu, C., Craig, R., Tobacman, L., Horowitz, R., \& Lehman, W. (1999). Tropomyosin positions in regulated thin filaments revealed by cryoelectron microscopy. Biophys. J. 77, 985-992.

160. Yount, R. G., Lawson, D., \& Rayment, I. (1995). Is myosin a "back door" enzyme? Biophys. J. 68, 44S-47S.

161. Zot, A. S. \& Potter, J. D. (1987). Structural aspects of troponin-tropomyosin regulation of skeletal muscle contraction. Annu. Rev. Biophys. Biophys. Chem 16, 535-559.

162. Zot, H. G. \& Potter, J. D. (1982). A structural role for the Ca2+-Mg2+ sites on troponin C in the regulation of muscle contraction. Preparation and properties of troponin $C$ depleted myofibrils. $J$. Biol. Chem 257, 7678-7683. 